NBER WORKING PAPER SERIES

\title{
HOW AMERICANS RESPOND TO IDIOSYNCRATIC AND EXOGENOUS CHANGES IN HOUSEHOLD WEALTH AND UNEARNED INCOME
}

\author{
Mikhail Golosov \\ Michael Graber \\ Magne Mogstad \\ David Novgorodsky \\ Working Paper 29000 \\ http://www.nber.org/papers/w29000
NATIONAL BUREAU OF ECONOMIC RESEARCH
1050 Massachusetts Avenue
Cambridge, MA 02138
July 2021

The opinions expressed in this paper are those of the authors alone and do not reflect the views of the Internal Revenue Service or the U.S. Treasury Department. This work is a component of a larger project on income risk in the United States, conducted through the SOI Joint Statistical Research Program. We appreciate the constructive comments and suggestions from Stefanie Stantcheva, four anonymous referees, Richard Blundell, Martin Holm, Claus Thustrup Kreiner, and Wojciech Kopczuk. The views expressed herein are those of the authors and do not necessarily reflect the views of the National Bureau of Economic Research.

NBER working papers are circulated for discussion and comment purposes. They have not been peer-reviewed or been subject to the review by the NBER Board of Directors that accompanies official NBER publications.

(C) 2021 by Mikhail Golosov, Michael Graber, Magne Mogstad, and David Novgorodsky. All rights reserved. Short sections of text, not to exceed two paragraphs, may be quoted without explicit permission provided that full credit, including $(\subset)$ notice, is given to the source. 
How Americans Respond to Idiosyncratic and Exogenous Changes in Household Wealth and Unearned Income Mikhail Golosov, Michael Graber, Magne Mogstad, and David Novgorodsky

NBER Working Paper No. 29000

July 2021

JEL No. D15,H2,J22

\section{ABSTRACT}

We study how Americans respond to idiosyncratic and exogenous changes in household wealth and unearned income. Our analyses combine administrative data on U.S. lottery winners with an event-study design that exploits variation in the timing of lottery wins. Our first contribution is to estimate the earnings responses to these windfall gains, finding significant and sizable wealth and income effects. On average, an extra dollar of unearned income in a given period reduces pre-tax labor earnings by about 50 cents, decreases total labor taxes by 10 cents, and increases consumption by 60 cents. These effects are heterogeneous across the income distribution, with households in higher quartiles of the income distribution reducing their earnings by a larger amount. Our second contribution is to develop and apply a rich life-cycle model in which heterogeneous households face non-linear taxes and make earnings choices along both intensive and extensive margins. By mapping this model to our estimated earnings responses, we obtain informative bounds on the impacts of two policy reforms: an introduction of UBI and an increase in top marginal tax rates. Our last contribution is to study how additional wealth and unearned income affect a wide range of behavior, including geographic mobility and neighborhood choice, retirement decisions and labor market exit, family formation and dissolution, entry into entrepreneurship, and job-to-job mobility.

Mikhail Golosov

Department of Economics

University of Chicago

1126 E. 59th Street

Chicago, IL 60637

and NBER

golosov@uchicago.edu

Michael Graber

Department of Economics

University of Chicago

5757 S. University Avenue

Chicago, IL 60637

m.graber@uchicago.edu
Magne Mogstad

Department of Economics

University of Chicago

1126 East 59th Street

Chicago, IL 60637

and NBER

magne.mogstad@gmail.com

David Novgorodsky

University of Chicago

Saieh Hall for Economics

1126 E. 59th St.

Chicago IL, 60637

david.novgorodsky@gmail.com 


\section{Introduction}

How do Americans respond to idiosyncratic and exogenous changes in household wealth and unearned income? Economists and policymakers are keenly interested in this question. For example, the earnings responses to such shocks are important, both to infer income and wealth effects and to assess the effects of public policy such as income taxation and cash transfers like universal basic income. However, giving a credible answer to this question has proven difficult. A key challenge is to find variation in wealth or unearned income that is both as good as random and specific to an individual as opposed to economy-wide. Such variation is necessary to isolate the effects of changes in wealth or unearned income, holding fixed other determinants of behavior such as preferences and prices.

The goal of our paper is to address this challenge and offer a credible answer as to how Americans respond to idiosyncratic and exogenous changes in household wealth and unearned income. We analyze a wide range of individual and household responses to lottery winnings and explore the economic implications of these responses for a number of key questions that economists and policymakers are interested in. The analyses combine administrative data for the U.S. for the period 1999 to 2016 with an event-study design that exploits variation in the timing of lottery wins. Winning a lottery can be viewed as a shock to household wealth or, equivalently, a permanent shock to unearned income. Importantly, the win is an idiosyncratic change that is difficult to anticipate and plausibly exogenous.

As described in Section 2, our analyses are based on a population-level panel data set which is constructed by combining the universe of worker tax records with third-party-reported lottery winnings. The worker data give us information about labor earnings and other sources of individual and household income, as well as various demographics. The data on lotteries contain a record for winnings in state lotteries, with information about the unique identifier of each winner and the winning amount.

In Section 3, we use the panel data set to estimate individual and household earnings and employment responses to winning the lottery. As described in this section, we employ an event-study design that exploits variation in the timing of lottery wins. This lets us eliminate unobserved time-invariant individual heterogeneity by comparing winners before and after they win, while accounting for age and time effects by using the later winners as a control group before they win. The event study shows evidence of sizable, swift, and persistent labor market responses to winning the lottery.

To interpret the magnitudes of these event-study estimates, we use the variation in the timing of lottery wins as an instrumental variable (IV) for lottery winnings. The resulting IV estimates tell us the individual and household responses per dollar of additional wealth due to the lottery winnings. We find that Americans respond to an exogenous increase in household wealth by significantly reducing their employment and labor earnings. For an extra 100 dollars in wealth, households reduce their annual earnings by approximately 2.3 dollars on average. The labor earnings responses per dollar of additional wealth are larger for higher income households as compared to lower income households. Households in the bottom quartile of the pre-win income distribution reduce their annual household labor earnings by 1.3 dollars per 100 dollars of additional wealth, whereas winners in the top quartile decrease their annual household labor earnings by 3.1 dollars per 100 dollars of additional wealth.

The size of these wealth effects can be hard to gauge as the observed responses to windfall gains should 
vary across individuals depending on a number of factors, such as the age at which the individual wins, her savings behavior, and the tax rates she faces. This issue motivates our analyses in Section 4. In this section, we first study how winning the lottery changes the unearned income that households allocate to consumption and leisure across years. We then estimate the share of yearly allocated unearned income that is spent on reducing labor versus increasing consumption. In other words, we estimate both the allocation of the windfall gains over time and the marginal propensities to earn (MPE) and consume (MPC) out of unearned income in a given period.

The analyses in Section 4 draw on two popular approaches to study the allocation of windfall gains over time: the annuitization method and the capitalization method. ${ }^{1}$ Under the annuitization method, one assumes that households smooth winnings over the remaining lifetime, while under the capitalization method one does not make any assumptions about household behavior, but rather uses observed capital income and rates of return to compute unearned income directly. Since there are pros and cons to each method, we apply both approaches and find that they produce remarkably similar measures of per-period unearned income and consumption expenditure. This similarity not only increases confidence in the estimated MPEs and MPCs, but also indicates that American lottery winners save most of the windfall for future periods, as predicted by textbook models of consumption smoothing.

To draw causal inference about the MPEs and MPCs, we use variation in the timing of lottery wins as an instrument for yearly unearned income. On average, an extra dollar of unearned income in a given period reduces pre-tax labor earnings by about 50 cents, decreases total labor taxes by 10 cents, and increases consumption by 60 cents. Interestingly, the MPEs and MPCs vary systematically across the pre-win income distribution. For example, individuals in the bottom quartile of the pre-win income distribution use most of the increase in unearned income on consumption, while individuals in the top quartile prioritize reducing labor over increasing consumption.

In Section 5, we illustrate the policy relevance of the estimated MPEs. We develop and apply a rich life-cycle model in which heterogenous households face non-linear taxes and make earnings choices along both intensive and extensive margins. Households have essentially arbitrary heterogeneity in income and substitution effects as well as in their propensity to stop working. We derive the exact mapping between the theoretical objects of interest and the estimated quantities from Section 4, such as the MPEs. This mapping allows us to empirically study two policy reforms: an introduction of a Universal Basic Income (UBI) and an increase in the top marginal tax rates.

The key identification challenge is that the effect of practically any policy reform depends on a number of parameters besides income effects; moreover, the number of such parameters increases with the complexity of the environment. We overcome this challenge by showing that it is possible to obtain informative bounds on the effects of policy reforms that we consider under weak conditions. Our bounds demonstrate that the introduction of a UBI will have a large effect on earnings and tax rates. For example, even if one abstracts from any disincentive effects from higher taxes that are needed to finance this transfer program, each dollar of UBI will reduce total earnings by at least 52 cents. With the relatively modest disincentive

\footnotetext{
${ }^{1}$ Blundell, Pistaferri and Preston (2008), Jappelli and Pistaferri (2010), and Blundell, Low and Preston (2013) are some examples of papers that use the annuitization method, while Stewart (1939), Saez and Zucman (2016), and Smith, Zidar and Zwick (2020) are examples of applications of the capitalization method.
} 
effects of a Marshallian earnings elasticity of 0.3, a UBI crowds out earnings essentially one for one. By comparison, income effects have less pronounced implications for the earnings reduction from increasing the top marginal tax rates.

We conclude our empirical analysis, in Section 6, with a broader evaluation of how Americans respond to idiosyncratic and exogenous changes in household wealth and unearned income. We provide new evidence on a number of key questions that economists and policymakers are interested in: To what extent does low wealth prevent households from moving to better neighborhoods? Are certain types of households more likely to move than others, and what type of neighborhood do they move to? Does a rise in unearned income make individuals more likely to choose jobs with lower wages in exchange for more favorable nonwage attributes? Are wealth effects important for retirement decisions and the design of public pension systems? Does a lack of wealth constitute an important barrier to entrepreneurship? How does an increase in household wealth affect the incentives to marry or divorce? What can we learn about models of household behavior from a comparison of earnings responses of the lottery winner and her spouse?

In our investigation of these questions, we describe the key identification and measurement challenges that arise, motivate how lottery winnings as a source of variation in wealth or unearned income can address these challenges, and discuss how our findings relate and contribute to existing work. To give just one example from this comprehensive and novel set of analyses, we find that winning a lottery leads to an immediate, one-off increase in the annual moving rate of approximately 3.5 percentage points (approximately 25 percent). Lower-income households, younger households, and renters constitute the groups that are most responsive to a change in wealth in terms of geographic mobility. One striking finding is that households do not systematically move to neighborhoods that are typically-measured (using local-area opportunity indices, poverty rates, and educational attainment) as having higher quality. This is true even for parents with young kids. This finding suggests that pure unconditional cash transfers do not lead households to systematically move to locations of higher quality, and non-financial barriers must play a big role. This is a useful contribution to the recent literature that emphasizes the lack of information about better neighborhoods as a friction that prevents moves to opportunity (e.g., Bergman, Chetty, DeLuca, Hendren, Katz and Palmer, 2020).

Our paper builds on and extends the analyses of labor market responses to lottery winnings in Imbens, Rubin and Sacerdote (2001), Cesarini, Lindqvist, Notowidigdo and Östling (2017) and Picchio, Suetens and van Ours (2018). ${ }^{2}$ We view Cesarini, Lindqvist, Notowidigdo and Östling (2017) as a particularly relevant comparison to our study. They use Swedish administrative data to not only estimate wealth effects, but also to compute labor supply elasticities and income effects using these estimates. Based on these computations, they conclude that income effects are modest. This conclusion, in turn, led a number of studies to build models specifically around the assumption that income effects are essentially negligible (Dyrda and Pedroni, 2018; Wolf, 2019; Auclert and Rognlie, 2020; Auclert, Bardóczy and Rognlie, 2020). ${ }^{3}$

\footnotetext{
${ }^{2}$ In Appendix J we provide a detailed comparison to this past work. There also exist a few studies that estimate the consumption effects of lottery winnings (e.g., Imbens, Rubin and Sacerdote, 2001, but also Kuhn, Kooreman, Soetevent and Kapteyn, 2011 and Fagereng, Holm and Natvik, 2020). The evidence is mixed. Some estimates suggest that individuals quickly consume most of the windfall. Other estimates suggest that neither durable nor non- durable consumption responds strongly to lottery winnings. Finally, Bulman, Fairlie, Goodman and Isen (2021) is a contemporaneous study utilizing administrative data on U.S. lottery winners to study the college attendance responses of college-age children to large, unanticipated income windfalls to their parents. The authors find relatively small effects of an increase in household resources on college attendance of college-age children.

${ }^{3}$ Moreover, Auclert and Rognlie (2020) show that standard New Keynesian models must fail in important ways if preferences
} 
Our analysis reveals that the earnings responses to lottery winnings are sizable and far from negligible in the U.S. The estimated wealth effect on pre-tax labor earnings is roughly twice as large as the effect estimated by Cesarini, Lindqvist, Notowidigdo and Östling (2017) for Sweden and Picchio, Suetens and van Ours (2018) for the Netherlands. This difference increases even further if one focuses on after-tax labor earnings, the headline earnings measure in Cesarini, Lindqvist, Notowidigdo and Östling (2017). This finding cautions against the use of wealth effects estimates from countries other than the U.S. as inputs for models that are otherwise calibrated or estimated using U.S. data, and emphasizes that it is important to distinguish between pre- and post-tax earnings responses.

Our paper is also related to two other sets of studies which attempt to isolate the labor market responses to an exogenous change in unearned income or wealth. The first utilizes various forms of natural experiments as sources of shocks to unearned income or wealth. Examples include changes in transfer income (e.g., Krueger and Pischke, 1992; Bengtsson, 2012; Jacob and Ludwig, 2012; Gelber, Isen and Song, 2016; Feinberg and Kuehn, 2018; Jones and Marinescu, 2019) and inheritances and bequests (e.g., Holtz-Eakin, Joulfaian and Rosen, 1994; Andersen and Nielsen, 2012). Such natural experiments are interesting because they present plausibly-exogenous variation in resources which can be used to draw causal inferences about labor market responses. However, responses to such shocks may be hard to gauge and economically interpret, as they should vary with individual characteristics as well as the nature of the shock, such as whether it is persistent or transitory, idiosyncratic or market-wide, and expected or unanticipated. For estimating responses to unearned income or wealth, lottery winning presents the advantage of being an idiosyncratic, plausibly-exogenous shock that is unlikely to be anticipated and, as we show in Section 5, the earnings responses to such shocks can be directly mapped into economically-relevant parameters.

The second set of studies uses models of labor supply to attempt to recover income effects and labor supply elasticities from observational variation in unearned income, wages, and tax rates. The models, data, and findings have been summarized and critiqued in multiple review articles including Pencavel (1986), Killingsworth and Heckman (1986), Blundell and Macurdy (1999), Keane (2011), and Saez, Slemrod and Giertz (2012). As emphasized in these reviews, there is no consensus about the size of income effects. One reason is that it has been difficult to find an exogenous source of variation in unearned income. Many studies use observational variation in spousal or capital income over time and across households to instrument for changes in unearned income. The challenge, however, is that it is difficult to ensure that such variation is independent of other determinants of behavior such as preferences and wages. Other studies use variation in take-home pay that arises either from tax reforms or from changes in observed earnings or wages. However, it is often not clear that these changes allow one to separately identify income and substitution effects without strong assumptions on functional form and the distribution of unobservables. ${ }^{4}$ By comparison, lottery winnings allow one to isolate the effects of changes in unearned income, holding fixed all other determinants of behavior such as preferences and wages. Thus, our paper offers credible evidence on income effects in the U.S., including how they vary across the income distribution.

are restricted such that wealth has no effect on labor supply. Thus, they argue, it is necessary to develop new classes of New Keynesian models.

${ }^{4}$ Reflecting this identification challenge, Kimball and Shapiro (2010) argue there is no consensus on the size of income and substitution effects in labor supply. 


\section{Data and sample selection}

In this section, we describe the institutional background and the data, explain the construction of the estimation sample, and define the key terms and conventions that we use throughout our paper.

\subsection{Institutional background}

Currently, 45 U.S. states conduct some type of state lottery. Any winning of at least $\$ 600$ and at least 300 times the purchase price of a ticket triggers generation of Form $\mathrm{W}-2 \mathrm{G}$. This form is provided to both the winner and to tax authorities, and is used for income tax filing. Form W-2G contains information about the amount of lottery winnings disbursed in a given year, a unique identification number for the winner, and her state of residence. ${ }^{5}$ For lottery drawings with multiple winners, the winnings are split before a Form W-2G is issued, and separate $\mathrm{W}-2 \mathrm{G}$ forms are furnished to each winner.

In the U.S., lottery winnings are considered ordinary taxable income in the year the payment is made. The vast majority of winnings are paid lump sum but there is a small fraction of winnings that are paid in installments over time. The legal treatment of the ownership of lottery winnings for married households is determined by state laws. Although there is some variation across states, de facto most lottery winnings accrued during marriage are treated as being owned by spouses equally. ${ }^{6}$

\subsection{Data sources}

We begin with the universe of $\mathrm{W}-2 \mathrm{G}$ forms generated between 1999 and 2016 . This data on W-2G forms is merged to two additional data sources. First, it is linked to each winner's data on wage earnings as reported on W-2 forms. Next, it is linked to each winner's federal tax returns (Form 1040 with various schedules), which contain data on income from other sources (self-employment, savings, Social Security, and unemployment insurance) as well as various household characteristics. We also observe data on spousal income for married winners who file tax returns. Most married households in the U.S. file tax returns jointly.

Most data are reported at an annual frequency. While we observe reported income and federal income taxes, we do not observe state income taxes directly. To compute total income taxes (federal and state) and marginal tax rates, we use the tax calculator of Bakija (2019). ${ }^{7}$ By comparing federal income taxes computed using this calculator to the observed federal income taxes, we confirm that the calculator is very accurate on our sample, with reported and calculated values being virtually identical. ${ }^{8}$

\footnotetext{
${ }^{5}$ Form W-2G is also used for other kinds of unusual payments, such as those from horse-race betting and casino gambling. However, we directly observe whether the Form W-2G is a payment from a state lottery for lottery winnings, and restrict attention to these payments.

${ }^{6}$ Broadly speaking, there are two groups of states: those that presume explicitly in their statutes that all property acquired during marriage should be divided equally in the event of a divorce, and those that do not have such a presumption explicitly stated (Hersch and Shinall, 2019). In practice, the prevailing tendency in all states is to treat lottery winnings as owned by spouses equally (see, e.g., In re Marriage of Mahaffey, 1990; Smith v. Smith, 1990; Ullah v. Ullah, 1990; In re Marriage of Swartz, 1993 ; DeVane v. DeVane, 1995; Thomas v. Thomas, 2003).

${ }^{7}$ We follow common practice (see, e.g., Brewer, Saez and Shephard, 2010; Chetty, Friedman, Olsen and Pistaferri, 2011; Saez, Slemrod and Giertz, 2012; Kleven and Schultz, 2014) and use a tax calculator to impute marginal tax rates. Accounting for additional distortions from future transfers, such as social security payments, would require specifying a full structural life-cycle model (see, e.g., Altig, Auerbach, Kotlikoff, Ilin and Ye, 2020).

${ }^{8} \mathrm{In}$ our data, reported and calculated values have a correlation of 0.997 and a median absolute deviation of \$47.
} 


\subsection{Terminology and key variables}

We now define key variables and conventions that we use throughout our paper. At the outset, we note that many economic outcomes are reported at the household level and cannot be attributed to a specific individual for married households. Therefore, for consistent comparison of all outcomes across both single and married households, we report all variables, unless we explicitly state otherwise, on a per-adult basis by normalizing them by the number of adults in the household (one if single and two if married).

Lottery win variables. We define the win year for any individual as the first year in which her Form $\mathrm{W}-2 \mathrm{G}$ from a lottery winning appears in our sample. Similarly, whenever we refer to the year in which an individual wins a lottery we mean the win year for that individual. Unless we explicitly state otherwise, we generally measure the size of the lottery win on a post-tax, per-adult basis. To compute post-tax lottery winnings, we begin with the (pre-tax) amount reported on Form W-2G for the win year. We then calculate additional taxes from the lottery winnings in the win year in three steps. We take total taxable income observed two years before the win year (i.e., pre-win taxable income) and calculate total income taxes in the win year absent behavioral response and lottery winnings. We then add lottery winnings to pre-win taxable income and re-calculate total income taxes in the win year. The increase in taxes after adding winnings is our measure of additional taxes from lottery winnings. Post-tax lottery winnings, then, are pre-tax winnings in the win year net of the calculated additional taxes. Form W-2G does not indicate whether the lottery win is paid lump-sum or in installments. However, we can infer the latter case when we observe multiple consecutive years of $\mathrm{W}-2 \mathrm{G}$ forms with similar reported amounts. When this occurs, we take the amount reported on the first-observed Form W-2G and convert it to the lump-sum present value by assuming that installments are paid in equal amounts over 25 years, using a 2.5 percent interest rate for discounting. ${ }^{9}$

Tax return and earnings variables. Wage earnings of any individual is the sum of pre-tax wages, tips, salary, taxable fringe benefits, and other forms of taxable compensation provided by all employers of that individual in a given year. Self-employment income consists of self-employment business income, farm income, and partnership income in a given calendar year. Total labor earnings is the sum of wage earnings and self-employment income. Capital income is the sum of dividend income, interest income, pension and annuity income, rental and royalty income, and non-labor income from estates, trusts, farms, and mortgage investments in a given calendar year. Gross income is sum of total labor earnings, capital income, and Social Security and unemployment insurance payments. We report all monetary values in inflation-adjusted 2016 U.S. dollars using the Consumer Price Index to adjust. ${ }^{10}$ Additional details on variable definitions are provided in Online Appendix C.

\footnotetext{
${ }^{9}$ There is some variation across installment-paid lotteries over whether the winner is required to take the winnings in installments or merely has an option to do so, the number of years over which the installments are paid, and whether and how nominal win amounts are adjusted for inflation. We do not have sufficient information to know which specific rules apply to a given lottery win. In any case, inferred installment-paid lottery disbursements are rare, as they comprise around 2 percent of all winners in U.S. administrative data, and dropping them from our sample barely moves our results.

${ }^{10}$ In the main analysis, we use unadjusted wage earnings as reported on Form W-2. We also explored winsorizing wage earnings and the results do not change. We report the results of this robustness check in Appendix Figure B.2.
} 
Research design variables. For our research design we generally use the following terminology and notation. We call all individuals who won a lottery in a given calendar year a cohort, and denote that year by $w$. The baseline year is defined as $s$ years prior to the lottery win and is used as the pre-treatment reference point in the event study. We report all our results for $s=2$ but our findings are virtually unchanged for other choices of $s$. The event time $\ell$ for cohort $w$ corresponds to calendar year $w+\ell$, where $\ell$ can be positive or negative depending on whether we look at the outcomes which occur after or before winning a lottery.

\subsection{Representativeness of lottery winners and lottery winnings}

To construct our main estimation sample, we impose three restrictions. First, we require each individual to be of working age (that is, between age 21 and 64) in their win year. Second, we require each individual to be in the sample for at least two years prior to generating their first Form W-2G. This ensures that we observe pre-win economic outcomes for each individual, as needed in an event study. Lastly, we restrict our main sample to lottery wins of at least $\$ 30,000$ per winner. We choose this amount since, if smoothed over her remaining lifetime, it amounts to an economically-meaningful increase in income of approximately $\$ 1,000$ per year for an average winner. ${ }^{11}$

Column 1 in Table 2.1 reports a set of key summary statistics for our sample. All summary statistics for the winners are measured in their baseline year, i.e., two years prior to their win year. Each statistic is calculated as a weighted average using cohort size as weights. We compare winners to the average workingage U.S. tax filer in column 2. We find that lottery winners have similar wage earnings, employment status, and age as compared to an average tax filer. However, lottery winners are more likely to be single and male, and slightly less likely to own a home.

\footnotetext{
${ }^{11}$ The point estimates of wealth effects and effects of unearned income in Sections 3 and 4, respectively, are even larger if we include smaller wins. Including the smallest wins makes the sample of lottery winners less comparable to the population at large in terms of observable characteristics. We thus prefer to focus on larger wins that yield observationally-representative samples and economically-meaningful increases in annual income.
} 
Table 2.1: Summary statistics of individual characteristics and labor market outcomes

\begin{tabular}{l|c|c|c}
\hline \hline & & $\frac{\text { Winners (Age 21-64) }}{(1)}$ & Tax Filers (Age 21-64) \\
\cline { 3 - 3 } Covariate & Statistic & & $(2)$ \\
Wage Earnings & Mean & $\$ 34,541$ & $\$ 33,005$ \\
Employment & Prop. & 0.79 & 0.80 \\
Age & Mean & 43.93 & 41.78 \\
Female & Prop. & 0.39 & 0.51 \\
Married & Prop. & 0.45 & 0.58 \\
Homeowner & Prop. & 0.45 & 0.49 \\
\hline Relative Q1 AGI Share & 0.28 & 0.25 \\
Relative Q2 AGI Share & 0.21 & 0.25 \\
Relative Q3 AGI Share & 0.24 & 0.25 \\
Relative Q4 AGI Share & 0.27 & 0.25 \\
\hline \multicolumn{2}{c}{$N$} & 90,731 & $154,372,671$ \\
\hline \hline
\end{tabular}

Notes: This table presents a summary of the descriptive statistics in our sample of working-age winners. All monetary values are reported in 2016 U.S. dollars, using the Consumer Price Index to adjust for inflation. In the first section of the table, we report mean characteristics. All values for the winners sample are measured two years prior to the win year and reported as cohort-size-weighted averages. The final column reports the same set of descriptive statistics for the universe of tax filers aged 21-64, taking a population-weighted average across the 1999 to 2015 tax years. In the second section of the table, we present a comparison of the pre-win distribution of per-adult adjusted gross income (AGI) among winners to that in the universe of tax filers aged 21-64. For each calendar year of tax-filer data, we map each winner to the corresponding quartile in the tax-filer AGI distribution. We then calculate the share of winners falling into each quartile of the tax-filer AGI distribution. Finally, we take the mean of the shares across calendar time (for each quartile). For the tax-filer population, this share is mechanically 0.25 .

The last four rows of Table 2.1 show how the income distribution of lottery winners compares to that of working-age tax filers. We do so by calculating the share of individuals in our sample that falls into each quartile of adjusted gross income (AGI) in the working-age tax filer population. We find that lottery winners are well represented in each income quartile. In Appendix Table A.1 we report a summary of the distribution of pre-tax lottery winnings in our sample. About half of our lottery winnings are between $\$ 30,000$ and $\$ 100,000$, but there is also a substantial fraction of winnings over $\$ 200,000$.

A natural question is how to think about the policy relevance of the lottery shocks in our data. In general, one would like to have exogenous shocks to wealth and unearned income that are similar in magnitude to changes associated with policy reforms. The shocks that we study are comparable in magnitude to both typical shocks to labor income and to the permanent income changes associated with many common policy proposals. To see this, note that our average size of lottery win is approximately equivalent to a $\$ 7,500$ posttax annuity payment. Such a permanent change in annual income is comparable to several other relevant permanent income changes considered in the literature. For example, in the U.S., a 1 standard deviation shock to the permanent component of log earnings approximately corresponds to $\$ 6,000$ annually, as follows from estimates in Meghir and Pistaferri (2004). We can also look at reforms to the tax and transfer system as a comparison to our lottery shocks. In terms of transfer policy, there is a range of popular proposals 
to introduce a UBI, which is an lump-sum payment to each adult. The suggested values of these transfers range from $\$ 500$ to $\$ 1000$ tax-free per month (see, e.g., Stern, 2016, Lowrey, 2018, and Yang, 2018), which corresponds to a $\$ 6,000$ to $\$ 12,000$ recurring annual payment. In terms of tax policy, among the most discussed policy levers to raise revenue is an increase to the top marginal tax rate on earnings. For each year that an individual works, an increase in the top marginal tax rate on earnings can be represented as an increase in the tax rate on all earnings plus an increase in post-tax unearned income equal in magnitude to the income cut-off for the top tax bracket scaled by the size of the tax rate increase. ${ }^{12}$ Thus, under the current tax code, evaluating the effect of each percentage point increase in the top marginal tax rate for a single taxpayer requires evaluating the effect of an increase in the unearned income of $\$ 5,184$ for each year that an individual's earnings are in the top tax bracket.

\section{Event-study design and wealth effect estimates}

In this section, we present and apply the event-study design that we use to draw causal inferences about how individuals and households respond to winning the lottery. This design exploits variation in the timing of lottery wins, and, thus, can be expressed as a difference-in-differences (DiD) estimator that compares the early winners to those who win later. We now demonstrate how we arrive at this estimator, assess the threats to identification, and show that a variety of alternative estimators yield remarkably similar estimates. For now, we focus on the labor market responses, while we, in Section 6, analyze a wide range of outcomes.

\subsection{Parameter of interest and research design}

We denote observed economic outcomes by $Y_{i, t}$. Let $D_{i, t}=1$ for individuals who have experienced their first lottery win by calendar year $t$, and $D_{i, t}=0$ otherwise. Let $Y_{i, t}(1)$ denote the potential economic outcome of an individual that has experienced her first-observed win, and $Y_{i, t}(0)$ denote the potential economic outcome of an individual that has not experienced her first-observed win. Potential economic outcomes are related to observed economic outcomes through $Y_{i, t}=Y_{i, t}(0)+D_{i, t}\left(Y_{i, t}(1)-Y_{i, t}(0)\right)$.

To define the parameter of interest, it is useful to consider a specific cohort of winners who win in year $w$. For this cohort, the parameter of interest is the cohort-specific average effect of the lottery win on outcome $Y$ as measured in post-win year $w+\ell$,

$$
\rho^{w, \ell} \equiv \mathbb{E}\left[Y_{i, w+\ell}(1)-Y_{i, w+\ell}(0) \mid i \text { won in } w\right]
$$

The identification challenge is that we do not observe $\mathbb{E}\left[Y_{i, w+\ell}(0) \mid i\right.$ won in $\left.w\right]$, which is the average outcome of winners in year $w+\ell$ had they, counterfactually, not won. In the rest of the paper, we refer to $\mathbb{E}\left[Y_{i, w+\ell}(0) \mid i\right.$ won in $\left.w\right]$ as the counterfactual outcome mean for winners in year $w+\ell$.

\footnotetext{
${ }^{12}$ See Saez (2001) for a concise discussion of this representation.
} 
First-difference estimator. One natural approach to recovering our parameter of interest is to use a firstdifference (FD) estimator,

$$
\underbrace{\mathbb{E}\left[Y_{i, w+\ell}-Y_{i, w-s} \mid i \text { won in } w\right]}_{\text {difference over time for winners in } w},
$$

where $w-s$ is a baseline, pre-win year. This FD estimator is illustrated using our data in Figure 3.1a, which presents the wage earnings of winners in a randomly drawn year, 2003. In the graph, we adjust for life-cycle effects on earnings by regressing winner wage earnings on a full set of dummies for each age. On the $y$-axis, we report mean annual wage earnings in a given time period. The running variable on the $x$-axis is event time, with 0 denoting the year of the lottery win.

The graphical evidence in Figure 3.1a highlights two important features of our data. First, there is a sizable, swift, and persistent change in wage earnings from before to after the year of the lottery win. Second, wage earnings change little if at all in the years prior to winning the lottery. This suggests that the FD estimator defined in expression (3.2) may produce credible estimates of the effects of winning the lottery. The reason is that this estimator produces consistent estimates under the assumption that wage earnings would not have changed from before to after the lottery win in the absence of winning the lottery (conditional on age). Under this assumption, the FD estimator (using $s=-2$ as the baseline year) suggests that the 2003 cohort of lottery winners reduced their wage earnings by $\$ 3,211$ (approximately 10 percent) in response to winning the lottery, as illustrated in Figure 3.1a.

Controlling for time effects. The key threat to the identifying assumption of the FD estimator defined in expression (3.2) is that economic outcomes may change over time (conditional on age) not only due to the lottery winnings but also due to other factors, such as contemporaneous aggregate changes in the economy. There are two ways to address this concern about confounding time effects.

One possibility is to take advantage of the fact that we observe many cohorts of lottery winners who win in different calendar years. In Figure 3.1b, we follow this approach, pooling the wage earnings data of winners across the 2001 to 2016 win years. We re-center the data so that period 0 is the year of win for all individuals (even if they win in different calendar years) and adjust for time effects in addition to age.

We report the estimates from this pooled approach in Figure 3.1b, using $s=-2$ as the baseline year. Estimates mirror the unadjusted estimates in Figure 3.1a for the subsample of 2003 winners. There is no evidence of significant changes in earnings prior to the year of win. By contrast, there is a sharp change in earnings from before to after the year of the lottery win. As illustrated in Figure 3.1b, the FD estimator net of calendar time effects suggests that lottery winners, on average, reduced their earnings by $\$ 3,768$ per year (approximately 12 percent) in response to winning the lottery.

Difference-in-differences estimator. An alternative approach to address concerns about time effects involves finding a control group that would arguably have experienced the same change in earnings from before to after the lottery win in the absence of winning the lottery. Such a control group allows one to difference out time effects by constructing a DiD estimator. A natural candidate for a control group is the 
individuals who first win the lottery in later years. Using such a control group, the resulting DiD estimator between the treatment and control groups for cohort $w$ is

$$
\underbrace{\mathbb{E}\left[Y_{i, w+\ell}-Y_{i, w-s} \mid i \text { won in } w\right]}_{\text {difference over time for treatment group }}-\underbrace{\mathbb{E}\left[Y_{i, w+\ell}-Y_{i, w-s} \mid i \text { has not won by } w^{*} \geq w+\ell\right]}_{\text {difference over time for control group }},
$$

where $w^{*}$ reflects the choice of how much later we look to find a later-winning control group.

The DiD estimator eliminates unobserved time-invariant individual heterogeneity by comparing winners before and after they win, while accounting for year and event-time effects by using the later winners as a control group before they win. As long as the individuals in the treatment and control groups would have had a common trend between years $w-s$ and $w+\ell$ in the expected potential outcomes in the absence of the lottery wins $Y(0)$, the DiD estimator defined in expression (3.3) recovers the average impact of lottery winning for cohort $w$ in year $w+\ell$ for $\ell \geq 0$.

In Figure 3.1c, we take this DiD estimator to our data. The dark line shows the mean wage earnings of the treatment group of lottery winners before and after their own lottery win. The lighter line shows the mean wage earnings of the control group of later winners (i.e., $w^{*}=w+\ell$ ) in the years prior to their own lottery win. The pre-trends of the two groups are remarkably similar, suggesting that later winners are a suitable choice of control group. As illustrated in the graph, the DiD estimate is given by the change in mean wage earnings before and after the win year of the treated individuals, in the treatment group relative to the control group. In our data, this estimate suggests that individuals, on average, reduce their earnings by approximately $\$ 3,800$ per year (approximately 11 percent) in response to winning the lottery, which is nearly identical to what we found using the FD estimator.

As an alternative control group, we consider individuals who did not win the lottery during the period we consider. In Figure 3.1d, we plot the mean earnings of this control group over time. The graph shows that the $\mathrm{DiD}$ estimate does not materially change if we use the never winners as the control group instead of the later winners.

Graphical comparison of estimators. In sum, we find that whether using a FD estimator (which relies on the absence of time effects) or a DiD estimator (which relies on a common trend between treatment and control groups), our conclusions are strikingly similar. The reason is simply that in this context, a control group is only needed to eliminate time effects. Our data, however, do not show any evidence of strong time effects on average, and, as a result, both the FD and DiD estimators produce remarkably similar results. This is true both if we use never winners or all later winners as the control group. We summarize these findings in Figure 3.2. In this graph, we plot the differences between the treatment and control group (if any) across event time, while normalizing the level of wage earnings of each group to be zero in event time $s=-2$. By examining the pattern of earnings in the years after the win, we can then directly compare the effects estimates across estimators, and they are remarkably similar. In light of this similarity, we use a $\mathrm{DiD}$ estimator using all available later winners as our preferred approach, given its attractive combination of flexibility in estimation and maximal use of later winners as control units. 


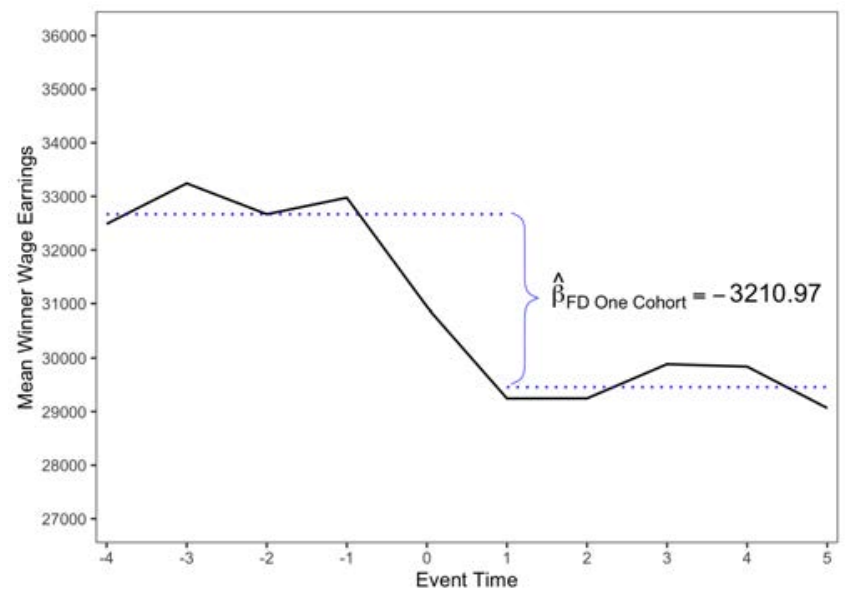

(a) First-Difference (Single Cohort)

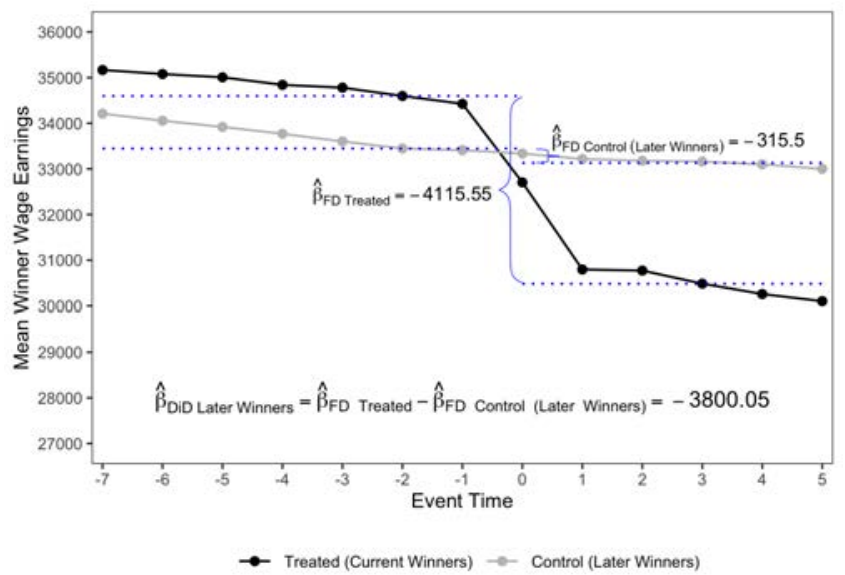

(c) Difference-in-Differences (Using Later Winners as Controls)

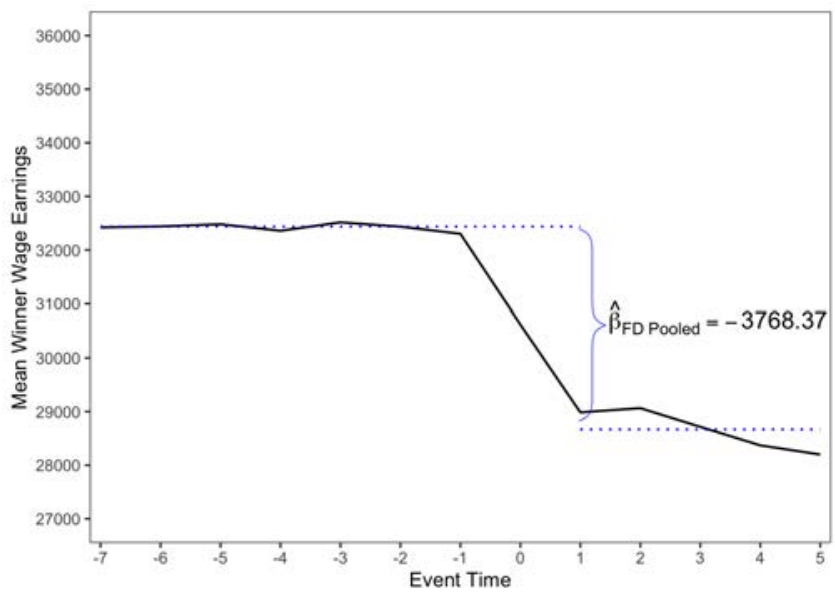

(b) First-Difference (Pooled Across Cohorts)

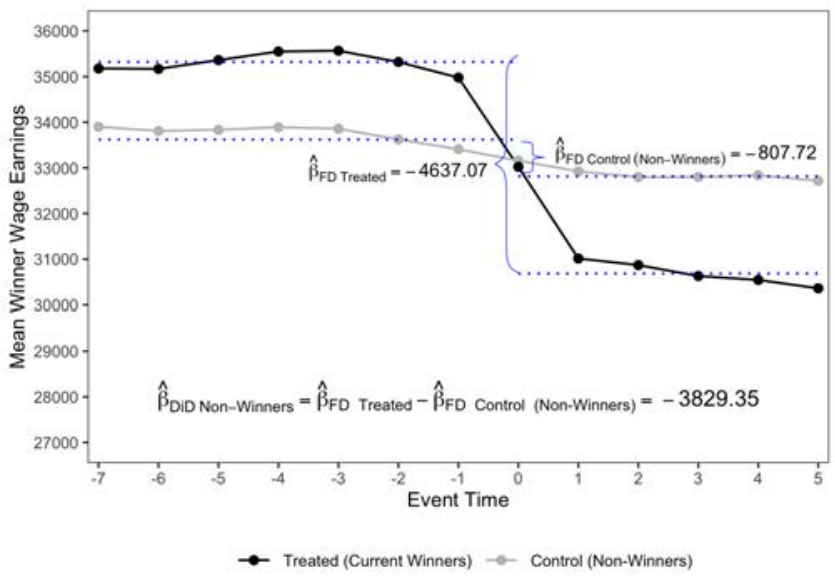

(d) Difference-in-Differences (Using Non-Winners as Controls)

Figure 3.1: Earnings paths across event time for treatment and control groups

Notes: This figure provides a comparison of various estimators for the effect of winning the lottery on winner wage earnings. In subfigure (a), we plot the life-cycle adjusted average wage earnings of the 2003 cohort of winners. We adjust for age effects by regressing winner wage earnings on a full set of dummies for each age. We then use the residual from this regression as our measure of earnings net of age effects, and add back in the population mean of winner wage earnings to get an intercept with the correct population average earnings level. In subfigure (b), we plot the average wage earnings of the pooled 2001-2016 cohort of winners. We adjust for age and time effects by regressing winner wage earnings on a full set of dummies for each age as well as a full set of time effects for each calendar year. In subfigure (c), we plot the cohort-weighted average of wage earnings of the treated group of winners (dark line) together with the cohort-weighted average of wage earnings of all later winners in the years before they win (lighter line). Finally, in subfigure (d), we produce an analog to subfigure (c), but only using individuals with control units who did not win the lottery during the period we consider. In each subfigure, we report the corresponding estimate of the effect of winning on winner wage earnings. 
Figure 3.2: Comparison of estimators

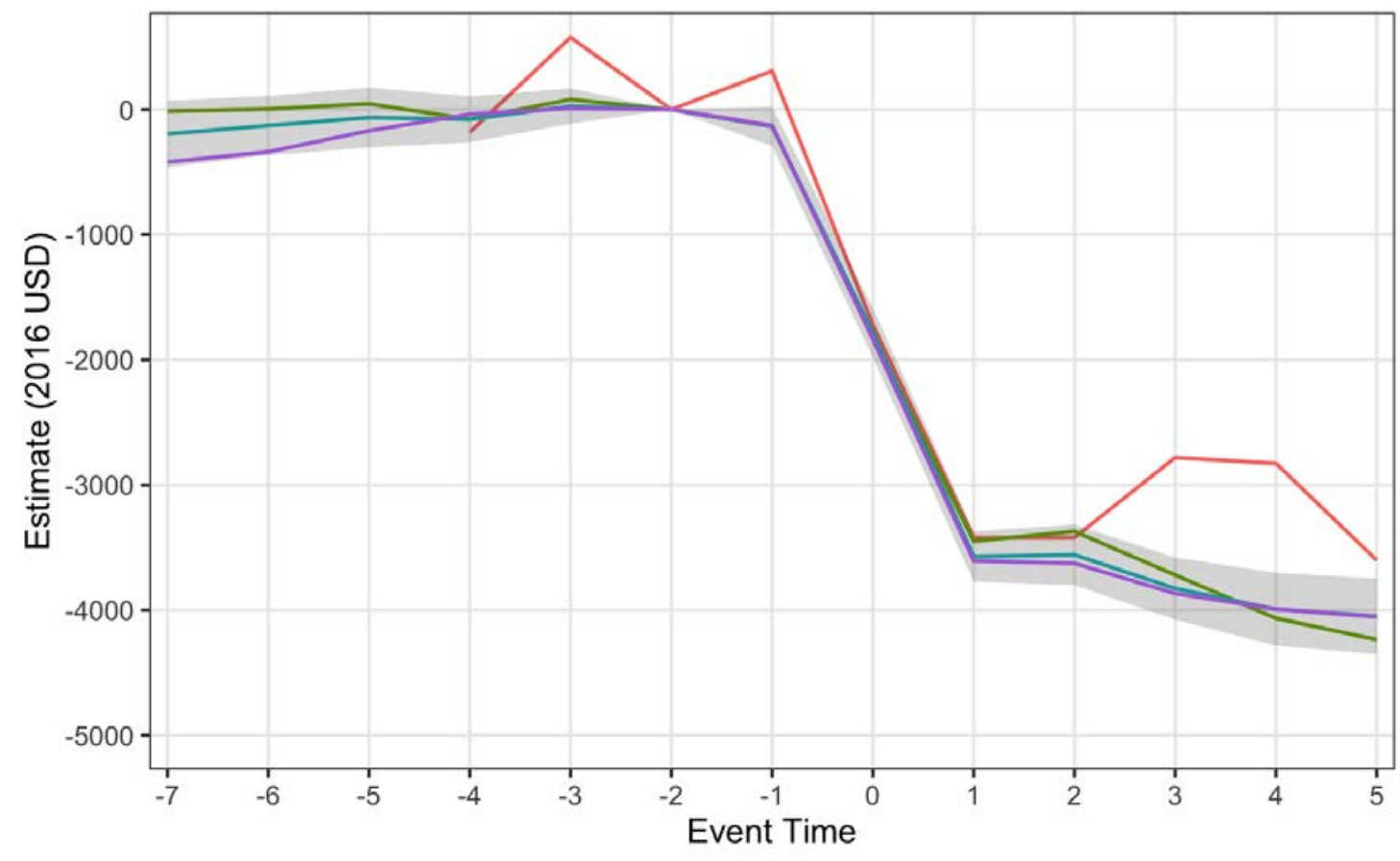

— FD (One Cohort) — FD (All Cohorts) — DiD (Later Winners) — DiD (Non-Winners)

Notes: In this figure, we summarize the estimates of the effect of winning the lottery on winner wage earnings at each event time corresponding to each of the four estimators discussed in Section 3.1. "FD (One Cohort)" corresponds to first-difference estimates using the 2003 cohort. "FD (All Cohorts)" corresponds to the pooled first-difference estimator using all 2001-2016 cohorts. "DiD (Later Winners)" corresponds to difference-indifferences estimates where the control group consists of all available later winners. "DiD (Non-Winners)" corresponds to difference-in-differences estimates where the control group consists of only using individuals who did not win the lottery during the period we consider. For the two difference-in-difference estimators, we take cohort-size-weighted averages for each event time. 90 percent confidence intervals are displayed, clustering on winner, for the " $\mathrm{DiD}$ (Later Winners)". Throughout, we use $w-2$ as the omitted event time. 
Regression model for the DiD estimator. To implement the DiD estimator defined in expression (3.3), we use a regression to make it easier to include additional covariates and calculate standard errors. For each cohort $w$ and each event time $\ell$ we create a subsample of the treated individuals who won in period $w$ and a control group of individuals who have not won by period $w$ or $w+\ell$, whichever is greater. Using this subsample, we run the regression

$$
Y_{i, t}=\alpha_{1}^{w, \ell}+\alpha_{2}^{w, \ell} 1\{i \text { won in } w\}+\alpha_{3}^{w, \ell} 1\{t=w+\ell\}+\rho^{w, \ell} Z_{i, t}+u_{i, t}^{w, \ell}
$$

where $Z_{i, t}$ represents the interaction term $1\{i$ won in $w\} \times 1\{t=w+\ell\}$. Here, $\alpha_{1}^{w, \ell}$ is the control group mean in the baseline year (i.e., $w-s$ ), $\alpha_{2}^{w, \ell}$ is a fixed effect for the treated individuals (cohort $w$ ), $\alpha_{3}^{w, \ell}$ is a time effect for event time $\ell$, and $\rho^{w, \ell}$ is an interaction effect and our parameter of interest as defined in expression (3.1). We estimate the model separately for each cohort $w$ and then take a weighted average of the estimates for each event time $\ell$, where the weights are determined by the cohort-size. ${ }^{13}$

To control for age composition, we include a full set of dummies for each age in regression model (3.4). ${ }^{14}$ These controls adjust for the fact that current winners are slightly older than later winners in year $w$, which is to be expected if the timing of win is as good as random. For other observables, current and later winners have very similar pre-win characteristics. This is shown in Table 3.1, where we report a set of key summary statistics for the treatment-control sample. For each cohort $w$, we compute the average characteristics of individuals in the treatment and control group in the baseline year $w-s$ and report cohort-size-weighted averages of those values. In addition, we report the cohort-weighted average size of the lottery win in each group. Table 3.1 shows that current and later winners (i.e., individuals in the treatment and control groups) have very similar pre-win characteristics, except current winners are slightly older. This is reassuring if one is worried that the changes in earnings over time could differ depending on the characteristics of individuals.

\footnotetext{
${ }^{13}$ By first estimating the parameter $\rho^{w, \ell}$ separately for each cohort $w$ and then averaging these parameters across cohorts, we avoid the problems pointed out by de Chaisemartin and D'Haultfoeuille (2018), Calloway and Sant'Anna (2020), and Sun and Abraham (2020), and we ensure that our event-study regressions produce positively-weighted averages of causal effects under the standard common trends assumption. To arrive at a joint variance-covariance matrix for all cohort-by-event time estimates, we estimate the model in a single, fully-interacted step.

${ }^{14}$ Including a full set of dummies for each age in our regression specification allows for parsimonious control for age differences between current and later winners, as well as potentially underlying life-cycle trends in earnings. In Appendix Figure B.1, we compare the results of our main specification to an non-parametric estimator due to Calloway and Sant'Anna (2020) which adjusts for age differences between current and later winners through an inverse-probability-weighted (IPW) DiD estimator. Results from both approaches are essentially identical.
} 
Table 3.1: Summary statistics of treatment-control sample

\begin{tabular}{l|c|c|c}
\hline \hline & & $\frac{\text { Treatment Group (Current Winners) }}{2}$ & Control Group (Later Winners) \\
\cline { 3 - 4 } Covariate & Statistic & $(1)$ & $(2)$ \\
Wage Earnings & Mean & $\$ 34,649$ & \\
Employment & Prop. & 0.80 & $\$ 34,278$ \\
Age & Mean & 43.94 & 0.80 \\
Female & Prop. & 0.39 & 41.84 \\
Married & Prop. & 0.45 & 0.39 \\
Homeowner & Prop. & 0.45 & 0.45 \\
Size of the Lottery Win & Mean & $\$ 182,902$ & 0.44 \\
\hline \hline
\end{tabular}

Notes: This table presents a summary of the descriptive statistics in our treatment-control sample. All monetary values are reported in 2016 U.S. dollars, using the Consumer Price Index to adjust for inflation. The treatment group is the collection of all cohorts of working-age winners in our sample with later-treated cohorts that can serve as a control group. The control group is the collection of all control units used across all treated units. All values are measured two years prior to the treated group's win year with the exception of the size of the lottery win, which is measured in each individual's win year.

\subsection{Average effects of lottery winning: Graphical evidence}

In Figure 3.3 we plot the estimated coefficients from regression (3.4). For each outcome and each event time $\ell$, we report a cohort-weighted average of regression coefficient $\rho^{w, \ell}$, with the baseline event time $w-2$ normalized to zero. There is no evidence of differential trends between current and later winners in pre-win event times -7 to -1 for any of the outcomes. This is consistent with the outcomes of current winners and the later winners evolving in the same way across years in the pre-win period, providing support for the common trends assumption.

Figure 3.3 shows that various measures of labor market outcomes fall significantly for lottery winners (relative to later winners) after they win a lottery. Since our observations are at an annual frequency, it is difficult to interpret estimates in event time 0 since they are affected by the timing of the win within the year. For this reason we focus our discussion on years 1 through 5. The wage earnings of the winner fall on average by $\$ 3,572$ (approximately 10 percent) in the first year following the lottery win, and continue to decline slightly in subsequent years. Per-adult wage earnings have a similar pattern to winner wage earnings, but they decline by slightly less: $\$ 3,234$ (approximately 10 percent) in the first year after the win. Recall that per-adult wage earnings for married households is the average wage earnings of the winner and the spouse. The smaller decrease in per-adult wage earnings compared to winner wage earnings implies that the spouse of the winner decreases his or her wage earnings by a smaller amount. It is also evident that the winner is more likely to stop working, and this probability grows over time. This pattern also persists after accounting for spousal responses.

Per-adult total labor earnings also include household income from self-employment. Self-employment income declines following the lottery win, and, as a result, per-adult total labor earnings decline by more than per-adult wage earnings. The decline in self-employment income rules out substitution towards self- 
employment as a means of offsetting the reduction in wage earnings. By comparison, per-adult capital income increases in the first year and then slightly declines over time. This pattern is consistent with lottery winners first expanding their savings and then gradually consuming out of their new wealth. Appendix Figure B.3 illustrates how various components of capital income such as interest payments, dividends, and other sources of capital income respond to winning.

\subsection{IV estimates of the individual and household responses to increases in wealth}

It is difficult to interpret the size of the effects reported in the previous subsection because the treatment variable captures whether a person wins but not the size of the lottery win. To get economically-interpretable estimates, we now shift to an IV model that uses variation in the timing of the lottery wins as an instrument for lottery winnings. The resulting IV estimates tell us individual and household responses per dollar of lottery winnings, which we will refer to as wealth effects.

We maintain the conventions and notation from our event-study regression model (3.4) in the prior subsection. For each cohort $w$ and each event time $\ell \geq 0$, we estimate the following IV model

$$
\begin{aligned}
X_{i, t} & =\mu_{1}^{w, \ell}+\mu_{2}^{w, \ell} 1\{i \text { won in } w\}+\mu_{3}^{w, \ell} 1\{t=w+\ell\}+\phi^{w, \ell} Z_{i, t}+\epsilon_{i, t}^{w, \ell} \\
Y_{i, t} & =\theta_{1}^{w, \ell}+\theta_{2}^{w, \ell} 1\{i \text { won in } w\}+\theta_{3}^{w, \ell} 1\{t=w+\ell\}+\beta^{w, \ell} X_{i, t}+\nu_{i, t}^{w, \ell} .
\end{aligned}
$$

Starting with the first-stage equation (3.5), the parameters $\left\{\mu_{1}^{w, \ell}, \mu_{2}^{w, \ell}, \mu_{3}^{w, \ell}\right\}$ are cohort and time effects. The endogenous variable $X$ in our estimation is the lottery winnings in the win year. Thus, the first-stage coefficient $\phi^{w, \ell}$, which captures the impact of a lottery win on lottery winnings, does not change over time. The second-stage equation (3.6) relates our outcome of interest $Y$ to changes in $X$. Our parameter of interest is $\beta^{w, \ell}$, which measures the average response of outcome $Y$ to changes in $X$. The reduced form of the IV model is given by the event-study regression in (3.4).

Column 1 of Table 3.2 reports estimates of the average annual response to an additional dollar of wealth in the post-win period across several economic outcomes. The reported estimates are constructed by taking cohort-size-weighted averages of $\beta^{w, \ell}$ for each event time $\ell \in\{1, \ldots ., 5\}$, and then taking the average over event times $\ell$. Going forward, we will use a similar weighting for other estimates, so we adopt the convention of referring to them as weighted-average estimates. To ease the interpretation of responses, we scale earnings and capital income responses by 100 and employment responses by 100,000 dollars in Table 3.2 .

These weighted-average estimates show that for an extra 100 dollars in wealth, winners reduce their earnings on average by 2.3 dollars in each of the five subsequent years. Per-adult total labor earnings similarly decrease by 2.3 dollars per 100 dollar of additional wealth. As both the earnings and winnings measures are per-adult, this 2.3 dollar response coincides with the mean response of total (not normalized per number of adults) household labor earnings. Capital income increases annually by 0.9 dollars per 100 dollars of additional wealth. Finally, the probability that the winner is employed decreases by 3.7 percentage points per 100,000 dollars of additional wealth. The response is similar for total employment, which also accounts for spousal labor supply. 
Figure 3.3: Effect of winning across outcomes

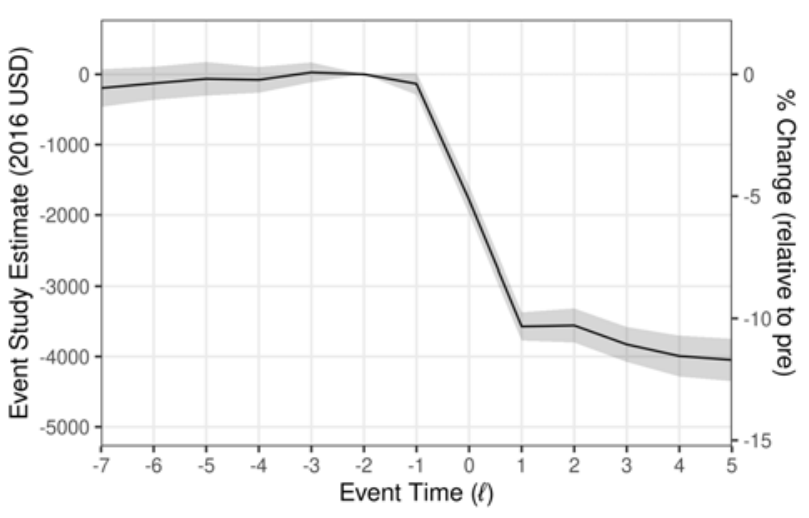

(a) Winner Wage Earnings

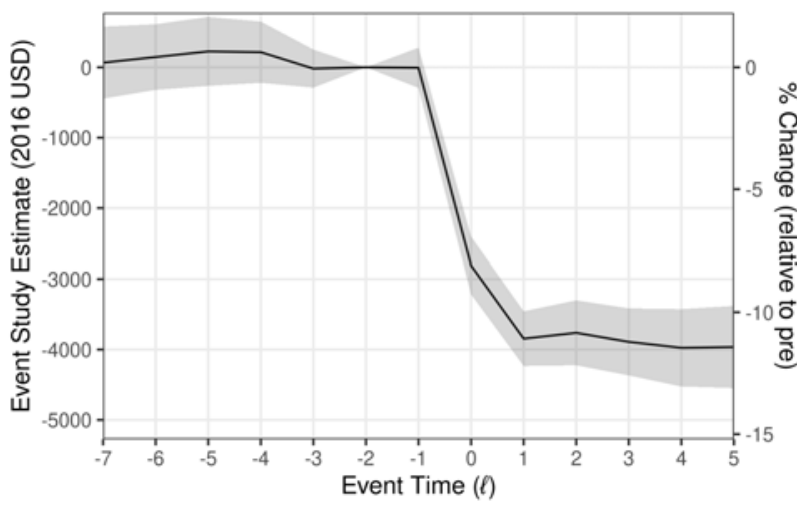

(c) Per-Adult Total Labor Earnings

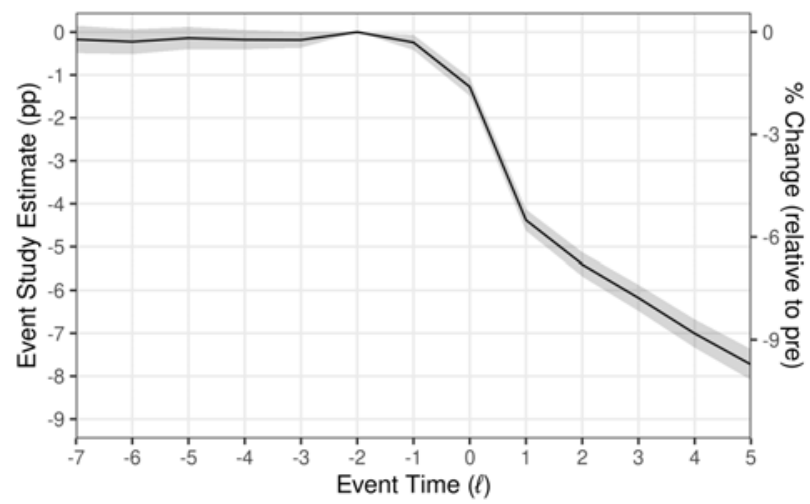

(e) Winner Employment

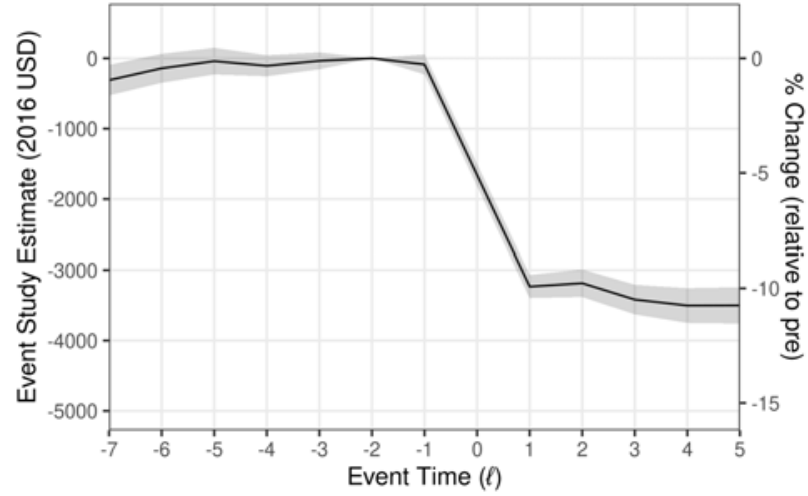

(b) Per-Adult Wage Earnings

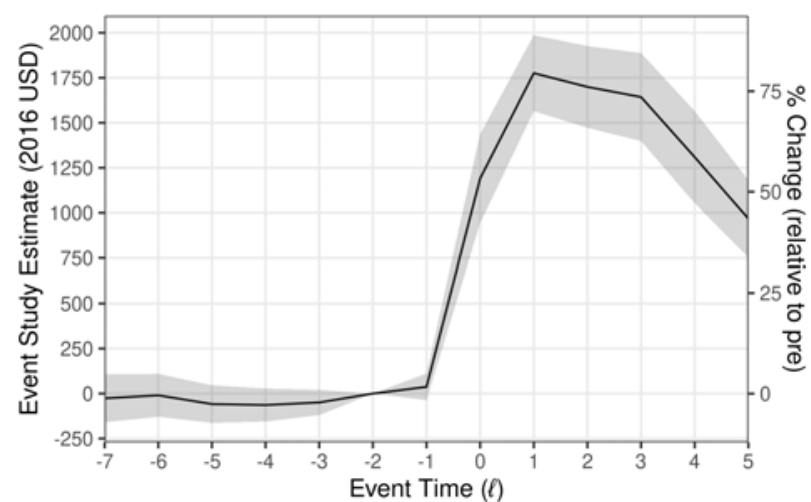

(d) Per-Adult Capital Income

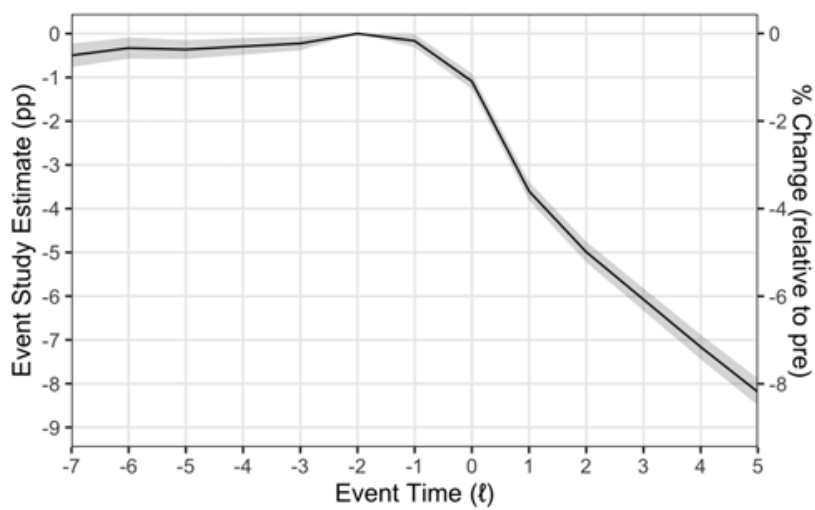

(f) Total Employment

Notes: This figure presents estimates of the impact of winning on six outcomes, based on estimating a version of equation (3.4) (as described in Section 3.1) for each outcome, and then taking cohort-size-weighted averages of $\rho^{w, \ell}$ for each event time $\ell .90$ percent confidence intervals are displayed, clustering on winner. Throughout, we use $w-2$ as the omitted event time. In addition to the cohort-size-weighted average effect in levels (left-hand axis), each subfigure also reports this average effect scaled by the mean of the outcome in omitted event time (right-hand axis) which can be interpreted as an average percentage change (relative to the baseline pre-win period) in the outcome. 
Table 3.2: Wealth effects across outcomes

\begin{tabular}{|c|c|c|c|c|c|}
\hline & & & Sample & & \\
\hline Outcome & $\begin{array}{l}\text { Full Sample } \\
\qquad \text { (1) }\end{array}$ & $\begin{array}{c}\text { Quartile } 1 \\
\text { Pre-Win Income } \\
\text { (2) }\end{array}$ & $\begin{array}{c}\text { Quartile } 2 \\
\text { Pre-Win Income } \\
\text { (3) }\end{array}$ & $\begin{array}{c}\text { Quartile } 3 \\
\text { Pre-Win Income } \\
\text { (4) }\end{array}$ & $\begin{array}{c}\text { Quartile } 4 \\
\text { Pre-Win Income } \\
\text { (5) }\end{array}$ \\
\hline $\begin{array}{l}\text { Winner Wage Earnings } \\
\text { (per } \$ 100)\end{array}$ & $\begin{array}{l}-2.2856 \\
(0.0571)\end{array}$ & $\begin{array}{l}-1.4003 \\
(0.0628)\end{array}$ & $\begin{array}{l}-2.2948 \\
(0.0861)\end{array}$ & $\begin{array}{l}-2.6196 \\
(0.0935)\end{array}$ & $\begin{array}{l}-3.0596 \\
(0.1541)\end{array}$ \\
\hline $\begin{array}{l}\text { Per-Adult Wage Earnings } \\
\text { (per \$100) }\end{array}$ & $\begin{array}{l}-2.0245 \\
(0.0492)\end{array}$ & $\begin{array}{l}-1.2514 \\
(0.0589)\end{array}$ & $\begin{array}{l}-2.0422 \\
(0.0764)\end{array}$ & $\begin{array}{l}-2.2590 \\
(0.0813)\end{array}$ & $\begin{array}{l}-2.7035 \\
(0.1311)\end{array}$ \\
\hline $\begin{array}{l}\text { Per-Adult Total Labor Earnings } \\
\text { (per } \$ 100)\end{array}$ & $\begin{array}{l}-2.3394 \\
(0.0657)\end{array}$ & $\begin{array}{l}-1.3339 \\
(0.1051)\end{array}$ & $\begin{array}{l}-2.2720 \\
(0.0867)\end{array}$ & $\begin{array}{l}-2.6450 \\
(0.0996)\end{array}$ & $\begin{array}{l}-3.1298 \\
(0.1820)\end{array}$ \\
\hline $\begin{array}{l}\text { Per-Adult Capital Income } \\
\text { (per \$100) }\end{array}$ & $\begin{array}{c}0.8738 \\
(0.0406)\end{array}$ & $\begin{array}{c}0.5784 \\
(0.0540)\end{array}$ & $\begin{array}{c}0.7626 \\
(0.0784)\end{array}$ & $\begin{array}{c}0.9658 \\
(0.0709)\end{array}$ & $\begin{array}{l}0.9265 \\
(0.0974)\end{array}$ \\
\hline $\begin{array}{c}\text { Winner Employment } \\
\text { (per } \$ 100,000)\end{array}$ & $\begin{array}{l}-0.0368 \\
(0.0008)\end{array}$ & $\begin{array}{l}-0.0517 \\
(0.0021)\end{array}$ & $\begin{array}{l}-0.0444 \\
(0.0019)\end{array}$ & $\begin{array}{l}-0.0350 \\
(0.0013)\end{array}$ & $\begin{array}{l}-0.0231 \\
(0.0010)\end{array}$ \\
\hline $\begin{array}{c}\text { Total Employment } \\
\quad(\text { per } \$ 100,000)\end{array}$ & $\begin{array}{l}-0.0361 \\
(0.0008)\end{array}$ & $\begin{array}{l}-0.0633 \\
(0.0025)\end{array}$ & $\begin{array}{l}-0.0421 \\
(0.0017)\end{array}$ & $\begin{array}{l}-0.0278 \\
(0.0010)\end{array}$ & $\begin{array}{l}-0.0196 \\
(0.0008)\end{array}$ \\
\hline
\end{tabular}

Notes: This table presents estimates of the mean effect of an extra dollar of wealth on six outcomes. These estimates are calculated by first estimating a 2SLS regression, as described in Section 3.3, for each outcome, then taking cohort-size-weighted averages of $\beta^{w, \ell}$ for each event time $\ell$, then taking the mean across estimates for post-win event times $\{1,2,3,4,5\}$ to recover the mean wealth effect in the post-win period. Column 1 reports wealth effects for the full analysis sample. In columns 2 to 5, we report wealth effects for subsamples of winners falling into each quartile of the pre-win distribution of per-adult adjusted gross income. We use the delta method to calculate standard errors (reported in parenthesis), clustering on winner. To ease interpretability, we scale earnings and capital income responses by $\$ 100$. In the case of employment responses, we scale each estimate by $\$ 100,000$.

Heterogeneity across the income distribution. Columns 2-5 of Table 3.2 explore heterogeneity in responses across the income distribution. To construct these estimates, we use the distribution of adjusted gross income (AGI) in the baseline pre-win period to assign treated and control individuals into quartiles of pre-win income, and then estimate our IV model separately for each quartile. As one can see from these columns, the average wage earnings reduction per dollar of additional wealth is increasing in pre-win income. For example, whereas individuals in the first quartile of pre-win income reduce their own annual wage earnings by 1.4 dollars per 100 dollars of additional wealth, individuals in the fourth quartile decrease their annual wage earnings by over twice as much. This pattern does not materially change when we look at other measures of earnings responses. The lower-income households, however, are more likely to stop working - the reduction in the probability of employment for the winners in the lowest quartile is more than twice as large as that of the winners in the highest quartile. This difference increases even further after 
accounting for responses in spousal labor supply.

One consideration with our estimated responses across the income distribution is that individuals with low pre-win income may have low initial labor force participation, effectively introducing a ceiling on how much earnings of lower-income individuals can respond to a given lottery prize. To shed additional light on this, in Appendix Table A.2 we explore heterogeneity in earnings responses in two distinct subsamples of our data. In one subsample, we restrict attention to only those individuals who had positive wage earnings in the baseline year. In the second subsample, we restrict attention to only those individuals who had wage earnings in excess of $\$ 15,000$ in the baseline year. ${ }^{15}$ For both subsamples, we find our point estimates to be slightly larger, but the general pattern of increasing earnings responses with income remains.

Responses over time. In Figure 3.4 we explore how earnings responses change over time. We aggregate estimated earnings response coefficients $\beta^{w, \ell}$ into short-run (corresponding to $\ell=\{1,2\}$ ) and long-run (corresponding to $\ell=\{3,4,5\}$ ) estimates. We report these estimates for our two main measures of earnings responses: winner wage earnings and per-adult total labor earnings. ${ }^{16}$ Earnings responses increase over time, but not substantially so, and the magnitude of the increases is similar across income distribution.

\footnotetext{
${ }^{15}$ The $\$ 15,000$ threshold approximately corresponds to the amount an individual would earn if working full time at U.S. federal minimum wage.

${ }^{16}$ Since the first-stage coefficient is essentially fixed over time, the time patterns of responses for other measures can be easily inferred from Figure 3.3 and we omit them for brevity.
} 


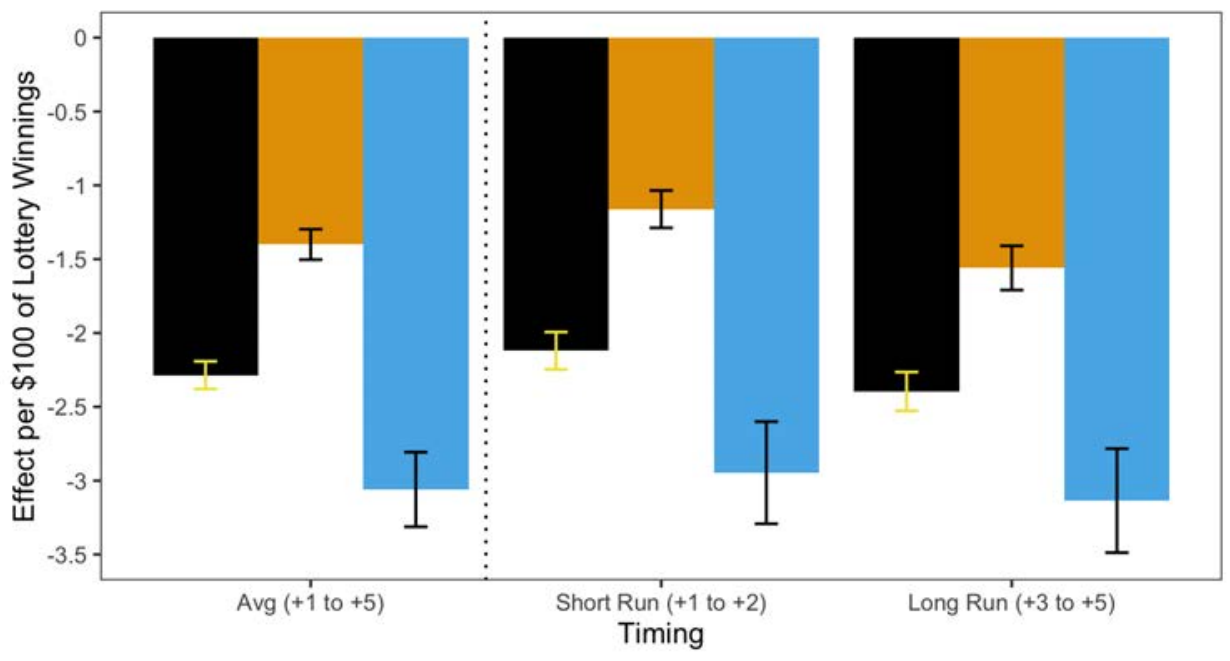

Full Sample $\quad$ Quartile 1

(a) Winner Wage Earnings

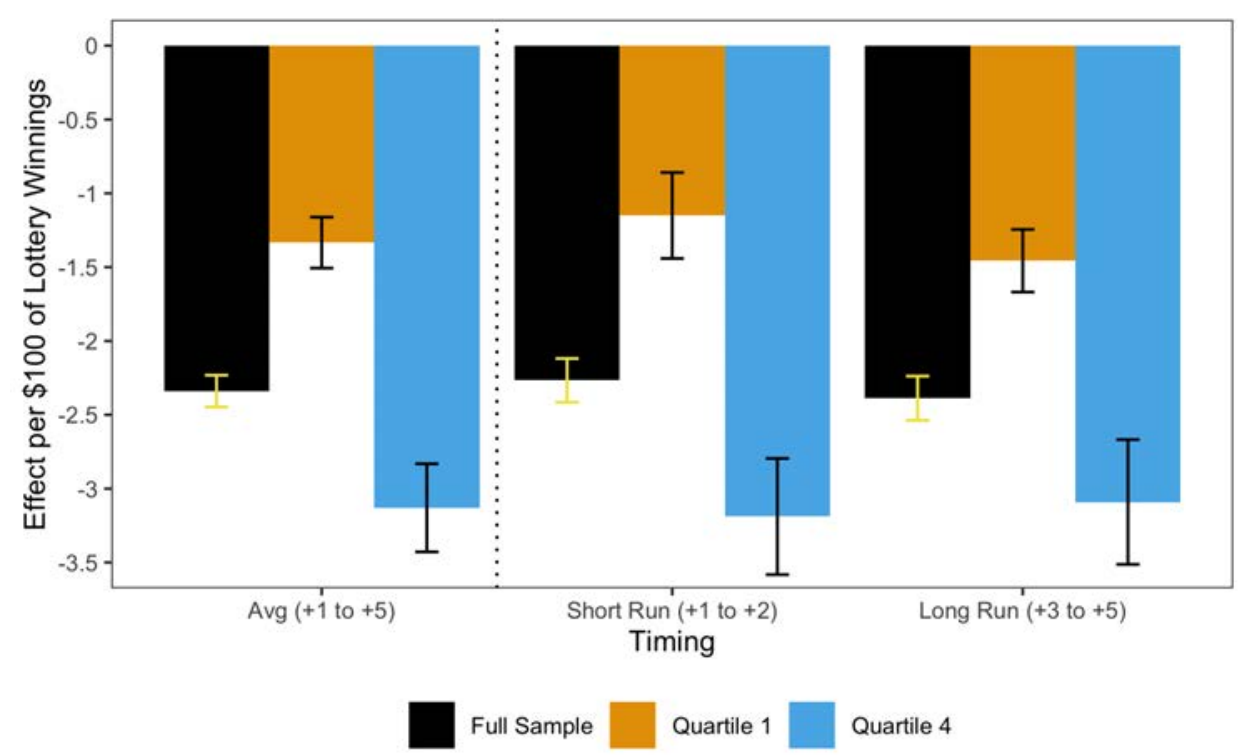

(b) Per-Adult Total Labor Earnings

Figure 3.4: Wealth effects across time and pre-win income

Notes: This figure presents estimates of the mean effect of an extra dollar of wealth on (a) winner wage earnings and (b) per-adult total labor earnings. These estimates are calculated by first estimating a 2SLS regression, as described in Section 3.3, for each outcome, then taking cohortsize-weighted averages of $\beta^{w, \ell}$ for each event time $\ell$, then taking the mean across estimates for all post-win event times $\{1,2,3,4,5\}$ ("Avg $(+1$ to +5 )"), a shorter-run set of post-win event times $\{1,2\}$ ("Short Run ( +1 to +2$)$ "), and a longer-run set of post-win event times $\{3,4,5\}$ ("Long Run (+3 to +5$)$ "). In addition, for each temporal average, we report wealth effects for the full analysis sample ("Full Sample") as well as for the subsample of winners falling in the first ("Quartile 1") and fourth ("Quartile 4") quartile of the pre-win distribution of per-adult adjusted gross income. To ease interpretability, we scale earnings responses by $\$ 100.90$ percent confidence intervals are displayed, clustering on winner.

Intensive- and extensive-margin responses. Figure 3.3 shows evidence of sizable and persistent earnings and employment responses to winning the lottery. This raises a natural question: How much of the overall 
earnings response is attributable to the extensive margin? To address this question, we decompose the earnings response into extensive- and intensive-margin contributions. Concretely, we take a standard statistical intensive-extensive decomposition of cross-sectional earnings effects (as in, e.g., Angrist, 2001) and adapt it to a DiD estimator (see Appendix D). Table 3.3 shows the share of the observed earnings response that is attributable to the extensive-margin response. In aggregate, we find that the extensive margin explains roughly half of the winner wage earnings response and 40 percent of the per-adult total labor earnings response. The importance of the extensive margin, however, decreases with pre-win income. For example, whereas the extensive margin explains $58 \%$ of the observed per-adult total labor earnings response for lowincome households, $36 \%$ of the response is explained by employment responses for households in the fourth quartile.

Table 3.3: Extensive-margin share of earnings response

\begin{tabular}{|c|c|c|c|c|c|}
\hline Outcome & $\begin{array}{c}\text { Quartile 1 } \\
\text { Pre-Win Income } \\
\text { (1) }\end{array}$ & $\begin{array}{c}\text { Quartile } 2 \\
\text { Pre-Win Income } \\
\text { (2) }\end{array}$ & $\begin{array}{c}\text { Quartile } 3 \\
\text { Pre-Win Income } \\
\text { (3) }\end{array}$ & $\begin{array}{c}\text { Quartile } 4 \\
\text { Pre-Win Income } \\
\text { (4) }\end{array}$ & $\begin{array}{c}\text { Aggregate } \\
\text { (5) }\end{array}$ \\
\hline Winner Wage Earnings & 0.65 & 0.50 & 0.52 & 0.50 & 0.53 \\
\hline Per-Adult Total Labor Earnings & 0.58 & 0.41 & 0.34 & 0.36 & 0.40 \\
\hline
\end{tabular}

Notes: This table presents the share of the observed earnings responses that is attributable to the extensive margin. For details on the decomposition see Appendix D.

Heterogeneity by prize size. Lastly, we examine heterogeneity in responses by prize size. To concisely summarize results allowing for variation in prizes, we report, in Figure 3.5, how average wealth effects on earnings and employment in the full analysis sample compare to a subset of smaller winners (winning $\$ 30,000$ up to $\$ 300,000$ ), a subset of larger winners (winning $\$ 300,000$ to $\$ 1$ million) and a subset of the largest winners (winning more than $\$ 1$ million). 
Figure 3.5: Wealth effects by prize size over time

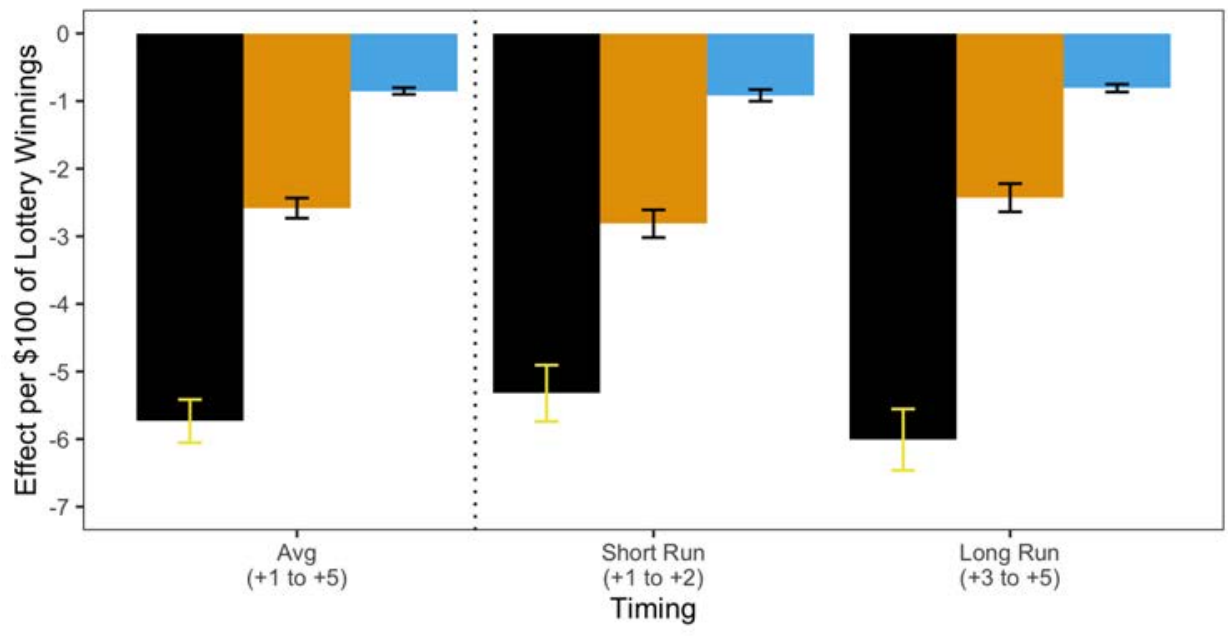

$30 \mathrm{~K}-300 \mathrm{~K} \quad 300 \mathrm{~K}-1 \mathrm{M}$

(a) Per-Adult Total Labor Earnings

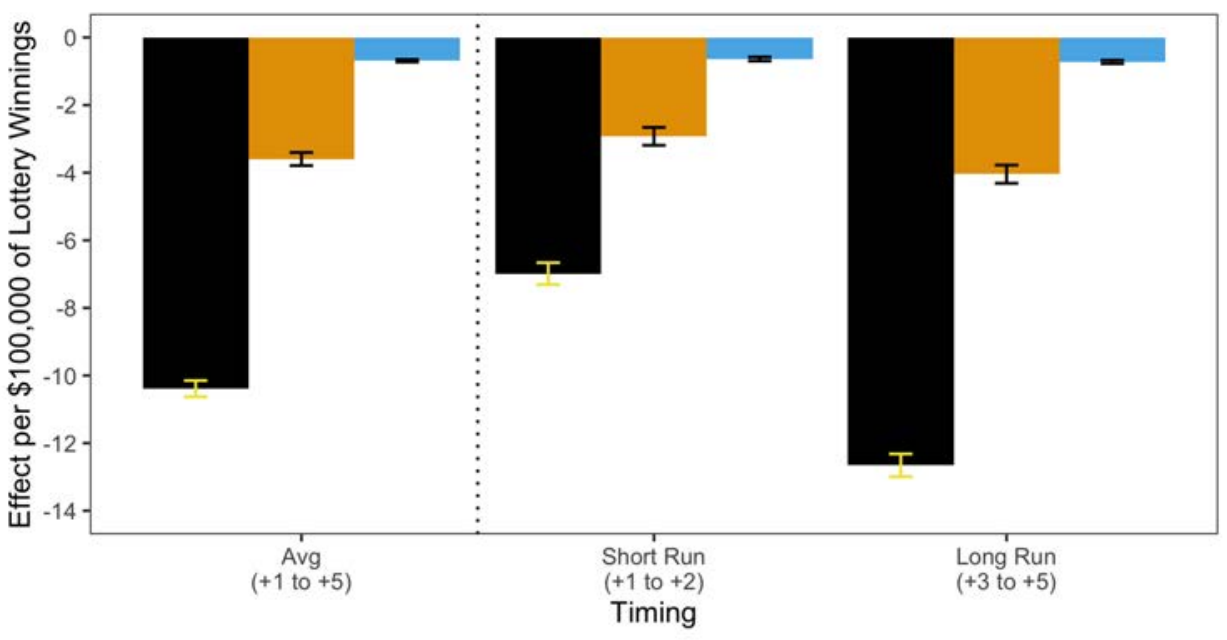

$30 \mathrm{~K}-300 \mathrm{~K}$

$300 \mathrm{~K}-1 \mathrm{M}$

$1 \mathrm{M}+$

(b) Total Employment

Notes: This figure presents estimates of the mean effect of an extra dollar of wealth on a) per-adult total labor earnings and b) total employment. These estimates are calculated by first estimating a 2SLS regression, as described in Section 3.3, for each outcome, then taking cohort-size-weighted averages of $\beta^{w, \ell}$ for each event time $\ell$, then taking the mean across estimates for all post-win event times $\{1,2,3,4,5\}$ ("Avg ( +1 to +5 )"), a shorterrun set of post-win event times $\{1,2\}$ ("Short Run $(+1$ to +2$)$ )"), and a longer-run set of post-win event times $\{3,4,5\}$ ("Long Run (+3 to +5 )"). In addition, for each temporal average, we report wealth effects separately by prize size. To ease interpretability, we scale earnings responses by $\$ 100$. In the case of employment responses, we scale each estimate by $\$ 100,000$. 90 percent confidence intervals are displayed, clustering on winner.

We find that wealth effects for both earnings and employment decrease with prize size. For smaller winners, the average per-adult total earnings reduction per 100 dollars of additional wealth is in excess of 
5.5 dollars, whereas for the largest winners, the reduction is less than 1 dollar per 100 dollars of additional wealth. This pattern of decreasing effects by prize size raises a natural question: How much of the crossprize difference in wage earnings responses is attributable to the extensive labor supply margin? To address this question, we decompose the difference in per-dollar earnings effects between smaller and larger prize winners into extensive- and intensive-margin contributions (see Appendix D). In particular, we focus our decomposition on the difference between the smaller $(\$ 30,000$ to $\$ 300,000)$ prize bin and the largest $(\$ 1$ million and up). We summarize the results of this decomposition of differences in Table 3.4. We find that the extensive margin explains a substantial fraction of the differences in per-dollar responses across prize size. For example, in aggregate, we find that for per-adult total labor earnings approximately half of the difference in wealth effects across prize size is attributable to differences along the extensive-margin response. The share of cross-prize-size differences attributable to the extensive margin declines as we look across the income distribution, falling from approximately $75 \%$ for lower-income (first quartile) winners to approximately $44 \%$ for higher-income (fourth quartile) winners.

Table 3.4: Extensive-margin share of cross-prize-size difference in earnings response per dollar

\begin{tabular}{|c|c|c|c|c|c|}
\hline Outcome & $\begin{array}{c}\text { Quartile } 1 \\
\text { Pre-Win Income } \\
\text { (1) }\end{array}$ & $\begin{array}{c}\text { Quartile } 2 \\
\text { Pre-Win Income } \\
\text { (2) }\end{array}$ & $\begin{array}{c}\text { Quartile } 3 \\
\text { Pre-Win Income } \\
\text { (3) }\end{array}$ & $\begin{array}{c}\text { Quartile } 4 \\
\text { Pre-Win Income } \\
\text { (4) }\end{array}$ & $\begin{array}{c}\text { Aggregate } \\
\text { (5) }\end{array}$ \\
\hline Winner Wage Earnings & 0.66 & 0.50 & 0.53 & 0.49 & 0.53 \\
\hline Per-Adult Total Labor Earnings & 0.75 & 0.47 & 0.42 & 0.44 & 0.48 \\
\hline
\end{tabular}

Notes: This table presents the share of the observed difference in per-dollar earnings responses across prize sizes that is attributable to the extensive margin. We construct this difference using two prize bins: smaller winners $(\$ 30,000$ to $\$ 300,000)$ and larger winners $(\$ 1$ million+). For details on the decomposition see Appendix D.

\section{Propensities to earn and consume out of unearned income}

The size of the wealth effects that we estimated in the previous section can be hard to gauge as the observed responses to windfall gains should vary across individuals depending on a number of factors, such as the age at which the individual wins, her savings behavior, and the tax rates she faces. This issue motivates our analyses in this section. We begin by first studying how winning the lottery changes the unearned income that households allocate to consumption and leisure across years. Next, we estimate the share of yearly allocated unearned income that is spent on reducing labor versus increasing consumption. In other words, we estimate both the allocation of the windfall gains over time and the marginal propensities to earn (MPE) and consume (MPC) out of unearned income in a given period. In Section 6, we broaden this analysis to study how unearned income affects a wider range of individual and household behaviors. 


\subsection{Approaches to allocate windfall gains over time}

We start with the household budget constraint. It will be convenient to write it in the following form:

$$
c_{t}=y_{t}-\mathcal{T}\left(y_{t}\right)+\underbrace{(1+r) a_{t-1}-a_{t}-\mathcal{T}_{a}\left(r a_{t-1}\right)}_{\text {unearned income } \equiv n_{t}} .
$$

Here $c_{t}, y_{t}$, and $a_{t}$ denote consumption, labor earnings, and assets of the household in period $t, r$ is the interest rate, and $\mathcal{T}_{a}$ and $\mathcal{T}$ are taxes on capital income and labor earnings, respectively. The variable $n_{t}$ represents the total amount of unearned income used by the household in period $t$, or unearned income for short. Lottery winnings provide an exogenous increase in unearned income, and responses of earnings and consumption to this variation will be informative about the size of income effects.

There are two popular approaches to inferring the effect of lottery winnings on unearned income: the annuitization method and the capitalization method. ${ }^{17}$ Under the annuitization method, one assumes that winnings are smoothed perfectly over the remaining lifetime. It is easy to show that if a $k$-year-old individual decides to smooth her lottery winning $L$ over remaining $T-k$ years of life using a post-tax interest rate $r^{\text {post-tax }}$, then unearned income must increase by

$$
\frac{r^{\text {post-tax }}}{1+r^{\text {post-tax }}}\left(1-\left(\frac{1}{1+r^{\text {post-tax }}}\right)^{T-k+1}\right)^{-1} L .
$$

Under the capitalization method, one does not make any assumptions a priori about household behavior, but rather uses observed information about pre-tax capital income $r a_{t-1}$ and rate of return $r$ to impute ("capitalize") the value of wealth $a_{t-1}$. With this information in hand, one can then compute unearned income directly.

The two methods have strengths and weaknesses. The annuitization method has minimal data requirements and is easy to implement, but it relies on the assumption that households smooth their winnings perfectly. The capitalization method makes no assumptions about how agents smooth their winnings, but the imputation of wealth using asset returns can only be done approximately. Since a priori it is not clear which method is preferable, we estimate the average effect of winning a lottery on unearned income using both methods. For the annuitization method, we assume that all individuals live for $T=80$ years, and set $r^{\text {post-tax }}=2.5 \%$, which is close to the average risk-free real interest rate in the U.S. for our period of observation. ${ }^{18}$ For the capitalization method, we follow Saez and Zucman (2016) who calculate that the average pre-tax rate of return on taxable capital and business assets between 1999-2010 is approximately 5.4\%. We observe capital income directly for each household and use it to impute a measure of beginning-of-period $t$ wealth, $a_{t-1}$. We calculate capital income taxes by applying the relevant marginal tax rate to each source of capital income and then summing them up. Using these measures of assets and capital income taxes we

\footnotetext{
${ }^{17}$ Blundell, Pistaferri and Preston (2008), Jappelli and Pistaferri (2010), and Blundell, Low and Preston (2013) are some examples of papers that use the annuitization method, while Stewart (1939), Saez and Zucman (2016), and Smith, Zidar and Zwick (2020) are examples of applications of the capitalization method.

${ }^{18}$ The World Bank, DataBank (2020). Real interest rate (\%) - United States. Retrieved from https://data.worldbank.org/indicator/FR.INR.RINR?locations=US.
} 
construct household-level unearned income, which we then convert to a per-adult measure for consistent comparison between single and married households.

\subsection{Allocation of lottery winnings over time}

To study the allocation of lottery winnings over time, we estimate the regression model in equation (3.4) of Section 3.1, but now with the outcome variable specified as a measure of unearned income. In Figure 4.1a, we report the results of these event-study regressions for each of the two approaches outlined in the prior subsection. Under the annuitization method, the outcome variable in equation (3.4) is zero in years prior to the win (as given by equation (4.2)) and equal to the annuitized size of the lottery win after the win. Under the capitalization method, the outcome variable in equation (3.4) is the imputed unearned income in all periods. ${ }^{19}$

The capitalization approach shows no evidence of differential trends in the allocation of lottery winnings in the pre-win period (no differential trends is mechanical under the annuitization approach), providing support for a common trend in unearned income between current and later winners. Looking in the post-win period, the key finding is that the two approaches produce remarkably similar estimates. On average in the post-win period, unearned income increases by $\$ 7,497$ per period using the annuitization method, and $\$ 8,265$ per period using the capitalization method. This similarity suggests that households smooth their lottery winnings and that the simple life-cycle model and annuitization method provide a good approximation to households' savings behavior. ${ }^{20}$ As expected, standard errors are larger under the capitalization method, likely because of the measurement error inherent with this approach.

\footnotetext{
${ }^{19}$ The values of $Y_{t}$ for $t=w-1$ and $t=w$ under the capitalization method are difficult to interpret because the time of the lottery win within the year is unknown. For this reason, we exclude the corresponding event times in Figure 4.1a.

${ }^{20}$ Cesarini, Lindqvist, Notowidigdo and Östling (2017) find that earnings responses to lump-sum prizes are similar to earnings responses to installment prizes. This is a complementary approach for assessing the quality of the annuitization method as an approximation to households' savings behavior. The similarity of responses adds support to modeling lottery winners as behaving as predicted by textbook models of consumption smoothing.
} 


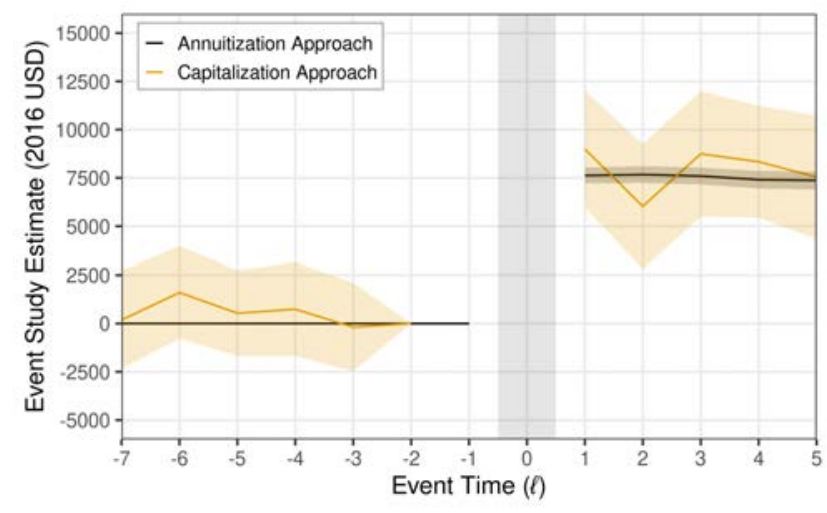

(a) Unearned Income

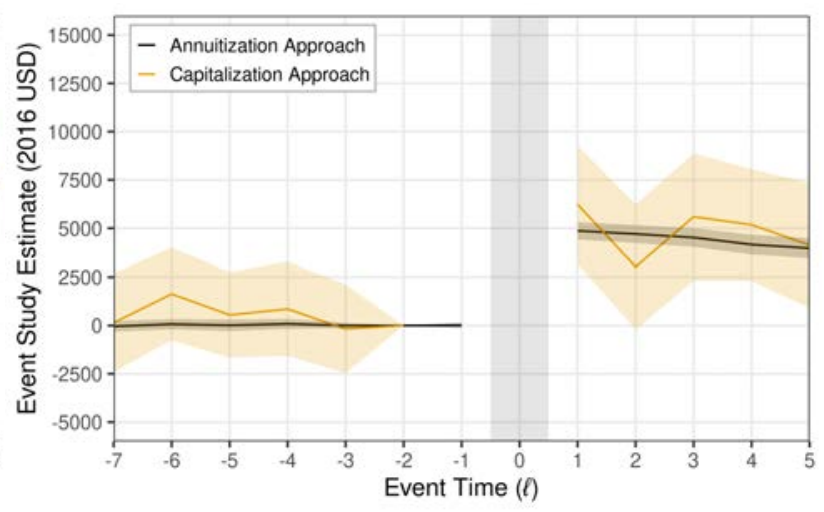

(b) Implied Consumption Expenditure

Figure 4.1: Comparing across methods to measure unearned income

Notes: This figure presents estimates of the impact of winning on unearned income $\left(n_{t}\right)$ and implied consumption expenditure $\left(c_{t}\right)$. All estimates are based on estimating a version of equation (3.4) (as described in Section 3.1) and reporting cohort-size-weighted averages of $\rho^{w, \ell}$ for each event time $\ell .90$ percent confidence intervals are displayed, clustering on winner. For each of unearned income and implied consumption expenditure, we plot the estimates for the annuitization and capitalization methods together to facilitate comparison. Due to our capitalization method inferring the change in wealth, the effect of winning on capital income in the win year (on-impact) directly affects the measure of wealth change in the win year as well as the prior year. For this reason, when estimating the effect of winning on $n_{t}$ and $c_{t}$ using the capitalization method, we require that not-yet treated cohorts win later than $\max \{w, w+\ell+1\}$ rather than $\max \{w, w+\ell\}$. For the same reason, we omit estimates for $\ell=-1$ and $\ell=0$ under the capitalization method.

Next, we estimate the same event-study regression as above, but replacing the outcome with household labor earnings taxes, $\mathcal{T}\left(y_{t}\right)$. Together with the event-study estimates for labor earnings which we reported in Section 3, this allows us to impute the effect of winning a lottery on consumption expenditure using the budget constraint identity (4.1). We report the response of consumption expenditure, imputed under both capitalization and annuitization methods, in Figure 4.1b. Using the annuitization method, we find that consumption increases in the first post-win year by $\$ 4,862$ (approximately 17 percent). This effect declines slightly over time such that on average in the post-win period, consumption increases by $\$ 4,413$ (approximately 15 percent) per period. Estimates of the consumption response using the capitalization method are very similar, with a post-win average increase in consumption of $\$ 5,176$ (approximately 16 percent) per period.

\subsection{Estimates of marginal propensities to earn and consume}

Using the IV model introduced in Section 3.3, defined by equations (3.5) and (3.6), we can estimate how an extra dollar in unearned income translates into an increase in consumption (MPC), a decrease in earnings (MPE), and a change in labor earnings taxes (MPT). This is done by 2SLS estimation of the two-equation system with the endogenous variable being the unearned income in a given period, and the outcome variable being labor earnings, consumption, or labor earnings taxes. Before discussing the results, it is useful to note that the MPC and the MPE must satisfy the accounting identity,

$$
\mathrm{MPC}-\mathrm{MPE}=1-\mathrm{MPT},
$$


and therefore MPC - MPE may exceed one.

Main estimates and heterogeneity across the income distribution. Table 4.1 presents the results both for the full sample and separately for each income quartile, similarly to Table 3.2. The estimates here are reported using the annuitization method; point estimates are very similar when we use the capitalization method and so we relegate them to the appendix (see Appendix Table A.3). Table 4.1 shows that labor earnings responses to a change in unearned income (i.e., MPEs) are quite large. An extra dollar in unearned income leads to a 52 cent reduction in labor earnings. Furthermore, there is substantial heterogeneity in MPEs across the income distribution. The MPE of households in the lowest quartile is -0.31 while the MPE of those in the highest quartile is -0.67 .

The imputed consumption responses are of similar magnitude to earnings responses, and also display heterogeneity across the income distribution. Imputed consumption increases, on average, by 58 cents in response to an extra dollar in unearned income. This response is largest for households in the lowest pre-win income quartile and it declines with pre-win income. Finally, the reduction in earnings leads to a reduction in labor earnings taxes of about 11 cents per extra dollar of unearned income.

Table 4.1: IV estimates of the effect of exogenous change in unearned income

\begin{tabular}{c|c|cccc}
\hline \hline & \multicolumn{5}{c}{ Sample } \\
\hline \multirow{2}{*}{ Outcome } & Full Sample & Quartile 1 & Quartile 2 & Quartile 3 & Quartile 4 \\
& & Pre-Win Income & Pre-Win Income & Pre-Win Income & Pre-Win Income \\
& $(1)$ & $(2)$ & $(3)$ & $(4)$ & $(5)$ \\
\hline \multirow{3}{*}{ Per-Adult Total Labor Earnings } & -0.5227 & -0.3080 & -0.5204 & -0.5893 & -0.6735 \\
& $(0.0146)$ & $(0.0240)$ & $(0.0197)$ & $(0.0221)$ & $(0.0389)$ \\
\hline \multirow{2}{*}{ Per-Adult Labor Earnings Taxes } & -0.1063 & -0.0395 & -0.0700 & -0.1254 & -0.1725 \\
& $(0.0051)$ & $(0.0063)$ & $(0.0075)$ & $(0.0063)$ & $(0.0155)$ \\
\hline \multirow{2}{*}{ Implied Consumption Expenditure } & 0.5836 & 0.7315 & 0.5496 & 0.5361 & 0.4990 \\
& $(0.0198)$ & $(0.0417)$ & $(0.0374)$ & $(0.0339)$ & $(0.0361)$ \\
\hline \hline
\end{tabular}

Notes: This table presents estimates of the mean effect of an extra dollar of unearned income. These estimates are calculated by first estimating a 2SLS regression, as described in Section 3.3, using unearned income $\left(n_{i, t}\right)$ as the endogenous variable. For each outcome, we then take cohortsize-weighted averages of $\beta^{w, \ell}$ for each event time $\ell$, and then take the mean across estimates for post-win event times $\{1,2,3,4,5\}$ to recover the mean effect of an extra dollar of unearned income. Column 1 reports mean effects of an extra dollar of unearned income for the full analysis sample. In columns 2 to 5, we report mean effects of an extra dollar of unearned income for subsamples of winners falling into each quartile of the pre-win distribution of per-adult adjusted gross income. We use the delta method to calculate standard errors (reported in parenthesis), clustering on winner.

Heterogeneity by age of the winner. Consistent with the life-cycle hypothesis, Appendix Figure B.4 shows that observed earnings responses to windfall gains increase with age. The annuitization method maps a windfall gain into a per-period flow of additional unearned income. Under the annuitization method, we 
can expect the effects of an additional dollar of unearned income to not vary by age. Figure 4.2 illustrates how an extra dollar in unearned income translates into changes in earnings and consumption for younger and older winners. The similarity of the effects between these two groups provides an additional piece of support for the annuitization method beyond our earlier comparison with the capitalization approach shown in Figure 4.1.

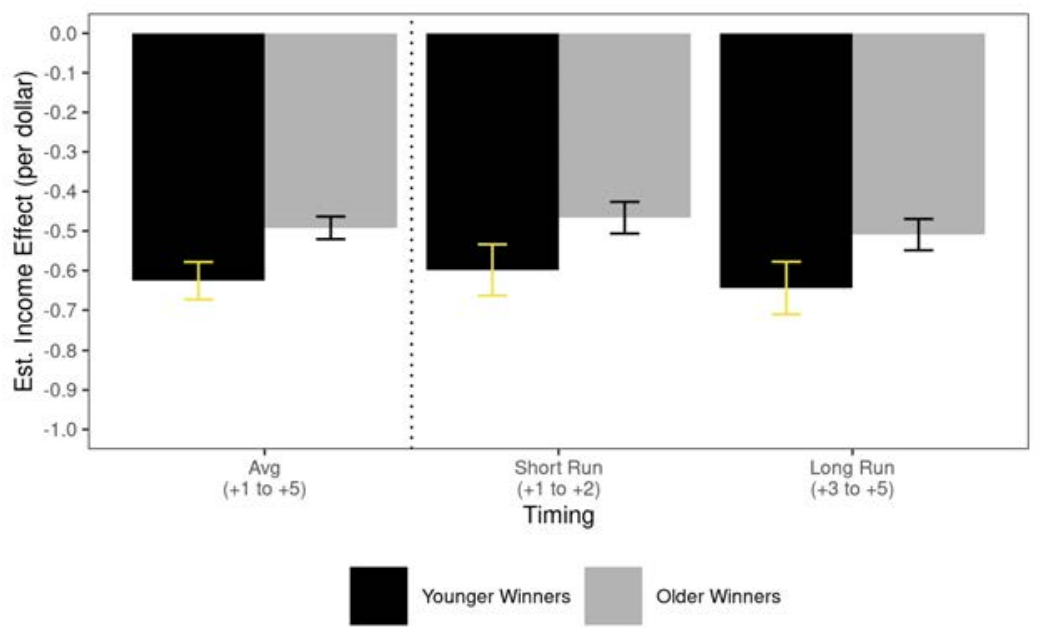

(a) Per-Adult Total Labor Earnings

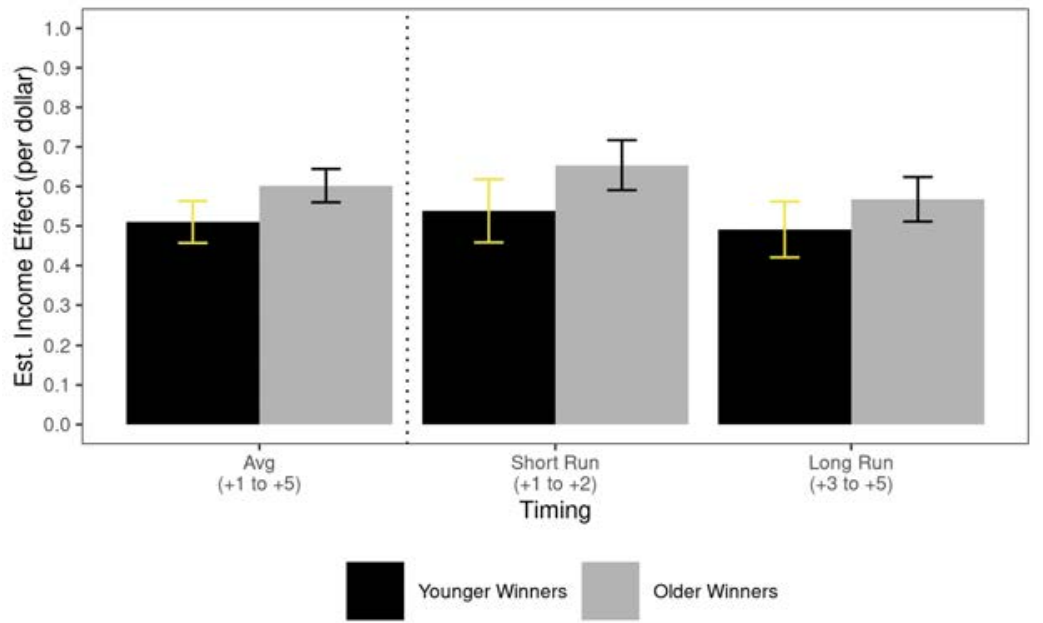

(b) Consumption Expenditure

Figure 4.2: Effects of exogenous change in unearned income by age of winner

Notes: This figure presents estimates of the mean effect of an extra dollar of unearned income on earnings and consumption expenditure. These estimates are calculated by first estimating a 2SLS regression, as described in Section 3.3, using unearned income $\left(n_{i, t}\right)$ as the endogenous variable. For each outcome, we then take cohort-size-weighted averages of $\beta^{w, \ell}$ for each event time $\ell$, and then take the mean across estimates for all postwin event times $\{1,2,3,4,5\}$ ("Avg $(+1$ to +5$)$ "), a shorter-run set of post-win event times $\{1,2\}$ ("Short Run (+1 to +2 )"), and a longer-run set of post-win event times $\{3,4,5\}$ ("Long Run $(+3$ to +5$)$ )"). For each temporal average, we report effects of unearned income for the subsample of younger winners (age 30 - 46) and older winners (age 47 - 64). 90 percent confidence intervals are displayed, clustering on winner. 


\section{Economic implications of earnings responses}

The labor market responses to exogenous changes in wealth and unearned income are important inputs for many questions in public finance. Here we illustrate the implications of our findings with two examples: the evaluation of the effect of introducing a UBI program and an increase in top marginal tax rates.

This section is organized as follows. In Section 5.1 we briefly review a canonical model of labor supply that helps us define the notions of income and substitution effects and serves as a point of departure for our model extensions. In Section 5.2 we present the extended model that we use throughout our analysis, making clear the exact mapping between our empirical estimates and the theoretical objects of interest. We then use this mapping to evaluate the impact of the introduction of a UBI program and an increase in the top marginal tax rate in Sections 5.3 and 5.4, respectively.

\subsection{A canonical model of labor supply}

A household $i$ chooses consumption $c_{i}$ and earnings $y_{i}$ to solve

$$
\max _{c_{i}, y_{i}} u_{i}\left(c_{i}, y_{i}\right)
$$

subject to a budget constraint

$$
c_{i}=(1-\tau) y_{i}+R \text {. }
$$

Here $\tau$ is the tax rate on earnings, $R$ is total unearned income, and $u_{i}$ is a twice-differentiable utility function that is concave in $(c,-y)$. We model households as deriving disutility from earnings rather than work hours since earnings responses will be the key object in our analysis, and this formulation does not require us taking a stance on how work hours translate into earnings or respond to tax changes. The optimal choice of this problem, $\left(c_{i}^{*}, y_{i}^{*}\right)$, is unique and, if interior, $y_{i}^{*}$ satisfies the first-order condition,

$$
u_{i, y}\left((1-\tau) y_{i}^{*}+R, y_{i}^{*}\right)=-(1-\tau) u_{i, c}\left((1-\tau) y_{i}^{*}+R, y_{i}^{*}\right),
$$

where $u_{i, c}$ and $u_{i, y}$ are the derivatives of $u_{i}$ with respect to consumption and earnings, respectively. Equation (5.3) implicitly defines the optimal earnings choice as a function of $(1-\tau)$ and $R$. Let $\zeta_{i}^{\mathrm{u}} \equiv \frac{\partial \ln y_{i}^{*}}{\partial \ln (1-\tau)}$ and $\eta_{i} \equiv \frac{\partial y_{i}^{*}}{\partial R}$ be the uncompensated (Marshallian) elasticity of earnings and the income effect, respectively. These two objects are a convenient way to summarize local properties of the utility function $u_{i}$ at the point $\left(c_{i}^{*}, y_{i}^{*}\right)$ (see Appendix H.1 for details). We assume that leisure is a normal good so that $\eta_{i} \leq 0$.

Closely-related to the Marshallian earnings function $y_{i}^{*}(1-\tau, R)$ is the Hicksian, or compensated, earnings function $h_{i}^{*}(1-\tau, \bar{u})$. This function is the solution to the cost-minimization dual of (5.1) for a given utility level $\bar{u}$. Let $\zeta_{i}^{\mathrm{c}} \equiv \frac{\partial \ln h_{i}^{*}}{\partial \ln (1-\tau)}$ be the compensated (Hicksian) elasticity of earnings. The relationship between the uncompensated and compensated elasticities is given by the Slutsky equation,

$$
\zeta_{i}^{\mathrm{c}}=\zeta_{i}^{\mathrm{u}}-(1-\tau) \eta_{i}
$$




\subsection{A dynamic heterogeneous-agent economy}

The canonical model of labor supply lacks many features that are needed to capture key patterns in the data, including savings, non-linearity in tax schedules, and extensive-margin responses. In this section we present a richer model that incorporates all of these features, and, therefore, can be taken to the data.

There is a measure one of heterogeneous households. Each household $i$ lives for $T \leq \infty$ periods and solves

$$
\max _{\left\{c_{i, t}, y_{i, t}, n_{i, t}\right\}_{t}} \sum_{t=1}^{T} \beta^{t-1} \mathfrak{u}_{i}\left(c_{i, t}, y_{i, t}\right)
$$

subject to a sequence of budget constraints,

$$
\begin{aligned}
c_{i, t} & =y_{i, t}-\mathcal{T}\left(y_{i, t}\right)+n_{i, t}, \\
n_{i, t} & =(1+\bar{r}) a_{i, t-1}-a_{i, t},
\end{aligned}
$$

and $a_{i, 0}$ are given initial assets of household $i . \mathcal{T}(\cdot)$ is a twice-differentiable tax function with $\mathcal{T}^{\prime}, \mathcal{T}^{\prime \prime} \geq 0$, and $\bar{r}$ is the post-tax interest rate that satisfies $\bar{r}=\beta^{-1}-1$.

Utility function $\mathfrak{u}_{i}$ takes the form,

$$
\mathfrak{u}_{i}(c, y)=\left\{\begin{array}{ll}
u_{i}(c, y) & \text { if } y>0 \\
u_{i}(c, y)+v_{i} & \text { if } y=0
\end{array},\right.
$$

where $u_{i}$ is a twice-differentiable function that is concave in $(c,-y)$, and $v_{i} \geq 0$. The parameter $v_{i}$ captures utility from quitting the labor force and is a simple modeling device to capture extensive-margin responses (see, e.g., Kleven and Kreiner, 2006; Jacquet, Lehmann and Van der Linden, 2013).

In this model, households are heterogeneous in their initial wealth levels $a_{i, 0}$, utility functions $u_{i}$, and benefits of non-working $v_{i}$. Hence, households have different optimal levels of earnings $\left\{y_{i, t}^{*}\right\}_{i, t}$. However, because the dynamic problem of the household is stationary, $y_{i, t}^{*}$ is independent of $t$. This feature of the model substantially simplifies our arguments and exposition, as we can drop subscripts $t$ from the analysis. This model specification, however, is not restrictive for our analysis. In Appendix I we consider an overlapping generations model in which households must retire at some fixed age, and show that the results derived in this section extend directly to that environment as well.

Let $H(y)$ be the earnings distribution in any period. We assume that $H(y)$ has a well-defined density $h(y)$. For any variable $\left\{x_{i}\right\}_{i}$, we use $\mathbb{E} x_{i}$ to denote its population average in equilibrium given function $\mathcal{T}(\cdot)$. We use $\mathbb{E}_{y}$ and $\mathbb{E}_{\geq y}$ to denote the average over all households who have earnings $y_{i}=y$ and $y_{i} \geq y$, respectively. Aggregate earnings $Y$ in this economy are

$$
Y \equiv \mathbb{E} y_{i}^{*}=\int\left[\mathbb{E}_{y} y_{i}^{*}\right] h(y) d y
$$

We use a perturbational approach to study the responses of this economy to various policy reforms. Since we allow for extensive-margin responses, small perturbations of taxes and transfers may have a dis- 
continuous effect on optimal choices of any household $i$. We assume that the underlying heterogeneity in preferences is such that the earnings density $h(y)$ changes smoothly to all perturbations we consider below.

We do not need to take a stand on whether a household consists of one or two adults. In both cases, $c_{i}$ and $y_{i}$ correspond to household $i$ 's total consumption and labor earnings, respectively. Our theory does not require us to take a stand on how household earnings and consumption are allocated between the adults within a two-person household. ${ }^{21}$

While our model is substantially richer than the framework presented in Section 5.1, there is a close connection between maximization problems (5.1) and (5.5). To see this, note that since the utility function is time-separable, household $i$ 's problem (5.5) can be split into two subproblems (see, e.g., MaCurdy, 1983; Blomquist, 1985; Blundell and Walker, 1986). An outer subproblem characterizes the optimal choice of unearned income $\left\{n_{i, t}^{*}\right\}_{t}$, where $n_{i, t}^{*}$ is independent of $t$ given our assumption that $\beta^{-1}=1+\bar{r}$. The optimal bundle $\left(c_{i}^{*}, y_{i}^{*}\right)$ is determined by the trade-off between the intensive and extensive margins. The optimal intensive-margin response $\left(c_{i}^{\mathrm{int}}, y_{i}^{\mathrm{int}}\right)$ is the solution to

$$
\max _{c_{i}, y_{i}} u_{i}\left(c_{i}, y_{i}\right)
$$

subject to

$$
c_{i}=y_{i}-\mathcal{T}\left(y_{i}\right)+n_{i}^{*} .
$$

The choice between intensive and extensive-margin responses is then determined by

$$
\max \left\{u_{i}\left(c_{i}^{\mathrm{int}}, y_{i}^{\mathrm{int}}\right), u_{i}\left(n_{i}^{*}-\mathcal{T}(0), 0\right)+v_{i}\right\}
$$

Importantly, the same properties of $u_{i}$ that are summarized by income and substitution effects in problem (5.1) also govern the optimal responses to perturbations in problem (5.8). We describe this in more detail below.

\subsubsection{Marginal propensities: MPE and MPT}

Before considering specific policy experiments, it will be useful to present the theoretical analogues to MPE and MPT that we estimated in Section 4. Suppose that wealth of household $i$ increases unexpectedly by the amount $L$ in period $t$, and that we set, without loss of generality, to 1 . We are interested in the marginal impact of this windfall. For any equilibrium variable $x\left(L^{\mathrm{ann}}\right)$ that is differentiable in $L^{\mathrm{ann}}$, let the marginal effect of this increase, $\partial_{L} x$, be defined as $\partial_{L} x \equiv \lim _{L^{\mathrm{ann}} \rightarrow 0} \frac{x\left(L^{\mathrm{ann}}\right)-x(0)}{L^{\mathrm{ann}}}$, where $L^{\text {ann }}$ is the annuitized value of $L$ as defined in equation (4.2). We choose this definition so that $\partial_{L} n_{i}^{*}=1$ and all marginal responses are expressed per dollar increase in unearned income in a given period.

Since households may respond to a change in wealth along the extensive margin, individual responses, such as $\partial_{L} y_{i}^{*}$, may not be well defined. Instead, we focus on earnings responses averaged over groups of

\footnotetext{
${ }^{21}$ Strictly speaking, when considering a two-adult household, one may want to introduce an additional utility benefit $\tilde{v}_{i}$ to capture the possibility that only one of the spouses responds to a given perturbation by quitting work. Extending our theory to this case is straightforward (and does not change any of our empirical insights), but it requires introducing additional notation that makes our discussion less transparent.
} 
households. Let $\Lambda_{L}\left(y, L^{\mathrm{ann}}\right)$ be the fraction of households with earnings $y$ who would stop working if their unearned income increased by $L^{\text {ann }}$. The parameter $\lambda_{L}(y) \equiv \partial_{L} \Lambda_{L}\left(y, L^{\text {ann }}\right)$ is the marginal propensity to stop working for households with earnings $y$. Similarly, we extend the definitions of the MPE and MPT for households with earnings $y$ :

$$
\operatorname{MPE}(y) \equiv \partial_{L} \mathbb{E}_{y} y_{i}^{*}, \quad \operatorname{MPT}(y) \equiv \partial_{L} \mathbb{E}_{y} \mathcal{T}\left(y_{i}^{*}\right)
$$

The population averages of these objects are the averages of $\operatorname{MPE}(y)$ and $\operatorname{MPT}(y)$ over the earnings distribution:

$$
\operatorname{MPE} \equiv \int \operatorname{MPE}(y) d H(y), \quad \operatorname{MPT} \equiv \int \operatorname{MPT}(y) d H(y)
$$

These correspond to the moments that we estimated in Section 4.

The marginal propensity to stop working, $\lambda_{L}(y)$, is well defined because we assume that the earnings density responds smoothly to all perturbations. This, in turn, implies that the $\operatorname{MPE}(y)$ and $\operatorname{MPT}(y)$ are also well defined. Lemma 1 presents explicit expressions for their values.

Lemma 1. $\operatorname{MPE}(y)$ and $\operatorname{MPT}(y)$ are well defined for all $y$ and satisfy

$$
\begin{aligned}
& \operatorname{MPE}(y)=\operatorname{MPE}^{\mathrm{int}}(y)+\operatorname{MPE}^{\text {ext }}(y), \\
& \operatorname{MPT}(y)=\operatorname{MPT}^{\mathrm{int}}(y)+\operatorname{MPT}^{\text {ext }}(y)
\end{aligned}
$$

where

$$
\begin{array}{rlrl}
\operatorname{MPE}^{\text {int }}(y) & \equiv \mathbb{E}_{y} \frac{\eta_{i}}{1+\theta_{i} \zeta_{i}^{\mathrm{c}}}, & \operatorname{MPE}^{\mathrm{ext}}(y) \equiv-y \lambda_{L}(y), \\
\operatorname{MPT}^{\text {int }}(y) \equiv \mathcal{T}^{\prime}(y) \mathbb{E}_{y} \frac{\eta_{i}}{1+\theta_{i} \zeta_{i}^{\mathrm{c}}}, & \operatorname{MPT}^{\text {ext }}(y) \equiv-[\mathcal{T}(y)-\mathcal{T}(0)] \lambda_{L}(y),
\end{array}
$$

and $\theta_{i} \equiv \frac{\mathcal{T}^{\prime \prime}\left(y_{i}^{*}\right) y_{i}^{*}}{1-\mathcal{T}^{\prime}\left(y_{i}^{*}\right)}$

Proof. See Appendix H.2.

Lemma 1 shows that the expressions for the $\operatorname{MPE}(y)$ and $\operatorname{MPT}(y)$ consist of two terms, capturing intensive- and extensive-margin responses. The extensive-margin responses are proportional to $\lambda_{L}(y)$, which is simply the marginal propensity to stop working of households making $y$ dollars on average. The intensive-margin responses are proportional to $\mathbb{E}_{y} \frac{\eta_{i}}{1+\theta_{i} \zeta_{i}^{\mathrm{c}}}$. To understand why they take this form, observe that an increase in unearned income has two effects. The direct effect is the standard income response that calls for a reduction in earnings by $\eta_{i}$. The second effect is indirect, and is driven by the nonlinearity in the tax function $\mathcal{T}(\cdot)$. When a household reduces its earnings, the marginal tax rate that it faces may fall due to tax progressivity. The substitution effect, then, leads to an earnings adjustment in response to the new marginal tax rate. The post-tax price of earnings (or retention rate) $1-\tau_{i}$ increases by $\mathcal{T}^{\prime}\left(y_{i}^{*}\right)-\mathcal{T}^{\prime}\left(y_{i}^{*}-\partial_{L} y_{i}^{\text {int }}\right)=-\mathcal{T}^{\prime \prime}\left(y_{i}^{*}\right) \partial_{L} y_{i}^{\text {int }}$. This change in the marginal price of earnings applies only to the last, marginal dollar. Therefore, the labor supply response to the marginal price change is governed by 
the compensated substitution effect $\frac{\partial h_{i}^{*}}{\partial(1-\tau)} \cdot{ }^{22}$ Putting these two results together and taking the average over all households with earnings $y$ implies that the intensive-margin effect is proportional to $\mathbb{E}_{y} \frac{\eta_{i}}{1+\theta_{i} \zeta_{i}^{c}}$.

One useful special case of Lemma 1 is when the tax function $\mathcal{T}(\cdot)$ takes the form $\mathcal{T}(y)=y-$ const. $\times$ $y^{1-\theta}$, where $\theta$ is a parameter capturing the progressivity in the tax code. It is immediate to verify that if the tax function takes this form then $\theta_{i}=\theta$ for all $i$. This tax function is commonly used in public finance. Heathcote, Storesletten and Violante (2017) showed that it is a good approximation of tax rates in the U.S. and estimated $\theta=0.18$.

Equipped with Lemma 1, we can now examine the economic implications of various policy reforms. Before that, however, it is useful to observe a few potential concerns. First, one might be concerned about extrapolating measures estimated on the set of households who won the lottery to the general population. Table 2.1 suggests that the winners in our data are broadly comparable to the general population, at least in terms of observable characteristics. As always, we cannot rule out differences between lottery winners and the general population in terms of characteristics that we do not observe. However, evidence from national surveys (e.g., National Opinion Research Center Survey on Gambling and the Gallup Poll) and past academic work (e.g., Kearney, 2005) find that a little over half of the U.S. population reports participating in lotteries each year. Second, in the case of a two-adult household, the theoretical MPE is a measure of how household earnings respond to changes in household wealth. This raises a possible concern that households respond to lottery winnings as if the change in wealth were exclusive to the winner rather than shared across household members. If this is the case, it may imply that households respond differentially depending on the identity of the winner. Empirically, we explore this concern in Section 6.4 and find that winner identity does not affect household responses. There are two possible explanations for this finding. The first explanation is legal in nature: in the U.S., lottery winnings are legally treated as shared household wealth in two-adult households. The second explanation is about the type of model that governs household behavior. Even if lottery wealth were not split equally among household members, a unitary household model would predict that labor supply only depends on the total amount of resources at the household's disposal.

\subsection{Universal Basic Income}

UBI has received a great deal of public interest in recent years (see, e.g., Kearney and Mogstad (2019) and Hoynes and Rothstein (2019) for an overview). Both policymakers and researchers have advocated for an unconditional, tax-exempt cash transfer. In this section we consider the implications of the introduction of a UBI program on tax rates and earnings.

We model a UBI as a uniform, annual lump-sum transfer of size $B$ to every household. Since there are few concrete proposals for how a UBI program should be funded, we chose the simplest financing scheme and assume that it is funded with a proportional surcharge $\delta(B)$ on labor earnings. The tax revenues are

$$
\mathcal{R}(B)=\mathbb{E}\left[-B+\delta(B) y_{i}^{*}(B)+\mathcal{T}\left(y_{i}^{*}(B)\right)\right],
$$

where $\delta(B)$ is set such that $\mathcal{R}(B)=\mathcal{R}(0)$, i.e., revenue neutral.

\footnotetext{
${ }^{22}$ See also Saez (2001) for a simple graphical proof of this fact.
} 
Consider the marginal impact of introducing a UBI program in our model. Let $\partial_{B} x \equiv \lim _{B \rightarrow 0} \frac{x(B)-x(0)}{B}$ be the marginal impact of UBI on any variable $x$ that is differentiable in $B$. Differentiating equation (5.10), we find that the marginal impact on tax revenues is

$$
\partial_{B} \mathcal{R}=-1+Y \partial_{B} \delta+\partial_{B} \mathbb{E} \mathcal{T}\left(y_{i}^{*}(B)\right)
$$

The first two terms on the right side of expression (5.11) capture mechanical effects, i.e., the effects on tax revenues if household earnings were unchanged by the perturbation. There are two types of mechanical effects. The first type of mechanical effect comes from the transfer itself. Each dollar of UBI decreases tax revenues by 1 dollar, which is captured by the -1 term on the right side of equation (5.11). The second type of mechanical effect emerges from the need to increase tax rates to finance the UBI, and is captured by $Y \partial_{B} \delta$. The last term on the right side of $(5.11), \partial_{B} \mathbb{E} \mathcal{T}\left(y_{i}^{*}(B)\right)$, is the behavioral effect, i.e., the change in tax revenues due to households' earnings responses to the introduction of the UBI.

In a similar fashion to our derivation of the $\operatorname{MPT}(y)$ in Lemma 1 , we can express $\partial_{B} \mathbb{E} \mathcal{T}\left(y_{i}^{*}(B)\right)$ as a function of income and substitution effects, extensive-margin responses, and $\partial_{B} \delta$. Since the UBI is revenue neutral, we must have $\partial_{B} \mathcal{R}=0$, which then allows us to find $\partial_{B} \delta$ from setting the right side of (5.11) to zero. Revenue neutrality also allows us to determine the total earnings response, $\partial_{B} Y$. We assume that $\mathcal{T}(\cdot)$ is to the left of the peak of the Laffer curve so that a small increase in marginal tax rates $\delta$ increases tax revenues.

Proposition 1. The marginal impact of the UBI is

$$
\begin{aligned}
\partial_{B} \mathbb{E} \mathcal{T}\left(y_{i}^{*}(B)\right) & =\mathbb{E} \tau_{i}\left[\frac{\eta_{i}}{1+\theta_{i} \zeta_{i}^{\mathrm{c}}}-\frac{y_{i}^{*}}{1-\tau_{i}} \frac{\zeta_{i}^{\mathrm{u}}}{1+\theta_{i} \zeta_{i}^{\mathrm{c}}} \partial_{B} \delta\right]-\int[\mathcal{T}(y)-\mathcal{T}(0)] \lambda_{B}(y) d H(y), \\
\partial_{B} \delta & =\frac{1-\mathbb{E}\left[\tau_{i} \frac{\eta_{i}}{1+\theta_{i} \zeta_{i}^{\mathrm{c}}}\right]+\int[\mathcal{T}(y)-\mathcal{T}(0)] \lambda_{B}(y) d H(y)}{Y-\mathbb{E} \frac{\tau_{i} y_{i}^{*}}{1-\tau_{i}} \frac{\zeta_{i}^{\mathrm{u}}}{1+\theta_{i} \zeta_{i}^{\mathrm{c}}}}, \\
\partial_{B} Y & =\mathbb{E}\left[\frac{\eta_{i}}{1+\theta_{i} \zeta_{i}^{\mathrm{c}}}-\frac{y_{i}^{*}}{1-\tau_{i}} \frac{\zeta_{i}^{\mathrm{u}}}{1+\theta_{i} \zeta_{i}^{\mathrm{c}}} \partial_{B} \delta\right]-\int y \lambda_{B}(y) d H(y) .
\end{aligned}
$$

Moreover, if $\mathcal{T}(\cdot)$ is to the left of the peak of the Laffer curve, then $\lambda_{B}(y) \geq \lambda_{L}(y)$ for all $y$, and $\partial_{B} \delta \geq 0$.

Proof. See Appendix H.3.

The expression for $\partial_{B} \mathbb{E} \mathcal{T}\left(y_{i}^{*}(B)\right)$ is closely related to the expression for the $\operatorname{MPT}(y)$ in Lemma 1, with two exceptions. First, there is an additional term that is proportional to $\zeta_{i}^{\mathrm{u}} \partial_{B} \delta$, which captures the intensive-margin response of earnings to higher tax rates. Second, the extensive-margin response depends on the parameter $\lambda_{B}(y)$, which is the marginal propensity to stop working in response to the UBI. This propensity is not the same as the marginal propensity to stop working following an increase in wealth, $\lambda_{L}(y)$, since $\lambda_{B}(y)$ captures extensive-margin responses to both higher unearned income and higher tax rates. However, since higher marginal tax rates lower the benefits of working relative to not working, we must have $\lambda_{B}(y) \geq \lambda_{L}(y)$. 
The expression for $\partial_{B} Y$ describes the response of earnings to the introduction of the UBI. There is a common view that the effect of the UBI on earnings is summarized by the compensated elasticity of labor supply. ${ }^{23}$ Lemma 1 shows that this view is correct only if one abstracts from extensive-margin responses (set $\lambda_{B}(y)=0$ for all $y$ ), heterogeneity $\left(y, \eta, \zeta^{\mathrm{u}}\right.$ and $\zeta^{\mathrm{c}}$ are all independent of $i$ ), and pre-existing taxes ( $\tau_{i}=\theta_{i}=0$ for all $i$ ). Under such assumptions, if we substitute expression (5.13) into (5.14), we indeed obtain that $\partial_{B} Y=\eta-\zeta^{\mathrm{u}}=-\zeta^{\mathrm{c}}$. However, if any of these simplifying assumptions do not hold, there is no simple link between the earnings response $\partial_{B} Y$ and any single notion of elasticity.

The responses characterized in Proposition 1 depend on parameters $\left\{\lambda_{B}(y)\right\}_{y}$ and $\left\{\zeta_{i}^{\mathrm{u}}\right\}_{i}$ which cannot be estimated using the variation in unearned income that we used in the empirical part of our paper. However, we can use Proposition 1 to establish bounds on earnings and tax responses. There is considerable disagreement in the literature about the values of uncompensated elasticities, but the prevailing consensus seems to be that the uncompensated elasticity is positive. For example, Saez (2001), in his analysis of the optimal tax system, considers $[0,0.5]$ to be a plausible range for $\zeta_{i}^{\mathrm{u}}$. If we only assume that the uncompensated elasticity is non-negative, we can calculate bounds on tax rate and earnings responses as simple functions of the MPT and MPE.

Corollary 1. Suppose $\zeta_{i}^{\mathrm{u}} \geq 0$ for all $i$. Then

$$
\partial_{B} Y \leq \mathrm{MPE}, \quad \partial_{B} \delta \geq \frac{1-\mathrm{MPT}}{Y} .
$$

Proof. See Appendix H.4.

The formulas derived in Corollary 1 provide simple expressions that relate the estimated quantities from Section 4 to the impact of the introduction of UBI on tax rates and earnings. These bounds are obtained by abstracting from any potential disincentives for earnings from higher marginal tax rates themselves, and purely focus on the contribution of transfers. Not surprisingly, each dollar of transfers reduces average household earnings, $\partial_{B} Y$, by the MPE. The expression for $\partial_{B} \delta$ captures both mechanical and behavioral effects. Each dollar of UBI would require an increase in marginal tax rates of $1 / Y$ percentage points, which is the mechanical effect. In response, households reduce their earnings and therefore tax revenues for the government. This is the behavioral effect, and Corollary 1 shows that it is equal to $-\mathrm{MPT} / Y$.

We can use the estimates from Table 4.1 to evaluate these expressions. As shown in Table 4.1, the average MPE is slightly less than -0.5 , while the MPT is slightly less than -0.1 . Thus, each dollar of UBI will reduce earnings by slightly over 50 cents, and require an increase in tax rates that is roughly 10 percent higher than what would have been in the absence of any behavioral earnings responses. Average household earnings are roughly $\$ 50,000$. Thus, a UBI of $\$ 12,000$ a year ${ }^{24}$ would reduce average household earnings

\footnotetext{
${ }^{23}$ For example, Keane (2011) in his widely-cited survey says (p. 969) "To a first order approximation (ignoring heterogeneity in wages/earnings in the population) the Hicks elasticity is the correct concept to use in evaluating the labor supply effects of such a policy change [i.e. a UBI financed by a flat rate tax on earnings]."

${ }^{24}$ The number $\$ 12,000$ is a popular suggested amount of UBI (see, e.g., Stern, 2016, Lowrey, 2018, and Yang, 2018). If anything, our calculation understates the impact of such proposals since some of them suggest a transfer of this amount to each adult, rather than each household. Also, for comparison, the average annuitized lottery win in our data is $\$ 7,500$ per adult.
} 
by more than $\$ 6,000$, and require an earnings surcharge of approximately 27 percent on all households, out of which 2.5 percentage points is due to the behavioral response.

We can further build on Proposition 1 to study how various assumptions about the strength of the disincentive effect from higher marginal tax rates affect tax rates and earnings responses. To this end, we assume that there is no heterogeneity in elasticities, $\zeta_{i}^{\mathrm{u}}=\zeta^{\mathrm{u}}$ for all $i$, and simply use the expressions in Proposition 1 together with $\lambda_{B}(y) \geq \lambda_{L}(y)$ to establish bounds on $\partial_{B} \delta$ and $\partial_{B} Y$ for an arbitrary value of $\zeta^{\mathrm{u}}$. While it is not necessary for the analysis, we derive this bound under the assumption of log-linear taxation, consistent with Heathcote, Storesletten and Violante (2017). This implies that $\theta_{i}=\theta$ for all $i$, which both simplifies the expressions and is consistent with empirical studies of U.S. tax rates.

Corollary 2. Suppose $\zeta_{i}^{\mathrm{u}}=\zeta^{\mathrm{u}}$ and $\theta_{i}=\theta$ for all $i$. Then

$$
\begin{aligned}
\partial_{B} \delta & \geq \frac{1-\mathrm{MPT}}{Y-\frac{\zeta^{\mathrm{u}}}{1+\theta \zeta^{\mathrm{u}}} \int \mathcal{T}^{\prime}(y) D(y) d H(y)}, \\
\partial_{B} Y & \leq \mathrm{MPE}-(1-\mathrm{MPT}) \frac{\frac{\zeta^{\mathrm{u}}}{1+\theta \zeta^{\mathrm{u}}} \int D(y) d H(y)}{Y-\frac{\zeta^{\mathrm{u}}}{1+\theta \zeta^{\mathrm{u}}} \int \mathcal{T}^{\prime}(y) D(y) d H(y)},
\end{aligned}
$$

where $D(y) \equiv \frac{y}{1-\mathcal{T}^{\prime}(y)}+\theta y \operatorname{MPE}^{\mathrm{int}}(y)$.

Proof. See Appendix H.5.

The new terms that appear in the expressions derived in Corollary 2 are proportional to the uncompensated elasticity $\zeta^{\mathrm{u}}$. This is not surprising, since this elasticity governs the response of earnings to the surcharge $\partial_{B} \delta$. Corollary 2 shows that income effects, proportional to $\operatorname{MPE}^{\text {int }}(y)$, also interact with the uncompensated elasticity. To understand why, recall that the earnings response to changes in tax rates is proportional to $\frac{\zeta^{\mathrm{u}}}{1+\theta \zeta^{\mathrm{c}}}$, and the gap between compensated and uncompensated elasticities, $\zeta^{\mathrm{c}}-\zeta^{\mathrm{u}}$, is pinned down by the intensive-margin income effect due to Slutsky equation (5.4), which depends on $\operatorname{MPE}^{\text {int }}(y)$. Using Table 3.3, we see that the intensive-margin earnings response accounts for about $60 \%$ of the total $\operatorname{MPE}(y)$ except for lower-income (first quartile) households.

In Figure 5.1 we plot the bounds derived in Corollary 2 for various values $\zeta^{\mathrm{u}} \cdot{ }^{25}$ Not surprisingly, higher uncompensated elasticities imply a larger reduction in earnings and therefore a larger increase in tax rates. Our estimated income effects increase taxes by 0.2 percentage points and reduce earnings by around 500 dollars per 1,000 dollars of UBI payments relative to the case of no income effect, consistent with our discussion following Corollary 1 . Beyond a value of approximately 0.3 for the uncompensated elasticity, the upper bound on the earnings response $\partial_{B} Y$ is smaller than -1 , which implies that the UBI crowds out earnings by more than one-for-one.

\footnotetext{
${ }^{25}$ Since $\zeta^{\mathrm{u}}$ and $\zeta^{\mathrm{c}}$ are linked through the income effect, one can also do an alternative thought experiment by obtaining bounds for a given compensated elasticity $\zeta^{\mathrm{c}}$. We report these expressions in Appendix H.6 and plot bounds in Appendix Figure B.10.
} 


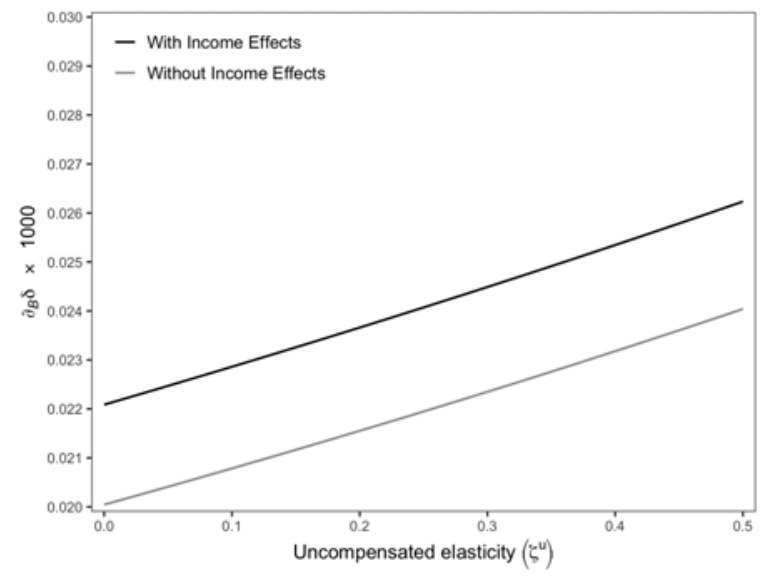

(a) Marginal tax rates

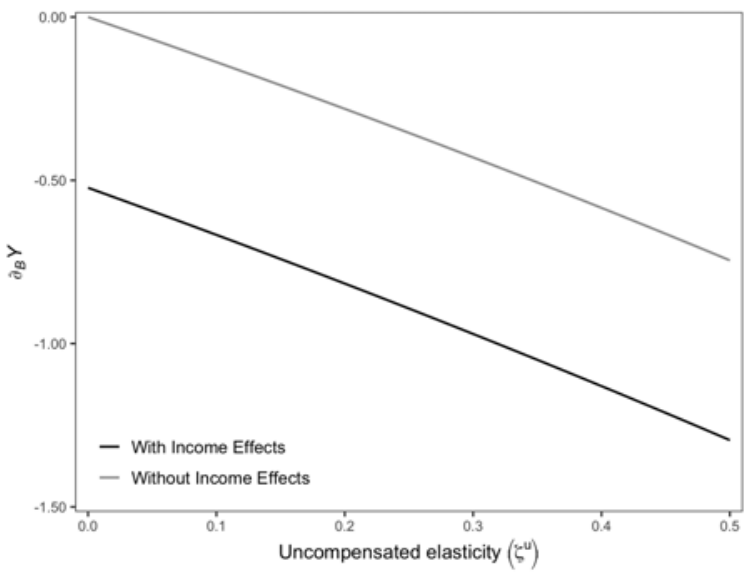

(b) Total labor earnings

Figure 5.1: The effect of an unconditional cash transfer on marginal tax rates and total labor earnings

Notes: In this figure, we report the results of our analysis of the effects of introducing a UBI program on a) marginal tax rates and b) total labor earnings. In both figures, the $x$-axis corresponds to a value of the uncompensated labor supply elasticity, $\zeta^{\mathrm{u}}$. In a), the dependent variable is a measure of the change in marginal tax rates due to the introduction of a marginal UBI, scaled by $\$ 1,000$. In $b$ ), the dependent variable is the change in total labor earnings due to the introduction of a marginal UBI. The darker line in both figures corresponds to the value of the dependent variable recovered using our estimated earnings responses for a given value of the uncompensated labor supply elasticity. The lighter line in both figures corresponds to the value of the dependent variable recovered for a given value of the uncompensated labor supply elasticity assuming no income effects.

\subsection{Top income tax rates}

We now consider effects of increasing the top marginal tax rate. In order to study top marginal tax rates, we assume that $\mathcal{T}^{\prime}(y)$ converges to some level $\bar{\tau}$ for all incomes above some threshold $\bar{y}$. Let $a \equiv \mathbb{E}_{\geq \bar{y}} \bar{y} \frac{y_{i}^{*}}{\bar{y}}$ be the average earnings of households in the top bracket, normalized by $\bar{y}$.

We define $\partial_{\tau} x$ to be the marginal impact on variable $x$ from an increase in the top rate $\bar{\tau}$, similarly to our earlier definitions of $\partial_{L}$ and $\partial_{B}$. The impact on tax revenues is given by

$$
\partial_{\tau} \mathcal{R}=(1-H(\bar{y}))\left[\mathbb{E}_{\geq \bar{y}}\left(y_{i}^{*}-\bar{y}\right)+\partial_{\tau} \mathbb{E}_{\geq \bar{y}} \mathcal{T}\left(y_{i}^{*}\right)\right]
$$

The terms in square brackets, $\mathbb{E}_{\geq \bar{y}}\left(y_{i}^{*}-\bar{y}\right)$ and $\partial_{\tau} \mathbb{E}_{\geq \bar{y}} \mathcal{T}\left(y_{i}^{*}\right)$, correspond to mechanical and behavioral effects, respectively. Following the same steps as in the proof of Proposition 1, we can establish Proposition 2.

Proposition 2. The marginal impact of higher top marginal tax rates on tax revenues is

$$
\partial_{\tau} \mathbb{E}_{\geq \bar{y}} \mathcal{T}\left(y_{i}^{*}\right)=\mathbb{E}_{\geq \bar{y}} \bar{\tau}\left[\bar{y} \eta_{i}-\frac{y_{i}^{*}}{1-\bar{\tau}} \zeta_{i}^{\mathrm{u}}\right]-\int_{\bar{y}}^{\infty}[\mathcal{T}(y)-\mathcal{T}(0)] \lambda_{\tau}(y) \frac{d H(y)}{1-H(\bar{y})},
$$

where $\lambda_{\tau}(y) \geq 0$ is the marginal propensity to stop working in response to an increase in the top rate $\bar{\tau}$.

Proof. See Appendix H.7.

The two terms on the right side of Proposition 2 capture the reduction in taxes due to adjustments in 
earnings along the intensive and extensive margins. To understand why the intensive-margin response takes this form, it is useful to review the intuition presented in Saez (2001). One can show (see, for example, Figure 1 in Saez, 2001) that from the point of view of a household with earnings $y \geq \bar{y}$, a 1 percentage point increase in the marginal tax rate on earnings above threshold $\bar{y}$ is equivalent to a 1 percentage point increase in marginal tax rates on all earnings together with an increase in unearned, or virtual, income of $0.01 \times \bar{y}$ dollars. Parameters $\zeta_{i}^{\mathrm{u}}$ and $\eta_{i}$ govern the intensive-margin earnings responses to each of these changes.

While we cannot recover $\lambda_{\tau}(y)$ from variation in unearned income, we know the sign of this parameter which allows us to establish bounds on revenue and earnings responses, similarly to those in Corollaries 1 and 2 .

Corollary 3. Let $\overline{\mathrm{MPE}}^{\mathrm{int}} \equiv \mathbb{E}_{\geq \bar{y}} \operatorname{MPE}^{\mathrm{int}}(y)$.

(a) If $\zeta_{i}^{\mathrm{u}} \geq 0$ for all $i$ who earn $y_{i}^{*} \geq \bar{y}$, then

$$
\begin{aligned}
& \partial_{\tau} Y \leq(1-H(\bar{y})) \bar{y} \times \overline{\mathrm{MPE}}^{\mathrm{int}}, \\
& \partial_{\tau} \mathcal{R} \leq(1-H(\bar{y})) \bar{y}\left[a-1+\bar{\tau} \times \overline{\mathrm{MPE}}^{\mathrm{int}}\right] .
\end{aligned}
$$

(b) If $\zeta_{i}^{\mathrm{u}}=\bar{\zeta}^{\mathrm{u}}$ for all $i$ who earn $y_{i}^{*} \geq \bar{y}$, then

$$
\begin{aligned}
& \partial_{\tau} Y \leq(1-H(\bar{y})) \bar{y}\left[\overline{\mathrm{MPE}}^{\mathrm{int}}-a \frac{\bar{\zeta}^{\mathrm{u}}}{1-\bar{\tau}}\right], \\
& \partial_{\tau} \mathcal{R} \leq(1-H(\bar{y})) \bar{y}\left[a-1+\bar{\tau}\left(\overline{\mathrm{MPE}}^{\mathrm{int}}-a \frac{\bar{\zeta}^{\mathrm{u}}}{1-\bar{\tau}}\right)\right] .
\end{aligned}
$$

Proof. See Appendix H.8.

Corollary 3 establishes upper bounds on revenue and total earnings responses from a marginal increase in the top tax rate. The inequalities in Corollary 3 become equalities if an increase in the top marginal rates leads to no extensive-margin response. All the expressions are per 100 percentage points tax increase. To understand these expressions and get an idea about their quantitative magnitude, consider expression (5.17). Each additional percentage point in top marginal tax rates raises the virtual income of households in the top bracket, conditional on them continuing to work, by $0.01 \times \bar{y}$. Since they continue to work, their average response to this increase in virtual income is governed by $\overline{\mathrm{MPE}}^{\text {int }}$. We saw in Table 4.1 that for the households in the highest bracket, the total MPE is -0.67 , with the intensive-margin response accounting for about 60 percent as shown in Table 3.3. Thus $\overline{\mathrm{MPE}}^{\mathrm{int}} \approx-0.4$. This implies that if the top marginal tax rates are increased for households earning over $\$ 500 \mathrm{~K}$ (which is approximately the top $1 \%$ of households), their virtual income will increase by $\$ 5,000$ for each percentage point of rate increase, and earnings would fall by at least $\$ 2,000$ per household. This implies that average household earnings $\partial_{\tau} Y$ would reduce by approximately $(1-H(\bar{y})) \times \$ 2,000=\$ 20$, or approximately 0.04 percent.

Similarly, expression (5.18) captures the effect on tax revenues of the increase in virtual income implied by the tax reform. The mechanical effect of this increase is proportional to $\bar{y}(a-1)$, while the behavioral effect is given by $\bar{y} \bar{\tau} \times \overline{\mathrm{MPE}}^{\text {int }}$. In the data, $a$ is approximately 3 and the top marginal tax rates are approxi- 
mately $0.5{ }^{26}$ This implies that the behavioral effect from higher virtual income is roughly 10 percent of the mechanical effect, and a 1 percentage point increase in top rates increases tax revenues by approximately $\$ 9,000$ from each household in the top 1 percent, or by about $\$ 90$ dollars per household. Since average tax revenues per household are approximately $\$ 13,000$ in our data, the upper bound on the increase in tax revenues is roughly 0.6 percent for each percentage point of increase in the top rates.

All of the calculations above only include effects from the change in virtual income, and abstract away from any disincentive effects from higher tax rates themselves. Part (b) of Corollary 2 shows how these disincentive effects can be incorporated into the analysis. In Figure 5.2, we use these formulas to plot $\partial_{\tau} Y$ and $\partial_{\tau} \mathcal{R}$, where everything is normalized per 1 percentage point increase in top marginal tax rates. ${ }^{27}$ To highlight the contribution of the income effect, we also plot the earnings and revenue responses if we set $\overline{\mathrm{MPE}}^{\text {int }}=0$. If the uncompensated elasticity takes values in the $[0,0.5]$ interval, a 1 percentage point increase in top tax rates increases revenues between 0.1 and 0.6 percent, and reduces earnings between 0.04 and 0.34 percent, with income effects contributing about 0.1 and 0.04 percentage points to these responses, respectively.

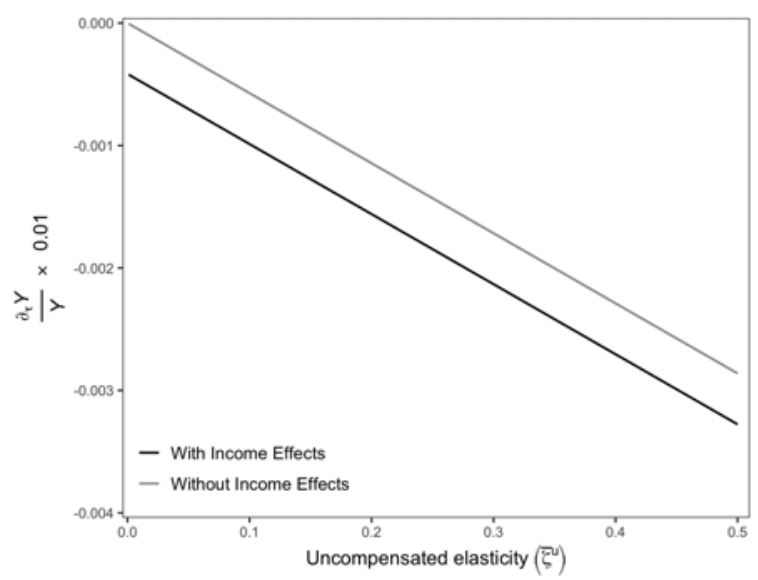

(a) \% change in total earnings $(Y)$

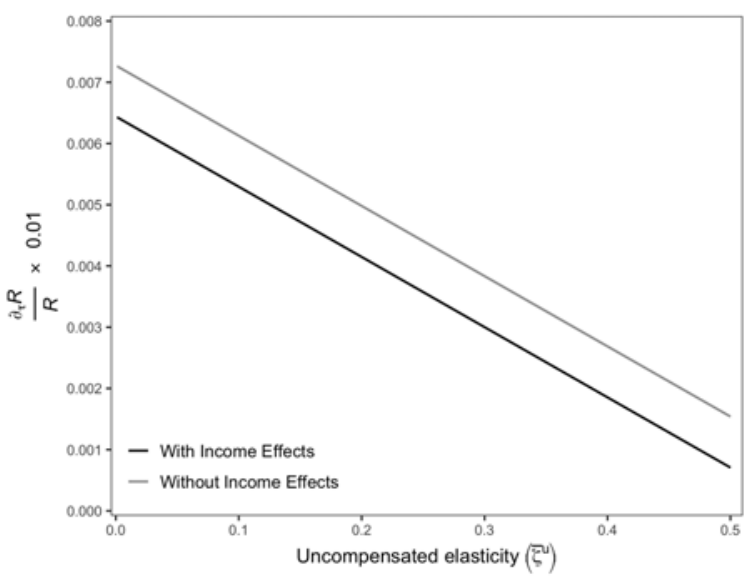

(b) \% change in revenues $(\mathcal{R})$

Figure 5.2: The effect of a $1 \mathrm{pp}$ increase in the top tax rate on total labor earnings and tax revenues

Notes: In this figure, we report the results of our analysis of the effects of an increase in top marginal tax rates on a) total labor earnings and b) total revenues. In both figures, the $x$-axis corresponds to a value of the uncompensated labor supply elasticity, $\zeta^{\mathrm{u}}$. In a), the dependent variable is a measure of the percentage change in total labor earnings due to an increase in top marginal tax rates. In $b$ ), the dependent variable is the percentage change in total revenues due to an increase in top marginal tax rates. In both figures, we scale the dependent variable by 0.01 , and so the units are the percentage change due to a 1 percentage point increase in the top marginal tax rate. The darker line in both figures corresponds to the value of the dependent variable recovered using our estimated earnings responses for a given value of the uncompensated labor supply elasticity. The lighter line in both figures corresponds to the value of the dependent variable recovered for a given value of the uncompensated labor supply elasticity assuming no income effects.

Finally, we note that there is a close connection between the formula derived in expression (5.20) and popular formulas for the optimal top marginal tax rates (see, e.g., Saez, 2001 and Diamond and Saez, 2011). If the social planner puts no weight on the utility of households at top of the income distribution, a common

\footnotetext{
${ }^{26}$ In 2016 tax returns, $a$ is 2.92 and $\bar{\tau}=39.6 \%$ (federal) $+11.3 \%$ (state, California).

${ }^{27}$ As in the UBI application, we also obtain bounds for a given compensated elasticity $\zeta^{\mathrm{c}}$. We report these expressions in Appendix H.9 and plot bounds in Appendix Figure B.11.
} 
assumption in the literature, then the optimal top marginal tax rate is the one that maximizes tax revenues, i.e., sets $\partial_{\tau} \mathcal{R}=0$. Furthermore, if the increase in the top marginal tax rates has no extensive-margin effects, then the optimal top tax rate, $\bar{\tau}^{*}$, satisfies

$$
a_{\bar{\tau}^{*}}-1+\bar{\tau}^{*}\left(\overline{\operatorname{MPE}}_{\bar{\tau}^{*}}^{\mathrm{int}}-a_{\bar{\tau}^{*}} \frac{\bar{\zeta}_{\bar{\tau}^{*}}^{\mathrm{u}}}{1-\bar{\tau}^{*}}\right)=0,
$$

where we use subscripts $\bar{\tau}^{*}$ to emphasize that all of the parameters should be measured under optimal tax rate $\bar{\tau}^{*}$ rather than the current tax rate $\bar{\tau}$ that we used in expression (5.20). The optimal tax rate used in Diamond and Saez (2011) is the solution to equation (5.21).

To make this formula operational one needs to assume how various economic parameters vary with $\bar{\tau}$. In applications, authors typically use estimates of parameters obtained under the current system directly in the optimal tax formula, implicitly assuming the these parameters are policy invariant. ${ }^{28}$ To illustrate the implications of equation (5.21) under this policy-invariance assumption, we assume that $a_{\bar{\tau}^{*}}, \overline{\mathrm{MPE}}_{\bar{\tau}^{*}}^{\text {int }}$, and $\bar{\zeta}_{\bar{\tau}^{*}}$ all take the same values as we estimate under the current system, and compute $\bar{\tau}^{*}$ which solves equation (5.21). We plot optimal values of $\bar{\tau}^{*}$ obtained using this approach in Figure 5.3, where we also compare how the results change if we set $\overline{\mathrm{MPE}}_{\bar{\tau}^{*}}^{\text {int }}=0 .{ }^{29}$ One insight from Figure 5.3 is that the importance of income effects in the top marginal tax rate formula depends on the value of the uncompensated elasticity. If that elasticity is zero, the mechanical effect from raising tax rates always exceeds the behavioral effect, and thus the revenue-maximizing top marginal tax rate is 100 percent. For higher values of the uncompensated elasticity of earnings, the importance of income effects increases, lowering optimal top tax rates.

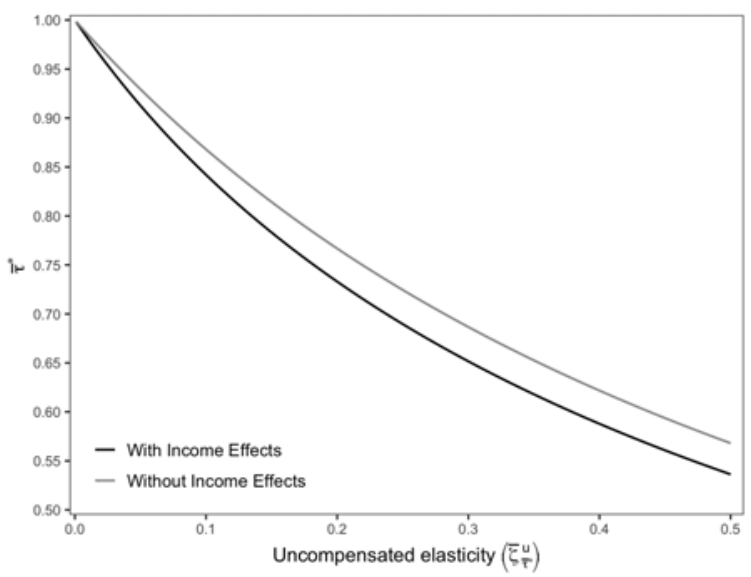

Figure 5.3: Revenue-maximizing top tax rates (with and without income effects)

Notes: In this figure, we report the results of our application of the optimal tax formula of Diamond and Saez (2011), taking expression (5.20) and assuming policy invariance to recover revenue-maximizing tax rates using equation (5.21). In the figure, the $x$-axis corresponds to a value of the uncompensated labor supply elasticity, $\bar{\zeta}_{\bar{\tau}^{*}}^{\mathrm{u}}$. The darker line corresponds to the value of the dependent variable recovered using our estimated earnings responses for a given value of the uncompensated labor supply elasticity. The lighter line corresponds to the value of the dependent variable recovered for a given value of the uncompensated labor supply elasticity assuming no income effects.

\footnotetext{
${ }^{28}$ Strictly speaking, it is impossible for $\zeta^{\mathrm{u}}, \eta$, and $\zeta^{\mathrm{c}}$ to all be independent of $\bar{\tau}$ as a quick glance at the Slutsky equation (5.4) confirms.

${ }^{29}$ We produce a version of this figure for a given compensated elasticity $\zeta^{\mathrm{c}}$ in Appendix Figure B.12.
} 


\section{Other empirical insights from lottery winnings}

So far, the analysis has been centered around the earnings responses to exogenous changes in household wealth and unearned income. We now broaden the analysis to address a number of other key economic questions: To what extent does low wealth prevent households from moving to better neighborhoods? Are certain types of households more likely to move than others, and what type of neighborhood do they move to? Does a rise in unearned income make individuals more likely to choose jobs with lower wages in exchange for more favorable non-wage attributes? Are wealth effects important for retirement decisions and the design of public pension systems? Does a lack of wealth constitute an important barrier to entrepreneurship? How does an increase in household wealth affect the incentives to marry or divorce? What can we learn about models of household behavior from a comparison of earnings responses of the winner and her spouse?

Below, we investigate these questions. In cases where the literature emphasizes the role of fixed costs of adjustment or financial constraints, we present estimates of wealth effects in the main text, and report estimated effects of unearned income in the appendix. Conversely, in cases where existing work primarily focuses on exogenous changes in unearned income, we present estimated effects of unearned income in the main text, and relegate estimates of wealth effects to the appendix. In both cases, we also report the counterfactual mean of the outcome of interest (i.e., the average outcome if counterfactually not winning the lottery) and the percentage change in the outcome implied by the size of the effect relative to the counterfactual outcome mean.

\subsection{Geographic mobility}

In this section, we study the effects of changes in wealth on geographic mobility and neighborhood choice. A large body of evidence has documented substantial and persistent geographic disparities in living standards, local labor market outcomes, and intergenerational mobility. ${ }^{30}$ These descriptive findings raise the question of why more households do not move in order to improve the local area that they and their families are exposed to. This pattern of immobility even arises when relatively short-distance moves would result in greater access to opportunity (Chetty, Friedman, Hendren, Jones and Porter, 2020).

Existing work in this literature has considered three distinct forces which may play a role in the apparent lack of moving to higher-quality neighborhoods. First, there may be preference-based explanations for the pattern of geographic sorting. For example, the presence of natural amenities (such as proximity to oceans, hills, and lakes) or lower costs of living may compensate residents in locations of lower quality in other dimensions. Second, households that are willing and able to move to a better neighborhood may not due to lack of information on the attributes of other neighborhoods, or on the potential benefits of moving to higher-quality locations (Bergman, Chetty, DeLuca, Hendren, Katz and Palmer, 2020; Bergman, Chan and Kapor, 2020). Lastly, households may wish to move to higher-quality neighborhoods, but face financial or non-financial frictions preventing them from doing so. For example, past work on internal migration in

\footnotetext{
${ }^{30}$ See for example Wilson (1987), Rosenbaum (1995), Ludwig, Liebman, Kling, Duncan, Katz, Kessler and Sanbonmatsu (2008); Ludwig, Duncan, Gennetian, Katz, Kessler, Kling and Sanbonmatsu (2013), Chetty, Hendren and Katz (2016a), De La Roca and Puga (2016), Chetty and Hendren (2018), Chyn (2018) and Aliprantis and Richter (2020).
} 
the U.S. argues that moving costs must be on the order of hundreds of thousands of dollars for the average household in order to rationalize the persistent differences in wages across places (Davies, Greenwood and Li, 2001; Kennan and Walker, 2011; Bayer and Juessen, 2012).

Our data has two advantages that allow us to contribute to this literature. First, we have a long and large panel data set of households. This enables us to study who moves and where, including features of both the origin and destination of the moves. Second, the lottery winnings allow us to infer how a change in wealth, in and of itself, affects geographic mobility. This variation allows us to isolate the effects of changes in wealth, holding fixed other determinants of mobility such as prices, preferences, information sets, and local economic conditions. In contrast to place-based policies and mobility vouchers, the variation in wealth induced by lottery winnings is specific to a household and not tied to geographic relocation.

Effect of wealth on geographic mobility. To measure geographic mobility, we use year-to-year changes in a household's Census tract. Our outcome of interest is a binary indicator equal to 1 if the household's Census tract in year $t$ is different from that in year $t-1$, and 0 otherwise. We study the effects of winning the lottery on geographic mobility by estimating regression model (3.4). The estimated coefficients of this regression are summarized in Figure 6.1. We find no evidence of differential trends in geographic mobility between current and later winners in years prior to winning. Winning the lottery leads to an immediate and sharp increase in the annual moving rate of approximately 3.5 percentage points (approximately 25 percent). As of the second year post-win, however, the effect of winning on annual moving rates largely dissipates, although annual moving rates of lottery winners remain elevated relative to those who have not yet won the lottery. Taken together, this temporal pattern suggests that winning the lottery induces households to move once shortly after winning.

Figure 6.1: Effect of winning on moving

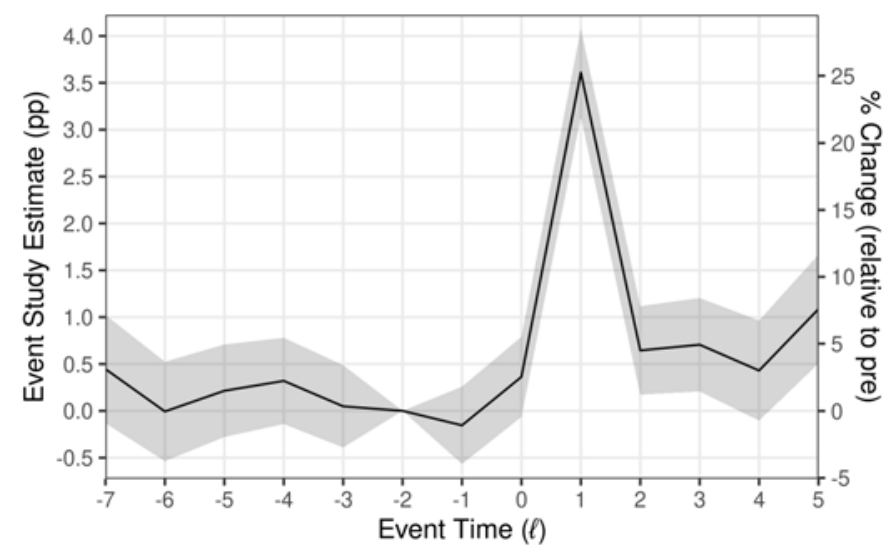

Notes: This figure presents estimates of the impact of winning on the propensity to move across Census tracts, based on estimating a version of equation (3.4) (as described in Section 3.1). The outcome is a binary indicator equal to 1 if the household has moved from their Census tract in that year (i.e., that the current Census tract is different from that in the prior year), and 0 otherwise. We then take cohort-size-weighted averages of $\rho^{w, \ell}$ for each event time $\ell .90$ percent confidence intervals are displayed, clustering on winner. Throughout, we use $w-2$ as the omitted event time. In addition to the cohort-size-weighted average effect in levels (left-hand axis), we also reports the average effect scaled by the mean of the outcome in omitted event time (right-hand axis) which can be interpreted as an average percentage change (relative to the baseline pre-win period) in the outcome. 
To study the importance of wealth for geographic mobility, we turn to estimating the IV model that we describe in Section 3.3. The resulting IV estimates are reported in Figure 6.2, where we scale responses per 100,000 dollars of additional wealth. The estimated effects mirror the temporal pattern discussed above: moving responses predominantly occur immediately after winning. Focusing on the first year post-win, we find that the propensity to move increases by approximately 2 percentage points for an extra 100,000 dollars in wealth. However, this average wealth effect masks a striking difference between households across the income distribution. Lower-income households are much more likely to move: the increase in the probability of moving for winners in the lowest quartile is around five times as large as that of the winners in the highest quartile for an extra 100,000 dollars in wealth.

Figure 6.2: Effect of wealth on geographic mobility

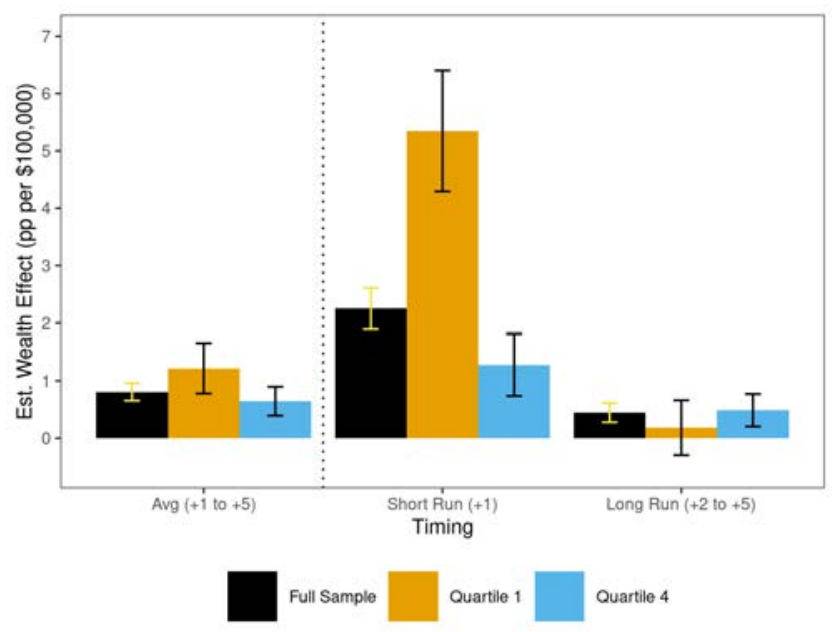

Notes: This figure presents estimates of the mean effect of an extra dollar of wealth on the propensity to move Census tract. The estimates are calculated by first estimating a 2SLS regression, as described in Section 3.3 for the binary outcome, then taking cohort-size-weighted averages of $\beta^{w, \ell}$ for each event time $\ell$, then taking the mean across estimates for all post-win event times $\{1,2,3,4,5\}$ ("Avg (+1 to +5 )"), a shorter-run set of post-win event times $\{1\}$ ("Short Run $(+1)$ "), and a longer-run set of post-win event times $\{2,3,4,5\}$ ("Long Run (+2 to +5 )"). In addition, for each temporal average, we report wealth effects for the full analysis sample ("Full Sample") as well as for the subsample of winners falling in the first ("Quartile 1") and fourth ("Quartile 4") quartile of the pre-win distribution of per-adult adjusted gross income. To ease interpretability, we scale moving responses by $\$ 100,000$.

Next, we explore the spatial dimension of the induced moves. We use the fact that Census tracts are nested within Census counties, and Census counties are nested within U.S. state boundaries. We use these three levels of geography to summarize the distance of a typical move. Let $d \in\{1,2,3\}$ denote three mutually exclusive and exhaustive types of moves, with $d=1$ corresponding to a move across tracts but within county, $d=2$ corresponding to a move across counties but within state, and $d=3$ corresponding to a move across states. Let $M_{i, t}$ be a binary indicator equal to 1 if the household's Census tract in year $t$ is different from that in year $t-1$, and 0 otherwise. Furthermore, let $M_{i, t}^{d}$ denote an indicator corresponding 
to a move of type $d$. By definition, we can decompose the total probability of moving as follows:

$$
\underbrace{\mathbb{P}\left[M_{i, t}=1\right]}_{\text {total prob. of moving }}=\underbrace{\mathbb{P}\left[M_{i, t}^{1}=1\right]}_{\begin{array}{c}
\text { prob. of moving } \\
\text { across tract \& within county }
\end{array}}+\underbrace{\mathbb{P}\left[M_{i, t}^{2}=1\right]}_{\begin{array}{c}
\text { prob. of moving } \\
\text { across county \& within state }
\end{array}}+\underbrace{\mathbb{P}\left[M_{i, t}^{3}=1\right]}_{\begin{array}{c}
\text { prob. of moving } \\
\text { across states }
\end{array}}
$$

It is straightforward to show that the total effect of winning on geographic mobility can be decomposed into the effect on each of the move types. ${ }^{31}$

In Figure 6.3 we focus on the first year post-win and quantify the contribution of each type of move $d$ on the total effect of winning on geographic mobility. On average and across the income distribution, we find that more than 80 percent of moves are within state, and the majority of moves occur across quite nearby locations, i.e., across tracts within the same county.

Figure 6.3: Decomposition of the moving response by geographic unit

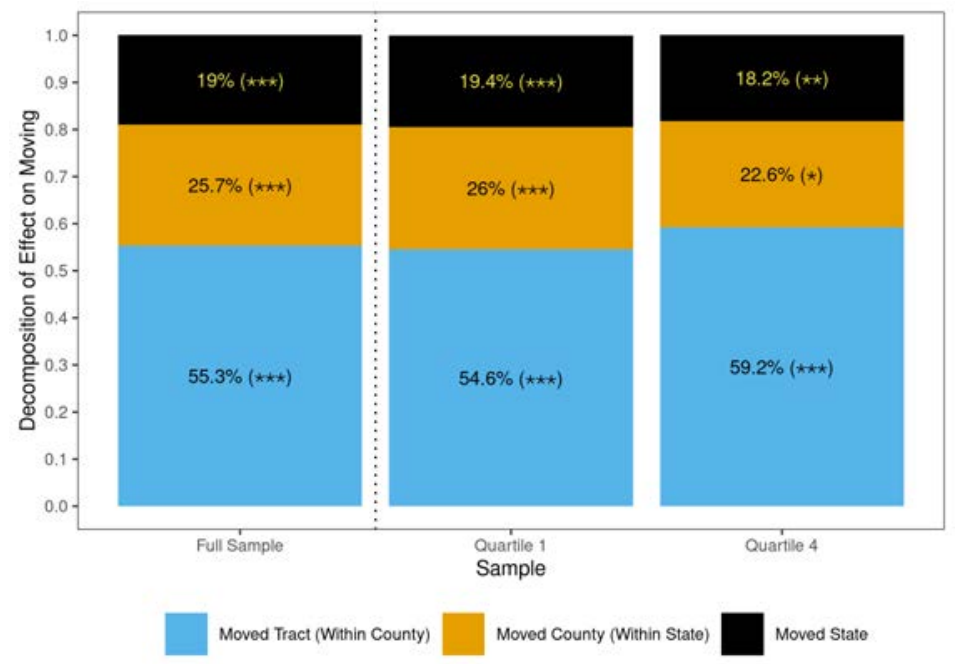

Notes: This figure presents a decomposition of the impact of winning on the propensity to move Census tracts in terms of the distance moved. Given that Census tracts are nested within Census counties, and Census counties are nested within U.S. states, we decompose overall Census tract moving into a) moves across Census tract but within Census county, b) moves across Census county but within state, and c) moves across state. For each, we define a corresponding binary outcome and estimate a version of equation (3.4) (as described in Section 3.1), focusing on effects in the first year post-win. We then divide each estimate by the total effect on across-tract moving, as reported in Figure 6.1, to arrive at the share of the total moving effect. We report this decomposition separately for the full analysis sample ("Full Sample") as well as for the subsample of winners falling in the first ("Quartile 1") and fourth ("Quartile 4") quartile of the pre-win distribution of per-adult adjusted gross income. Next to each share, we also summarize the statistical significance of the underlying estimate, with $\star \star \star$ for significance at the $99 \%$ level, $\star \star$ for significance at the $95 \%$ level, and $\star$ for significance at the $90 \%$ level.

Taken together, the above results suggest that winning the lottery leads to a sizable, swift, and nonrecurring moving response, especially among lower-income households. Among these moves, the vast majority takes place across locations close to the winner's current home. This observation guides the subsequent analysis in two ways. First, it motivates our choice of Census tract as the main geographic unit of interest when defining the relevant characteristics of a local area. Second, it sharpens our focus on the first

\footnotetext{
${ }^{31}$ See Appendix F for a formal discussion of this decomposition.
} 
year following the lottery win, corresponding to the period in which households predominantly respond to the change in wealth.

Who moves? Are certain types of households more likely to move than others in response to a wealth shock? Motivated by empirical evidence that suggests a relationship between certain demographic characteristics and moving costs and attitudes (see, e.g., Koşar, Ransom and van der Klaauw, 2021), we estimate the IV model introduced in Section 3.3 separately by demographic groups.

Figure 6.4a presents the IV estimates that correspond to the first year post-win. As discussed above, we find that lower-income households are about five times more likely to move than higher-income households in response to an unexpected change in wealth. Closely related, households without a strong attachment to the work force are also significantly more likely to move.

Motivated by the literature on the impact of neighborhoods on long-term economic outcomes of young children (Chetty, Hendren and Katz, 2016b; Chetty and Hendren, 2018), we also explore whether the presence of young children leads to differential moving responses. Figure 6.4a shows that additional wealth makes parents with young children slightly more likely to move compared to other parents, but the difference is not significant at conventional levels.

Past work has found that young households are more mobile, suggestive of moving costs that increase with age (Molloy, Smith and Wozniak, 2011; Koşar, Ransom and van der Klaauw, 2021). When we compare young and old winners, we find that young winners tend to be slightly more responsive, but the difference is not statistically significant. Lastly, we find that renters are more than 3 times more likely to move their location in response to an additional dollar of wealth, in line with evidence that suggests that moving costs are considerably higher for homeowners (Oswald, 2019).

Where do they move? Are households moving to places with higher quality than their previous locations? How do local labor market attributes of the destination compare to their origin location? We conduct a decomposition of the moving response using origin and destination characteristics to shed light on these questions.

Let $C_{i, t}$ denote a continuous-valued attribute of household $i$ 's tract in $t$. As a convention, we will refer to moves to tracts with lower $C$ as downward moves, and moves to tracts with the same or higher $C$ as upward moves. By definition, we can decompose the total probability of moving as follows:

$$
\underbrace{\mathbb{P}\left[M_{i, t}=1\right]}_{\text {total prob. of moving }}=\underbrace{\mathbb{P}\left[M_{i, t}=1 \cap C_{i, t} \geq C_{i, t-1}\right]}_{\text {prob. of moving upward }}+\underbrace{\mathbb{P}\left[M_{i, t}=1 \cap C_{i, t}<C_{i, t-1}\right]}_{\text {prob. of moving downward }} .
$$

For each characteristic $C$, we estimate the IV model introduced in Section 3.3 for each component in expression (6.1), allowing us to quantify the contribution of each to the total moving effect and thereby address whether the overall moving response is driven by moves upward versus moves downward.

In Figure $6.4 \mathrm{~b}$ we report the results of this decomposition for various attributes of local labor markets. Overall, we find some evidence that households are moving increasingly to less densely-populated areas, and local labor markets that are characterized by a longer typical commute from home to work and fewer 
jobs. For instance, close to $65 \%$ of the increase in moving propensity is due to moves to locations with a longer typical commute to work, whereas more than $60 \%$ is due to moves to less densely-populated areas. Overall, this pattern is suggestive of households moving towards less urban areas.

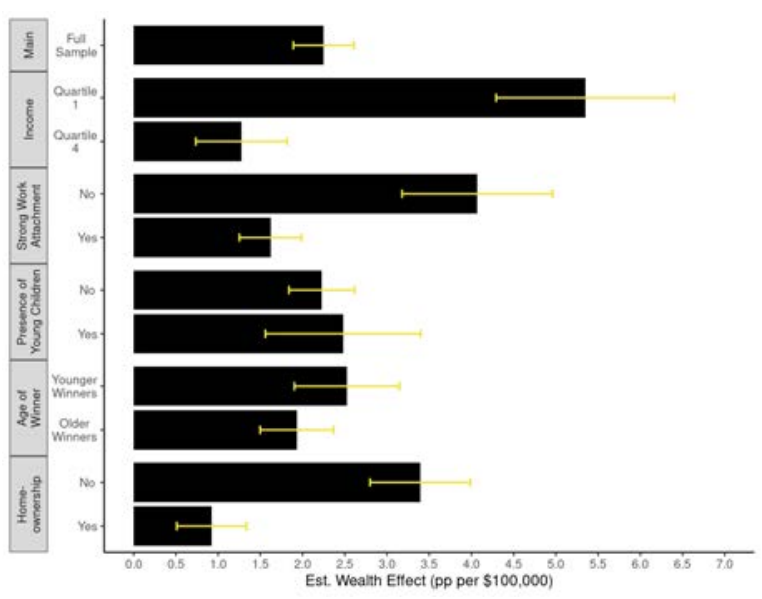

(a) Winner Characteristics

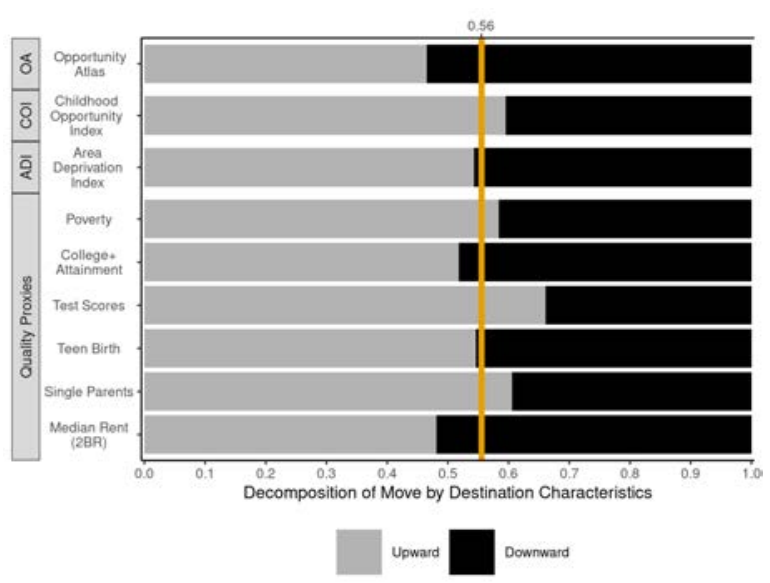

(c) Destination Characteristics: Neighborhood Quality

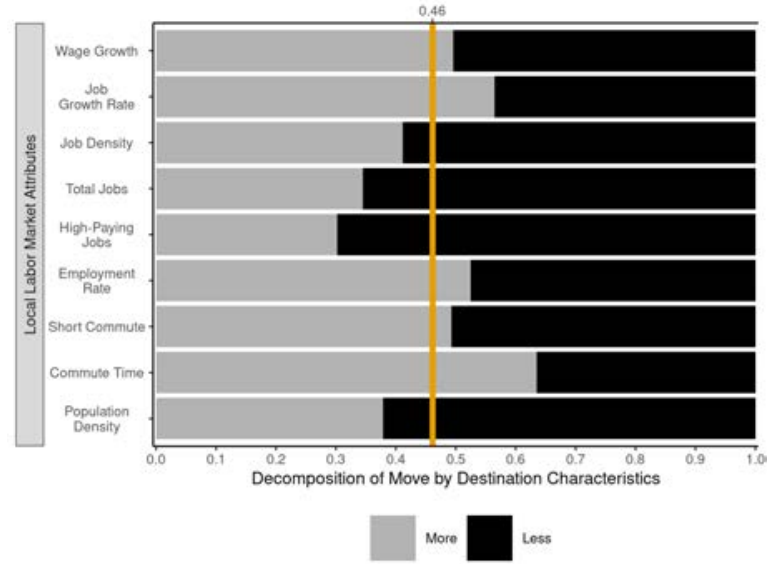

(b) Destination Characteristics: Local Labor Market

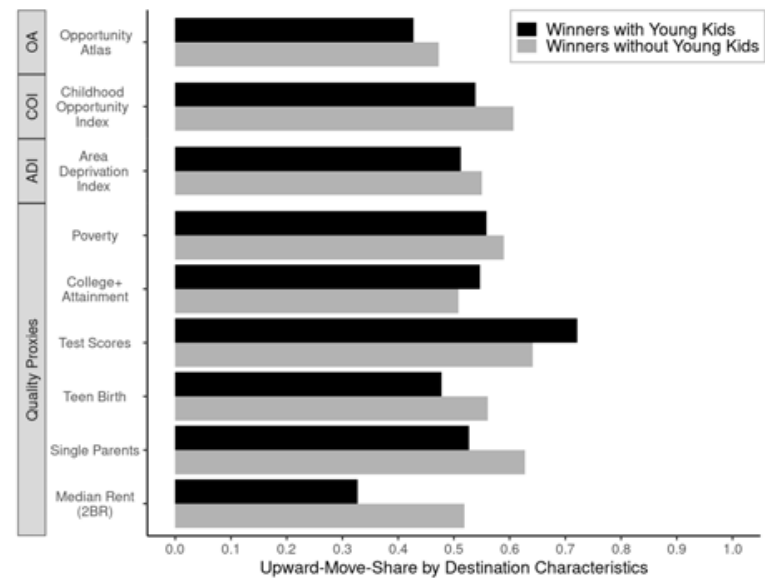

(d) Neighborhood Quality for Winners with Young Kids

Figure 6.4: Decomposition of the moving response by characteristics

Notes: Subfigure (a) presents an analysis of heterogeneity in the mean effect of an extra dollar of wealth on moving by characteristics of the winner. These estimates are calculated by first estimating a 2SLS regression, as described in Section 3.3, separately for each demographic group. The dependent variable is a binary indicator for moving Census tract. We then take cohort-size-weighted averages of $\beta^{w, \ell}$ for event time $\ell=1$. To ease interpretability, each estimate is scaled by $\$ 100,000$. Subfigures (b) and (c) show a decomposition of the overall effect of winning on moving by characteristics of the destination. These estimates are calculated by estimating a version of equation (3.4) (as described in Section 3.1), focusing on effects in the first year post-win. The dependent variables are binary indicators for moving Census tract and moving upwards and moving downwards along a given measure of local labor market attribute or neighborhood quality. The resulting estimates are then scaled by the total moving response. Subfigure (d) shows a comparison between winners with and without young kids in terms of the share of the total moving response that is due to a move upward.

In Figure 6.4c we explore whether the overall moving response is driven by a reallocation to to neighborhoods that are typically-measured as having higher quality. We judge the quality of neighborhoods based on measures used explicitly in past work, such as the Opportunity Atlas (Chetty, Friedman, Hendren, Jones and Porter, 2020), Childhood Opportunity Index (Noelke, McArdle, Baek, Huntington, Huber, Hardy 
and Acevedo-Garcia, 2020; Aliprantis and Martin, 2020), Area Deprivation Index (Kind and Buckingham, 2018), poverty rate (Wilson, 1987), and college attainment (Couture, Gaubert, Handbury and Hurst, 2019) among others. Overall, we do not find strong evidence that the overall moving response is driven by moves to higher-quality neighborhoods. In Figure $6.4 \mathrm{~d}$, we shift attention to parents with young kids which is a group of particular interest given past research on the impact of neighborhoods on intergenerational mobility. We find that, if anything, they are even less likely to move to a higher-quality neighborhood than the other winners without young kids. Taken together, the evidence on geographic mobility of lottery winners suggests that pure unconditional cash transfers do not lead households to systematically move to locations of higher quality, consistent with the argument in Bergman, Chetty, DeLuca, Hendren, Katz and Palmer (2020) on the importance of non-financial barriers to moving to better neighborhoods.

\subsection{Labor market dynamics}

In this section, we study the effects of changes in wealth or unearned income on dynamics in the labor market. We begin by estimating retirement responses, and then turn to studying the effects on the propensity to start a business and job mobility.

Take-up of retirement benefits and labor market exit. Assuming leisure is a normal good, economic theory predicts that an unanticipated increase in wealth or unearned income leads to a reduction in lifetime labor supply and accelerates retirement. Understanding the magnitude of this effect is key to assess the effects of public policy, such as reforms of the tax and public pension system. Existing work in this area has studied the wealth effect on retirement by focusing on changes in wealth stemming from inheritances (Holtz-Eakin, Joulfaian and Rosen, 1993; Brown, Coile and Weisbenner, 2010), stock market performance (Hurd, Reti and Rohwedder, 2009; Gustman, Steinmeier and Tabatabai, 2010), and house prices (Disney and Gathergood, 2018; Begley and Chan, 2018).

This literature faces two main challenges. The first challenge is that it may be difficult to empirically isolate variation in wealth that is unanticipated. Isolating unanticipated changes in wealth is important because individuals adjust their behavior prior to an expected change in wealth. Ignoring this behavioral response and treating all wealth changes as unexpected will tend to understate the true effect of wealth on retirement behavior. The second challenge is the endogeneity problem arising from the contemporaneous correlation between asset prices and labor market conditions. We address both challenges by studying retirement responses to lottery winnings, which are an idiosyncratic change to wealth that is difficult to anticipate and plausibly exogenous.

In our analysis we focus on winners aged 62 - 64 and follow two distinct approaches to define entry into retirement. The first approach is centered around the receipt of Old-Age and Survivors Insurance (OASI) benefits, commonly known as Social Security retirement benefits. Depending on year of birth, Americans are eligible for full retirement benefits as early as age 65 or as late as age 67. However, early retirement is common among Americans even though actuarial calculations suggest that there are strong financial disincentives to drawing benefits before the full retirement age. One possible explanation for this behavior is liquidity constraints: individuals may decide to claim benefits before the full retirement age due to a lack 
of alternative funds to finance early retirement. Winning the lottery eases these financial constraints, so the effect of winning on receiving benefits is ambiguous. For this reason, our second approach to defining entry into retirement is based on the level of earnings rather than the receipt of benefits. Specifically, we use consecutive years with zero total labor earnings as a proxy for an exit from the labor force in our analysis of retirement responses to lottery winnings.

In Appendix Figure B.7a and B.7b we plot the estimated coefficients from regression (3.4), where the dependent variables are binary indicators for the receipt of OASI benefits and labor force exit respectively. ${ }^{32}$ There is no evidence of differential trends in these outcomes between current and later winners aged 62 - 64 in pre-win event times. ${ }^{33}$ We find a small positive effect of winning the lottery on the propensity to receive OASI benefits in the first year post-win, but this effect does not persist over time. In contrast, we find significant positive effects on the propensity to exit the labor force, and these effects increase over time.

To quantify the effects of additional wealth on retirement behavior, we estimate the IV model from Section 3.3. Table 6.1 reports the resulting IV estimates which inform us about the propensity to retire in response to an extra 100,000 dollars in wealth. ${ }^{34}$ We find a small positive, but statistically insignificant, effect of additional wealth on the propensity to claim OASI benefits. For an extra 100,000 dollars in wealth, the propensity to claim OASI benefits increases by around 1.1 percentage points on average. In contrast, the propensity to leave the labor force for at least one, two or five consecutive years increases by around 5 percentage points per $\$ 100,000$ of additional wealth on average. These average effects correspond to an 11-14 percent increase in the propensity to leave the labor force, similar to the wealth effects reported in Holtz-Eakin, Joulfaian and Rosen (1993) and Brown, Coile and Weisbenner (2010).

\footnotetext{
${ }^{32}$ Results that do not condition on no receipt of Social Security retirement benefits pre-win are very similar as Social Security retirement benefit receipt in this older population is essentially always an absorbing state.

${ }^{33}$ Our design, which uses later winners as a control group, necessarily means that holding aged fixed, earlier winners can leave the sample through mortality whereas later winners cannot until they win. For older winners, where this might be meaningful, we restrict the sample to the living and include individual fixed effects to account for compositional differences.

${ }^{34}$ Effects of unearned income on retirement behavior are reported in Appendix Table A.4.
} 
Table 6.1: Effects of wealth on take-up of retirement benefits and labor market exit

\begin{tabular}{c|c|c|cc}
\hline \hline \multirow{2}{*}{ Outcome } & Value & Full Sample & $\begin{array}{c}\text { Quartile 1 } \\
\text { Pre-Win Income } \\
(2)\end{array}$ & $\begin{array}{c}\text { Quartile 4 } \\
\text { Pre-Win Income } \\
(3)\end{array}$ \\
& & $(1)$ & \multicolumn{2}{|c}{ Take-Up of Retirement Benefits } \\
\hline \multirow{5}{*}{ Claiming OASI Benefits } & Estimate & 0.0114 & 0.0224 & 0.0077 \\
& Counterfactual Mean & 0.77 & $(0.0122)$ & $(0.0077)$ \\
& Percentage Change & 1.5 & 0.74 & 0.73 \\
& & & 3.0 & 1.1 \\
\hline \multirow{5}{*}{ One-Year Exit } & Labor Market Exit & \\
& Standard Error & $(0.0053)$ & $(0.0095)$ & 0.0392 \\
& Counterfactual Mean & 0.43 & 0.63 & 0.33 \\
& Percentage Change & 11.3 & 5.8 & 11.7 \\
\hline \multirow{5}{*}{ Two-Year Exit } & Estimate & 0.0536 & 0.0477 & 0.0457 \\
& Standard Error & $(0.0058)$ & $(0.0106)$ & $(0.0111)$ \\
& Counterfactual Mean & 0.40 & 0.58 & 0.30 \\
& Percentage Change & 13.4 & 8.3 & 15.0 \\
\hline \hline \multirow{5}{*}{ Five-Year Exit } & Estimate & 0.0490 & 0.0599 & 0.0195 \\
& Standard Error & $(0.0098)$ & $(0.0265)$ & $(0.0170)$ \\
& Counterfactual Mean & 0.35 & 0.48 & 0.31 \\
& Percentage Change & 14.0 & 12.6 & 6.4 \\
\hline \hline
\end{tabular}

Notes: This table presents estimates of the mean effect of an extra dollar of wealth on take up of retirement benefits and labor market exit for winners aged 62-64. The dependent variables are binary indicators for the receipt of OASI benefits and labor force exit respectively. These estimates are calculated by first estimating a 2SLS regression, as described in Section 3.3, for each outcome, then taking cohort-size-weighted averages of $\beta^{w, \ell}$ for each event time $\ell$, then taking the mean across estimates for post-win event times $\{1,2,3,4,5\}$ to recover the mean wealth effect in the post-win period. Column 1 reports mean effects of an extra dollar of wealth for the full analysis sample. In columns 2 and 3, we report mean effects of an extra dollar of wealth for subsamples of winners falling into the first and fourth quartile of the pre-win distribution of per-adult adjusted gross income. We use the delta method to calculate standard errors (reported in parenthesis), clustering on winner. To ease interpretability, each estimate is scaled by $\$ 100,000$. The counterfactual means correspond to the fraction of winners that would have taken up retirement benefits or exited the labor market in the absence of winning (see Appendix E for details). The row "Percentage Change" reports the effect per $\$ 100,000$ in percentage change terms relative to the counterfactual mean.

Entrepreneurship and self-employment. A lack of personal wealth and the existence of financial constraints are potentially important barriers to entrepreneurship. Many studies have therefore explored the relationship between wealth and business creation. For example, Holtz-Eakin, Joulfaian and Rosen (1994) and Blanchflower and Oswald (1998) find that changes in wealth stemming from inheritance and gifts increase the probability of becoming self-employed. Lindh and Ohlsson (1996) reach similar conclusions using windfall gains from inheritances and lotteries from Sweden. ${ }^{35}$ These findings are often interpreted as evidence of the existence and importance of liquidity constraints, and as such provide potential justification

\footnotetext{
${ }^{35}$ See also Evans and Jovanovic (1989), Evans and Leighton (1989), Fairlie (1999), Taylor (2001), Hurst and Lusardi (2004), Nykvist (2008), and Fairlie and Krashinsky (2012).
} 
for many government policies that support the financing of start-ups. ${ }^{36}$

We contribute to this literature by studying the role of wealth in the transition from paid employment to low- and high-paying self-employment in the U.S. We distinguish between these two types of self-employment by defining two binary indicators. One for receiving income from self-employment of $\$ 15,000$ or less, the other one indicates profits above $\$ 15,000$. Appendix Figure B.7c shows the estimated coefficients from regression (3.4) with the two indicators as dependent variables. We find no evidence of differential trends in both of these outcomes between current and later winners in pre-win event times. The event study shows that the propensity to start a low-paying business increases significantly in the years following the lottery, whereas winning the lottery appears to have no effect on the propensity to start a business with annual profits of at least $\$ 15,000$.

Table 6.2: Effects of wealth on entrepreneurship and self-employment

\begin{tabular}{|c|c|c|c|c|}
\hline Outcome & Value & $\begin{array}{c}\text { Full Sample } \\
\text { (1) }\end{array}$ & $\begin{array}{c}\text { Quartile } 1 \\
\text { Pre-Win Income } \\
\text { (2) }\end{array}$ & $\begin{array}{c}\text { Quartile } 4 \\
\text { Pre-Win Income } \\
\text { (3) }\end{array}$ \\
\hline Transition to Low-Paying SE & $\begin{array}{c}\text { Estimate } \\
\text { Standard Error } \\
\text { Counterfactual Mean } \\
\text { Percentage Change }\end{array}$ & $\begin{array}{c}0.0047 \\
(0.0003) \\
0.03 \\
13.7\end{array}$ & $\begin{array}{c}0.0037 \\
(0.0010) \\
0.05 \\
6.8\end{array}$ & $\begin{array}{c}0.0053 \\
(0.0004) \\
0.03 \\
19.4\end{array}$ \\
\hline Transition to High-Paying SE & $\begin{array}{c}\text { Estimate } \\
\text { Standard Error } \\
\text { Counterfactual Mean } \\
\text { Percentage Change }\end{array}$ & $\begin{array}{c}-0.0002 \\
(0.0002) \\
0.01 \\
-1.3\end{array}$ & $\begin{array}{c}-0.0005 \\
(0.0005) \\
0.01 \\
-3.2\end{array}$ & $\begin{array}{c}-0.0005 \\
(0.0003) \\
0.02 \\
-3.0\end{array}$ \\
\hline
\end{tabular}

Notes: This table presents estimates of the mean effect of an extra dollar of wealth on the propensity to start a business associated with annual profits of $\$ 15,000$ or less (low-paying SE), or a business with profits of more than $\$ 15,000$ (high-paying SE). The estimation sample is restricted to winners and not-yet winners in paid-employment at event time $w-2$. These estimates are calculated by first estimating a 2 SLS regression, as described in Section 3.3, for each outcome, then taking cohort-size-weighted averages of $\beta^{w, \ell}$ for each event time $\ell$, then taking the mean across estimates for post-win event times $\{1,2,3,4,5\}$ to recover the mean wealth effect in the post-win period. Column 1 reports mean effects of an extra dollar of wealth for the full analysis sample. In columns 2 and 3, we report mean effects of an extra dollar of wealth for subsamples of winners falling into the first and fourth quartile of the pre-win distribution of per-adult adjusted gross income. We use the delta method to calculate standard errors (reported in parenthesis), clustering on winner. To ease interpretability, each estimate is scaled by $\$ 100,000$. The counterfactual means correspond to the fraction of employed winners that would have received income from self-employment in the absence of winning (see Appendix E for details). The row "Percentage Change" reports the effect per $\$ 100,000$ in percentage change terms relative to the counterfactual mean.

To quantify the role of wealth in business creation, we now shift to the estimates of the IV model described in Section 3.3. Table 6.2 reports the effects of an additional $\$ 100,000$ in wealth on the propensity to start a business. ${ }^{37}$ On average we find an increase of around 0.5 percentage points (a change of approximately 14 percent) in the probability of transitioning from employee to self-employed with income of $\$ 15,000$ or less. In contrast, we find no effect on the probability to start a business associated with annual

\footnotetext{
${ }^{36}$ See OECD (2010) for an overview of policies across several countries.

${ }^{37}$ Effects of unearned income on the propensity to become self-employed are reported in Appendix Table A.5.
} 
profits of more than $\$ 15,000$. This finding may be suggestive that the marginal entrepreneur may be of lower quality (Andersen and Nielsen, 2012).

Job mobility. Non-wage job characteristics are important determinants of job mobility. In addition to their wage, jobs differ in their non-wage attributes, such as the level of fringe benefits, flexibility of work schedules, the type of tasks performed, and the amount of effort required. Workers treat these as consumption goods, and thus face a trade off between the wage- and non-wage attributes in their labor supply decision. ${ }^{38}$ Employers with undesirable working conditions then must pay a compensating wage premium in order to attract labor, whereas employers that offer favorable job amenities can attract labor at lower than average wages. Differences in wages between otherwise identical workers then reflect differences in the value of non-wage characteristics between different jobs in a competitive labor market (Rosen, 1986).

Assuming that job amenities are a normal good, we would expect an increase in wealth or unearned income to induce workers to move to employers that pay lower wages on average, but offer more favorable job amenities in exchange. We explore this channel by studying the job mobility decisions of individuals who were employed prior to winning the lottery and continue to be employees post-win. To study the effect of winning on the job mobility rate, we define an indicator $J_{i, t}$ equal to 1 if household $i$ 's employer in year $t$ is different from the employer in year $w-2$, i.e. two years prior to winning the lottery, and 0 otherwise. In order to explore the effect of winning on the direction of job moves, we rank employers according to the mean wage paid to their employees. ${ }^{39}$ By definition, we can then decompose the total probability of changing jobs as follows:

$$
\underbrace{\mathbb{P}\left[J_{i, t}=1\right]}_{\text {total prob. of job change }}=\underbrace{\mathbb{P}\left[J_{i, t}=1 \cap \Psi_{i, t} \geq \Psi_{i, w-2}\right]}_{\text {prob. of upward job move }}+\underbrace{\mathbb{P}\left[J_{i, t}=1 \cap \Psi_{i, t}<\Psi_{i, w-2}\right]}_{\text {prob. of downward job move }},
$$

where $\Psi_{i, t}$ denotes the wage rank of household $i$ 's employer in year $t$.

Appendix Figure B.7d shows the estimated coefficients from regression (3.4) for the total moving probability and each of its components. We find no evidence of differential trends in all of these outcomes between current and later winners in pre-win event times. ${ }^{40}$ The event study shows a small decline in the probability of having changed job by the first year post-win, but this effect does not persist over time. Interestingly, we find an increase in the probability of a downward job move in the first year post-win, whereas the probability of an upward job move declines. The gap between the estimated effects is growing over time, which is consistent with frictional labor markets in which moving to the preferred job takes time.

\footnotetext{
${ }^{38}$ For example, survey and experimental evidence shows that workers are willing to take lower pay in exchange for more job flexibility, e.g., Hamermesh (1999), Eriksson and Kristensen (2014), Mas and Pallais (2017), Wiswall and Zafar (2017), Maestas, Mullen, Powell, von Wachter and Wenger (2018), Katz and Krueger (2019) and Chen, Ding, List and Mogstad (2020).

${ }^{39}$ Specifically, we calculate a time-invariant measure of firm-level mean wages per employee by taking raw mean wage earnings per employee and removing aggregate time effects to construct residual mean wage earnings for each firm in each calendar year. We then take an average of the residuals for each firm across calendar years. Our results barely change if we do not adjust for aggregate time effects in the construction of time-invariant firm-level mean wages.

${ }^{40} \mathrm{By}$ construction of the outcome variables, $\mathbb{P}\left[J_{i, w-2}=1\right]=0$ for both current and later winners. To allow for potentially different annual job-to-job transition rates between current and later winners, we then normalize the effect in event time $w-1$ to be zero in these regressions.
} 
Table 6.3: Effects of unearned income on job mobility

\begin{tabular}{|c|c|c|c|c|}
\hline Outcome & Value & $\begin{array}{c}\text { Full Sample } \\
\text { (1) }\end{array}$ & $\begin{array}{c}\text { Quartile } 1 \\
\text { Pre-Win Income } \\
\text { (2) }\end{array}$ & $\begin{array}{c}\text { Quartile } 4 \\
\text { Pre-Win Income } \\
\text { (3) }\end{array}$ \\
\hline Any Job-to-Job Move & $\begin{array}{c}\text { Estimate } \\
\text { Standard Error } \\
\text { Counterfactual Mean } \\
\text { Percentage Change }\end{array}$ & $\begin{array}{c}0.0010 \\
(0.0042) \\
0.46 \\
0.2\end{array}$ & $\begin{array}{c}0.0081 \\
(0.0127) \\
0.67 \\
1.2\end{array}$ & $\begin{array}{c}-0.0094 \\
(0.0066) \\
0.36 \\
-2.6\end{array}$ \\
\hline Downward Move & $\begin{array}{c}\text { Estimate } \\
\text { Standard Error } \\
\text { Counterfactual Mean } \\
\text { Percentage Change }\end{array}$ & $\begin{array}{c}0.0222 \\
(0.0039) \\
0.23 \\
9.8\end{array}$ & $\begin{array}{c}0.0305 \\
(0.0131) \\
0.31 \\
9.9\end{array}$ & $\begin{array}{c}0.0025 \\
(0.0058) \\
0.19 \\
1.3\end{array}$ \\
\hline Upward Move & $\begin{array}{c}\text { Estimate } \\
\text { Standard Error } \\
\text { Counterfactual Mean } \\
\text { Percentage Change }\end{array}$ & $\begin{array}{c}-0.0212 \\
(0.0037) \\
0.24 \\
-9.0\end{array}$ & $\begin{array}{c}-0.0224 \\
(0.0127) \\
0.36 \\
-6.2\end{array}$ & $\begin{array}{c}-0.0118 \\
(0.0052) \\
0.17 \\
-6.9\end{array}$ \\
\hline
\end{tabular}

Notes: This table presents estimates of the mean effect of an extra dollar of unearned income on the frequency and direction of job-to-job moves. The estimation sample is restricted to winners and not-yet winners in paid-employment pre- and post-win. Outcomes are defined as binary and equal to 1 if the firm is either different from, or higher or lower ranked than the firm prior to winning the lottery. Firms are ranked by the mean wage paid to its employees. These estimates are calculated by first estimating a 2SLS regression, as described in Section 3.3, using unearned income as the endogenous variable. For each outcome, we then take cohort-size-weighted averages of $\beta^{w, \ell}$ for each event time $\ell$, and then take the mean across estimates for post-win event times $\{1,2,3,4,5\}$ to recover the mean effect of an extra dollar of unearned income. Column 1 reports mean effects of an extra dollar of unearned income for the full analysis sample. In columns 2 and 3, we report mean effects of an extra dollar of unearned income for subsamples of winners falling into the first and fourth quartile of the pre-win distribution of per-adult adjusted gross income. We use the delta method to calculate standard errors (reported in parenthesis), clustering on winner. To ease interpretability, each estimate is scaled by $\$ 10,000$. The counterfactual means correspond to the job mobility rates that would have occurred in the absence of winning (see Appendix E for details). The row "Percentage Change" reports the effect per $\$ 10,000$ in percentage change terms relative to the counterfactual mean.

To study the effects of changes in unearned income, we estimate the IV model described in Section 3.3, only now using unearned income as the endogenous variable. In Table 6.3 we report the estimated effects of an additional $\$ 10,000$ in unearned income on both the frequency and the direction of job moves. ${ }^{41}$ On average and across the income distribution, we do not find an effect on the frequency of job moves. However, we find a significant increase of around 2 percentage points (roughly a 10 percent change) in the probability of moving to an employer that pays lower wages on average, whereas the probability of moving to an employer that pays higher wages on average decreases by around the same amount. This finding is suggestive that job amenities are a normal good. Looking across the income distribution, we find that highearning individuals respond to changes in unearned income by reducing their efforts to move upward rather than increasingly moving downward.

\footnotetext{
${ }^{41}$ Wealth effects on job mobility are reported in Appendix Table A.6.
} 


\subsection{Gender, marital status and family stability}

In this section, we begin by studying heterogeneity in the earnings responses by gender and marital status, and then turn to estimating the effect of an extra dollar of wealth on the propensity to marry and divorce.

Heterogeneity in responses by gender and marital status. We begin by studying how the earnings responses to exogenous changes in wealth and unearned income vary by gender. Appendix Figure B.7 shows the estimated coefficients from the earnings regression (3.4) when we split the sample by the gender of the winner. We find no evidence of differential trends between current and later winners in pre-win event times. The event study shows a sizable, swift, and persistent change in earnings for both male and female winners. However, the earnings of male winners tend to decrease more compared to female winners.

To study gender differences in the earnings response to an extra dollar of unearned income, we estimate the IV model described in Section 3.3 separately by gender of the winner. In Table 6.4 we report these estimates. $^{42}$ On average we find that labor earnings responses are larger for males. An extra dollar of unearned income leads to a 60 cent reduction in total labor earnings for male winners, whereas female winners reduce their total labor earnings by 38 cent. A similar discrepancy in responses has also been reported in Cesarini, Lindqvist, Notowidigdo and Östling (2017) and Picchio, Suetens and van Ours (2018). However, taking into account that earnings of females in the absence of winning are substantially lower on average, we find that the relative earnings responses are similar across gender. Just as in Table 4.1, we continue to find substantial heterogeneity in MPEs across the income distribution: the earnings reduction due to an extra dollar of unearned income is increasing in pre-win income regardless of the winner's gender.

\footnotetext{
${ }^{42}$ Wealth effects are reported in Appendix Table A.7.
} 
Table 6.4: Effects of unearned income on earnings by gender of the winner

\begin{tabular}{|c|c|c|c|c|}
\hline Group & Value & $\begin{array}{l}\text { Full Sample } \\
\qquad(1)\end{array}$ & $\begin{array}{c}\text { Quartile } 1 \\
\text { Pre-Win Income } \\
\text { (2) }\end{array}$ & $\begin{array}{c}\text { Quartile } 4 \\
\text { Pre-Win Income } \\
\text { (3) }\end{array}$ \\
\hline & & \multicolumn{3}{|c|}{ Winner Wage Earnings (per dollar) } \\
\hline Male Winner & $\begin{array}{c}\text { Estimate } \\
\text { Standard Error } \\
\text { Counterfactual Mean } \\
\text { Percentage Change }\end{array}$ & $\begin{array}{c}-0.5733 \\
(0.0186) \\
38235.23 \\
-1.5\end{array}$ & $\begin{array}{c}-0.3934 \\
(0.0197) \\
14288.29 \\
-2.8\end{array}$ & $\begin{array}{c}-0.6839 \\
(0.0442) \\
66641.39 \\
-1.0\end{array}$ \\
\hline \multirow[t]{2}{*}{ Female Winner } & $\begin{array}{c}\text { Estimate } \\
\text { Standard Error } \\
\text { Counterfactual Mean } \\
\text { Percentage Change }\end{array}$ & $\begin{array}{c}-0.4113 \\
(0.0144) \\
26576.05 \\
-1.5\end{array}$ & $\begin{array}{c}-0.2277 \\
(0.0179) \\
10946.22 \\
-2.1\end{array}$ & $\begin{array}{c}-0.6936 \\
(0.0436) \\
47967.19 \\
-1.4\end{array}$ \\
\hline & & \multicolumn{3}{|c|}{ Per-Adult Total Labor Earnings (per dollar) } \\
\hline Male Winner & $\begin{array}{c}\text { Estimate } \\
\text { Standard Error } \\
\text { Counterfactual Mean } \\
\text { Percentage Change }\end{array}$ & $\begin{array}{c}-0.6031 \\
(0.0190) \\
36131.60 \\
-1.7\end{array}$ & $\begin{array}{c}-0.4047 \\
(0.0290) \\
15015.03 \\
-2.7\end{array}$ & $\begin{array}{c}-0.7683 \\
(0.0437) \\
62948.19 \\
-1.2\end{array}$ \\
\hline Female Winner & $\begin{array}{c}\text { Estimate } \\
\text { Standard Error } \\
\text { Counterfactual Mean } \\
\text { Percentage Change }\end{array}$ & $\begin{array}{c}-0.3817 \\
(0.0234) \\
31112.13 \\
-1.2\end{array}$ & $\begin{array}{c}-0.1905 \\
(0.0442) \\
12875.22 \\
-1.5\end{array}$ & $\begin{array}{c}-0.5588 \\
(0.0856) \\
58251.54 \\
-1.0\end{array}$ \\
\hline
\end{tabular}

Notes: This table presents estimates of the mean effect of an extra dollar of unearned income on earnings separately by gender of the winner. These estimates are calculated by first estimating a 2SLS regression, as described in Section 3.3, using unearned income as the endogenous variable. For each outcome, we then take cohort-size-weighted averages of $\beta^{w, \ell}$ for each event time $\ell$, and then take the mean across estimates for post-win event times $\{1,2,3,4,5\}$ to recover the mean effect of an extra dollar of unearned income. Column 1 reports mean effects of an extra dollar of unearned income for the full analysis sample. In columns 2 and 3, we report mean effects of an extra dollar of unearned income for subsamples of winners falling into the first and fourth quartile of the pre-win distribution of per-adult adjusted gross income. We use the delta method to calculate standard errors (reported in parenthesis), clustering on winner. The counterfactual means correspond to the average earnings the winner would have received in the absence of winning (see Appendix E for details). The row "Percentage Change" reports the effect per $\$ 1,000$ in percentage change terms relative to the counterfactual mean.

We now turn to possible differences in earnings responses by marital status. Appendix Figure B.7 shows the estimated coefficients from the earnings regression (3.4) when we split the sample by the marital status of the winner. As before, we find no evidence of differential trends between current and later winners in pre-win event times. The event studies show a sharp and persistent change in earnings for both single and married winners. 
Table 6.5: Effects of unearned income on earnings by marital status of the winner

\begin{tabular}{|c|c|c|c|c|}
\hline Group & Value & $\begin{array}{c}\text { Full Sample } \\
\text { (1) }\end{array}$ & $\begin{array}{c}\text { Quartile } 1 \\
\text { Pre-Win Income } \\
\text { (2) }\end{array}$ & $\begin{array}{c}\text { Quartile } 4 \\
\text { Pre-Win Income } \\
\text { (3) }\end{array}$ \\
\hline & & \multicolumn{3}{|c|}{ Winner Wage Earnings (per dollar) } \\
\hline Married Winner & $\begin{array}{c}\text { Estimate } \\
\text { Standard Error } \\
\text { Counterfactual Mean } \\
\text { Percentage Change }\end{array}$ & $\begin{array}{c}-0.6376 \\
(0.0254) \\
38275.25 \\
-1.7\end{array}$ & $\begin{array}{c}-0.5456 \\
(0.0471) \\
11892.97 \\
-4.6\end{array}$ & $\begin{array}{c}-0.6728 \\
(0.0633) \\
62152.53 \\
-1.1\end{array}$ \\
\hline Single Winner & $\begin{array}{c}\text { Estimate } \\
\text { Standard Error } \\
\text { Counterfactual Mean } \\
\text { Percentage Change }\end{array}$ & $\begin{array}{c}-0.4579 \\
(0.0138) \\
29816.89 \\
-1.5\end{array}$ & $\begin{array}{c}-0.2982 \\
(0.0147) \\
13198.26 \\
-2.3\end{array}$ & $\begin{array}{c}-0.6507 \\
(0.0375) \\
57815.81 \\
-1.1\end{array}$ \\
\hline & & \multicolumn{3}{|c|}{ Per-Adult Total Labor Earnings (per dollar) } \\
\hline Married Winner & $\begin{array}{c}\text { Estimate } \\
\text { Standard Error } \\
\text { Counterfactual Mean } \\
\text { Percentage Change }\end{array}$ & $\begin{array}{c}-0.6009 \\
(0.0300) \\
38033.72 \\
-1.6\end{array}$ & $\begin{array}{c}-0.4818 \\
(0.1096) \\
12365.40 \\
-3.9\end{array}$ & $\begin{array}{c}-0.6892 \\
(0.0759) \\
63576.97 \\
-1.1\end{array}$ \\
\hline Single Winner & $\begin{array}{c}\text { Estimate } \\
\text { Standard Error } \\
\text { Counterfactual Mean } \\
\text { Percentage Change }\end{array}$ & $\begin{array}{c}-0.5051 \\
(0.0158) \\
30994.56 \\
-1.6\end{array}$ & $\begin{array}{c}-0.3117 \\
(0.0222) \\
14686.77 \\
-2.1\end{array}$ & $\begin{array}{c}-0.6836 \\
(0.0408) \\
58302.67 \\
-1.2\end{array}$ \\
\hline
\end{tabular}

Notes: This table presents estimates of the mean effect of an extra dollar of unearned income on earnings separately by marital status of the winner. These estimates are calculated by first estimating a 2SLS regression, as described in Section 3.3, using unearned income as the endogenous variable. For each outcome, we then take cohort-size-weighted averages of $\beta^{w, \ell}$ for each event time $\ell$, and then take the mean across estimates for post-win event times $\{1,2,3,4,5\}$ to recover the mean effect of an extra dollar of unearned income. Column 1 reports mean effects of an extra dollar of unearned income for the full analysis sample. In columns 2 and 3, we report mean effects of an extra dollar of unearned income for subsamples of winners falling into the first and fourth quartile of the pre-win distribution of per-adult adjusted gross income. We use the delta method to calculate standard errors (reported in parenthesis), clustering on winner. The counterfactual means correspond to the average earnings the winner would have received in the absence of winning (see Appendix E for details). The row "Percentage Change" reports the effect per $\$ 1,000$ in percentage change terms relative to the counterfactual mean.

To interpret the magnitudes of these event-study estimates, we estimate the IV model described in Section 3.3. As shown in Table 6.5, we find that married winners reduce their earnings by more than single winners for every additional dollar of unearned income. ${ }^{43}$ For example, whereas married individuals reduce their own annual wage earnings by 64 cents for an extra dollar of unearned income on average, singles decrease their annual wage earnings by 46 cents for an extra dollar of unearned income. However, taking into account that earnings of singles in the absence of winning are around 20 percent lower on average, we

\footnotetext{
${ }^{43}$ Wealth effects are reported in Appendix Table A.8.
} 
find that the relative earnings responses are similar across single and married winners. Irrespective of the marital status of the winner, the earnings reduction due to an extra dollar of unearned income is increasing in pre-win income.

Effects on family formation and stability. Changes in unearned income or wealth can affect the likelihood of marriage and divorce for a number of reasons. While an increase in wealth makes singles more attractive as potential marriage partners, it also increases the option value of remaining single. Additional wealth can have a stabilizing effect on existing marriages, but may also help to cover the legal costs of a divorce for otherwise financially constrained households (see Burstein, 2007; Hankins and Hoekstra, 2011). Building on Hankins and Hoekstra (2011), we use changes in wealth due to lottery winnings to analyze the extent to which a change in economic resources affects the likelihood of marriage and divorce.

To study the effect of winning the lottery on marriage, we restrict our sample to tax filers that were unmarried 2 years prior to winning the lottery. Our outcome of interest is a time-varying indicator equal to 1 if the winner is married. Similarly, we restrict our sample to tax filers that were married 2 years prior to winning the lottery and study the effect of winning the lottery on a binary outcome variable indicating singlehood. Appendix Figure B.8 shows the estimated coefficients from regression (3.4). We find no evidence of differential trends in both of these outcomes between current and later winners in pre-win event times. The event study shows that winning the lottery increases the propensity to get married for single lottery winners (relative to single non-yet-winners), while the likelihood for married winners to get divorced (relative to married non-yet-winners) decreases on average. 
Table 6.6: Effects of wealth on marriages and divorce

\begin{tabular}{c|c|c|cc}
\hline \hline \multirow{5}{*}{ Outcome } & Value & Full Sample & $\begin{array}{c}\text { Quartile 1 } \\
\text { Pre-Win Income } \\
(1)\end{array}$ & $\begin{array}{c}\text { Quartile 4 } \\
\text { Pre-Win Income } \\
(3)\end{array}$ \\
\hline \multirow{5}{*}{ New Marriage } & Estimate & 0.0077 & 0.0167 & 0.0006 \\
& Standard Error & $(0.0008)$ & $(0.0024)$ & $(0.0013)$ \\
& Counterfactual Mean & 0.14 & 0.14 & 0.15 \\
& Percentage Change & 5.5 & 11.7 & 0.4 \\
\hline \multirow{5}{*}{ Divorce } & Estimate & -0.0067 & -0.0146 & -0.0058 \\
& Standard Error & $(0.0010)$ & $(0.0041)$ & $(0.0015)$ \\
& Counterfactual Mean & 0.11 & 0.17 & 0.09 \\
& Percentage Change & -5.9 & -8.6 & -6.3 \\
\hline \hline
\end{tabular}

Notes: This table presents estimates of the mean effect of an extra dollar of wealth on the propensity to enter or leave marriage. The estimation sample is restricted to winners and not-yet winners that are tax filers. When we study the effect on new marriages (divorce), we further restrict the sample to individuals that were not married (married) in $w-2$. These estimates are calculated by first estimating a 2SLS regression, as described in Section 3.3, for each outcome, then taking cohort-size-weighted averages of $\beta^{w, \ell}$ for each event time $\ell$, then taking the mean across estimates for post-win event times $\{1,2,3,4,5\}$ to recover the mean wealth effect in the post-win period. Column 1 reports mean effects of an extra dollar of wealth for the full analysis sample. In columns 2 and 3, we report mean effects of an extra dollar of wealth for subsamples of winners falling into the first and fourth quartile of the pre-win distribution of per-adult adjusted gross income. We use the delta method to calculate standard errors (reported in parenthesis), clustering on winner. To ease interpretability, each estimate is scaled by $\$ 100,000$. The counterfactual means correspond to the marriage and divorce rates that would have occurred in the absence of winning (see Appendix E for details). The row "Percentage Change" reports the effect per $\$ 100,000$ in percentage change terms relative to the counterfactual mean.

To quantify the role of an increase in wealth on family formation and stability, we estimate the IV model from Section 3.3. Table 6.6 shows that for every $\$ 100,000$ of additional wealth, the propensity to marry increases by around 0.8 percentage points, while the likelihood of divorce decreases by around 0.7 percentage points on average. ${ }^{44}$ Especially for lower-income households we find that additional wealth leads to an increase in marriages and family stability.

\subsection{Within-household responses}

In this section we document differences in earnings responses between winners and their spouses, and discuss the implications for models of household behavior.

Heterogeneity in responses between winner and spouse. We focus on married couples and begin by estimating regression (3.4) separately for wage earnings of the winner and his or her spouse. As shown by the event studies in Appendix Figure B.9, we find no evidence of differential trends between current and later winners in the years before the lottery win. This finding holds whether we look at winners or their spouses. The event studies show a sharp and persistent decline in wage earnings in response to winning, with winner wage earnings decline by more than spousal wage earnings.

\footnotetext{
${ }^{44}$ The effects of changes in unearned income on family formation and stability are reported in Appendix Table A.9.
} 
Table 6.7: Effects of unearned income on wage earnings of winners and their spouse

\begin{tabular}{|c|c|c|c|c|}
\hline Group & Value & $\begin{array}{l}\text { Full Sample } \\
\qquad(1)\end{array}$ & $\begin{array}{c}\text { Quartile } 1 \\
\text { Pre-Win Income } \\
\text { (2) }\end{array}$ & $\begin{array}{c}\text { Quartile } 4 \\
\text { Pre-Win Income } \\
\text { (3) }\end{array}$ \\
\hline Winner & $\begin{array}{c}\text { Estimate } \\
\text { Standard Error } \\
\text { Counterfactual Mean } \\
\text { Percentage Change }\end{array}$ & $\begin{array}{c}-0.6376 \\
(0.0254) \\
38275.25 \\
-1.7\end{array}$ & $\begin{array}{c}-0.5456 \\
(0.0471) \\
11892.97 \\
-4.6\end{array}$ & $\begin{array}{c}-0.6728 \\
(0.0633) \\
62152.53 \\
-1.1\end{array}$ \\
\hline Spouse & $\begin{array}{c}\text { Estimate } \\
\text { Standard Error } \\
\text { Counterfactual Mean } \\
\text { Percentage Change }\end{array}$ & $\begin{array}{c}-0.2249 \\
(0.0221) \\
27141.85 \\
-0.8\end{array}$ & $\begin{array}{c}-0.0706 \\
(0.0452) \\
6727.89 \\
-1.0\end{array}$ & $\begin{array}{c}-0.3706 \\
(0.0668) \\
46890.46 \\
-0.8\end{array}$ \\
\hline
\end{tabular}

Notes: This table presents estimates of the mean effect of an extra dollar of unearned income on wage earnings for winners and non-winning spouses. The estimation sample is restricted to married couples. Estimates are calculated by first estimating separate regressions for the firstand second-stage model as described in Section 3.3, only now using unearned income as the endogenous variable. For each outcome, we then take cohort-size-weighted averages of $\rho^{w, \ell}$ and $\phi^{w, \ell}$ for each event time $\ell$, and then take the mean across estimates for post-win event times $\{1,2,3,4,5\}$, and then form the ratio to recover the mean effect of an extra dollar of unearned income. Column 1 reports mean effects of an extra dollar of unearned income for the full analysis sample. In columns 2 and 3, we report mean effects of an extra dollar of unearned income for subsamples of winners falling into the first and fourth quartile of the pre-win distribution of per-adult adjusted gross income. We use the delta method to calculate standard errors (reported in parenthesis), clustering on winner. The counterfactual means correspond to the average earnings the winner and spouse would have received in the absence of winning (see Appendix E for details). The row "Percentage Change" reports the effect per $\$ 1,000$ in percentage change terms relative to the counterfactual mean.

We examine differences in earnings responses between winners and their spouses by estimating the IV model described in Section 3.3 separately for each household member. The estimated wage earnings responses are reported in Table 6.7. For an additional dollar of unearned income, winners decrease their wage earnings by 64 cents on average, whereas the non-winning spouse reduces his wage earnings by only a third of that amount. These findings are broadly similar to those reported in Cesarini, Lindqvist, Notowidigdo and Östling (2017) using Swedish data.

Implications for models of household behavior. Cesarini, Lindqvist, Notowidigdo and Östling (2017) argue that differential responses of winners and their non-winning spouses, such as those reported in Table 6.7, are seemingly at odds with the unitary model of the household. ${ }^{45}$ However, as recognized by Cesarini, Lindqvist, Notowidigdo and Östling (2017), this argument implicitly relies on the assumption that lottery winnings are not only as good as randomly assigned across households, but also across members within a household (see Appendix $G$ for details). Otherwise, differences in earnings responses between winners and non-winning spouses may be due to either non-random assignment of winning within households or a violation of the unitary model.

To investigate this, we explore whether the winner within a family is systematically different from the

\footnotetext{
${ }^{45}$ For a recent overview of models of household behavior see Chiappori and Mazzocco (2017).
} 
non-winner. As shown in Appendix Table A.11, we find that household members who win the lottery are significantly more likely to be male, employed, and primary earners of the household. Consistent with this finding, Cesarini, Lindqvist, Notowidigdo and Östling (2017, Table A.6) also provide evidence for nonrandom assignment of winning across household members in Swedish data.

In the absence of random assignment of winning across household members, we can still test a key prediction of the unitary model that all incomes from different sources are pooled. Under the income pooling hypothesis, it is only the total amount of resources, and not its distribution across household members, that matters for aggregate household behavior. ${ }^{46}$ This, in turn, implies that the identity of the winner cannot make a difference in terms of household labor supply. To shed additional light on this, we restrict ourselves to two-earner households, consistent with the theory outlined in Appendix G, and split the sample by the identity of the winner. We then estimate the IV model described in Section 3.3 separately by the identity of the winner.

Table 6.8: Effects of unearned income on earnings by identity of winner

\begin{tabular}{|c|c|c|c|c|c|}
\hline \multirow[b]{2}{*}{ Conditioning } & \multirow[b]{2}{*}{ Value } & \multicolumn{2}{|c|}{ Gender of Winner } & \multicolumn{2}{|c|}{ Relative Wage Earnings of Winner } \\
\hline & & $\begin{array}{c}\text { Male Winner } \\
\text { (1) }\end{array}$ & $\begin{array}{l}\text { Female Winner } \\
\text { (2) }\end{array}$ & $\begin{array}{c}\text { Primary Earner } \\
\text { (3) }\end{array}$ & $\begin{array}{c}\text { Secondary Earner } \\
\text { (4) }\end{array}$ \\
\hline \multirow{2}{*}{ Two-Earner Household } & Estimate & -0.7829 & -0.7882 & -0.7437 & -0.8698 \\
\hline & Standard Error & $(0.0409)$ & $(0.0557)$ & $(0.0425)$ & $(0.0519)$ \\
\hline
\end{tabular}

Notes: This table presents estimates of the mean effect for an extra dollar of unearned income on total per-adult labor earnings by identity of the winner. The estimation sample is restricted to two-earner households. Estimates are calculated by first estimating separate regressions for the first- and second-stage model as described in Section 3.3, only now using unearned income as the endogenous variable. For each outcome, we then take cohort-size-weighted averages of $\rho^{w, \ell}$ and $\phi^{w, \ell}$ for each event time $\ell$, and then take the mean across estimates for post-win event times $\{1,2,3,4,5\}$, and then form the ratio to recover the mean effect of an extra dollar of unearned income. Columns 1 and 2 report the mean effects of an extra dollar of unearned income depending on the gender of the winner. Columns 3 and 4 report the mean effects of an extra dollar of unearned income depending on the relative earnings status of the winner within the household. We use the delta method to calculate standard errors (reported in parenthesis), clustering on winner.

Table 6.8 reports the estimated household earnings responses separately by the identity of the winning household member. We find that household earnings responses do not vary materially and are never significantly different by gender or earnings status of the winner. These findings are broadly similar to those reported in Cesarini, Lindqvist, Notowidigdo and Östling (2017, Table A.7) and provide no evidence against the unitary model.

\footnotetext{
${ }^{46}$ There is a large literature that has tested the income pooling hypothesis, e.g., Schultz (1990), Bourguignon, Browning, Chiappori and Lechene (1993), Fortin and Lacroix (1997) and Attanasio and Lechene (2002).
} 


\section{Conclusion}

The goal of this paper was to study how Americans respond to idiosyncratic and exogenous changes in household wealth and unearned income. Our analyses combined administrative data on U.S. lottery winners with an event-study design that exploits variation in the timing of lottery wins. Our first contribution was to estimate the earnings responses to these windfall gains, finding significant and sizable wealth and income effects. On average, an extra dollar of unearned income in a given period reduces pre-tax labor earnings by about 50 cents, decreases total labor taxes by 10 cents, and increases consumption by 60 cents. These effects are heterogeneous across the income distribution, with households in higher quartiles of the income distribution reducing their earnings by a larger amount.

Our second contribution was to develop and apply a rich life-cycle model in which heterogeneous households face non-linear taxes and make earnings choices along both intensive and extensive margins. By mapping this model to our estimated earnings responses, we obtained informative bounds on the impacts of two policy reforms: an introduction of UBI and an increase in top marginal tax rates.

Our last contribution was to study how additional wealth and unearned income affect a wide range of behavior, including geographic mobility and neighborhood choice, retirement decisions and labor market exit, family formation and dissolution, entry into entrepreneurship, and job-to-job mobility. In our analyses, we described the key identification and measurement challenges that arise, motivated how lottery winnings as a source of variation in wealth or unearned income can address these challenges, and discussed how our findings relate and contribute to existing work. 


\section{References}

AlipRAnTIS, D. AND H. MARTIN (2020): "Neighborhood sorting obscures neighborhood effects in the Opportunity Atlas,".

Aliprantis, D. And F. G.-C. Richter (2020): "Evidence of Neighborhood Effects from Moving to Opportunity: Lates of Neighborhood Quality," The Review of Economics and Statistics, 102(4), 633-647.

Altig, D., A. J. Auerbach, L. J. Kotlikoff, E. Ilin and V. Ye (2020): "Marginal Net Taxation of Americans’ Labor Supply,” Working Paper 27164, National Bureau of Economic Research.

Andersen, S. And K. M. Nielsen (2012): “Ability or Finances as Constraints on Entrepreneurship? Evidence from Survival Rates in a Natural Experiment," The Review of Financial Studies, 25(12), 36843710.

ANGRIST, J. D. (2001): "Estimation of Limited Dependent Variable Models With Dummy Endogenous Regressors," Journal of Business \& Economic Statistics, 19(1), 2-28.

Attanasio, O. And V. Lechene (2002): “Tests of Income Pooling in Household Decisions," Review of Economic Dynamics, 5(4), 720-748.

Auclert, A., B. BARdóczy And M. Rognlie (2020): "MPCs, MPEs and Multipliers:A Trilemma for New Keynesian Models," Working paper.

Auclert, A. And M. Rognlie (2020): “Inequality and Aggregate Demand,” Working paper.

BAKIJA, J. (2019): "Documentation for a Comprehensive Historial U.S. Federal and State Income Tax Calculator Program,” Discussion paper.

BAYER, C. AND F. JUESSEN (2012): "On the dynamics of interstate migration: Migration costs and selfselection," Review of Economic Dynamics, 15(3), 377-401.

BEGLEY, J. AND S. CHAN (2018): “The effect of housing wealth shocks on work and retirement decisions," Regional Science and Urban Economics, 73, 180-195.

Bengtsson, N. (2012): "The Marginal Propensity to Earn and Consume out of Unearned Income: Evidence Using an Unusually Large Cash Grant Reform," The Scandinavian Journal of Economics, 114(4), $1393-1413$.

Bergman, P., E. Chan And A. Kapor (2020): "Housing Search Frictions: Evidence from Detailed Search Data and a Field Experiment," Working Paper 27209, National Bureau of Economic Research.

Bergman, P., R. Chetty, S. Deluca, N. Hendren, L. F. Katz and C. Palmer (2020): “Creating Moves to Opportunity: Experimental Evidence on Barriers to Neighborhood Choice," Working Paper.

BlanchFlower, D. G. AND A. J. Oswald (1998): “What Makes an Entrepreneur?," Journal of Labor Economics, 16(1), 26-60. 
Blomquist, N. S. (1985): "Labour Supply in a Two-Period Model: The Effect of a Nonlinear Progressive Income Tax," The Review of Economic Studies, 52(3), 515.

Blundell, R., H. LOW And I. PReston (2013): "Decomposing changes in income risk using consumption data," Quantitative Economics, 4(1), 1-37.

Blundell, R. And T. Macurdy (1999): "Labor Supply: A Review of Alternative Approaches," in Handbook of Labor Economics, vol. 3, pp. 1559-1695. Elsevier.

Blundell, R., L. Pistaferri And I. Preston (2008): “Consumption Inequality and Partial Insurance," American Economic Review, 98(5), 1887-1921.

Blundell, R. And I. WAlKer (1986): “A Life-Cycle Consistent Empirical Model of Family Labour Supply Using Cross-Section Data," The Review of Economic Studies, 53(4), 539.

Bourguignon, F., M. Browning, P.-A. Chiappori And V. Lechene (1993): "Intra Household Allocation of Consumption: A Model and Some Evidence from French Data," Annales d'Économie et de Statistique, (29), 137-156.

Brewer, M., E. SAez and A. Shephard (2010): "Means-Testing and Tax Rates on Earnings," in Dimensions of Tax Design: The Mirrlees Review, ed. by S. J. Mirrlees, pp. 90-173. Oxford University Press, London.

Brown, J. R., C. C. Coile and S. J. Weisbenner (2010): "The Effect of Inheritance Receipt on Retirement," The Review of Economics and Statistics, 92(2), 425-434.

Bulman, G., R. Fairlie, S. Goodman and A. Isen (2021): "Parental Resources and College Attendance: Evidence from Lottery Wins," American Economic Review, 111(4), 1201-40.

Burstein, N. R. (2007): "Economic influences on marriage and divorce," Journal of Policy Analysis and Management, 26(2), 387-429.

Calloway, B. And P. H. Sant'Anna (2020): "Difference-in-Differences with Multiple Time Periods," Working Paper.

Cesarini, D., E. Lindqvist, M. J. Notowidigdo and R. Östling (2017): "The Effect of Wealth on Individual and Household Labor Supply: Evidence from Swedish Lotteries," American Economic Review, 107(12), 3917-3946.

Chen, K.-M., C. Ding, J. A. List and M. Mogstad (2020): "Reservation Wages and Workers' Valuation of Job Flexibility: Evidence from a Natural Field Experiment," Working Paper 27807, National Bureau of Economic Research.

Chetty, R., J. Friedman, N. Hendren, M. R. Jones and S. Porter (2020): “The Opportunity Atlas: Mapping the Childhood Roots of Social Mobility," . 
Chetty, R., J. N. Friedman, N. Hilger, E. Saez, D. W. Schanzenbach and D. Yagan (2011):

"How Does Your Kindergarten Classroom Affect Your Earnings? Evidence from Project Star ," The Quarterly Journal of Economics, 126(4), 1593-1660.

Chetty, R., J. N. Friedman, T. Olsen and L. Pistaferri (2011): “ Adjustment Costs, Firm Responses, and Micro vs. Macro Labor Supply Elasticities: Evidence from Danish Tax Records *," The Quarterly Journal of Economics, 126(2), 749-804.

Chetty, R. And N. Hendren (2018): “The Impacts of Neighborhoods on Intergenerational Mobility I: Childhood Exposure Effects*," The Quarterly Journal of Economics, 133(3), 1107-1162.

Chetty, R., N. Hendren and L. F. Katz (2016a): “The Effects of Exposure to Better Neighborhoods on Children: New Evidence from the Moving to Opportunity Experiment," American Economic Review, 106(4), 855-902.

(2016b): "The Effects of Exposure to Better Neighborhoods on Children: New Evidence from the Moving to Opportunity Experiment," American Economic Review, 106(4), 855-902.

Chiappori, P.-A. And M. MAZzocco (2017): “Static and Intertemporal Household Decisions,” Journal of Economic Literature, 55(3), 985-1045.

Chyn, E. (2018): "Moved to Opportunity: The Long-Run Effects of Public Housing Demolition on Children," American Economic Review, 108(10), 3028-56.

CilKe, J. (1998): “A Profile of Non-Filers,” Discussion paper.

Couture, V., C. Gaubert, J. Handbury and E. Hurst (2019): "Income growth and the distributional effects of urban spatial sorting," Discussion paper, National Bureau of Economic Research.

Davies, P. S., M. J. Greenwood and H. Li (2001): "A Conditional Logit Approach to U.S. State-toState Migration," Journal of Regional Science, 41(2), 337-360.

De Chaisemartin, C. and X. D’Haultfoeuille (2018): "Fuzzy Differences-in-Differences," The Review of Economic Studies, 85(2), 999-1028.

De La RocA, J. And D. Puga (2016): "Learning by Working in Big Cities," The Review of Economic Studies, 84(1), 106-142.

DeVane V. DeVAne (1995):. 280 N.J. Super. 488 (N.J. Super.).

Diamond, P. And E. SAEZ (2011): "The Case for a Progressive Tax: From Basic Research to Policy Recommendation,” Journal of Economic Perspectives, 25(4), 165-190.

Disney, R. And J. Gathergood (2018): “House Prices, Wealth Effects and Labour Supply,” Economica, 85(339), 449-478. 
Dyrda, S. And M. Pedroni (2018): "Optimal Fiscal Policy in a Model with Uninsurable Idiosyncratic Shocks," Working paper.

ERIKSson, T. And N. Kristensen (2014): "Wages or Fringes? Some Evidence on Trade-Offs and Sorting," Journal of Labor Economics, 32(4), 899-928.

Evans, D. S. AND B. JovanoviC (1989): "An Estimated Model of Entrepreneurial Choice under Liquidity Constraints," Journal of Political Economy, 97(4), 808-827.

Evans, D. S. AND L. S. LEIGHTON (1989): "Some Empirical Aspects of Entrepreneurship," The American Economic Review, 79(3), 519-535.

Fagereng, A., M. B. Holm and G. J. NATViK (2020): "MPC Heterogeneity and Household Balance Sheets," Working paper.

FAIRlie, R. W. (1999): "The Absence of the African-American Owned Business: An Analysis of the Dynamics of Self-Employment," Journal of Labor Economics, 17(1), 80-108.

Fairlie, R. W. And H. A. Krashinsky (2012): "Liquidity Constraints, Household Wealth, and Entrepreneurship Revisited," Review of Income and Wealth, 58(2), 279-306.

Feinberg, R. M. and D. Kuehn (2018): "Guaranteed Nonlabor Income and Labor Supply: The Effect of the Alaska Permanent Fund Dividend," The B.E. Journal of Economic Analysis \& Policy, 18(3), 20180042.

Fortin, B. And G. LACROIX (1997): "A Test of the Unitary and Collective Models of Household Labour Supply," The Economic Journal, 107(443), 933-955.

Gelber, A. M., A. Isen And J. Song (2016): "The Effect of Pension Income on Elderly Earnings: Evidence from Social Security," Discussion paper.

Gustman, A. L., T. L. Steinmeier and N. Tabatabai (2010): "What the Stock Market Decline Means for the Financial Security and Retirement Choices of the Near-Retirement Population," Journal of Economic Perspectives, 24(1), 161-82.

Hamermesh, D. S. (1999): “Changing Inequality in Markets for Workplace Amenities," The Quarterly Journal of Economics, 114(4), 1085-1123.

Hankins, S. And M. Hoekstra (2011): "Lucky in Life, Unlucky in Love?: The Effect of Random Income Shocks on Marriage and Divorce," Journal of Human Resources, 46(2), 403-426.

Heathcote, J., K. Storesletten and G. L. Violante (2017): "Optimal Tax Progressivity: An Analytical Framework," The Quarterly Journal of Economics, 132(4), 1693-1754.

Hersch, J. AND J. B. Shinall (2019): "When equitable is not equal: experimental evidence on the division of marital assets in divorce," Review of Economics of the Household, pp. 1-28. 
Holtz-Eakin, D., D. Joulfaian and H. S. Rosen (1993): “The Carnegie Conjecture: Some Empirical Evidence," The Quarterly Journal of Economics, 108(2), 413-435.

(1994): “Sticking it Out: Entrepreneurial Survival and Liquidity Constraints," Journal of Political Economy, 102(1), 53-75.

Hoynes, H. And J. Rothstein (2019): "Universal basic income in the United States and advanced countries," Annual Review of Economics, 11, 929-958.

Hurd, M. D., M. Reti And S. Rohwedder (2009): “The Effect of Large Capital Gains or Losses on Retirement," in Developments in the Economics of Aging, NBER Chapters, pp. 127-163. National Bureau of Economic Research, Inc.

Hurst, E. AND A. LuSARDi (2004): "Liquidity Constraints, Household Wealth, and Entrepreneurship," Journal of Political Economy, 112(2), 319-347.

Imbens, G. W., D. B. Rubin And B. I. SACERdote (2001): "Estimating the Effect of Unearned Income on Labor Earnings, Savings, and Consumption: Evidence from a Survey of Lottery Players," American Economic Review, 91(4), 778-794.

In RE MARRiAge of MAhAFFey (1990):. 206 Ill. App. 3d 859 (Ill. App. Ct.).

In RE MARRiage of SWARTZ (1993):. 512 N.W.2d 825 (Iowa Ct. App.).

JACOB, B. A. AND J. Ludwig (2012): "The Effects of Housing Assistance on Labor Supply: Evidence from a Voucher Lottery," American Economic Review, 102(1), 272-304.

JACQUET, L., E. LEHMANN AND B. VAN DER LINDEN (2013): "Optimal redistributive taxation with both extensive and intensive responses," Journal of Economic Theory, 148(5), 1770-1805.

JAPPElli, T. And L. Pistaferri (2010): “The Consumption Response to Income Changes,” Annual Review of Economics, pp. 479-506.

Jones, D. AND I. MARINESCU (2019): "The Labor Market Impacts of Universal and Permanent Cash Transfers: Evidence from the Alaska Permanent Fund," Manuscript, pp. 1-72.

Katz, L. F. And A. B. Krueger (2019): "The Rise and Nature of Alternative Work Arrangements in the United States, 1995-2015," ILR Review, 72(2), 382-416.

KeAne, M. P. (2011): “Labor Supply and Taxes: A Survey,” Journal of Economic Literature, 49(4), 9611075.

Kearney, M. S. (2005): “State Lotteries and Consumer Behavior," Journal of Public Economics, 89(1112), 2269-2299.

KeARney, M. S. And M. Mogstad (2019): "Universal basic income (UBI) as a policy response to current challenges," Report, Aspen Institute, pp. 1-19. 
Kennan, J. And J. R. WALKer (2011): "The Effect of Expected Income on Individual Migration Decisions," Econometrica, 79(1), 211-251.

Killingsworth, M. And J. Heckman (1986): "Female Labor Supply: A Survey," in Handbook of Labor Economics, ed. by O. Ashenfelter and R. Layard, vol. 1, pp. 103-204. Elsevier.

Kimball, M. S. And M. D. Shapiro (2010): "Labor Supply: Are the Income and Substitution Effects Both Large or Both Small?," Working paper.

Kind, A. J. And W. R. Buckingham (2018): "Making Neighborhood-Disadvantage Metrics Accessible — The Neighborhood Atlas," New England Journal of Medicine, 378(26), 2456-2458, PMID: 29949490.

Kleven, H. J. And C. T. Kreiner (2006): "The marginal cost of public funds: Hours of work versus labor force participation,” Journal of Public Economics, 90(10-11), 1955-1973.

Kleven, H. J. And E. A. Schultz (2014): "Estimating Taxable Income Responses Using Danish Tax Reforms," American Economic Journal: Economic Policy, 6(4), 271-301.

KoŞAR, G., T. RANSOM And W. VAN DER KlAAUW (2021): "Understanding migration aversion using elicited counterfactual choice probabilities," Journal of Econometrics.

Krueger, A. B. And J.-S. PischKe (1992): “The Effect of Social Security on Labor Supply: A Cohort Analysis of the Notch Generation," Journal of Labor Economics, 10(4), 412-437.

Kuhn, P., P. Kooreman, A. Soetevent And A. Kapteyn (2011): "The Effects of Lottery Prizes on Winners and Their Neighbors: Evidence from the Dutch Postcode Lottery," American Economic Review, 101(5), 2226-47.

Lindh, T. AND H. OHLSSON (1996): "Self-Employment and Windfall Gains: Evidence from the Swedish Lottery," The Economic Journal, 106(439), 1515-1526.

LOWREY, A. (2018): Give people money: How a universal basic income would end poverty, revolutionize work, and remake the world. Broadway books.

Ludwig, J., G. J. Duncan, L. A. Gennetian, L. F. Katz, R. C. Kessler, J. R. Kling and L. SanBONMATSU (2013): "Long-Term Neighborhood Effects on Low-Income Families: Evidence from Moving to Opportunity," American Economic Review, 103(3), 226-31.

Ludwig, J., J. B. Liebman, J. R. Kling, G. J. Duncan, L. F. Katz, R. C. Kessler and L. SanBONMATSU (2008): "What Can We Learn about Neighborhood Effects from the Moving to Opportunity Experiment?," American Journal of Sociology, 114(1), 144-188.

MaCurdy, T. E. (1983): "A Simple Scheme for Estimating an Intertemporal Model of Labor Supply and Consumption in the Presence of Taxes and Uncertainty," International Economic Review, 24(2), 265-289. 
Maestas, N., K. J. Mullen, D. Powell, T. von Wachter and J. B. Wenger (2018): "The Value of Working Conditions in the United States and Implications for the Structure of Wages," Working Paper 25204, National Bureau of Economic Research.

MAS, A. And A. PAllais (2017): "Valuing Alternative Work Arrangements," American Economic Review, 107(12), 3722-59.

Meghir, C. And L. PISTAFERri (2004): “Income variance dynamics and heterogeneity," Econometrica, $72(1), 1-32$.

Molloy, R., C. L. Smith and A. Wozniak (2011): “Internal Migration in the United States," Journal of Economic Perspectives, 25(3), 173-96.

Noelke, C., N. McArdle, M. Baek, N. Huntington, R. Huber, E. Hardy and D. AcevedoGARCIA (2020): “Technical Documentation,”.

NyKVIST, J. (2008): "Entrepreneurship and Liquidity Constraints: Evidence from Sweden," The Scandinavian Journal of Economics, 110(1), 23-43.

OECD (2010): SMEs, Entrepreneurship and Innovation.

OSWALD, F. (2019): “The effect of homeownership on the option value of regional migration," Quantitative Economics, 10(4), 1453-1493.

Pacini, D. ANd F. WindmeIJer (2016): “Robust inference for the Two-Sample 2SLS estimator," Economics Letters, 146, 50-54.

PENCAVEL, J. (1986): “Labor supply of men: A survey,” Handbook of Labor Economics, 1, 3-102.

Picchio, M., S. Suetens And J. C. VAn OuRs (2018): “Labour Supply Effects of Winning a Lottery," The Economic Journal, 128(611), 1700-1729.

Rosen, S. (1986): "The theory of equalizing differences," Handbook of Labor Economics, 1, 641-692.

RosenBAum, J. (1995): "Changing the geography of opportunity by expanding residential choice: Lessons from the Gautreaux program," Housing Policy Debate, 6, 231-269.

SAEZ, E. (2001): “Using Elasticities to Derive Optimal Income Tax Rates," The Review of Economic Studies, 68(1), 205-229.

Saez, E., J. Slemrod and S. H. Giertz (2012): "The elasticity of taxable income with respect to marginal tax rates: A critical review," Journal of Economic Literature, 50(1), 3-50.

SAEZ, E. AND G. ZuCMAN (2016): "Wealth inequality in the United States since 1913: Evidence from capitalized income tax data," The Quarterly Journal of Economics, 131(2), 519-578. 
SCHUltz, T. P. (1990): “Testing the Neoclassical Model of Family Labor Supply and Fertility,” The Journal of Human Resources, 25(4), 599-634.

Smith, M., O. ZidAR And E. ZwICK (2020): “Top Wealth in America: New Estimates and Implications for Taxing the Rich," Manuscript, pp. 1-117.

Sмith v. Smith (1990):: 162 A.D.2d 346 (N.Y. App. Div.).

STERN, A. (2016): Raising the floor: How a universal basic income can renew our economy and rebuild the American dream. Public Affairs.

Stewart, C. (1939): "Income Capitalization as a Method of Estimating the Distribution of Wealth By Size Groups," in Studies in Income and Wealth, Volume 3, pp. 95-146. NBER.

Sun, L. And S. Abraham (2020): "Estimating Dynamic Treatment Effects in Event Studies with Heterogeneous Treatment Effects,” Working Paper.

TAYlor, M. P. (2001): "Self-Employment and Windfall Gains in Britain: Evidence from Panel Data," Economica, 68(272), 539-565.

Thomas v. Thomas (2003):. 353 S.C. 523 (S.C.).

Ullah v. Ullah (1990):. 161 A.D.2d 699 (N.Y. App. Div.).

Wilson, W. J. (1987): The Truly Disadvantaged: The Inner City, the Underclass, and Public Policy. University of Chicago Press.

Wiswall, M. AND B. ZAFAR (2017): "Preference for the Workplace, Investment in Human Capital, and Gender*," The Quarterly Journal of Economics, 133(1), 457-507.

WOLF, C. (2019): “The missing intercept: A demand equivalence approach,” Discussion paper.

YANG, A. (2018): The war on normal people: The truth about America's disappearing jobs and why universal basic income is our future. Hachette UK. 


\section{Online Appendix}

\section{A Appendix Tables}

Table A.1: Distribution of lottery winnings

\begin{tabular}{l|c|c|c}
\hline \hline Prize Range & Count & $\begin{array}{c}\text { Mean Pre-Tax Winnings } \\
\text { (per winner) } \\
(2)\end{array}$ & $\begin{array}{c}\text { Median Pre-Tax Winnings } \\
\text { (per winner) } \\
(3)\end{array}$ \\
\hline$<50 \mathrm{~K}$ & 24,800 & $\$ 36,512$ & $\$ 34,700$ \\
$50 \mathrm{~K}$ to $100 \mathrm{~K}$ & 28,689 & $\$ 63,374$ & $\$ 59,400$ \\
$100 \mathrm{~K}$ to $200 \mathrm{~K}$ & 17,521 & $\$ 126,020$ & $\$ 119,100$ \\
$200 \mathrm{~K}+$ & 19,721 & $\$ 1,405,008$ & $\$ 307,200$ \\
\hline All Winners & 90,731 & $\$ 359,743$ & $\$ 67,800$ \\
\hline \hline
\end{tabular}

Notes: The table summarizes the distribution of pre-tax lottery winnings in our sample of working-age winners. All monetary values are reported in 2016 U.S. dollars, using the Consumer Price Index to adjust for inflation. Medians are rounded to the nearest hundred. 
Table A.2: Wealth effects by labor market attachment

\begin{tabular}{|c|c|c|c|c|c|c|}
\hline \multirow[b]{2}{*}{ Outcome } & \multirow[b]{2}{*}{$\begin{array}{l}\text { Labor Force } \\
\text { Attachment }\end{array}$} & \multicolumn{5}{|c|}{ Sample } \\
\hline & & $\begin{array}{l}\text { Full Sample } \\
\text { (1) }\end{array}$ & $\begin{array}{c}\text { Quartile } 1 \\
\text { Pre-Win Income } \\
\text { (2) }\end{array}$ & $\begin{array}{c}\text { Quartile } 2 \\
\text { Pre-Win Income } \\
\text { (3) }\end{array}$ & $\begin{array}{c}\text { Quartile } 3 \\
\text { Pre-Win Income } \\
\text { (4) }\end{array}$ & $\begin{array}{c}\text { Quartile } 4 \\
\text { Pre-Win Income } \\
\text { (5) }\end{array}$ \\
\hline \multirow{3}{*}{ Winner Wage Earnings } & Baseline & $\begin{array}{l}-2.2856 \\
(0.0571)\end{array}$ & $\begin{array}{l}-1.4003 \\
(0.0628)\end{array}$ & $\begin{array}{l}-2.2948 \\
(0.0861)\end{array}$ & $\begin{array}{l}-2.6196 \\
(0.0935)\end{array}$ & $\begin{array}{l}-3.0596 \\
(0.1541)\end{array}$ \\
\hline & Employed Pre-Win & $\begin{array}{l}-2.6437 \\
(0.0661)\end{array}$ & $\begin{array}{l}-1.7358 \\
(0.0968)\end{array}$ & $\begin{array}{l}-2.6309 \\
(0.0903)\end{array}$ & $\begin{array}{l}-2.8243 \\
(0.0995)\end{array}$ & $\begin{array}{l}-3.3511 \\
(0.1580)\end{array}$ \\
\hline & FT Employed Pre-Win & $\begin{array}{l}-2.9566 \\
(0.0792)\end{array}$ & $\begin{array}{l}-2.6015 \\
(0.3019)\end{array}$ & $\begin{array}{l}-2.9885 \\
(0.0987)\end{array}$ & $\begin{array}{l}-2.9500 \\
(0.1046)\end{array}$ & $\begin{array}{l}-3.4603 \\
(0.1621)\end{array}$ \\
\hline \multirow{3}{*}{ Per-Adult Wage Earnings } & Baseline & $\begin{array}{l}-2.0245 \\
(0.0492)\end{array}$ & $\begin{array}{l}-1.2514 \\
(0.0589)\end{array}$ & $\begin{array}{l}-2.0422 \\
(0.0764)\end{array}$ & $\begin{array}{l}-2.2590 \\
(0.0813)\end{array}$ & $\begin{array}{l}-2.7035 \\
(0.1311)\end{array}$ \\
\hline & Employed Pre-Win & $\begin{array}{l}-2.2414 \\
(0.0546)\end{array}$ & $\begin{array}{l}-1.4446 \\
(0.0896)\end{array}$ & $\begin{array}{l}-2.2479 \\
(0.0781)\end{array}$ & $\begin{array}{l}-2.3421 \\
(0.0847)\end{array}$ & $\begin{array}{c}-2.8994 \\
(0.1269)\end{array}$ \\
\hline & FT Employed Pre-Win & $\begin{array}{l}-2.4729 \\
(0.0644)\end{array}$ & $\begin{array}{l}-1.9109 \\
(0.2741)\end{array}$ & $\begin{array}{l}-2.5386 \\
(0.0833)\end{array}$ & $\begin{array}{l}-2.4170 \\
(0.0887)\end{array}$ & $\begin{array}{l}-2.9483 \\
(0.1283)\end{array}$ \\
\hline \multirow{3}{*}{ Per-Adult Total Labor Earnings } & Baseline & $\begin{array}{l}-2.3394 \\
(0.0657)\end{array}$ & $\begin{array}{l}-1.3339 \\
(0.1051)\end{array}$ & $\begin{array}{l}-2.2720 \\
(0.0867)\end{array}$ & $\begin{array}{l}-2.6450 \\
(0.0996)\end{array}$ & $\begin{array}{l}-3.1298 \\
(0.1820)\end{array}$ \\
\hline & Employed Pre-Win & $\begin{array}{l}-2.5170 \\
(0.0972)\end{array}$ & $\begin{array}{l}-1.5688 \\
(0.1764)\end{array}$ & $\begin{array}{l}-2.2965 \\
(0.1185)\end{array}$ & $\begin{array}{l}-2.5543 \\
(0.1320)\end{array}$ & $\begin{array}{l}-3.4340 \\
(0.2471)\end{array}$ \\
\hline & FT Employed Pre-Win & $\begin{array}{l}-2.7651 \\
(0.1140)\end{array}$ & $\begin{array}{l}-2.5804 \\
(0.5710)\end{array}$ & $\begin{array}{l}-2.6287 \\
(0.1365)\end{array}$ & $\begin{array}{l}-2.6342 \\
(0.1366)\end{array}$ & $\begin{array}{l}-3.4363 \\
(0.2499)\end{array}$ \\
\hline
\end{tabular}

Notes: This table presents estimates of the mean effect of an extra dollar of wealth on three earnings outcomes. These estimates are calculated by first estimating a 2SLS regression, as described in Section 3.3, for each outcome, then taking cohort-size-weighted averages of $\beta^{w, \ell}$ for each event time $\ell$, then taking the mean across estimates for post-win event times $\{1,2,3,4,5\}$ to recover the mean wealth effect in the post-win period. Column 1 reports wealth effects for the full analysis sample. In columns 2 to 5, we report wealth effects for subsamples of winners falling into each quartile of the pre-win distribution of adjusted gross income. For each outcome, along the rows, we report the wealth effects for the main, unconditional analysis sample ("Baseline") as well as for the subsample of winners who were employed (that is, had positive winner wage earnings) in the baseline pre-win period ("Employed Pre-Win") and the subsample of winners who received wage earnings of at least $\$ 15,000$ (in 2016 USD) in the baseline pre-win period ("FT Employed Pre-Win"). We use the delta method to calculate standard errors (reported in square brackets), clustering on winner. To ease of interpretability, we scale earnings responses by $\$ 100$. 
Table A.3: IV estimates of the effect of an exogenous change in unearned income (capitalization approach)

\begin{tabular}{|c|c|c|c|c|c|}
\hline & & & Sample & & \\
\hline Outcome & $\begin{array}{c}\text { Full Sample } \\
\text { (1) }\end{array}$ & $\begin{array}{c}\text { Quartile 1 } \\
\text { Pre-Win Income } \\
\text { (2) }\end{array}$ & $\begin{array}{c}\text { Quartile } 2 \\
\text { Pre-Win Income } \\
\text { (3) }\end{array}$ & $\begin{array}{c}\text { Quartile } 3 \\
\text { Pre-Win Income } \\
\text { (4) }\end{array}$ & $\begin{array}{c}\text { Quartile } 4 \\
\text { Pre-Win Income } \\
\text { (5) }\end{array}$ \\
\hline Per-Adult Total Labor Earnings & $\begin{array}{l}-0.5182 \\
(0.0815)\end{array}$ & $\begin{array}{l}-0.2925 \\
(0.0669)\end{array}$ & $\begin{array}{l}-0.4278 \\
(0.0874)\end{array}$ & $\begin{array}{l}-0.5283 \\
(0.1041)\end{array}$ & $\begin{array}{l}-0.7385 \\
(0.3306)\end{array}$ \\
\hline Per-Adult Labor Earnings Taxes & $\begin{array}{l}-0.1077 \\
(0.0201)\end{array}$ & $\begin{array}{l}-0.0404 \\
(0.0221)\end{array}$ & $\begin{array}{l}-0.0609 \\
(0.0244)\end{array}$ & $\begin{array}{l}-0.1143 \\
(0.0277)\end{array}$ & $\begin{array}{l}-0.1941 \\
(0.0892)\end{array}$ \\
\hline Implied Consumption Expenditure & $\begin{array}{c}0.5882 \\
(0.1689)\end{array}$ & $\begin{array}{c}0.7463 \\
(0.2294)\end{array}$ & $\begin{array}{c}0.6318 \\
(0.2280)\end{array}$ & $\begin{array}{c}0.5858 \\
(0.2159)\end{array}$ & $\begin{array}{c}0.4533 \\
(0.4781)\end{array}$ \\
\hline
\end{tabular}

Notes: This table presents estimates of the mean effect of an extra dollar of unearned income. These estimates are calculated by first estimating separate regressions for the first- and second-stage model as described in Section 3.3, only now using unearned income as the endogenous variable. For each outcome, we then take cohort-size-weighted averages of $\rho^{w, \ell}$ and $\phi^{w, \ell}$ for each event time $\ell$, and then take the mean across estimates for post-win event times $\{1,2,3,4,5\}$, and then form the ratio to recover the mean effect of an extra dollar of unearned income. Column 1 reports mean effects of an extra dollar of unearned income for the full analysis sample. In columns 2 to 5, we report mean effects of an extra dollar of unearned income for subsamples of winners falling into each quartile of the pre-win distribution of adjusted gross income. We use the delta method to calculate two-sample IV standard errors as in Pacini and Windmeijer (2016) (reported in parenthesis), clustering on winner. We use a ratio of weighted-averages due to the additional imprecision in the cohort-by-event-time ratios when using the capitalization method. 
Table A.4: Effects of unearned income on take-up of retirement benefits and labor market exit

\begin{tabular}{|c|c|c|c|c|}
\hline Outcome & Value & $\begin{array}{l}\text { Full Sample } \\
\qquad(1)\end{array}$ & $\begin{array}{c}\text { Quartile } 1 \\
\text { Pre-Win Income } \\
\text { (2) }\end{array}$ & $\begin{array}{c}\text { Quartile } 4 \\
\text { Pre-Win Income } \\
\text { (3) }\end{array}$ \\
\hline & & \multicolumn{3}{|c|}{ Take-Up of Retirement Benefits } \\
\hline Claiming OASI Benefits & $\begin{array}{c}\text { Estimate } \\
\text { Standard Error } \\
\text { Counterfactual Mean } \\
\text { Percentage Change }\end{array}$ & $\begin{array}{c}0.0169 \\
(0.0061) \\
0.77 \\
2.2\end{array}$ & $\begin{array}{c}0.0333 \\
(0.0181) \\
0.74 \\
4.5\end{array}$ & $\begin{array}{c}0.0114 \\
(0.0115) \\
0.73 \\
1.6\end{array}$ \\
\hline & & \multicolumn{3}{|c|}{ Labor Market Exit } \\
\hline One-Year Exit & $\begin{array}{c}\text { Estimate } \\
\text { Standard Error } \\
\text { Counterfactual Mean } \\
\text { Percentage Change }\end{array}$ & $\begin{array}{c}0.0720 \\
(0.0078) \\
0.43 \\
16.7\end{array}$ & $\begin{array}{c}0.0532 \\
(0.0140) \\
0.63 \\
8.5\end{array}$ & $\begin{array}{c}0.0581 \\
(0.0152) \\
0.33 \\
17.4\end{array}$ \\
\hline Two-Year Exit & $\begin{array}{c}\text { Estimate } \\
\text { Standard Error } \\
\text { Counterfactual Mean } \\
\text { Percentage Change }\end{array}$ & $\begin{array}{c}0.0790 \\
(0.0086) \\
0.40 \\
19.7\end{array}$ & $\begin{array}{c}0.0703 \\
(0.0156) \\
0.58 \\
12.2\end{array}$ & $\begin{array}{c}0.0678 \\
(0.0164) \\
0.30 \\
22.3\end{array}$ \\
\hline Five-Year Exit & $\begin{array}{c}\text { Estimate } \\
\text { Standard Error } \\
\text { Counterfactual Mean } \\
\text { Percentage Change }\end{array}$ & $\begin{array}{c}0.0721 \\
(0.0144) \\
0.35 \\
20.6\end{array}$ & $\begin{array}{c}0.0879 \\
(0.0390) \\
0.48 \\
18.5\end{array}$ & $\begin{array}{c}0.0290 \\
(0.0251) \\
0.31 \\
9.5\end{array}$ \\
\hline
\end{tabular}

Notes: This table presents estimates of the mean effect of an extra dollar of unearned income on take up of retirement benefits and labor market exit for winners aged 62-64. The dependent variables are binary indicators for the receipt of OASI benefits and labor force exit respectively. These estimates are calculated by first estimating a 2SLS regression, as described in Section 3.3, using unearned income $\left(n_{t}\right)$ as the endogenous variable. For each outcome, we then take cohort-size-weighted averages of $\rho^{w, \ell}$ and $\phi^{w, \ell}$ for each event time $\ell$, and then take the mean across estimates for post-win event times $\{1,2,3,4,5\}$, and then form the ratio to recover the mean effect of an extra dollar of unearned income. Column 1 reports mean effects of an extra dollar of unearned income for the full analysis sample. In columns 2 and 3, we report mean effects of an extra dollar of unearned income for subsamples of winners falling into the first and fourth quartile of the pre-win distribution of per-adult adjusted gross income. We use the delta method to calculate standard errors (reported in parenthesis), clustering on winner. To ease interpretability, each estimate is scaled by $\$ 10,000$. The counterfactual means correspond to the fraction of winners that would have taken up retirement benefits or exited the labor market in the absence of winning (see Appendix E for details). The row "Percentage Change" reports the effect per $\$ 10,000$ in percentage change terms relative to the counterfactual mean. 
Table A.5: Effects of unearned income on entrepreneurship and self-employment

\begin{tabular}{|c|c|c|c|c|}
\hline Outcome & Value & $\begin{array}{l}\text { Full Sample } \\
\qquad(1)\end{array}$ & $\begin{array}{c}\text { Quartile } 1 \\
\text { Pre-Win Income } \\
\text { (2) }\end{array}$ & $\begin{array}{c}\text { Quartile } 4 \\
\text { Pre-Win Income } \\
\text { (3) }\end{array}$ \\
\hline Transition to Low-Paying SE & $\begin{array}{c}\text { Estimate } \\
\text { Standard Error } \\
\text { Counterfactual Mean } \\
\text { Percentage Change }\end{array}$ & $\begin{array}{c}0.0107 \\
(0.0006) \\
0.03 \\
31.1\end{array}$ & $\begin{array}{c}0.0092 \\
(0.0025) \\
0.05 \\
17.1\end{array}$ & $\begin{array}{c}0.0115 \\
(0.0009) \\
0.03 \\
42.1\end{array}$ \\
\hline Transition to High-Paying SE & $\begin{array}{c}\text { Estimate } \\
\text { Standard Error } \\
\text { Counterfactual Mean } \\
\text { Percentage Change }\end{array}$ & $\begin{array}{c}-0.0004 \\
(0.0004) \\
0.01 \\
-2.9\end{array}$ & $\begin{array}{c}-0.0009 \\
(0.0012) \\
0.01 \\
-6.3\end{array}$ & $\begin{array}{c}-0.0011 \\
(0.0006) \\
0.02 \\
-6.3\end{array}$ \\
\hline
\end{tabular}

Notes: This table presents estimates of the mean effect of an extra dollar of unearned income on the propensity to start a business associated with annual profits of $\$ 15,000$ or less (low-paying SE), or a business with profits of more than $\$ 15,000$ (high-paying SE). The estimation sample is restricted to winners and not-yet winners in paid-employment at event time $w-2$. These estimates are calculated by first estimating a 2SLS regression, as described in Section 3.3, using unearned income $\left(n_{t}\right)$ as the endogenous variable. For each outcome, we then take cohort-sizeweighted averages of $\rho^{w, \ell}$ and $\phi^{w, \ell}$ for each event time $\ell$, and then take the mean across estimates for post-win event times $\{1,2,3,4,5\}$, and then form the ratio to recover the mean effect of an extra dollar of unearned income. Column 1 reports mean effects of an extra dollar of unearned income for the full analysis sample. In columns 2 and 3, we report mean effects of an extra dollar of unearned income for subsamples of winners falling into the first and fourth quartile of the pre-win distribution of per-adult adjusted gross income. We use the delta method to calculate standard errors (reported in parenthesis), clustering on winner. To ease interpretability, each estimate is scaled by $\$ 10,000$. The counterfactual means correspond to the fraction of employed winners that would have received income from self-employment in the absence of winning (see Appendix E for details). The row "Percentage Change" reports the effect per $\$ 10,000$ in percentage change terms relative to the counterfactual mean. 
Table A.6: Effects of wealth on job mobility

\begin{tabular}{|c|c|c|c|c|}
\hline Outcome & Value & $\begin{array}{l}\text { Full Sample } \\
\qquad(1)\end{array}$ & $\begin{array}{c}\text { Quartile } 1 \\
\text { Pre-Win Income } \\
\text { (2) }\end{array}$ & $\begin{array}{c}\text { Quartile } 4 \\
\text { Pre-Win Income } \\
\text { (3) }\end{array}$ \\
\hline Any Job-to-Job Move & $\begin{array}{c}\text { Estimate } \\
\text { Standard Error } \\
\text { Counterfactual Mean } \\
\text { Percentage Change }\end{array}$ & $\begin{array}{c}0.0004 \\
(0.0018) \\
0.46 \\
0.1\end{array}$ & $\begin{array}{c}0.0033 \\
(0.0052) \\
0.67 \\
0.5\end{array}$ & $\begin{array}{c}-0.0043 \\
(0.0030) \\
0.36 \\
-1.2\end{array}$ \\
\hline Downward Move & $\begin{array}{c}\text { Estimate } \\
\text { Standard Error } \\
\text { Counterfactual Mean } \\
\text { Percentage Change }\end{array}$ & $\begin{array}{c}0.0096 \\
(0.0017) \\
0.23 \\
4.3\end{array}$ & $\begin{array}{c}0.0123 \\
(0.0053) \\
0.31 \\
4.0\end{array}$ & $\begin{array}{c}0.0011 \\
(0.0026) \\
0.19 \\
0.6\end{array}$ \\
\hline Upward Move & $\begin{array}{c}\text { Estimate } \\
\text { Standard Error } \\
\text { Counterfactual Mean } \\
\text { Percentage Change }\end{array}$ & $\begin{array}{c}-0.0092 \\
(0.0016) \\
0.24 \\
-3.9\end{array}$ & $\begin{array}{c}-0.0090 \\
(0.0052) \\
0.36 \\
-2.5\end{array}$ & $\begin{array}{c}-0.0054 \\
(0.0023) \\
0.17 \\
-3.2\end{array}$ \\
\hline
\end{tabular}

Notes: This table presents estimates of the mean effect of an extra dollar of wealth on the frequency and direction of job-to-job moves. The estimation sample is restricted to winners and not-yet winners in paid-employment pre- and post-win. Outcomes are defined as binary and equal to 1 if the firm is either different from, or higher or lower ranked than the firm prior to winning the lottery. Firms are ranked by the mean wage paid to its employees. These estimates are calculated by first estimating a 2SLS regression, as described in Section 3.3. For each outcome, we then take cohort-size-weighted averages of $\beta^{w, \ell}$ for each event time $\ell$, and then take the mean across estimates for post-win event times $\{1,2,3,4,5\}$ to recover the mean effect of an extra dollar of wealth. Column 1 reports mean effects of an extra dollar of wealth for the full analysis sample. In columns 2 and 3, we report mean effects of an extra dollar of wealth for subsamples of winners falling into the first and fourth quartile of the pre-win distribution of per-adult adjusted gross income. We use the delta method to calculate standard errors (reported in parenthesis), clustering on winner. To ease interpretability, each estimate is scaled by $\$ 100,000$. The counterfactual means correspond to the job mobility rates that would have occurred in the absence of winning (see Appendix E for details). The row "Percentage Change" reports the effect per $\$ 100,000$ in percentage change terms relative to the counterfactual mean. 
Table A.7: Effects of wealth on earnings by gender of the winner

\begin{tabular}{|c|c|c|c|c|}
\hline Group & Value & $\begin{array}{c}\text { Full Sample } \\
\text { (1) }\end{array}$ & $\begin{array}{c}\text { Quartile } 1 \\
\text { Pre-Win Income } \\
\text { (2) }\end{array}$ & $\begin{array}{c}\text { Quartile } 4 \\
\text { Pre-Win Income } \\
\text { (3) }\end{array}$ \\
\hline & & \multicolumn{3}{|c|}{ Winner Wage Earnings (per \$100) } \\
\hline Male Winner & $\begin{array}{c}\text { Estimate } \\
\text { Standard Error } \\
\text { Counterfactual Mean } \\
\text { Percentage Change }\end{array}$ & $\begin{array}{c}-2.5714 \\
(0.0826) \\
38235.23 \\
-6.7\end{array}$ & $\begin{array}{c}-1.6983 \\
(0.0859) \\
14288.29 \\
-11.9\end{array}$ & $\begin{array}{c}-3.1973 \\
(0.2081) \\
66641.39 \\
-4.8\end{array}$ \\
\hline \multirow[t]{2}{*}{ Female Winner } & $\begin{array}{c}\text { Estimate } \\
\text { Standard Error } \\
\text { Counterfactual Mean } \\
\text { Percentage Change }\end{array}$ & $\begin{array}{c}-1.8539 \\
(0.0651) \\
26576.05 \\
-7.0\end{array}$ & $\begin{array}{c}-1.0093 \\
(0.0785) \\
10946.22 \\
-9.2\end{array}$ & $\begin{array}{c}-3.2610 \\
(0.2026) \\
47967.19 \\
-6.8\end{array}$ \\
\hline & & \multicolumn{3}{|c|}{ Per-Adult Total Labor Earnings (per \$100) } \\
\hline Male Winner & $\begin{array}{c}\text { Estimate } \\
\text { Standard Error } \\
\text { Counterfactual Mean } \\
\text { Percentage Change }\end{array}$ & $\begin{array}{c}-2.7046 \\
(0.0852) \\
36131.60 \\
-7.5 \\
\end{array}$ & $\begin{array}{c}-1.7517 \\
(0.1267) \\
15015.03 \\
-11.7 \\
\end{array}$ & $\begin{array}{c}-3.5947 \\
(0.2065) \\
62948.19 \\
-5.7 \\
\end{array}$ \\
\hline Female Winner & $\begin{array}{c}\text { Estimate } \\
\text { Standard Error } \\
\text { Counterfactual Mean } \\
\text { Percentage Change }\end{array}$ & $\begin{array}{c}-1.7193 \\
(0.1041) \\
31112.13 \\
-5.5\end{array}$ & $\begin{array}{c}-0.8651 \\
(0.1926) \\
12875.22 \\
-6.7\end{array}$ & $\begin{array}{c}-2.6204 \\
(0.3929) \\
58251.54 \\
-4.5\end{array}$ \\
\hline
\end{tabular}

Notes: This table presents estimates of the mean effect of an extra dollar of wealth on earnings separately by gender of the winner. These estimates are calculated by first estimating a 2SLS regression, as described in Section 3.3. For each outcome, we then take cohort-size-weighted averages of $\beta^{w, \ell}$ for each event time $\ell$, and then take the mean across estimates for post-win event times $\{1,2,3,4,5\}$ to recover the mean effect of an extra dollar of wealth. Column 1 reports mean effects of an extra dollar of wealth for the full analysis sample. In columns 2 and 3, we report mean effects of an extra dollar of wealth for subsamples of winners falling into the first and fourth quartile of the pre-win distribution of per-adult adjusted gross income. We use the delta method to calculate standard errors (reported in parenthesis), clustering on winner. The counterfactual means correspond to the average earnings the winner would have received in the absence of winning (see Appendix E for details). The row "Percentage Change" reports the effect per $\$ 100,000$ in percentage change terms relative to the counterfactual mean. 
Table A.8: Effects of wealth on earnings by marital status of the winner

\begin{tabular}{|c|c|c|c|c|}
\hline Group & Value & $\begin{array}{c}\text { Full Sample } \\
\text { (1) }\end{array}$ & $\begin{array}{c}\text { Quartile } 1 \\
\text { Pre-Win Income } \\
\text { (2) }\end{array}$ & $\begin{array}{c}\text { Quartile } 4 \\
\text { Pre-Win Income } \\
\text { (3) }\end{array}$ \\
\hline & & \multicolumn{3}{|c|}{ Winner Wage Earnings (per \$100) } \\
\hline Married Winner & $\begin{array}{c}\text { Estimate } \\
\text { Standard Error } \\
\text { Counterfactual Mean } \\
\text { Percentage Change }\end{array}$ & $\begin{array}{c}-2.9677 \\
(0.1194) \\
38275.25 \\
-7.8\end{array}$ & $\begin{array}{c}-2.6210 \\
(0.2250) \\
11892.97 \\
-22.0\end{array}$ & $\begin{array}{c}-3.1574 \\
(0.3004) \\
62152.53 \\
-5.1\end{array}$ \\
\hline Single Winner & $\begin{array}{c}\text { Estimate } \\
\text { Standard Error } \\
\text { Counterfactual Mean } \\
\text { Percentage Change }\end{array}$ & $\begin{array}{c}-2.0146 \\
(0.0603) \\
29816.89 \\
-6.8\end{array}$ & $\begin{array}{c}-1.2763 \\
(0.0634) \\
13198.26 \\
-9.7\end{array}$ & $\begin{array}{c}-3.0077 \\
(0.1749) \\
57815.81 \\
-5.2\end{array}$ \\
\hline & & \multicolumn{3}{|c|}{ Per-Adult Total Labor Earnings (per \$100) } \\
\hline Married Winner & $\begin{array}{c}\text { Estimate } \\
\text { Standard Error } \\
\text { Counterfactual Mean } \\
\text { Percentage Change }\end{array}$ & $\begin{array}{c}-2.8043 \\
(0.1400) \\
38033.72 \\
-7.4\end{array}$ & $\begin{array}{c}-2.3592 \\
(0.5071) \\
12365.40 \\
-19.1\end{array}$ & $\begin{array}{c}-3.2473 \\
(0.3593) \\
63576.97 \\
-5.1\end{array}$ \\
\hline Single Winner & $\begin{array}{c}\text { Estimate } \\
\text { Standard Error } \\
\text { Counterfactual Mean } \\
\text { Percentage Change }\end{array}$ & $\begin{array}{c}-2.2221 \\
(0.0693) \\
30994.56 \\
-7.2\end{array}$ & $\begin{array}{c}-1.3374 \\
(0.0961) \\
14686.77 \\
-9.1\end{array}$ & $\begin{array}{c}-3.1445 \\
(0.1907) \\
58302.67 \\
-5.4\end{array}$ \\
\hline
\end{tabular}

Notes: This table presents estimates of the mean effect of an extra dollar of wealth on earnings separately by marital status of the winner. These estimates are calculated by first estimating a 2SLS regression, as described in Section 3.3. For each outcome, we then take cohort-size-weighted averages of $\beta^{w, \ell}$ for each event time $\ell$, and then take the mean across estimates for post-win event times $\{1,2,3,4,5\}$ to recover the mean effect of an extra dollar of wealth. Column 1 reports mean effects of an extra dollar of wealth for the full analysis sample. In columns 2 and 3 , we report mean effects of an extra dollar of wealth for subsamples of winners falling into the first and fourth quartile of the pre-win distribution of per-adult adjusted gross income. We use the delta method to calculate standard errors (reported in parenthesis), clustering on winner. The counterfactual means correspond to the average earnings the winner would have received in the absence of winning (see Appendix E for details). The row "Percentage Change" reports the effect per $\$ 100,000$ in percentage change terms relative to the counterfactual mean. 
Table A.9: Effects of unearned income on marriages and divorce

\begin{tabular}{c|c|c|cc}
\hline \hline \multirow{3}{*}{ Outcome } & Value & Full Sample & $\begin{array}{c}\text { Quartile 1 } \\
\text { Pre-Win Income } \\
(2)\end{array}$ & $\begin{array}{c}\text { Quartile 4 } \\
\text { Pre-Win Income } \\
(3)\end{array}$ \\
\hline \multirow{5}{*}{ New Marriage } & Estimate & 0.0174 & 0.0388 & 0.0009 \\
& Standard Error & $(0.0018)$ & $(0.0056)$ & $(0.0029)$ \\
& Counterfactual Mean & 0.14 & 0.14 & 0.15 \\
& Percentage Change & 12.3 & 27.1 & 0.6 \\
\hline \multirow{5}{*}{ Divorce } & Estimate & -0.0143 & -0.0309 & -0.0122 \\
& Standard Error & $(0.0022)$ & $(0.0087)$ & $(0.0032)$ \\
& Counterfactual Mean & 0.11 & 0.17 & 0.09 \\
& Percentage Change & -12.4 & -18.1 & -13.4 \\
\hline \hline
\end{tabular}

Notes: This table presents estimates of the mean effect of an extra dollar of unearned income on the propensity to enter or leave marriage. The estimation sample is restricted to winners and not-yet winners that are tax filers. When we study the effect on new marriages (divorce), we further restrict the sample to individuals that were not married (married) in $w-2$. These estimates are calculated by first estimating a 2SLS regression, as described in Section 3.3, using unearned income $\left(n_{t}\right)$ as the endogenous variable. For each outcome, we then take cohort-size-weighted averages of $\rho^{w, \ell}$ and $\phi^{w, \ell}$ for each event time $\ell$, and then take the mean across estimates for post-win event times $\{1,2,3,4,5\}$, and then form the ratio to recover the mean effect of an extra dollar of unearned income. Column 1 reports mean effects of an extra dollar of unearned income for the full analysis sample. In columns 2 and 3, we report mean effects of an extra dollar of unearned income for subsamples of winners falling into the first and fourth quartile of the pre-win distribution of per-adult adjusted gross income. We use the delta method to calculate standard errors (reported in parenthesis), clustering on winner. To ease interpretability, each estimate is scaled by $\$ 10,000$. The counterfactual means correspond to the marriage and divorce rates that would have occurred in the absence of winning (see Appendix E for details). The row "Percentage Change" reports the effect per $\$ 10,000$ in percentage change terms relative to the counterfactual mean. 
Table A.10: Effects of wealth on wage earnings of winners and their spouse

\begin{tabular}{|c|c|c|c|c|}
\hline Group & Value & $\begin{array}{l}\text { Full Sample } \\
\qquad(1)\end{array}$ & $\begin{array}{c}\text { Quartile } 1 \\
\text { Pre-Win Income } \\
\text { (2) }\end{array}$ & $\begin{array}{c}\text { Quartile } 4 \\
\text { Pre-Win Income } \\
\text { (3) }\end{array}$ \\
\hline \multirow{4}{*}{ Winner } & Estimate & -2.9677 & -2.6210 & -3.1574 \\
\hline & Standard Error & $(0.1194)$ & $(0.2250)$ & $(0.3004)$ \\
\hline & Counterfactual Mean & 38275.25 & 11892.97 & 62152.53 \\
\hline & Percentage Change & -7.8 & -22.0 & -5.1 \\
\hline \multirow{4}{*}{ Spouse } & Estimate & -1.0505 & -0.3263 & -1.7283 \\
\hline & Standard Error & $(0.1032)$ & $(0.2175)$ & $(0.3223)$ \\
\hline & Counterfactual Mean & 27141.85 & 6727.89 & 46890.46 \\
\hline & Percentage Change & -3.9 & -4.8 & -3.7 \\
\hline
\end{tabular}

Notes: This table presents estimates of the mean effect of an extra dollar of wealth on wage earnings for winners and non-winning spouses. The estimation sample is restricted to married couples. Estimates are calculated by first estimating separate regressions for the first- and second-stage model as described in Section 3.3. For each outcome, we then take cohort-size-weighted averages of $\beta^{w, \ell}$ for each event time $\ell$, and then take the mean across estimates for post-win event times $\{1,2,3,4,5\}$ to recover the mean effect of an extra dollar of wealth. Column 1 reports mean effects of an extra dollar of wealth for the full analysis sample. In columns 2 and 3, we report mean effects of an extra dollar of wealth for subsamples of winners falling into the first and fourth quartile of the pre-win distribution of per-adult adjusted gross income. We use the delta method to calculate standard errors (reported in parenthesis), clustering on winner. The counterfactual means correspond to the average earnings the winner and spouse would have received in the absence of winning (see Appendix E for details). The row "Percentage Change" reports the effect per $\$ 100,000$ in percentage change terms relative to the counterfactual mean.

Table A.11: Summary statistics for winning member of the household

\begin{tabular}{l|c|c|c}
\hline \hline & & $\frac{\text { Winner }}{(1)}$ & $\frac{\text { Spouse }}{(2)}$ \\
Covariate & Statistic & & \\
Wage Earnings & Mean & $\$ 42,465$ & $\$ 33,037$ \\
Employment & Prop. & 0.80 & 0.73 \\
Age & Prop. & 47.07 & 46.65 \\
Female & Prop. & 0.36 & 0.64 \\
Primary Earner & Prop. & 0.62 & 0.38 \\
Older Member & Prop. & 0.50 & 0.50 \\
Same Age & Prop. & 0.11 & 0.11 \\
\hline
\end{tabular}

Notes: This table presents a summary of the descriptive statistics in our sample of married winners, separately for the winner and spouse. All monetary values are reported in 2016 U.S. dollars, using the Consumer Price Index to adjust for inflation. All values are measured two years prior to the win year. At the bottom of the table, we report the $p$-value from an $F$-test that one or more of the covariate means is different between winners and their spouses. 


\section{B Appendix Figures}

Figure B.1: Comparison of approaches to control for life-cycle effects

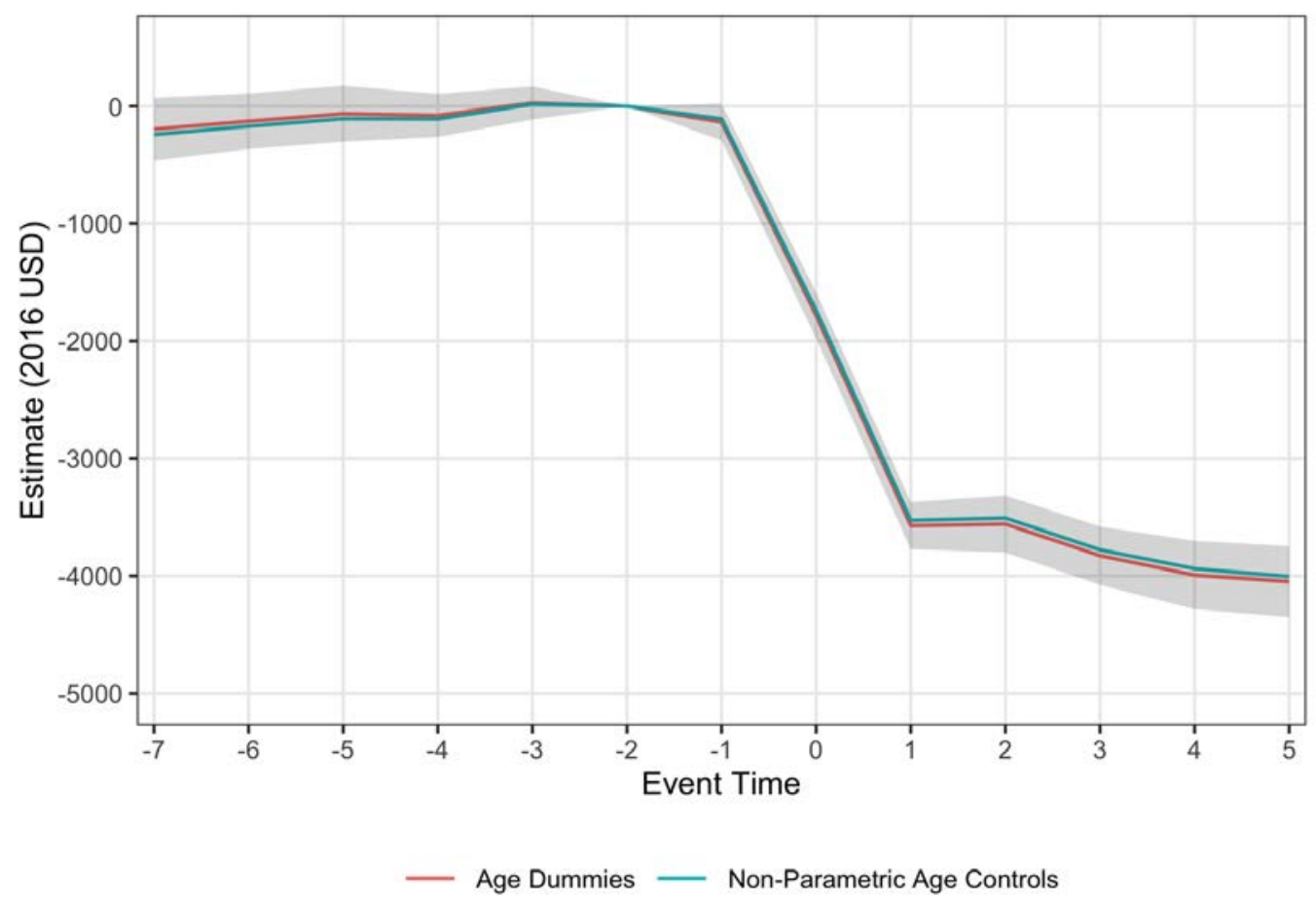

Notes: This figure presents estimates of the impact of winning on winner wage earnings. For the red series, each set of estimates is based on estimating a version of equation (3.4) (as described in Section 3.1) for each outcome, and then taking cohort-size-weighted averages of $\rho^{w, \ell}$ for each event time $\ell$. For the blue series, we instead use a non-parametric estimator due to Calloway and Sant'Anna (2020) which adjusts for age differences between current and later winners through an inverse-probability-weighted (IPW) DiD estimator. 90 percent confidence intervals are displayed for the red series, clustering on winner. Throughout, we use $w-2$ as the omitted event time. 
Figure B.2: Unadjusted versus winsorized estimates of effect of winning

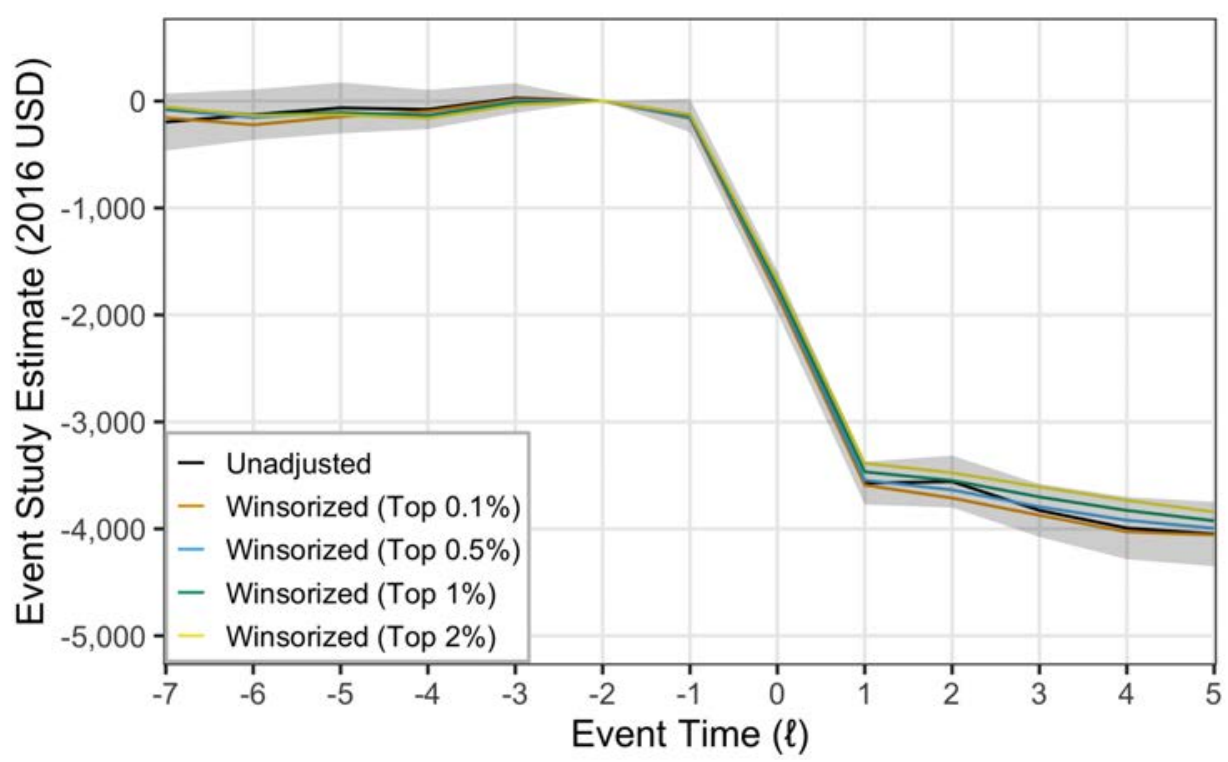

Notes: In this figure, we summarize the estimates of the effect of winning the lottery on winner wage earnings corresponding to an unadjusted measure of wage earnings ("Unadjusted") as well as various winsorized measures. Each set of estimates is based on estimating a version of equation (3.4) (as described in Section 3.1) for each outcome, and then taking cohort-size-weighted averages of $\rho^{w, \ell}$ for each event time $\ell$. 90 percent confidence intervals are displayed for the "Unadjusted" estimates, clustering on winner. Throughout, we use $w-2$ as the omitted event time.

Figure B.3: Effect of winning on per-adult capital income and its components

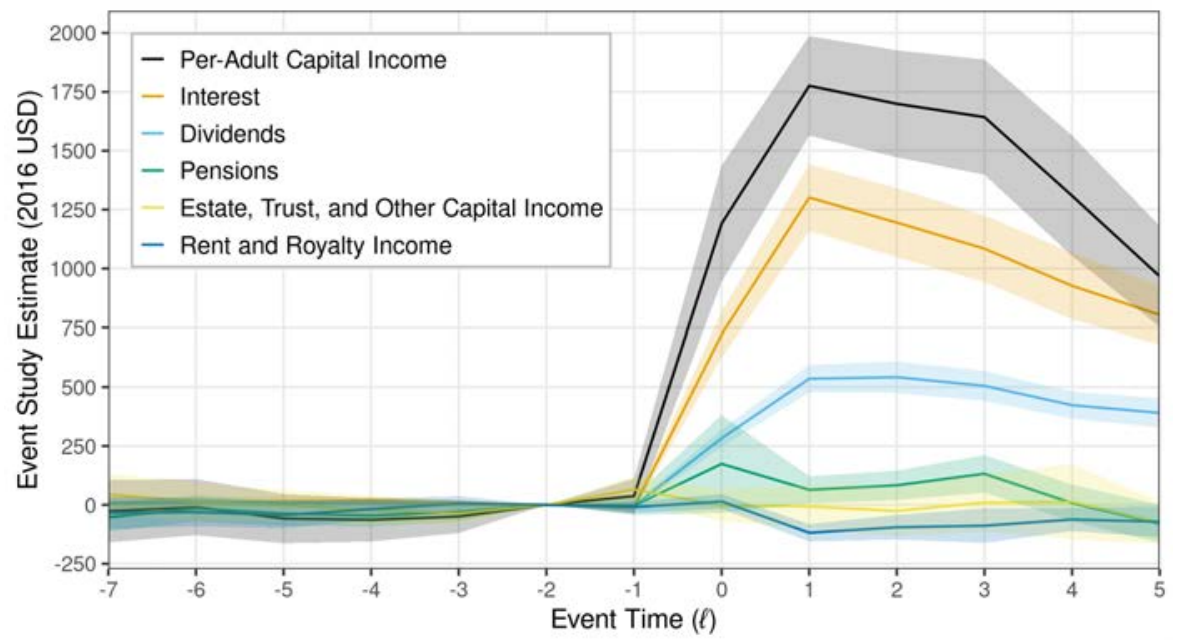

Notes: This figure presents estimates of the impact of winning on per-adult capital income, as well as all of the components comprising capital income. Each set of estimates is based on estimating a version of equation (3.4) (as described in Section 3.1) for each outcome, and then taking cohort-size-weighted averages of $\rho^{w, \ell}$ for each event time $\ell .90$ percent confidence intervals are displayed, clustering on winner. Throughout, we use $w-2$ as the omitted event time. 


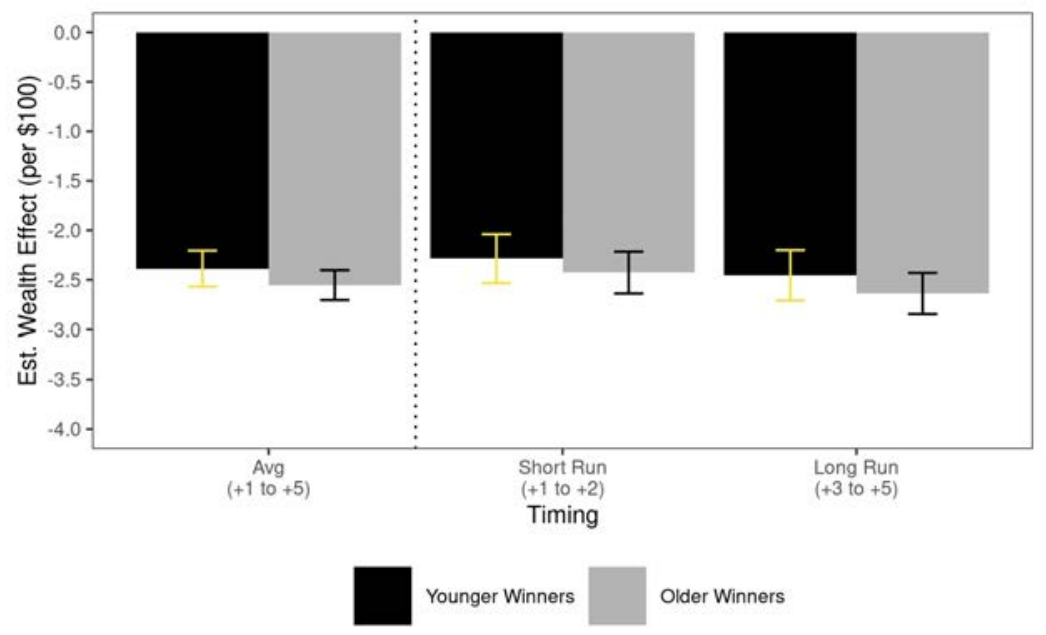

(a) Per-Adult Total Labor Earnings

Figure B.4: Wealth effects by age of winner

Notes: This figure presents estimates of the mean effect of an extra dollar of wealth on per-adult total labor earnings. The estimates are calculated by first estimating a 2SLS regression, as described in Section 3.3 for the binary outcome, then taking cohort-size-weighted averages of $\beta^{w, \ell}$ for each event time $\ell$, then taking the mean across estimates for all post-win event times $\{1,2,3,4,5\}$ ("Avg $(+1$ to +5$)$ "), a shorter-run set of post-win event times $\{1,2\}$ ("Short Run ( +1 to +2$)$ "), and a longer-run set of post-win event times $\{3,4,5\}$ ("Long Run ( +3 to +5 )"). For each temporal average, we report wealth effects for the subsample of younger winners (age 30 - 46) and older winners (age 47 - 64). 90 percent confidence intervals are displayed, clustering on winner. 
Figure B.5: Effect of winning on geographic mobility

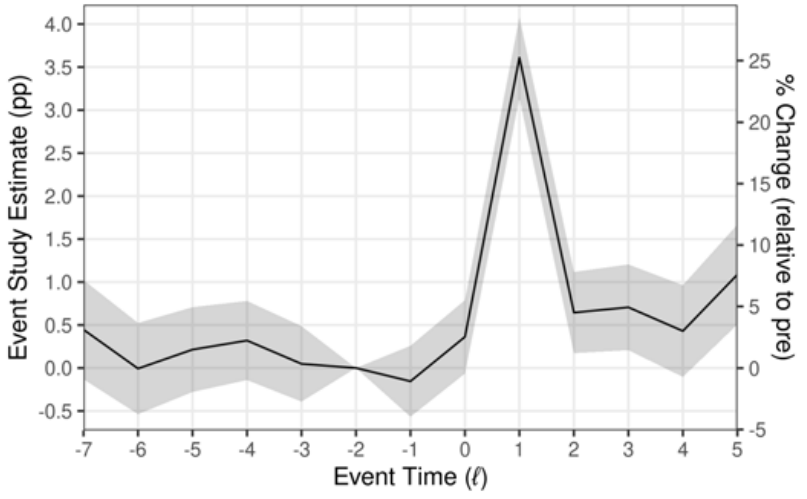

(a) Full sample

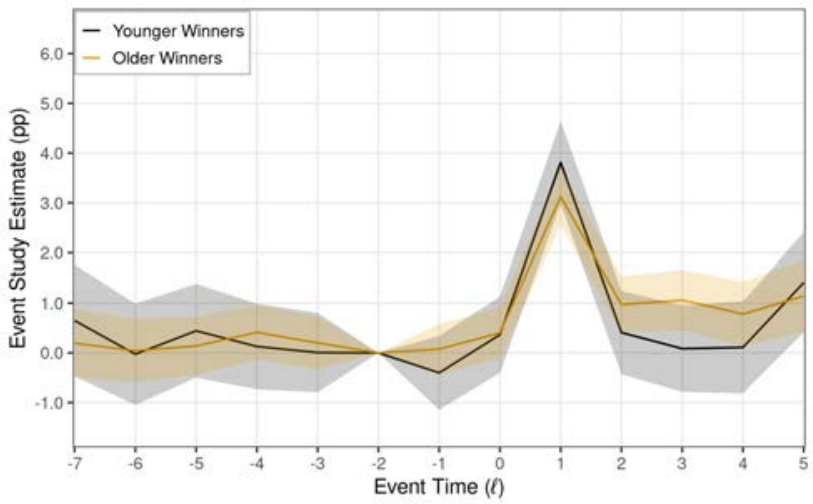

(c) Young and old winners

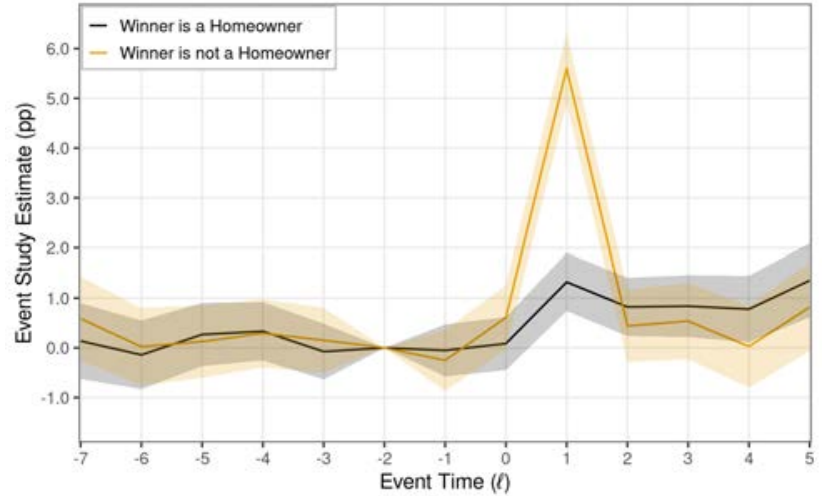

(b) Homeowners and renters

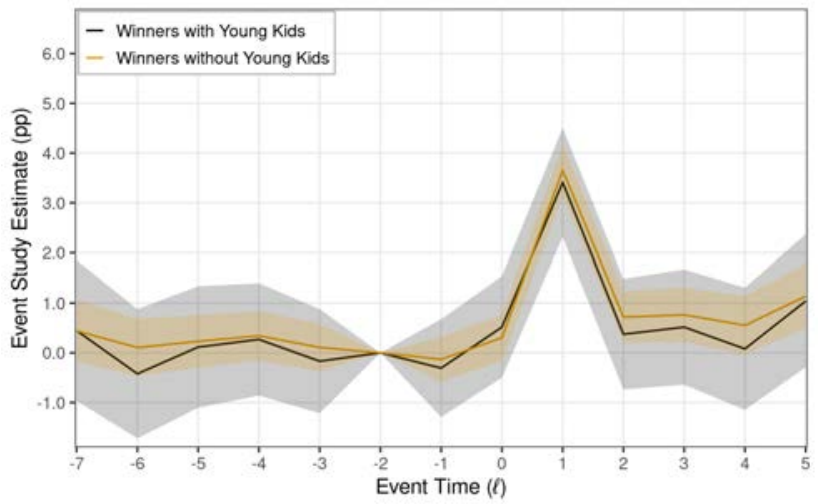

(d) Parents with young kids

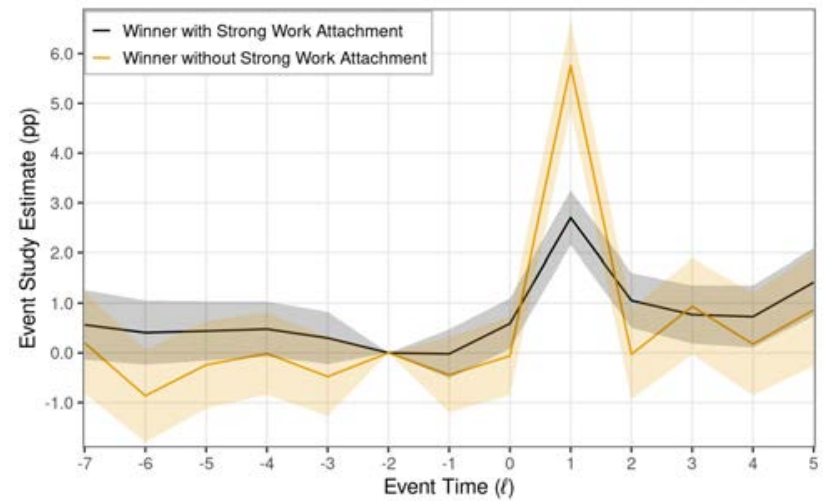

(e) Work attachment

Notes: This figure presents estimates of the impact of winning on geographic mobility by demographic characteristics. Each set of estimates is based on estimating a version of equation (3.4) (as described in Section 3.1) for each outcome, and then taking cohort-size-weighted averages of $\rho^{w, \ell}$ for each event time $\ell .90$ percent confidence intervals are displayed, clustering on winner. Throughout, we use $w-2$ as the omitted event time. 
Figure B.6: Effect of winning on labor market dynamics

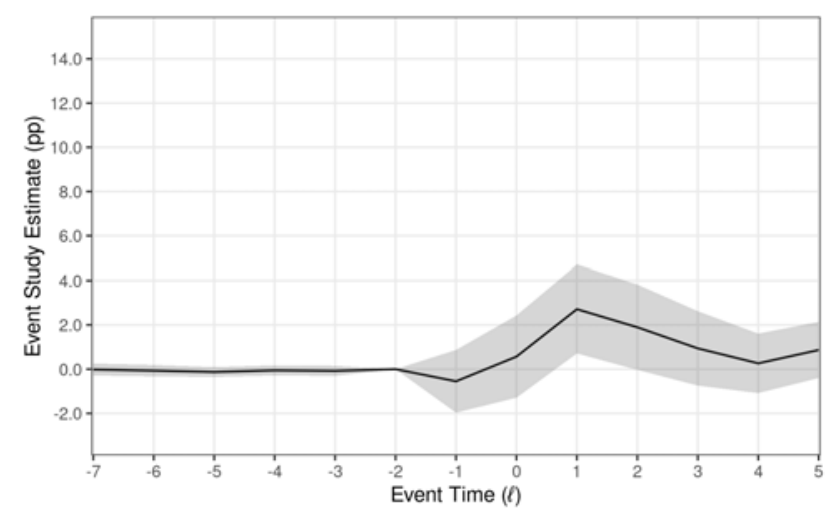

(a) Claiming social security benefits

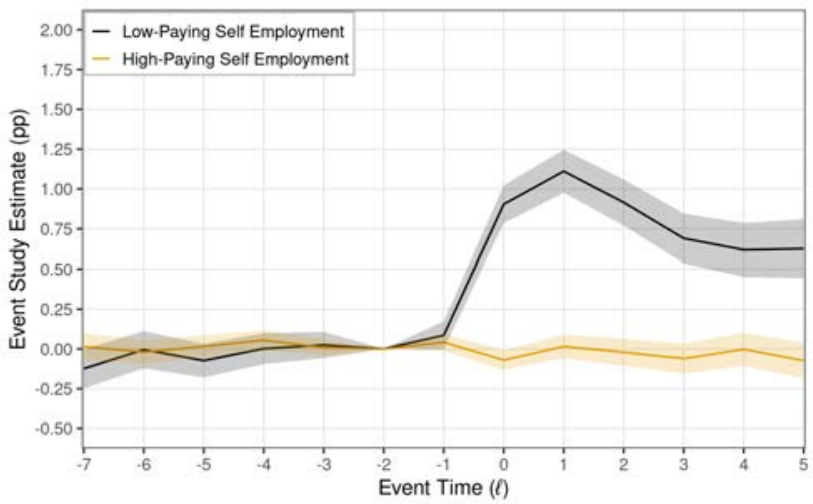

(c) Transition from paid employment into self-employment

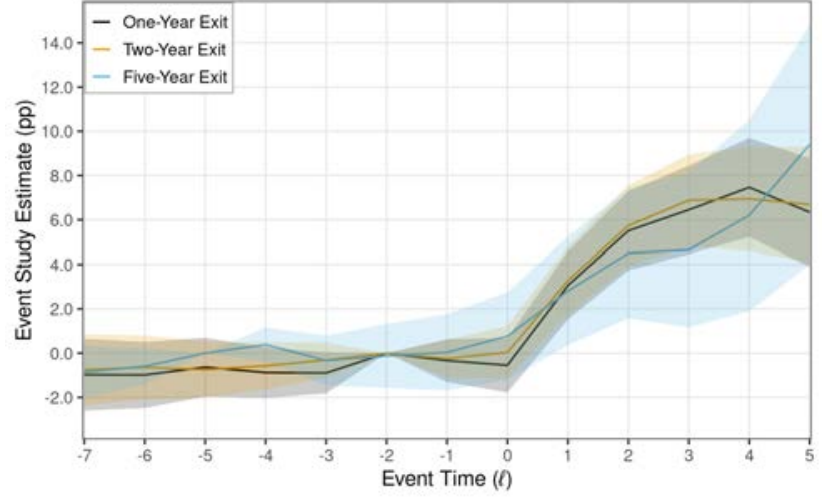

(b) Labor market exit

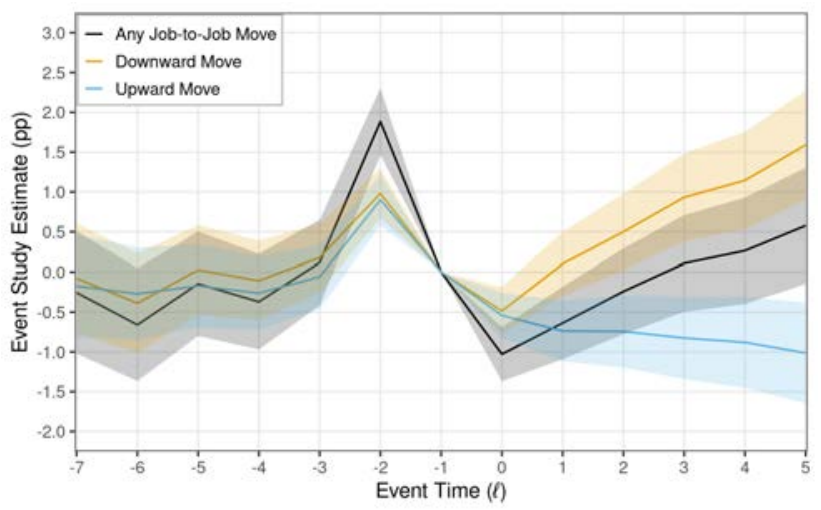

(d) Job-to-job transitions

Notes: This figure presents estimates of the impact of winning on various outcomes related to labor market dynamics, based on estimating a version of equation (3.4) (as described in Section 3.1) for each outcome, and then taking cohort-size-weighted averages of $\rho^{w, \ell}$ for each event time $\ell$. 90 percent confidence intervals are displayed, clustering on winner. In the regressions for subfigures (a)-(c), we use $w-2$ as the omitted event time. In the regressions for subfigure (d), by construction of the outcome variables, the regression coefficients in $w-2$ are zero. To allow for potentially different annual transition rates between current and later winners, we then normalize the effect in event time $w-1$ to be zero in these regressions. 
Figure B.7: Effect of winning by gender and marital status

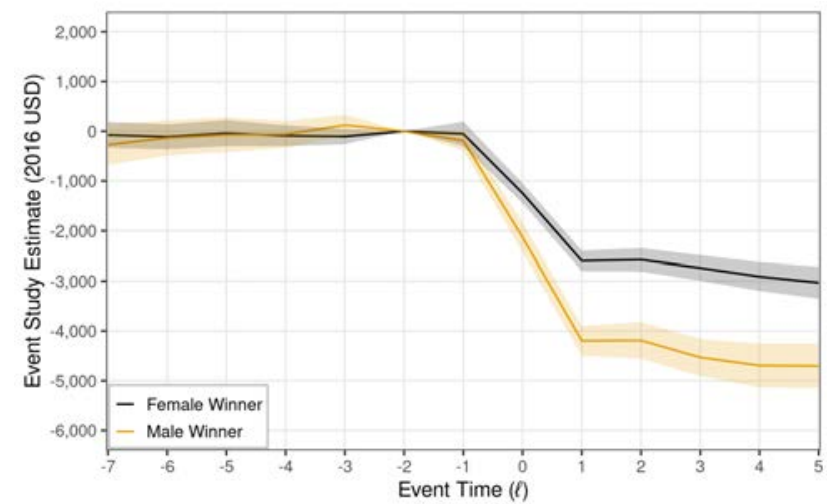

(a) Wage earnings of male and female winners

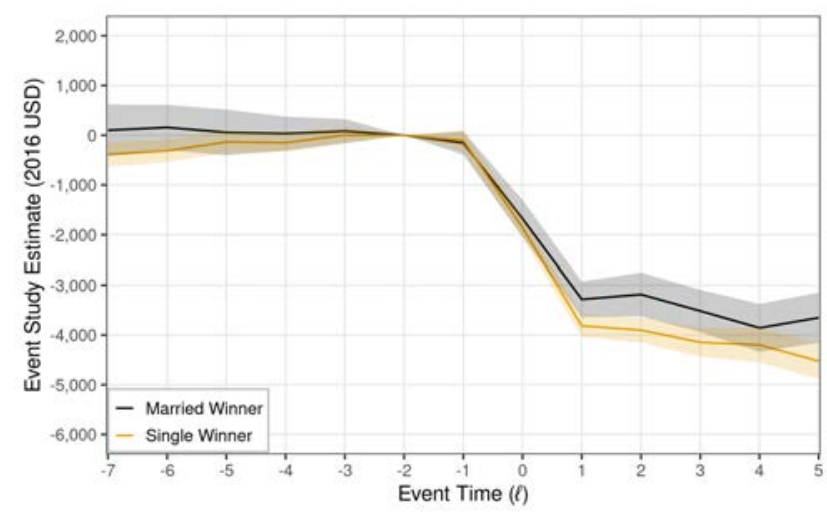

(c) Wage earnings of single and married winners

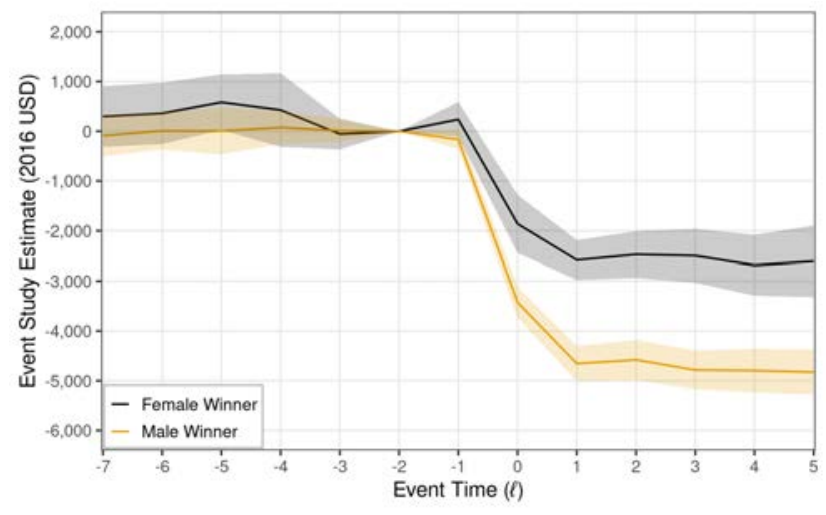

(b) Total per-adult labor income of male and female winners

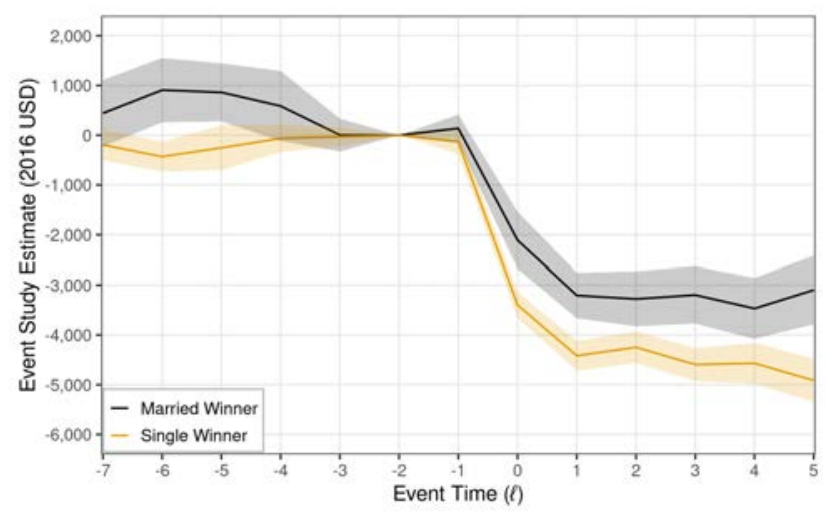

(d) Total per-adult labor income of single and married winners

Notes: This figure presents estimates of the impact of winning on earnings by gender and marital status of the winner. Each set of estimates is based on estimating a version of equation (3.4) (as described in Section 3.1) for each outcome, and then taking cohort-size-weighted averages of $\rho^{w, \ell}$ for each event time $\ell .90$ percent confidence intervals are displayed, clustering on winner. Throughout, we use $w-2$ as the omitted event time. 


\section{Figure B.8: Effect of winning on family formation and stability}

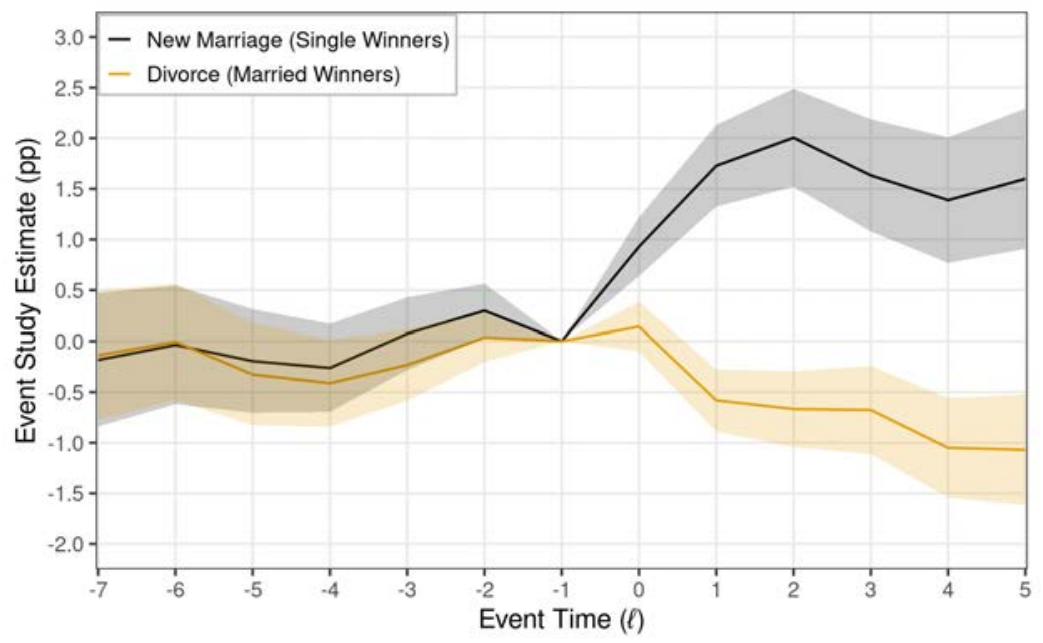

Notes: This figure presents estimates of the impact of winning on family formation and stability. The estimation sample is restricted to winners and not-yet winners that are tax filers. When we study the effect on new marriages (divorce), we further restrict the sample to individuals that were not married (married) in $w-2$. Each set of estimates is based on estimating a version of equation (3.4) (as described in Section 3.1) for each outcome, and then taking cohort-size-weighted averages of $\rho^{w, \ell}$ for each event time $\ell .90$ percent confidence intervals are displayed, clustering on winner. Throughout, we use $w-2$ as the omitted event time.

Figure B.9: Effect of winning on wage earnings of the winner and his or her spouse

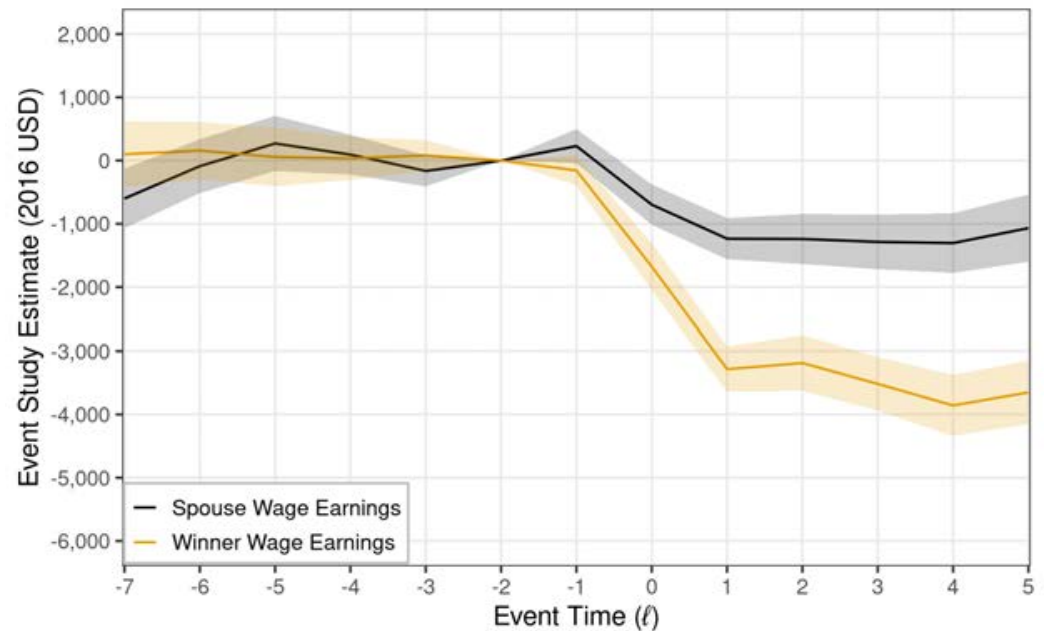

Notes: This figure presents estimates of the impact of winning on wage earnings for winners and non-winning spouses. The estimation sample is restricted to married couples. Each set of estimates is based on estimating a version of equation (3.4) (as described in Section 3.1) for each outcome, and then taking cohort-size-weighted averages of $\rho^{w, \ell}$ for each event time $\ell .90$ percent confidence intervals are displayed, clustering on winner. Throughout, we use $w-2$ as the omitted event time. 


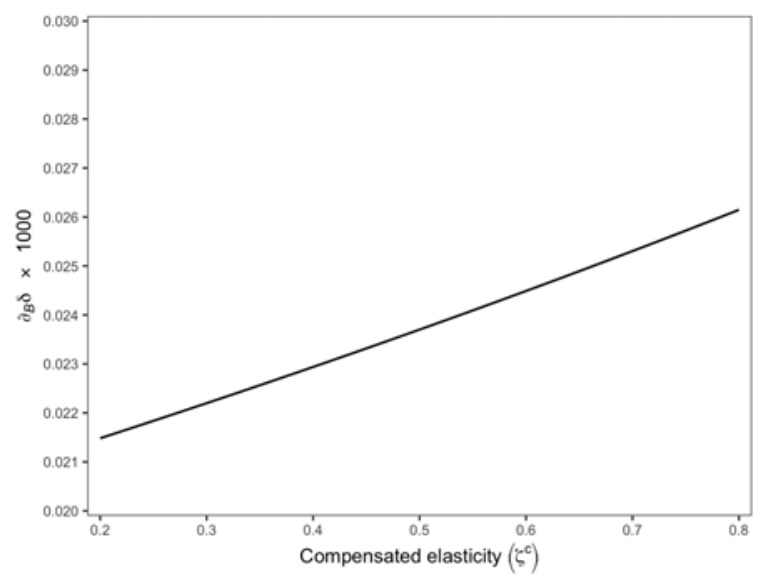

(a) Marginal tax rates

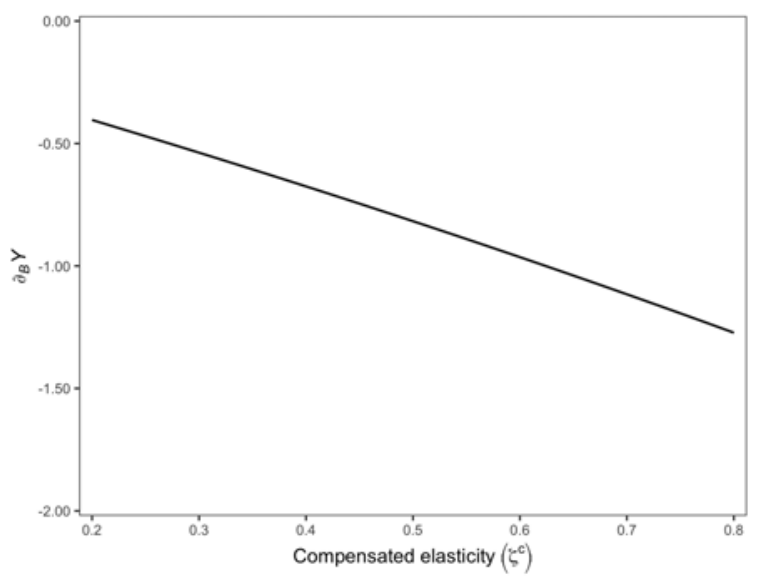

(b) Total labor earnings

Figure B.10: The effect of an unconditional cash transfer on marginal tax rates and total labor earnings

Notes: In this figure, we report the results of our analysis of the effects of UBI program on a) marginal tax rates and b) total labor earnings. In both figures, the $x$-axis corresponds to a value of the compensated labor supply elasticity, $\zeta^{\mathrm{c}}$. In a), the dependent variable is a measure of the change in marginal tax rates due to the introduction of a marginal UBI, scaled by $\$ 1,000$. In $b$ ), the dependent variable is the change in total labor earnings due to the introduction of a marginal UBI. The line in both figures corresponds to the value of the dependent variable recovered using our estimated earnings responses for a given value of the compensated labor supply elasticity. 


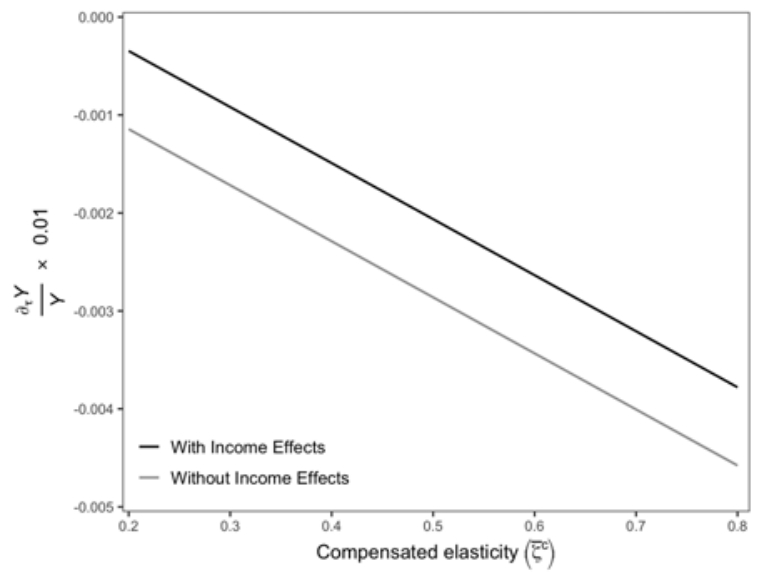

(a) \% change in total earnings $(Y)$

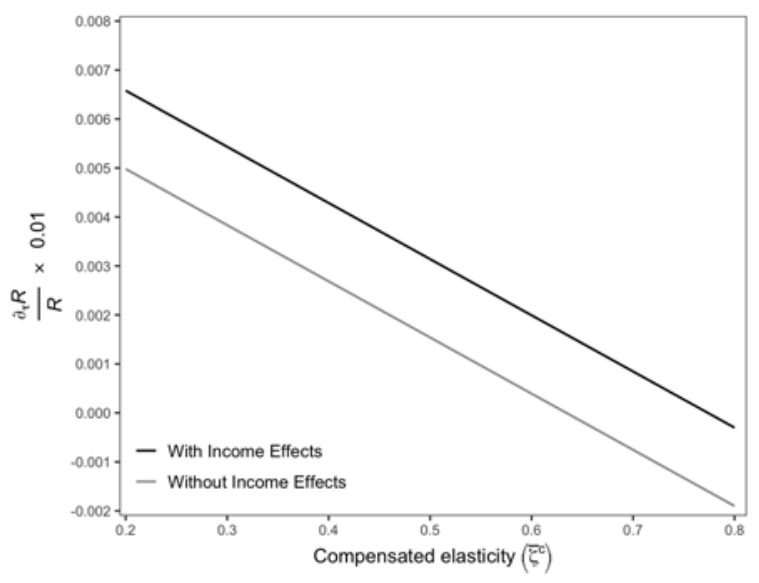

(b) \% change in revenues $(\mathcal{R})$

Figure B.11: The effect of a $1 \mathrm{pp}$ increase in the top tax rate on total labor earnings and tax revenues

Notes: In this figure, we report the results of our analysis of the effects of an increase in top marginal tax rates on a) total labor earnings and b) total revenues. In both figures, the $x$-axis corresponds to a value of the compensated labor supply elasticity, $\zeta^{\mathrm{c}}$. In a), the dependent variable is a measure of the percentage change in total labor earnings due to an increase in top marginal tax rates. In b), the dependent variable is the percentage change in total revenues due to an increase in top marginal tax rates. In both figures, we scale the dependent variable by 0.01 , and so the units are the percentage change due to a 1 percentage point increase in the top marginal tax rate. The darker line in both figures corresponds to the value of the dependent variable recovered using our estimated earnings responses for a given value of the compensated labor supply elasticity. The lighter line in both figures corresponds to the value of the dependent variable recovered for a given value of the compensated labor supply elasticity assuming no income effects.

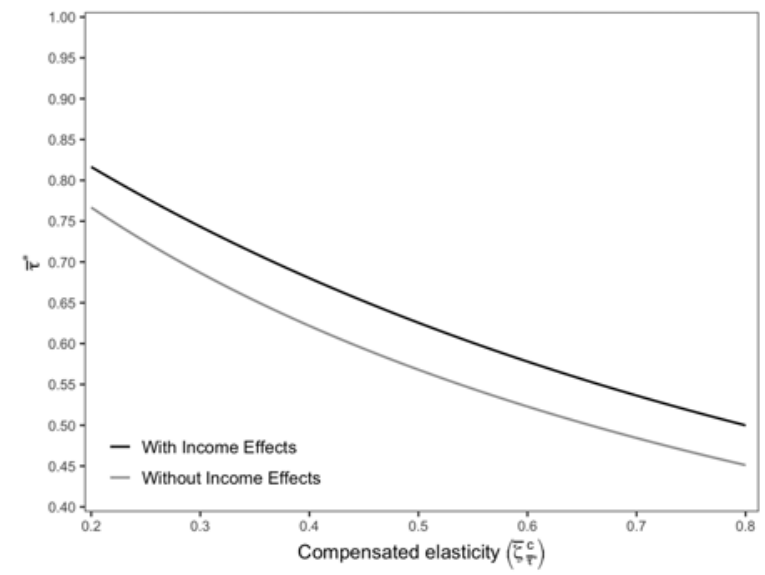

Figure B.12: Revenue-maximizing top tax rates (with and without income effects)

Notes: In this figure, we report the results of our application of the optimal tax formula of Diamond and Saez (2011), taking expression (H.48) and assuming policy invariance to recover revenue-maximizing tax rates using equation (5.21). In the figure, the $x$-axis corresponds to a value of the compensated labor supply elasticity, $\bar{\zeta}_{\bar{\tau}^{*}}^{\mathrm{c}}$. The darker line corresponds to the value of the dependent variable recovered using our estimated earnings responses for a given value of the compensated labor supply elasticity. The lighter line corresponds to the value of the dependent variable recovered for a given value of the compensated labor supply elasticity assuming no income effects. 


\section{Definition of variables and their sources}

- Age: Age of an individual in calendar year $t$ is measured as the difference between $t$ and birth year reported for each de-identified Taxpayer Identification Number (TIN) on Data Master-1 (DM-1) from the Social Security Administration.

- Gender: Gender of an individual is reported for each de-identified TIN on DM-1 from the Social Security Administration.

- Marital status: For tax filers, marital status is determined based on the filing status observed on Form 1040 at the tax-paying unit (TPU) level. All non-filers are treated as single, in line with Cilke (1998), Chetty, Friedman, Hilger, Saez, Schanzenbach and Yagan (2011), and subsequent work utilizing administrative tax records in the U.S.

- Form W-2G reported gross winnings: Reported in box 1 ("Gross winnings") of Form W-2G for each de-identified TIN. In the administrative data, the source of the winnings is labeled, with a separate category for payments from state lotteries. We only utilize Form W-2G issued by state lotteries for lottery payments.

- Wage earnings: Reported in box 1 of Form W-2 for each de-identified TIN. For individuals receiving multiple W-2s in a given calendar year (from multiple employers), we sum across all W-2s in the same calendar year. This measure of wage earnings corresponds to total taxable remuneration for labor services of a direct employee, and includes wages, tips, salary, and taxable fringe benefits. For individuals with no Form W-2 in a given calendar year, wage earnings are set to 0 .

- Employment: A binary indicator for having positive wage earnings (as defined above) for each deidentified TIN in each calendar year.

- Employer: For individuals linked to a single firm through Form W-2, this is the identity of their employer (which is a de-identified employer ID number, or EIN). For individuals linked to multiple firms through Form W-2, this is the identity of the highest-paying employer.

- Per-adult wage earnings: For single workers, this is equivalent to wage earnings as defined above. For married workers, this is the sum of own and spouse wage earnings in a given calendar year, divided by 2 (that is, per-adult). We use Form 1040 filing in order to identify married workers and make spousal links.

- Self-employment income: For single tax filers, we define self-employment income as the sum of self-employment business income (Form 1040), farm income (Form 1040), and partnership income (Schedule E) in a given calendar year. For married tax filers, this is self-employment income of the TPU, divided by 2 (that is, per-adult). For non-filers, self-employment income is set to 0 .

- Total labor earnings: The sum of per-adult wage earnings and self-employment income, both as defined above. 
- Capital income: For single tax filers, we define capital income as the sum of dividend income (Form 1040), interest income (Form 1040), pension and annuity income (Form 1040), rental and royalty income (Form 1040 Schedule E), and non-labor income from estates, trusts, farms, and mortgage investments (Form 1040 Schedule E) in a given calendar year. For married tax filers, this is capital income of the TPU, divided by 2 (that is, per-adult). For non-filers, capital income is set to 0 .

- Social Security benefit payments: For single tax filers, we define Social Security benefit payments as the gross Social Security benefit payments reported on Form 1040 in a given calendar year. For married tax filers, this is Social Security benefit payments of the TPU, divided by 2 (that is, per-adult). For non-filers, Social Security benefit payments is set to 0 .

- Unemployment insurance payments: For single tax filers, we define unemployment insurance payments as the gross unemployment insurance payments reported on Form 1040 in a given calendar year. For married tax filers, this is unemployment insurance payments of the TPU, divided by 2 (that is, per-adult). For non-filers, unemployment insurance payments is set to 0 .

- Gross income: For single tax filers, this is the sum of total labor earnings, capital income, Social Security payments, and unemployment insurance payments. For married tax filers, this is the gross income of the TPU, divided by 2 (that is, per-adult).

- Adjusted gross income: For single tax filers, this is adjusted gross income as reported on Form 1040. For married tax filers, this is the adjusted gross income reported for the TPU, divided by 2 (that is, per-adult). For non-filers, adjusted gross income is set to 0 .

- Homeownership: A binary indicator for the receipt of at least one Form 1098 for each de-identified TIN in each calendar year. All individuals paying mortgage interest in excess of $\$ 600$ (per mortgage) in a calendar year receive a Form 1098 . Using such a binary indicator as a proxy for homeownership is in line with past work utilizing tax return data in the U.S. (e.g., Chetty, Friedman, Hilger, Saez, Schanzenbach and Yagan, 2011).

- Total income taxes: For single tax filers, this is the combined federal and state income taxes owed, as calculated using the combined federal and state tax calculator of Bakija (2019). For married tax filers, this is the combined federal and state income taxes owed for the TPU, divided by 2 (that is, per-adult). For non-filers, total income taxes are set to 0 .

- Marginal tax rate: The change in total income taxes of the TPU (as defined above) from a mechanical $\$ 1$ increase in wage earnings (i.e., a forward difference approximation), using the combined federal and state tax calculator of Bakija (2019).

- Census tract: The 2010 Census tract (Census-defined geographic aggregation) corresponding to the ZIP Code of an individual in calendar year $t$. To map ZIP Code to 2010 Census tract, we use quarterly crosswalk files provided in HUD crosswalk files, accessible here: https: //www . huduser.gov/ portal/datasets/usps_crosswalk.html. 
- Census county: The 2010 Census county corresponding to the ZIP Code of an individual in calendar year $t$. A Census county nests multiple Census tracts.

- Tract-level local labor market measures: We consider several measures of local labor markets, each defined as a time-invariant measure for each 2010 Census tract. The source of these tractlevel measures is the Opportunity Atlas, as introduced in Chetty, Friedman, Hendren, Jones and Porter (2020). Details on each measure, and the crosswalk files, are accessible here: https:// opportunityinsights.org/paper/the-opportunity-atlas/. We briefly describe each measure below, taking descriptions from: https : //opportunityinsights .org/wp-content/uploads/ 2019/07/Codebook-for-Table-9.pdf

- Wage growth: Wage growth for high school graduates. Wages are constructed by dividing the average high school graduate annual earnings by the product of overall average weekly hours worked and 52. High school graduate wage growth is then computed as the difference in logarithms between high school graduate wages in 2010-2014 and school graduate wages in 20052009. Wages are measured in the 2005-2009 and 2010-2014 American Community Surveys.

- Job growth: Average annualized job growth rate over the time period 2004 to 2013. Constructed using LODES - WAC data files provided by the Census Bureau. Data unavailable for Massachusetts and Washington D.C.

- Job density: Number of jobs per square mile in each tract. Constructed using LODES - WAC data files provided by the Census Bureau.

- Total jobs: Total number of jobs in own and neighboring tracts whose centroids fall within a radius of 5 miles from own tract centroid. Constructed using information from the Workplace Area Characteristics (WAC) data files in the LEHD Origin-Destination Employment Statistics (LODES) provided by the Census Bureau.

- High-paying jobs: Number of jobs with earnings greater than $\$ 3,333$ per month in own and neighboring tracts whose centroids fall within a radius of 5 miles from own tract centroid. Constructed using LODES - WAC data files provided by the Census Bureau.

- Employment rate: The rate of employment computed as total employed population (the sum of employed females and employed males) divided by the total population 16 years and over. Obtained from 2000 Decennial Census

- Short commute: Share of workers 16 years and over who do not work at home whose commute is shorter than 15 minutes. Measured in the 2006-2010 ACS.

- Commute time: Mean commute time for workers over 16 years old in the tract, as measured in the 2000 Decennial Census.

- Population density: Number of residents per square mile, calculated by dividing the total tract level population in the Decennial Census from 2010 with tract land area given in square miles from the 2010 Census Gazetteer Files 
- Tract-level neighborhood quality measures: We consider several measures of neighborhood quality, each defined as a time-invariant measure for each 2010 Census tract. The descriptions and sources of these tract-level measures are as follows:

- Opportunity Atlas (Chetty, Friedman, Hendren, Jones and Porter, 2020): Average family income for children with parents at the 25th percentile of income; source:https : //opportunityinsights . org/paper/the-opportunity-atlas/

- Childhood Opportunity Index (Noelke, McArdle, Baek, Huntington, Huber, Hardy and AcevedoGarcia, 2020): Omnibus index of neighborhood quality, with a focus on conditions that encourage upward mobility of children; source: https://data.diversitydatakids .org/dataset/ coi20-child-opportunity-index-2-0-database

- Area Deprivation Index (Kind and Buckingham, 2018): Omnibus index of neighborhood disadvantage, with a focus on susceptibility to disease and poor health; source: https://www . neighborhoodatlas.medicine.wisc.edu/

- Poverty rate (Chetty, Friedman, Hendren, Jones and Porter, 2020): Share of individuals in the tract below the federal poverty line, measured in the 2006-2010 ACS; source: https: //opportunityinsights.org/paper/the-opportunity-atlas/

- College attainment (Chetty, Friedman, Hendren, Jones and Porter, 2020): Number of people aged 25 or older who have a bachelor's degree, master's degree, professional school degree, or doctorate degree, divided by the total number of people aged 25 or older in a Census tract. Estimated using the 2006-2010 ACS; source: https://opportunityinsights.org/paper/ the-opportunity-atlas/

- Test scores (Chetty, Friedman, Hendren, Jones and Porter, 2020): Mean 3rd grade math test scores in 2013; source: https: //opportunityinsights .org/paper/the-opportunity-atlas/

- Teen birth (Chetty, Friedman, Hendren, Jones and Porter, 2020): Fraction of women who grew up in the given tract who ever claimed a child who was born when they were between the ages of 13 and 19 as a dependent at any point; source: https://opportunityinsights .org/paper/ the-opportunity-atlas/

- Single parents (Chetty, Friedman, Hendren, Jones and Porter, 2020): The number of households with females heads (and no husband present) or male heads (and no wife present) with own children under 18 years old present divided by the total number of households with own children present. Estimated using the 2006-2010 ACS; source: https: //opportunityinsights .org/ paper/the-opportunity-atlas/

- Median rent (2BR) (Chetty, Friedman, Hendren, Jones and Porter, 2020): The median gross rent for renter-occupied housing units with two bedrooms that pay cash rent (from the 2011-2015 ACS); source: https://opportunityinsights.org/paper/the-opportunity-atlas/ 


\section{Decomposition into intensive and extensive margin contributions}

Preliminaries. For an earnings variable $Y$, let $Y_{i, t}(1)$ and $Y_{i, t}(0)$ be the potential outcomes of an individual that has experienced or has not experienced her first-observed win, respectively. Furthermore, let $E_{i, t} \equiv$ $\mathbf{1}\left\{Y_{i, t} \neq 0\right\}$ be a binary random variable indicating whether an individual works. Observed outcomes are linked to potential outcomes as follows

$$
\begin{aligned}
& Y_{i, t}=Y_{i, t}(0)+D_{i, t}\left(Y_{i, t}(1)-Y_{i, t}(0)\right) \\
& E_{i, t}=E_{i, t}(0)+D_{i, t}\left(E_{i, t}(1)-E_{i, t}(0)\right)
\end{aligned}
$$

where $D_{i, t}$ is an indicator variable that takes value 1 if individual $i$ experiences the first-observed lottery win by year $t$.

For simplicity, we focus on a particular cohort $w$ and event time $\ell>0$. Specifically, we are interested in decomposing the effect of winning in year $w$ on earnings $Y$ in the event time $\ell>0$ into extensive- and intensive-margin responses. It is well known that under a common trends assumption, the average effect of winning in $w$ in the event time $\ell$ can be identified with a DiD estimator as follows:

$$
\begin{aligned}
\rho^{w, \ell} & \equiv \mathbb{E}\left[Y_{i, w+\ell}(1)-Y_{i, w+\ell}(0) \mid \tilde{D}_{i, w}=1\right] \\
& =\mathbb{E}\left[Y_{i, w+\ell}-Y_{i, w-s} \mid \tilde{D}_{i, w}=1\right]-\mathbb{E}\left[Y_{i, w+\ell}-Y_{i, w-s} \mid \tilde{D}_{i, w}=0\right] \quad\left(\equiv \operatorname{DiD}\left(Y_{w+\ell}\right)\right) \\
& =\underbrace{\mathbb{E}\left[Y_{i, w+\ell} \mid \tilde{D}_{i, w}=1\right]-\mathbb{E}\left[Y_{i, w+\ell} \mid \tilde{D}_{i, w}=0\right]}_{(\mathbf{A})}-\underbrace{\left(\mathbb{E}\left[Y_{i, w-s} \mid \tilde{D}_{i, w}=1\right]-\mathbb{E}\left[Y_{i, w-s} \mid \tilde{D}_{i, w}=0\right]\right)}_{(\mathbf{B})},
\end{aligned}
$$

where

$$
\tilde{D}_{i, w}=\left\{\begin{array}{ll}
1 & \text { if } i \text { won in } w \\
0 & \text { if } i \text { has not won by } w+\ell
\end{array} .\right.
$$

Main decomposition of $\operatorname{DiD}\left(Y_{w+\ell}\right)$. We decompose each of the terms $(\mathbf{A})$ and $(\mathbf{B})$ :

$$
\begin{aligned}
\mathbf{A} & =\mathbb{E}\left[Y_{i, w+\ell} \mid \tilde{D}_{i, w}=1, E_{i, w+\ell}=1\right] \mathbb{P}\left\{E_{i, w+\ell}=1 \mid \tilde{D}_{i, w}=1\right\} \\
& -\mathbb{E}\left[Y_{i, w+\ell} \mid \tilde{D}_{i, w}=0, E_{i, w+\ell}=1\right] \mathbb{P}\left\{E_{i, w+\ell}=1 \mid \tilde{D}_{i, w}=0\right\} \\
& =\underbrace{\left(\mathbb{E}\left[Y_{i, w+\ell} \mid \tilde{D}_{i, w}=1, E_{i, w+\ell}=1\right]-\mathbb{E}\left[Y_{i, w+\ell} \mid \tilde{D}_{i, w}=0, E_{i, w+\ell}=1\right]\right) \mathbb{P}\left\{E_{i, w+\ell}=1 \mid \tilde{D}_{i, w}=0\right\}}_{\alpha_{w+\ell} \equiv \Delta \text { intensive margin (post-win) }} \\
& +\underbrace{\mathbb{E}\left[Y_{i, w+\ell} \mid \tilde{D}_{i, w}=1, E_{i, w+\ell}=1\right]\left(\mathbb{P}\left\{E_{i, w+\ell}=1 \mid \tilde{D}_{i, w}=1\right\}-\mathbb{P}\left\{E_{i, w+\ell}=1 \mid \tilde{D}_{i, w}=0\right\}\right)}_{\beta_{w+\ell} \equiv \Delta \text { extensive margin (post-win) }}
\end{aligned}
$$

and analogously, 


$$
\begin{aligned}
\mathbf{B} & =\underbrace{\left(\mathbb{E}\left[Y_{i, w-s} \mid \tilde{D}_{i, w}=1, E_{i, w-s}=1\right]-\mathbb{E}\left[Y_{i, w-s} \mid \tilde{D}_{i, w}=0, E_{i, w-s}=1\right]\right) \mathbb{P}\left\{E_{i, w-s}=1 \mid \tilde{D}_{i, w}=0\right\}}_{\alpha_{w-s} \equiv \Delta \text { intensive margin (pre-win) }} \\
& +\underbrace{\mathbb{E}\left[Y_{i, w-s} \mid \tilde{D}_{i, w}=1, E_{i, w-s}=1\right]\left(\mathbb{P}\left\{E_{i, w-s}=1 \mid \tilde{D}_{i, w}=1\right\}-\mathbb{P}\left\{E_{i, w-s}=1 \mid \tilde{D}_{i, w}=0\right\}\right)}_{\beta_{w-s} \equiv \Delta \text { extensive margin (pre-win) }}
\end{aligned}
$$

Then, bringing the two separate decompositions together, we have

$$
\operatorname{DiD}\left(Y_{w+\ell}\right)=\underbrace{\alpha_{w+\ell}-\alpha_{w-s}}_{\text {intensive margin }}+\underbrace{\beta_{w+\ell}-\beta_{w-s}}_{\text {extensive margin }}
$$

We perform these decompositions for each cohort $w$ and each event time $\ell$. In Table 3.3, we report the share of the observed earnings response that is attributable to the extensive-margin response for each quartile,

$$
\frac{\sum_{\ell(w)} \sum_{w} \omega_{w}\left(\beta_{w+\ell}-\beta_{w-s}\right)}{\sum_{\ell(w)} \sum_{w} \omega_{w} \operatorname{DiD}\left(Y_{w+\ell}\right)} .
$$

We then construct the aggregate share of the observed earnings response that is attributable to the extensivemargin as the mean of the weighted-average extensive contribution $\sum_{\ell(w)} \sum_{w} \omega_{w}\left(\beta_{w+\ell}-\beta_{w-s}\right)$ across quartiles divided by the mean of the weighted-average total response $\sum_{\ell(w)} \sum_{w} \omega_{w} \operatorname{DiD}\left(Y_{w+\ell}\right)$ across quartiles. $^{47}$

Decomposition of per-unit $\operatorname{DiD}\left(Y_{w+\ell}\right)$. From the above expression, it follows immediately that the decomposition of earnings response per dollar of lottery winnings is

$$
\frac{\operatorname{DiD}\left(Y_{w+\ell}\right)}{\mathbb{E}\left[L_{i, w} \mid \tilde{D}_{i, w}=1\right]}=\underbrace{\frac{\alpha_{w+\ell}-\alpha_{w-s}}{\mathbb{E}\left[L_{i, w} \mid \tilde{D}_{i, w}=1\right]}}_{\text {intensive margin (per unit) }}+\underbrace{\frac{\beta_{w+\ell}-\beta_{w-s}}{\mathbb{E}\left[L_{i, w} \mid \tilde{D}_{i, w}=1\right]}}_{\text {extensive margin (per unit) }},
$$

where $L_{i, w}$ are the lottery winnings of household $i$ of cohort $w$. where $\omega_{w}$ is the weight for cohort $w$ and we use $\ell(w)$ as each cohort $w$ may have a distinct set of identified event-time estimates.

Decomposing differences across subset-specific per-unit $\operatorname{DiD}\left(Y_{w+\ell}\right)$. In Figure 3.5, we report how wealth effects differ across prize size. Next, we are interested in decomposing the difference in the observed earnings response per dollar of lottery winnings between two subsets of winners defined according to a time-invariant covariate $X \in\left\{x^{\prime}, x^{\prime \prime}\right\}$. Specifically, we decompose the difference in the per-dollar earnings response between those who won between $\$ 30,000$ to $\$ 300,000\left(x^{\prime}\right)$ and those who won more than $\$ 1,000,000\left(x^{\prime \prime}\right)$.

\footnotetext{
${ }^{47}$ Using our theoretical framework in Section 5, we can conduct an alternative decomposition using our estimates of MPE $(y)$ in Table 4.1 and the change in employment per dollar of unearned income as an estimate of $\lambda_{L}(y)$. This decomposition yields very similar results.
} 
As shown in Figure 3.5, we observe

$$
\Delta=\sum_{\ell(w)} \sum_{w} \omega_{w \mid x^{\prime}} \frac{\operatorname{DiD}\left(Y_{w+\ell}, X=x^{\prime}\right)}{\mathbb{E}\left[L_{i, w} \mid \tilde{D}_{i, w}=1, X_{i}=x^{\prime}\right]}-\sum_{\ell(w)} \sum_{w} \omega_{w \mid x^{\prime \prime}} \frac{\operatorname{DiD}\left(Y_{w+\ell}, X=x^{\prime \prime}\right)}{\mathbb{E}\left[L_{i, w} \mid \tilde{D}_{i, w}=1, X_{i}=x^{\prime \prime}\right]}>0 .
$$

Using the decomposition in equation (D.2), we can equivalently write this as

$$
\begin{aligned}
\Delta & =\sum_{\ell(w)} \sum_{w} \omega_{w \mid x^{\prime}} \frac{\alpha_{w+\ell}\left(x^{\prime}\right)-\alpha_{w-s}\left(x^{\prime}\right)+\beta_{w+\ell}\left(x^{\prime}\right)-\beta_{w-s}\left(x^{\prime}\right)}{\mathbb{E}\left[L_{i, w} \mid \tilde{D}_{i, w}=1, X_{i}=x^{\prime}\right]} \\
& -\sum_{\ell(w)} \sum_{w} \omega_{w \mid x^{\prime \prime}} \frac{\alpha_{w+\ell}\left(x^{\prime \prime}\right)-\alpha_{w-s}\left(x^{\prime \prime}\right)+\beta_{w+\ell}\left(x^{\prime \prime}\right)-\beta_{w-s}\left(x^{\prime \prime}\right)}{\mathbb{E}\left[L_{i, w} \mid \tilde{D}_{i, w}=1, X_{i}=x^{\prime \prime}\right]} .
\end{aligned}
$$

Re-arranging the terms yields

$$
\begin{aligned}
\Delta & =\underbrace{\sum_{\ell(w)} \sum_{w} \omega_{w \mid x^{\prime}} \frac{\alpha_{w+\ell}\left(x^{\prime}\right)-\alpha_{w-s}\left(x^{\prime}\right)}{\mathbb{E}\left[L_{i, w} \mid \tilde{D}_{i, w}=1, X_{i}=x^{\prime}\right]}-\sum_{\ell(w)} \sum_{w} \omega_{w \mid x^{\prime \prime}} \frac{\left(\alpha_{w+\ell}\left(x^{\prime \prime}\right)-\alpha_{w-s}\left(x^{\prime \prime}\right)\right)}{\mathbb{E}\left[L_{i, w} \mid \tilde{D}_{i, w}=1, X_{i}=x^{\prime \prime}\right]}}_{\text {between-group difference in intensive margin (per unit) }} \\
& +\underbrace{\sum_{\ell(w)} \sum_{w} \omega_{w \mid x^{\prime}} \frac{\beta_{w+\ell}\left(x^{\prime}\right)-\beta_{w-s}\left(x^{\prime}\right)}{\mathbb{E}\left[L_{i, w} \mid \tilde{D}_{i, w}=1, X_{i}=x^{\prime}\right]}-\sum_{\ell(w)} \sum_{w} \omega_{w \mid x^{\prime \prime}} \frac{\left(\beta_{w+\ell}\left(x^{\prime \prime}\right)-\beta_{w-s}\left(x^{\prime \prime}\right)\right)}{\mathbb{E}\left[L_{i, w} \mid \tilde{D}_{i, w}=1, X_{i}=x^{\prime \prime}\right]}}_{\text {between-group difference in extensive margin (per unit) }}
\end{aligned}
$$

In Table 3.4, we report the share that is attributable to the between-group difference on the extensive margin for each quartile,

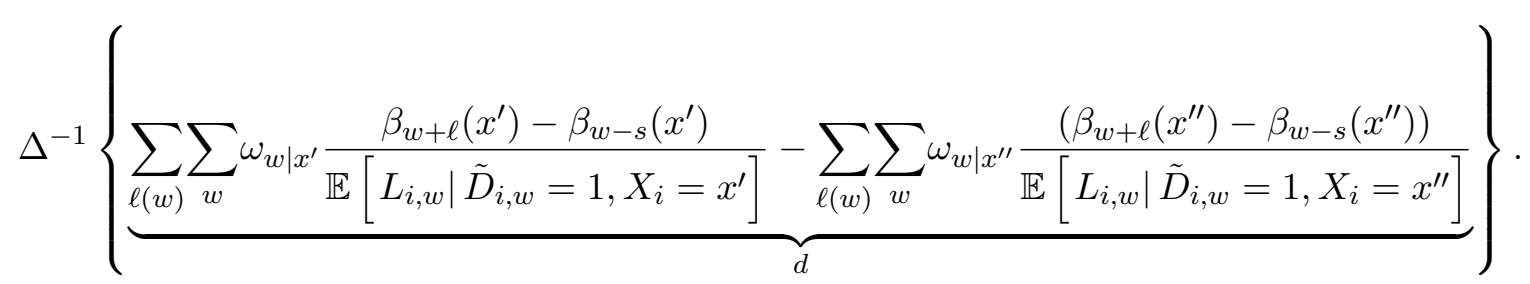

We then construct the aggregate share that is attributable to the between-group difference on the extensive margin as the mean of the weighted-average extensive contribution per dollar $d$ across quartiles divided by the mean of the weighted-average total response per dollar $\Delta$ across quartiles. 


\section{E Recovering counterfactual means with DiD}

In this section, we discuss how we can recover the counterfactual mean of an outcome for lottery winners had they not won. Throughout, for simplicity, we focus on a particular cohort $w$ and event time $\ell>0$, and so the discussion below is implicitly conditional on $w$ and $\ell$.

For an economic outcome variable $Y$, let $Y_{i, t}(1)$ and $Y_{i, t}(0)$ be the potential outcomes of an individual that has experienced or has not experienced her first-observed win, respectively. We can represent observed $Y_{i, t}$ as

$$
Y_{i, t}=Y_{i, t}(0)+D_{i, t}\left(Y_{i, t}(1)-Y_{i, t}(0)\right)
$$

where $D_{i, t}$ is an indicator variable that takes value 1 if individual $i$ experiences the first-observed lottery win by year $t$. We are interested in estimating the average effect of winning in year $w$ on outcome $Y$ in the event time $\ell \geq 0$, which we define as $\rho^{w, \ell} \equiv \mathbb{E}\left[Y_{i, w+\ell}(1)-Y_{i, w+\ell}(0) \mid i\right.$ won in $\left.w\right]$. The obvious difficulty is that while $\mathbb{E}\left[Y_{i, w+\ell}(1) \mid i\right.$ won in $\left.w\right]$ is observed directly, the counterfactual $\mathbb{E}\left[Y_{i, w+\ell}(0) \mid i\right.$ won in $\left.w\right]$ is not. Under an identifying common trend assumption

$$
\mathbb{E}\left[Y_{i, w+\ell}(0)-Y_{i, w-s}(0) \mid i \text { won in } w\right]=\mathbb{E}\left[Y_{i, w+\ell}(0)-Y_{i, w-s}(0) \mid i \text { has not won by } w+\ell\right],
$$

standard arguments imply that DiD estimator (3.3) recovers $\rho^{w, \ell}$. Under the same common trend assumption, we can also identify $\mathbb{E}\left[Y_{i, w+\ell}(1) \mid i\right.$ won in $\left.w\right]$ with a simple rearrangement of terms: $\mathbb{E}\left[Y_{i, w+\ell}(0) \mid i\right.$ won in $\left.w\right]=$ $\mathbb{E}\left[Y_{i, w+\ell} \mid i\right.$ won in $\left.w\right]-\rho^{w, \ell}$.

When we implement this approach, we calculate $\mathbb{E}\left[Y_{i, w+\ell}(1) \mid i\right.$ won in $\left.w\right]$ directly as the observed mean for cohort $w$ in event time $\ell$, and we use our cohort-specific event-study estimates of equation (3.4) as our estimate of $\rho^{w, \ell}$. 


\section{F Decomposition of moving probabilities}

In this section, we discuss how we can decompose the total effect of moving into the contribution from mutually exclusive and exhaustive types of moves. Throughout, for simplicity, we focus on a particular cohort $w$ and event time $\ell>0$, and so the discussion below is implicitly conditional on $w$ and $\ell$.

Following the discussion in Section 6.1, let $M_{i, t}$ be a binary indicator equal to 1 if the household's Census tract is different from that in the prior year, and 0 otherwise. Let $d \in\{1,2,3\}$ denote three mutually exclusive and exhaustive types of moves. Let $M_{i, t}^{d}$ denote an indicator corresponding to a move of type $d$. By definition, we can decompose the total probability of moving as follows:

$$
\underbrace{\mathbb{P}\left[M_{i, t}=1\right]}_{\text {total probability of moving }}=\underbrace{\mathbb{P}\left[M_{i, t}^{1}=1\right]}_{\text {probability of type-1 move }}+\underbrace{\mathbb{P}\left[M_{i, t}^{2}=1\right]}_{\text {probability of type-2 move }}+\underbrace{\mathbb{P}\left[M_{i, t}^{3}=1\right]}_{\text {probability of type-3 move }}
$$

Now, we consider the total effect on moving for cohort $w$ in event time $l$. As elsewhere, we define potential outcomes for moving: $M_{i, t}(1)$ and $M_{i, t}(0)$ are the potential outcomes of an individual that has experienced or has not experienced her first-observed win, respectively. We define analogous potential outcomes for each type- $d$ move. The average effect of winning in year $w$ on moving probability in the event time $\ell \geq 0$ is

$$
\mathbb{E}\left[M_{i, w+\ell}(1)-M_{i, w+\ell}(0) \mid i \text { won in } w\right] .
$$

By substituting (F.1) into (F.2), we can re-write as follows:

$$
\begin{aligned}
\underbrace{\mathbb{E}\left[M_{i, w+\ell}(1)-M_{i, w+\ell}(0) \mid i \text { won in } w\right]}_{\text {total effect on probability of moving }}= & \underbrace{\mathbb{E}\left[M_{i, w+\ell}^{1}(1)-M_{i, w+\ell}^{1}(0) \mid i \text { won in } w\right]}_{\text {effect on type-1 move }} \\
& +\underbrace{\mathbb{E}\left[M_{i, w+\ell}^{2}(1)-M_{i, w+\ell}^{2}(0) \mid i \text { won in } w\right]}_{\text {effect on type-2 move }} \\
& +\underbrace{\mathbb{E}\left[M_{i, w+\ell}^{3}(1)-M_{i, w+\ell}^{3}(0) \mid i \text { won in } w\right]}_{\text {effect on type-3 move }} .
\end{aligned}
$$

Finally, we can calculate the contribution of each component to the total moving effect by dividing the component effect by the total effect (F.2). 


\section{G A static unitary model of household labor supply}

Consider a family with two decision-making members $i \in\{1,2\}$ of working age. In the unitary model of family labor supply, the household behaves as if it maximizes a joint, price-independent social utility function subject to a family budget constraint. The household's maximization problem reads

$$
\max _{\left\{c, y_{1}, y_{2}\right\}} u\left(c, y_{1}, y_{2}\right)
$$

subject to

$$
c=y_{1}+y_{2}-\mathcal{T}\left(y_{1}+y_{2}\right)+n_{1}+n_{2}
$$

where $c=c_{1}+c_{2}$ is household consumption, and $y_{i}$ and $n_{i}$ are earned and unearned income of household member $i$, respectively. Our objective is to analyze how a change in $n_{1}$ and $n_{2}$ affects the labor supply of both household members.

Assuming an interior solution, the FOCs of this optimization problem are

$$
\begin{aligned}
& \left(1-\mathcal{T}^{\prime}\left(y_{1}+y_{2}\right)\right) u_{c}\left(c, y_{1}, y_{2}\right)+u_{y_{1}}\left(c, y_{1}, y_{2}\right)=0 \\
& \left(1-\mathcal{T}^{\prime}\left(y_{1}+y_{2}\right)\right) u_{c}\left(c, y_{1}, y_{2}\right)+u_{y_{2}}\left(c, y_{1}, y_{2}\right)=0
\end{aligned}
$$

These first-order conditions implicitly define the Marshallian labor supply functions $y_{1}=y_{1}\left(n_{1}, n_{2}\right)$ and $y_{2}=y_{2}\left(n_{1}, n_{2}\right)$ of each household member. Total differentiation yields

$$
\begin{aligned}
-\left[\left(\left(1-\mathcal{T}^{\prime}\right)^{2} u_{c c}+u_{y_{1} c}\right) d n_{1}+\left(\left(1-\mathcal{T}^{\prime}\right)^{2} u_{c c}+u_{y_{1} c}\right) d n_{2}\right] & =\left(\left(1-\mathcal{T}^{\prime}\right)^{2} u_{c c}+2\left(1-\mathcal{T}^{\prime}\right) u_{c y_{1}}+u_{y_{1} y_{1}}-\mathcal{T}^{\prime \prime} u_{c}\right) d y_{1} \\
& +\left(\left(1-\mathcal{T}^{\prime}\right)^{2} u_{c c}+\left(1-\mathcal{T}^{\prime}\right)\left(u_{c y_{2}}+u_{c y_{1}}\right)+u_{y_{1} y_{2}}-\mathcal{T}^{\prime \prime} u_{c}\right) d y_{2} \\
-\left[\left(\left(1-\mathcal{T}^{\prime}\right)^{2} u_{c c}+u_{y_{2} c}\right) d n_{1}+\left(\left(1-\mathcal{T}^{\prime}\right)^{2} u_{c c}+u_{y_{2} c}\right) d n_{2}\right] & =\left(\left(1-\mathcal{T}^{\prime}\right)^{2} u_{c c}+\left(1-\mathcal{T}^{\prime}\right)\left(u_{c y_{1}}+u_{c y_{2}}\right)+u_{y_{2} y_{1}}-\mathcal{T}^{\prime \prime} u_{c}\right) d y_{1} \\
& +\left(\left(1-\mathcal{T}^{\prime}\right)^{2} u_{c c}+2\left(1-\mathcal{T}^{\prime}\right) u_{c y_{2}}+u_{y_{2} y_{2}}-\mathcal{T}^{\prime \prime} u_{c}\right) d y_{2}
\end{aligned}
$$

Moreover, we can write

$$
\begin{aligned}
d y_{1} & =\frac{\partial y_{1}}{\partial n_{1}} d n_{1}+\frac{\partial y_{1}}{\partial n_{2}} d n_{2} \\
d y_{2} & =\frac{\partial y_{2}}{\partial n_{1}} d n_{1}+\frac{\partial y_{2}}{\partial n_{2}} d n_{2} .
\end{aligned}
$$

Next, we consider, without loss of generality, an increase in unearned income for household member 1, while unearned income of household member 2 remains unchanged, i.e., $d n_{1}>0$ and $d n_{2}=0$. Substituting (G.3) 
into (G.2) and dividing through by $d n_{1}$ yields

$$
\begin{aligned}
-\left(\left(1-\mathcal{T}^{\prime}\right)^{2} u_{c c}+u_{y_{1} c}\right) & =\underbrace{\left(\left(1-\mathcal{T}^{\prime}\right)^{2} u_{c c}+2\left(1-\mathcal{T}^{\prime}\right) u_{c y_{1}}+u_{y_{1} y_{1}}-\mathcal{T}^{\prime \prime} u_{c}\right)}_{\equiv J_{11}} \frac{\partial y_{1}}{\partial n_{1}} \\
& +\underbrace{\left(\left(1-\mathcal{T}^{\prime}\right)^{2} u_{c c}+\left(1-\mathcal{T}^{\prime}\right)\left(u_{c y_{2}}+u_{c y_{1}}\right)+u_{y_{1} y_{2}}-\mathcal{T}^{\prime \prime} u_{c}\right)}_{\equiv J_{12}} \frac{\partial y_{2}}{\partial n_{1}} \\
-\left(\left(1-\mathcal{T}^{\prime}\right)^{2} u_{c c}+u_{y_{2} c}\right) & =\underbrace{\left(\left(1-\mathcal{T}^{\prime}\right)^{2} u_{c c}+\left(1-\mathcal{T}^{\prime}\right)\left(u_{c y_{1}}+u_{c y_{2}}\right)+u_{y_{2} y_{1}}-\mathcal{T}^{\prime \prime} u_{c}\right)}_{\equiv J_{21}} \frac{\partial y_{1}}{\partial n_{1}} \\
& +\underbrace{\left(\left(1-\mathcal{T}^{\prime}\right)^{2} u_{c c}+2\left(1-\mathcal{T}^{\prime}\right) u_{c y_{2}}+u_{y_{2} y_{2}}-\mathcal{T}^{\prime \prime} u_{c}\right)}_{\equiv J_{22}} \frac{\partial y_{2}}{\partial n_{1}}
\end{aligned}
$$

We can re-write this system of equations in matrix form as

$$
\underbrace{\left[\begin{array}{ll}
J_{11} & J_{12} \\
J_{21} & J_{22}
\end{array}\right]}_{\equiv J}\left[\begin{array}{l}
\frac{\partial y_{1}}{\partial n_{1}} \\
\frac{\partial y_{2}}{\partial n_{1}}
\end{array}\right]=\left[\begin{array}{l}
-\left(\left(1-\mathcal{T}^{\prime}\right)^{2} u_{c c}+u_{y_{1} c}\right) \\
-\left(\left(1-\mathcal{T}^{\prime}\right)^{2} u_{c c}+u_{y_{2} c}\right)
\end{array}\right]
$$

By Cramer's rule, the solution then reads

$$
\frac{\partial y_{1}}{\partial n_{1}}=\frac{\left|J_{1}\right|}{|J|} \text { and } \frac{\partial y_{2}}{\partial n_{1}}=\frac{\left|J_{2}\right|}{|J|}
$$

where $|J|$ is the determinant of the matrix $J$ and

$$
\begin{aligned}
\left|J_{1}\right| & =-\left(\left(1-\mathcal{T}^{\prime}\right)^{2} u_{c c}+u_{y_{1} c}\right)\left(\left(1-\mathcal{T}^{\prime}\right)^{2} u_{c c}+2\left(1-\mathcal{T}^{\prime}\right) u_{c y_{2}}+u_{y_{2} y_{2}}-\mathcal{T}^{\prime \prime} u_{c}\right) \\
& +\left(\left(1-\mathcal{T}^{\prime}\right)^{2} u_{c c}+u_{y_{2} c}\right)\left(\left(1-\mathcal{T}^{\prime}\right)^{2} u_{c c}+\left(1-\mathcal{T}^{\prime}\right)\left(u_{c y_{2}}+u_{c y_{1}}\right)+u_{y_{1} y_{2}}-\mathcal{T}^{\prime \prime} u_{c}\right)
\end{aligned}
$$

and

$$
\begin{aligned}
\left|J_{2}\right| & =-\left(\left(1-\mathcal{T}^{\prime}\right)^{2} u_{c c}+u_{y_{2} c}\right)\left(\left(1-\mathcal{T}^{\prime}\right)^{2} u_{c c}+2\left(1-\mathcal{T}^{\prime}\right) u_{c y_{1}}+u_{y_{1} y_{1}}-\mathcal{T}^{\prime \prime} u_{c}\right) \\
& +\left(\left(1-\mathcal{T}^{\prime}\right)^{2} u_{c c}+u_{y_{1} c}\right)\left(\left(1-\mathcal{T}^{\prime}\right)^{2} u_{c c}+\left(1-\mathcal{T}^{\prime}\right)\left(u_{c y_{1}}+u_{c y_{2}}\right)+u_{y_{2} y_{1}}-\mathcal{T}^{\prime \prime} u_{c}\right)
\end{aligned}
$$

This formulation highlights that household members may differentially adjust their individual labor supply in response to a given change in unearned income, unless $u_{y_{1} c}=u_{y_{2} c}$ and $u_{y_{2} y_{2}}=u_{y_{1} y_{1}}$. Moreover, the system of equations (G.2) implies that individual labor supply responses are symmetric,

$$
\frac{\partial y_{1}}{\partial n_{1}}=\frac{\partial y_{1}}{\partial n_{2}} \quad \text { and } \frac{\partial y_{2}}{\partial n_{1}}=\frac{\partial y_{2}}{\partial n_{2}}
$$

This, in turn, implies that household labor supply does not vary as a function of the recipient of the unearned income. That is, we have

$$
\frac{\partial\left(y_{1}+y_{2}\right)}{\partial n_{1}}=\frac{\partial\left(y_{1}+y_{2}\right)}{\partial n_{2}}
$$


Testing the unitary model under random assignment of winning within households. Let households be indexed by $i=1, \ldots, N$ and let $D_{i}$ be an indicator variable that takes value 1 if household $i$ wins the lottery. Furthermore, let $I_{i} \in\{1,2\}$ be a random variable that indicates the identity of the household member who wins the lottery. Suppose that household member 1, on average, reduces his or her labor supply by more than household member 2 in response to winning the lottery, i.e.,

$$
\mathbb{E}\left[\frac{d y_{1, i}}{d n_{i}} \mid D_{i}=1\right]<\mathbb{E}\left[\frac{d y_{2, i}}{d n_{i}} \mid D_{i}=1\right] .
$$

For concreteness, we begin with our empirical observation that winners adjust their labor supply on average by more than the non-winning spouse:

$\underbrace{\mathbb{E}_{I}\left[\mathbb{E}\left[\frac{d y_{1, i}}{d n_{i}} \mid D_{i}=1, I_{i}=1\right]+\mathbb{E}\left[\frac{d y_{2, i}}{d n_{i}} \mid D_{i}=1, I_{i}=2\right]\right]}_{\text {winner response }}<\underbrace{\mathbb{E}_{I}\left[\mathbb{E}\left[\frac{d y_{2, i}}{d n_{i}} \mid D_{i}=1, I_{i}=1\right]+\mathbb{E}\left[\frac{d y_{1, i}}{d n_{i}} \mid D_{i}=1, I_{i}=2\right]\right]}_{\text {spouse response }}$

which, in light of equation (G.6), can be re-written as

$$
\frac{\mathbb{P}\left(I_{i}=1 \mid D_{i}=1\right)}{\mathbb{P}\left(I_{i}=2 \mid D_{i}=1\right)}>\frac{\mathbb{E}\left[\frac{d y_{1, i}}{d n_{i}} \mid D_{i}=1, I_{i}=2\right]-\mathbb{E}\left[\frac{d y_{2, i}}{d n_{i}} \mid D_{i}=1, I_{i}=2\right]}{\mathbb{E}\left[\frac{d y_{1, i}}{d n_{i}} \mid D_{i}=1, I_{i}=1\right]-\mathbb{E}\left[\frac{d y_{2, i}}{d n_{i}} \mid D_{i}=1, I_{i}=1\right]}
$$

Under random assignment of winning within households, we have $\frac{\mathbb{P}\left(I_{i}=1 \mid D_{i}=1\right)}{\mathbb{P}\left(I_{i}=2 \mid D_{i}=1\right)}=1$. Under the symmetry condition (G.4), we then also have that $\frac{\mathbb{E}\left[\frac{d y_{1, i}}{d n_{i}} \mid D_{i}=1, I_{i}=2\right]-\mathbb{E}\left[\frac{d y_{2, i}}{d n_{i}} \mid D_{i}=1, I_{i}=2\right]}{\mathbb{E}\left[\frac{d y_{1, i}}{d n_{i}} \mid D_{i}=1, I_{i}=1\right]-\mathbb{E}\left[\frac{d y_{2, i}}{d n_{i}} \mid D_{i}=1, I_{i}=1\right]}=1$, which in turn implies that winners cannot be more responsive than their spouses if winning is randomly assigned within the household and the assumptions of the unitary model hold. Conversely, a finding of differential responses between spouses may be due to either non-random assignment of winning within household or a violation of the unitary model. 


\section{H Appendix for Section 5}

\section{H.1 The canonical model of labor supply}

In this section we derive explicit expressions for income and substitution effects in terms of properties of the utility function $u_{i}$. We apply the implicit function theorem to equation (5.3) to show that

$$
\begin{aligned}
\zeta_{i}^{\mathrm{u}} & =-\frac{\frac{u_{i, c}}{y_{i}^{*}}+(1-\tau) u_{i, c c}+u_{i, c y}}{(1-\tau) u_{i, c c}+2 u_{i, c y}+\frac{u_{i, y y}}{1-\tau}}, \\
\eta_{i} & =-\frac{(1-\tau) u_{i, c c}+u_{i, c y}}{(1-\tau)^{2} u_{i, c c}+2(1-\tau) u_{i, c y}+u_{i, y y}} .
\end{aligned}
$$

Using Slutsky (5.4), we can also show that

$$
\zeta_{i}^{\mathrm{c}}=-\frac{u_{i, c}}{y_{i}^{*}\left((1-\tau) u_{i, c c}+2 u_{i, c y}+\frac{u_{i, y y}}{1-\tau}\right)} .
$$

At the optimum, condition (5.3) implies that

$$
-\frac{u_{i, y}}{u_{i, c}}=1-\tau
$$

Using this relationship, we can write equations (H.1), (H.2), and (H.3) as

$$
\begin{gathered}
\zeta_{i}^{\mathrm{u}}=\frac{\frac{u_{i, y}}{y_{i}^{*}}-\left(\frac{u_{i, y}}{u_{i, c}}\right)^{2} u_{i, c c}+\left(\frac{u_{i, y}}{u_{i, c}}\right) u_{i, c y}}{\left(\frac{u_{i, y}}{u_{i, c}}\right)^{2} u_{i, c c}-2\left(\frac{u_{i, y}}{u_{i, c}}\right) u_{i, c y}+u_{i, y y}}, \\
\eta_{i}=\frac{\left(\frac{u_{i, y}}{u_{i, c}}\right) u_{i, c c}-u_{i, c y}}{\left(\frac{u_{i, y}}{u_{i, c}}\right)^{2} u_{i, c c}-2\left(\frac{u_{i, y}}{u_{i, c}}\right) u_{i, c y}+u_{i, y y}}, \\
\zeta_{i}^{\mathrm{c}}=\frac{\frac{u_{i, y}}{y_{i}^{*}}}{\left(\frac{u_{i, y}}{u_{i, c}}\right)^{2} u_{i, c c}-2\left(\frac{u_{i, y}}{u_{i, c}}\right) u_{i, c y}+u_{i, y y}} .
\end{gathered}
$$

\section{H.2 Proof of Lemma 1}

Preliminaries. As a preliminary step, we consider maximization problem (5.8). The first-order condition reads

$$
u_{i, y}\left(y_{i}^{\mathrm{int}}-\mathcal{T}\left(y_{i}^{\mathrm{int}}\right)+n_{i}^{*}, y_{i}^{\mathrm{int}}\right)=-\left(1-\mathcal{T}^{\prime}\left(y_{i}^{\mathrm{int}}\right)\right) u_{i, c}\left(y_{i}^{\mathrm{int}}-\mathcal{T}\left(y_{i}^{\mathrm{int}}\right)+n_{i}^{*}, y_{i}^{\mathrm{int}}\right) .
$$

Taking into account that $\partial_{L} n_{i}^{*}=1$, we apply the implicit function theorem to show

$$
\partial_{L} y_{i}^{\text {int }}=-\frac{\left(1-\mathcal{T}^{\prime}\left(y_{i}^{\text {int }}\right)\right) u_{i, c c}+u_{i, c y}}{-\mathcal{T}^{\prime \prime}\left(y_{i}^{\text {int }}\right) u_{i, c}+\left(1-\mathcal{T}^{\prime}\left(y_{i}^{\text {int }}\right)\right)^{2} u_{i, c c}+2\left(1-\mathcal{T}^{\prime}\left(y_{i}^{\text {int }}\right)\right) u_{i, c y}+u_{i, y y}} .
$$


Let $\mathcal{K}_{i} \equiv\left(1-\mathcal{T}^{\prime}\left(y_{i}^{\text {int }}\right)\right)^{2} u_{i, c c}+2\left(1-\mathcal{T}^{\prime}\left(y_{i}^{\text {int }}\right)\right) u_{i, c y}+u_{i, y y}$ and let $\tau_{i} \equiv \mathcal{T}^{\prime}\left(y_{i}^{\text {int }}\right)$. We then write equation (H.8) as

$$
\partial_{L} y_{i}^{\text {int }}\left[1-\frac{\mathcal{T}^{\prime \prime}\left(y_{i}^{\text {int }}\right) u_{i, c}}{\mathcal{K}_{i}}\right]=-\frac{\left(1-\tau_{i}\right) u_{i, c c}+u_{i, c y}}{\mathcal{K}_{i}} .
$$

By substituting expressions (H.2) and (H.3) into equation (H.9), we obtain,

$$
\partial_{L} y_{i}^{\mathrm{int}}=\frac{\eta_{i}}{1+\theta_{i} \zeta_{i}^{\mathrm{c}}}
$$

where $\theta_{i} \equiv \frac{\mathcal{T}^{\prime \prime}\left(y_{i}^{\mathrm{int}}\right) y_{i}^{\text {int }}}{1-\mathcal{T}^{\prime}\left(y_{i}^{\text {int }}\right)}$

MPE. We now show that the $\operatorname{MPE}(y)$ is well-defined, and given by the expression in Lemma 1 . Since $\Lambda_{L}(y, 0)=0$ by definition, we get

$$
\begin{aligned}
\operatorname{MPE}(y) \equiv \partial_{L} \mathbb{E}_{y} y_{i}^{*} & =\lim _{L^{\mathrm{ann}} \rightarrow 0} \frac{\mathbb{E}_{y}\left[y_{i}^{*}\left(L^{\mathrm{ann}}\right)-y\right]}{L^{\mathrm{ann}}} \\
& =\lim _{L^{\mathrm{ann}} \rightarrow 0} \frac{\left(1-\Lambda_{L}\left(y, L^{\mathrm{ann}}\right)\right) \mathbb{E}_{y}\left[y_{i}^{\mathrm{int}}\left(L^{\mathrm{ann}}\right)-y\right]}{L^{\mathrm{ann}}}+\lim _{L^{\mathrm{ann}} \rightarrow 0} \frac{\Lambda_{L}\left(y, L^{\mathrm{ann}}\right)(0-y)}{L^{\mathrm{ann}}} \\
& =\mathbb{E}_{y}\left[\lim _{L^{\mathrm{ann}} \rightarrow 0} \frac{y_{i}^{\mathrm{int}}\left(L^{\mathrm{ann}}\right)-y}{L^{\mathrm{ann}}}\right]-y \lim _{L^{\mathrm{ann}} \rightarrow 0} \frac{\Lambda_{L}\left(y, L^{\mathrm{ann}}\right)}{L^{\mathrm{ann}}} \\
& =\mathbb{E}_{y} \partial_{L} y_{i}^{\mathrm{int}}-y \lim _{L^{\mathrm{ann}} \rightarrow 0} \frac{\Lambda_{L}\left(y, L^{\mathrm{ann}}\right)}{L^{\mathrm{ann}}}
\end{aligned}
$$

Since the earnings density $h(y)$ is assumed to respond smoothly to a perturbation in $L^{\text {ann }}$,

$$
\lambda_{L}(y) \equiv \lim _{L^{\mathrm{ann}} \rightarrow 0} \frac{\Lambda_{L}\left(y, L^{\mathrm{ann}}\right)}{L^{\mathrm{ann}}} \geq 0
$$

exists. Therefore, $\operatorname{MPE}(y)$ is well-defined.

The first term in expression (H.11) is the intensive-margin contribution, while the second term represents the extensive-margin contribution to $\operatorname{MPE}(y)$. By substituting expression (H.10) into (H.11), we then obtain

$$
\operatorname{MPE}(y)=\operatorname{MPE}^{\mathrm{int}}(y)+\operatorname{MPE}^{\mathrm{ext}}(y),
$$

where

$$
\operatorname{MPE}^{\mathrm{int}}(y) \equiv \mathbb{E}_{y} \frac{\eta_{i}}{1+\theta_{i} \zeta_{i}^{c}}, \quad \operatorname{MPE}^{\mathrm{ext}}(y) \equiv-y \lambda_{L}(y)
$$


MPT. We take similar steps to derive the expression for the MPT $(y)$ in Lemma 1. Concretely, we have

$$
\begin{aligned}
\operatorname{MPT}(y) \equiv \partial_{L} \mathbb{E}_{y} \mathcal{T}\left(y_{i}^{*}\right) & =\lim _{L^{\mathrm{ann}} \rightarrow 0} \frac{\mathbb{E}_{y}\left[\mathcal{T}\left(y_{i}^{*}\left(L^{\mathrm{ann}}\right)\right)-\mathcal{T}(y)\right]}{L^{\mathrm{ann}}} \\
& =\lim _{L^{\mathrm{ann}} \rightarrow 0} \frac{\left(1-\Lambda_{L}\left(y, L^{\mathrm{ann}}\right)\right) \mathbb{E}_{y}\left[\mathcal{T}\left(y_{i}^{\mathrm{int}}\left(L^{\mathrm{ann}}\right)\right)-\mathcal{T}(y)\right]}{L^{\mathrm{ann}}}+\lim _{L^{\mathrm{ann}} \rightarrow 0} \frac{\Lambda_{L}\left(y, L^{\mathrm{ann}}\right)(\mathcal{T}(0)-\mathcal{T}(y))}{L^{\mathrm{ann}}} \\
& =\lim _{L^{\mathrm{ann}} \rightarrow 0} \frac{\mathbb{E}_{y}\left[\mathcal{T}\left(y_{i}^{\mathrm{int}}\left(L^{\mathrm{ann}}\right)\right)-\mathcal{T}(y)\right]}{L^{\mathrm{ann}}}-(\mathcal{T}(y)-\mathcal{T}(0)) \lim _{L^{\mathrm{ann}} \rightarrow 0} \frac{\Lambda_{L}\left(y, L^{\mathrm{ann}}\right)}{L^{\mathrm{ann}}} \\
& =\mathcal{T}^{\prime}(y) \mathbb{E}_{y}\left[\lim _{L^{\mathrm{ann}} \rightarrow 0} \frac{y_{i}^{\mathrm{int}}\left(L^{\mathrm{ann}}\right)-y}{L^{\mathrm{ann}}}\right]-(\mathcal{T}(y)-\mathcal{T}(0)) \lim _{L^{\mathrm{ann}} \rightarrow 0} \frac{\Lambda_{L}\left(y, L^{\mathrm{ann}}\right)}{L^{\mathrm{ann}}} \\
& =\mathcal{T}^{\prime}(y) \mathbb{E}_{y} \partial_{L} y_{i}^{\mathrm{int}}-(\mathcal{T}(y)-\mathcal{T}(0)) \lim _{L^{\mathrm{ann}} \rightarrow 0} \frac{\Lambda_{L}\left(y, L^{\mathrm{ann}}\right)}{L^{\mathrm{ann}}}
\end{aligned}
$$

Since the earnings density $h(y)$ is assumed to respond smoothly to a perturbation in $L^{\text {ann }}$,

$$
\lambda_{L}(y) \equiv \lim _{L^{\mathrm{ann}} \rightarrow 0} \frac{\Lambda_{L}\left(y, L^{\mathrm{ann}}\right)}{L^{\mathrm{ann}}} \geq 0
$$

exists. Therefore, $\operatorname{MPT}(y)$ is well-defined.

The first term in expression (H.12) is the intensive-margin contribution, while the second term represents the extensive-margin contribution to MPT $(y)$. By substituting expression (H.10) into (H.12), we then obtain

$$
\operatorname{MPT}(y)=\operatorname{MPT}^{\mathrm{int}}(y)+\operatorname{MPT}^{\mathrm{ext}}(y),
$$

where

$$
\operatorname{MPT}^{\text {int }}(y) \equiv \mathcal{T}^{\prime}(y) \mathbb{E}_{y} \frac{\eta_{i}}{1+\theta_{i} \zeta_{i}^{c}}, \quad \operatorname{MPT}^{\text {ext }}(y) \equiv-(\mathcal{T}(y)-\mathcal{T}(0)) \lambda_{L}(y)
$$

\section{H.3 Proof of Proposition 1}

Preliminaries. As a preliminary step, we consider the maximization problem (5.8) under the UBI program,

$$
\max _{c_{i}, y_{i}} u_{i}\left(c_{i}, y_{i}\right)
$$

subject to

$$
c_{i}=y_{i}-\mathcal{T}\left(y_{i}\right)-\delta(B) y_{i}+n_{i}^{*} .
$$

The first-order condition reads

$u_{i, y}\left(y_{i}^{\mathrm{int}}-\mathcal{T}\left(y_{i}^{\mathrm{int}}\right)-\delta(B) y_{i}^{\mathrm{int}}+n_{i}^{*}, y_{i}^{\mathrm{int}}\right)=-\left(1-\mathcal{T}^{\prime}\left(y_{i}^{\mathrm{int}}\right)-\delta(B)\right) u_{i, c}\left(y_{i}^{\mathrm{int}}-\mathcal{T}\left(y_{i}^{\mathrm{int}}\right)-\delta(B) y_{i}^{\mathrm{int}}+n_{i}^{*}, y_{i}^{\mathrm{int}}\right)$

Taking into account that $\partial_{B} n_{i}^{*}=1$ and $\delta(0)=0$, we apply the implicit function theorem to show

$$
\partial_{B} y_{i}^{\mathrm{int}}=-\frac{\left(1-y_{i}^{\mathrm{int}} \partial_{B} \delta\right)\left[\left(1-\mathcal{T}^{\prime}\left(y_{i}^{\mathrm{int}}\right)\right) u_{i, c c}+u_{i, c y}\right]-u_{i, c} \partial_{B} \delta}{-\mathcal{T}^{\prime \prime}\left(y_{i}^{\mathrm{int}}\right) u_{i, c}+\left(1-\mathcal{T}^{\prime}\left(y_{i}^{\mathrm{int}}\right)\right)^{2} u_{i, c c}+2\left(1-\mathcal{T}^{\prime}\left(y_{i}^{\mathrm{int}}\right)\right) u_{i, c y}+u_{i, y y}} .
$$


Let $\mathcal{K}_{i} \equiv\left(1-\mathcal{T}^{\prime}\left(y_{i}^{\text {int }}\right)\right)^{2} u_{i, c c}+2\left(1-\mathcal{T}^{\prime}\left(y_{i}^{\text {int }}\right)\right) u_{i, c y}+u_{i, y y}$ and $\tau_{i} \equiv \mathcal{T}^{\prime}\left(y_{i}^{\text {int }}\right)$. We then write equation (H.16) as

$$
\partial_{B} y_{i}^{\text {int }}\left[1-\frac{\mathcal{T}^{\prime \prime}\left(y_{i}^{\text {int }}\right) u_{i, c}}{\mathcal{K}_{i}}\right]=-\frac{\left(1-\tau_{i}\right) u_{i, c c}+u_{i, c y}}{\mathcal{K}_{i}}+\frac{y_{i}^{\text {int }}}{1-\tau_{i}}\left[\frac{\left(1-\tau_{i}\right) u_{i, c c}+u_{i, c y}+\frac{u_{i, c}}{y_{i}^{\text {int }}}}{\frac{\mathcal{K}_{i}}{1-\tau_{i}}}\right] \partial_{B} \delta
$$

By substituting expressions (H.2) and (H.3) in equation (H.17), we get

$$
\partial_{B} y_{i}^{\mathrm{int}}\left[1+\theta_{i} \zeta_{i}^{\mathrm{c}}\right]=\eta_{i}+\frac{y_{i}^{\mathrm{int}}}{1-\tau_{i}}\left[\frac{\left(1-\tau_{i}\right) u_{i, c c}+u_{i, c y}+\frac{u_{i, c}}{y_{i}^{\text {int }}}}{\frac{\mathcal{K}_{i}}{1-\tau_{i}}}\right] \partial_{B} \delta
$$

where $\theta_{i} \equiv \frac{y_{i}^{\text {int }} \mathcal{T}^{\prime \prime}\left(y_{i}^{\mathrm{int}}\right)}{1-\tau_{i}}$. By substituting expression (H.1) in (H.18), we end up with

$$
\partial_{B} y_{i}^{\mathrm{int}}=\frac{\eta_{i}}{1+\theta_{i} \zeta_{i}^{\mathrm{c}}}-\frac{y_{i}^{\mathrm{int}}}{1-\tau_{i}} \frac{\zeta_{i}^{\mathrm{u}}}{1+\theta_{i} \zeta_{i}^{\mathrm{c}}} \partial_{B} \delta
$$

Total earnings response. We now show that $\partial_{B} Y \equiv \partial_{B} \mathbb{E} y_{i}^{*}$ is well-defined, and given by the expression in Proposition 1. By definition, we have $\Lambda_{B}(y, 0)=0$ for all $y$. We then get

$$
\begin{aligned}
\partial_{B} Y \equiv \partial_{B} \mathbb{E} y_{i}^{*} & =\lim _{B \rightarrow 0} \frac{\int \mathbb{E}_{y}\left[y_{i}^{*}(B)-y\right] d H(y)}{B} \\
& =\lim _{B \rightarrow 0} \frac{\int\left[1-\Lambda_{B}(y, B)\right] \mathbb{E}_{y}\left[y_{i}^{\text {int }}(B)-y\right] d H(y)}{B}+\lim _{B \rightarrow 0} \frac{\int \Lambda_{B}(y, B)[0-y] d H(y)}{B} \\
& =\int \lim _{B \rightarrow 0} \frac{\mathbb{E}_{y}\left[y_{i}^{\text {int }}(B)-y\right]}{B} d H(y)-\int y \lim _{B \rightarrow 0} \frac{\Lambda_{B}(y, B)}{B} d H(y) \\
& =\int \mathbb{E}_{y}\left[\lim _{B \rightarrow 0} \frac{y_{i}^{\text {int }}(B)-y}{B}\right] d H(y)-\int y \lim _{B \rightarrow 0} \frac{\Lambda_{B}(y, B)}{B} d H(y) \\
& =\int \mathbb{E}_{y} \partial_{B} y_{i}^{\text {int }} d H(y)-\int y \lim _{B \rightarrow 0} \frac{\Lambda_{B}(y, B)}{B} d H(y) .
\end{aligned}
$$

Since the earnings density $h(y)$ is assumed to respond smoothly to a perturbation in $B$,

$$
\lambda_{B}(y) \equiv \lim _{B \rightarrow 0} \frac{\Lambda_{B}(y, B)}{B} \geq 0
$$

exists. Therefore, $\partial_{B} Y$ is well-defined. By substituting expression (H.19) in (H.20), we end up with

$$
\partial_{B} Y=\mathbb{E}\left[\frac{\eta_{i}}{1+\theta_{i} \zeta_{i}^{\mathrm{c}}}-\frac{y_{i}^{*}}{1-\tau_{i}} \frac{\zeta_{i}^{\mathrm{u}}}{1+\theta_{i} \zeta_{i}^{\mathrm{c}}} \partial_{B} \delta\right]-\int y \lambda_{B}(y) d H(y)
$$

where $y_{i}^{*}=y_{i}^{*}(0)=y_{i}^{\text {int }}(0)$. 
Total tax responses. We take similar steps to derive the expression for $\partial_{B} \mathbb{E} \mathcal{T}\left(y_{i}^{*}(B)\right)$ in Proposition 1 . Concretely, we have

$$
\begin{aligned}
\partial_{B} \mathbb{E} \mathcal{T}\left(y_{i}^{*}(B)\right) & =\lim _{B \rightarrow 0} \frac{\int \mathbb{E}_{y}\left[\mathcal{T}\left(y_{i}^{*}(B)\right)-\mathcal{T}(y)\right] d H(y)}{B} \\
& =\lim _{B \rightarrow 0} \frac{\int\left[1-\Lambda_{B}(y, B)\right] \mathbb{E}_{y}\left[\mathcal{T}\left(y_{i}^{\text {int }}(B)\right)-\mathcal{T}(y)\right] d H(y)}{B}+\lim _{B \rightarrow 0} \frac{\int \Lambda_{B}(y, B)[\mathcal{T}(0)-\mathcal{T}(y)] d H(y)}{B} \\
& =\int \mathcal{T}^{\prime}(y) \lim _{B \rightarrow 0} \frac{\mathbb{E}_{y}\left[y_{i}^{\text {int }}(B)-y\right]}{B} d H(y)-\int[\mathcal{T}(y)-\mathcal{T}(0)] \lim _{B \rightarrow 0} \frac{\Lambda_{B}(y, B)}{B} d H(y) \\
& =\int \mathcal{T}^{\prime}(y) \mathbb{E}_{y}\left[\lim _{B \rightarrow 0} \frac{y_{i}^{\text {int }}(B)-y}{B}\right] d H(y)-\int[\mathcal{T}(y)-\mathcal{T}(0)] \lim _{B \rightarrow 0} \frac{\Lambda_{B}(y, B)}{B} d H(y) \\
& =\int \mathcal{T}^{\prime}(y) \mathbb{E}_{y} \partial_{B} y_{i}^{\text {int }} d H(y)-\int[\mathcal{T}(y)-\mathcal{T}(0)] \lim _{B \rightarrow 0} \frac{\Lambda_{B}(y, B)}{B} d H(y) .
\end{aligned}
$$

Since the earnings density $h(y)$ is assumed to respond smoothly to a perturbation in $B$,

$$
\lambda_{B}(y) \equiv \lim _{B \rightarrow 0} \frac{\Lambda_{B}(y, B)}{B} \geq 0
$$

exists, and $\partial_{B} \mathbb{E} \mathcal{T}\left(y_{i}^{*}(B)\right)$ therefore is well-defined. By substituting expression (H.19) in (H.21), we get

$$
\partial_{B} \mathbb{E} \mathcal{T}\left(y_{i}^{*}(B)\right)=\mathbb{E} \tau_{i}\left[\frac{\eta_{i}}{1+\theta_{i} \zeta_{i}^{\mathrm{c}}}-\frac{y_{i}^{*}}{1-\tau_{i}} \frac{\zeta_{i}^{\mathrm{u}}}{1+\theta_{i} \zeta_{i}^{\mathrm{c}}} \partial_{B} \delta\right]-\int[\mathcal{T}(y)-\mathcal{T}(0)] \lambda_{B}(y) d H(y)
$$

where $\tau_{i} \equiv \mathcal{T}^{\prime}\left(y_{i}^{*}\right)$, and $y_{i}^{*}=y_{i}^{*}(0)=y_{i}^{\text {int }}(0)$.

Tax rate increase. In the first step, we derive the expression for $\partial_{B} \delta$ in Proposition 1. By substituting expression (H.22) into equation (5.11), we get

$$
\partial_{B} \mathcal{R}=-1+Y \partial_{B} \delta+\mathbb{E} \tau_{i}\left[\frac{\eta_{i}}{1+\theta_{i} \zeta_{i}^{\mathrm{c}}}-\frac{y_{i}^{*}}{1-\tau_{i}} \frac{\zeta_{i}^{\mathrm{u}}}{1+\theta_{i} \zeta_{i}^{\mathrm{c}}} \partial_{B} \delta\right]-\int[\mathcal{T}(y)-\mathcal{T}(0)] \lambda_{B}(y) d H(y) .
$$

Since the UBI is assumed to be revenue neutral, we must have $\partial_{B} \mathcal{R}=0$. Therefore, $\partial_{B} \delta$ must satisfy

$$
\partial_{B} \delta=\frac{1-\mathbb{E} \tau_{i} \frac{\eta_{i}}{1+\theta_{i} \zeta_{i}^{\mathrm{c}}}+\int[\mathcal{T}(y)-\mathcal{T}(0)] \lambda_{B}(y) d H(y)}{Y-\mathbb{E} \frac{\tau_{i} y_{i}^{*}}{1-\tau_{i}} \frac{\zeta_{i}^{\mathrm{u}}}{1+\theta_{i} \zeta_{i}^{\mathrm{c}}}}
$$

In the second step, we prove that $\partial_{B} \delta \geq 0$. Let $\partial_{\delta} x \equiv \lim _{\delta \rightarrow 0} \frac{x(\delta)-x(0)}{\delta}$ be the marginal impact of the labor tax surcharge $\delta$ on any variable $x$ that is differentiable in $\delta$. As stated in Proposition 1, we assume that $\mathcal{T}(\cdot)$ is to the left of the peak of the Laffer curve. This implies that a small increase in marginal tax rates increases tax revenues,

$$
\partial_{\delta} \mathcal{R}(\delta)=Y+\partial_{\delta} \mathbb{E} \mathcal{T}\left(y_{i}^{*}(\delta)\right)>0
$$


Following similar steps as above, we can show that

$$
\partial_{\delta} \mathbb{E} \mathcal{T}\left(y_{i}^{*}(\delta)\right)=\int \mathcal{T}^{\prime}(y) \mathbb{E}_{y} \partial_{\delta} y_{i}^{\mathrm{int}} d H(y)-\int[\mathcal{T}(y)-\mathcal{T}(0)] \lambda_{\delta} d H(y) .
$$

To find $\partial_{\delta} y_{i}^{\text {int }}$, we apply the implicit function theorem to the first-order condition (H.15). Taking into account that $\partial_{\delta} n_{i}^{*}=0$, we get

$$
\partial_{\delta} y_{i}^{\mathrm{int}}=-\frac{y_{i}^{*}}{1-\tau_{i}} \frac{\zeta_{i}^{\mathrm{u}}}{1+\theta_{i} \zeta_{i}^{\mathrm{c}}} .
$$

Substituting expression (H.26) in (H.25) yields

$$
\partial_{\delta} \mathbb{E} \mathcal{T}\left(y_{i}^{*}(\delta)\right)=-\mathbb{E} \frac{\tau_{i} y_{i}^{*}}{1-\tau_{i}} \frac{\zeta_{i}^{\mathrm{u}}}{1+\theta_{i} \zeta_{i}^{\mathrm{c}}}-\int[\mathcal{T}(y)-\mathcal{T}(0)] \lambda_{\delta}(y) d H(y)
$$

Substituting this expression into (H.24) implies

$$
Y-\mathbb{E} \frac{\tau_{i} y_{i}^{*}}{1-\tau_{i}} \frac{\zeta_{i}^{\mathrm{u}}}{1+\theta_{i} \zeta_{i}^{\mathrm{c}}}-\int[\mathcal{T}(y)-\mathcal{T}(0)] \lambda_{\delta}(y) d H(y)>0
$$

Since $\lambda_{\delta}(y) \geq 0$ for all $y$ and taxes are increasing in earnings, it follows that the denominator in (H.23) is positive. Since $\eta_{i} \leq 0, \lambda_{B}(y) \geq 0$ for all $y$, and taxes are increasing in earnings, it is straightforward to verify that the numerator in expression (H.23) is also positive. Therefore, $\partial_{B} \delta \geq 0$.

Marginal propensity to stop working. Lastly, we prove that $\lambda_{B}(y) \geq \lambda_{L}(y) \geq 0$. Consider any household $i$ who receives a lottery $L$ with an annuity $L^{\text {ann }}$ that is equal to the UBI payment $B$. The per-period utility from not working, $u_{i}\left(n_{i}^{*}-\mathcal{T}(0), 0\right)+v_{i}$, is the same under the lottery and under UBI. As we established above, marginal taxes weakly increase under UBI, $\partial_{B} \delta \geq 0$. This, in turn, implies that the maximal attainable utility from working under UBI is weakly smaller than the maximal attainable utility from working under the lottery. Therefore, every household who stops working under the lottery also wants to stop working under the UBI program for a given change in unearned income $\Delta$. This implies $\Lambda_{L}(y, \Delta) \leq \Lambda_{B}(y, \Delta)$, and by taking the limit $\Delta \rightarrow 0$, we get $0 \leq \lambda_{L}(y) \leq \lambda_{B}(y)$.

\section{H.4 Proof of Corollary 1}

From Proposition 1, we know that $\lambda_{B}(y) \geq \lambda_{L}(y) \geq 0$ and

$$
\partial_{B} \delta=\frac{1-\mathbb{E} \tau_{i} \frac{\eta_{i}}{1+\theta_{i} \zeta_{i}^{\mathrm{c}}}+\int[\mathcal{T}(y)-\mathcal{T}(0)] \lambda_{B}(y) d H(y)}{Y-\mathbb{E} \frac{\tau_{i} y_{i}^{*}}{1-\tau_{i}} \frac{\zeta_{i}^{\mathrm{u}}}{1+\theta_{i} \zeta_{i}^{\mathrm{c}}}} .
$$

Therefore,

$$
\partial_{B} \delta \geq \frac{1-\mathbb{E} \tau_{i} \frac{\eta_{i}}{1+\theta_{i} \zeta_{i}^{\mathrm{c}}}+\int[\mathcal{T}(y)-\mathcal{T}(0)] \lambda_{L}(y) d H(y)}{Y-\mathbb{E} \frac{\tau_{i} y_{i}^{*}}{1-\tau_{i}} \frac{\zeta_{i}^{\mathrm{u}}}{1+\theta_{i} \zeta_{i}^{\mathrm{c}}}}
$$


Since $\mathcal{T}(\cdot)$ is assumed to be to the left of the peak of the Laffer curve, we know from the proof of Proposition 1 that $Y-\mathbb{E} \frac{\tau_{i} y_{i}^{*}}{1-\tau_{i}} \frac{\zeta_{i}^{\mathrm{u}}}{1+\theta_{i} \zeta_{i}^{\mathrm{c}}}>0$. If $\zeta_{i}^{\mathrm{u}} \geq 0$ for all $i$,we obtain

$$
\partial_{B} \delta \geq \frac{1-\mathbb{E} \tau_{i} \frac{\eta_{i}}{1+\theta_{i} \zeta_{i}^{\mathrm{c}}}+\int[\mathcal{T}(y)-\mathcal{T}(0)] \lambda_{L}(y) d H(y)}{Y}=\frac{1-\mathrm{MPT}}{Y}
$$

where the equality follows from Lemma 1 . Taking further into account that $\eta_{i} \leq 0$ for all $i$ and $\partial_{B} \delta \geq 0$, it is also easy to verify that

$$
\begin{aligned}
\partial_{B} Y & =\mathbb{E}\left[\frac{\eta_{i}}{1+\theta_{i} \zeta_{i}^{\mathrm{c}}}-\frac{y_{i}^{*}}{1-\tau_{i}} \frac{\zeta_{i}^{\mathrm{u}}}{1+\theta_{i} \zeta_{i}^{\mathrm{c}}} \partial_{B} \delta\right]-\int y \lambda_{B}(y) d H(y) \\
& \leq \mathbb{E} \frac{\eta_{i}}{1+\theta_{i} \zeta_{i}^{\mathrm{c}}}-\int y \lambda_{L}(y) d H(y) \\
& =\text { MPE. }
\end{aligned}
$$

\section{H.5 Proof of Corollary 2}

Preliminaries. As a preliminary step, it is useful to derive the object $\mathbb{E}_{y} \frac{1}{1+\theta_{i} \zeta_{i}^{\mathrm{c}}}$. By rearranging the intensivemargin earnings response (H.10) we get

$$
\eta_{i}=\left(1+\theta_{i} \zeta_{i}^{\mathrm{c}}\right) \partial_{L} y_{i}^{\mathrm{int}}
$$

Using Slutsky (5.4) we obtain

$$
\zeta_{i}^{\mathrm{c}}=\frac{\zeta_{i}^{\mathrm{u}}-\left(1-\tau_{i}\right) \partial_{L} y_{i}^{\mathrm{int}}}{1+\theta_{i}\left(1-\tau_{i}\right) \partial_{L} y_{i}^{\mathrm{int}}}
$$

and since $\zeta_{i}^{\mathrm{u}}=\zeta^{\mathrm{u}}$ and $\theta_{i}=\theta$ for all $i$, we find

$$
\mathbb{E}_{y} \frac{1}{1+\theta \zeta_{i}^{\mathrm{c}}}=\frac{1+\theta\left[1-\mathcal{T}^{\prime}(y)\right] \mathbb{E}_{y} \partial_{L} y_{i}^{\mathrm{int}}}{1+\theta \zeta^{\mathrm{u}}} .
$$

By substituting expression (H.10) and applying Lemma 1, we obtain

$$
\mathbb{E}_{y} \frac{1}{1+\theta \zeta_{i}^{\mathrm{c}}}=\frac{1+\theta\left[1-\mathcal{T}^{\prime}(y)\right] \operatorname{MPE}^{\mathrm{int}}(y)}{1+\theta \zeta^{\mathrm{u}}}
$$


Tax rate increase. With $\zeta_{i}^{\mathrm{u}}=\zeta^{\mathrm{u}}$ and $\theta_{i}=\theta$ for all $i$, we know from Proposition 1 that

$$
\begin{aligned}
\partial_{B} \delta & =\frac{1-\mathbb{E} \tau_{i} \frac{\eta_{i}}{1+\theta \zeta_{i}^{\mathrm{c}}}+\int[\mathcal{T}(y)-\mathcal{T}(0)] \lambda_{B}(y) d H(y)}{Y-\mathbb{E} \frac{\tau_{i} y_{i}^{*}}{1-\tau_{i}} \frac{\zeta^{\mathrm{u}}}{1+\theta \zeta_{i}^{\mathrm{c}}}} \\
& =\frac{1-\mathbb{E} \tau_{i} \frac{\eta_{i}}{1+\theta \zeta_{i}^{\mathrm{c}}}+\int[\mathcal{T}(y)-\mathcal{T}(0)] \lambda_{B}(y) d H(y)}{Y-\zeta^{\mathrm{u}} \int \frac{\mathcal{T}^{\prime}(y) y}{1-\mathcal{T}^{\prime}(y)} \mathbb{E}_{y} \frac{1}{1+\theta \zeta_{i}^{\mathrm{c}}} d H(y)} \\
& \geq \frac{1-\mathbb{E} \tau_{i} \frac{\eta_{i}}{1+\theta \zeta_{i}^{\mathrm{c}}}+\int[\mathcal{T}(y)-\mathcal{T}(0)] \lambda_{L}(y) d H(y)}{Y-\zeta^{\mathrm{u}} \int \frac{\mathcal{T}^{\prime}(y) y}{1-\mathcal{T}^{\prime}(y)} \mathbb{E}_{y} \frac{1}{1+\theta \zeta_{i}^{\mathrm{c}}} d H(y)}
\end{aligned}
$$

By Lemma 1 we then get

$$
\partial_{B} \delta \geq \frac{1-\mathrm{MPT}}{Y-\zeta^{\mathrm{u}} \int \frac{\mathcal{T}^{\prime}(y) y}{1-\mathcal{T}^{\prime}(y)} \mathbb{E}_{y} \frac{1}{1+\theta \zeta_{i}^{\mathrm{c}}} d H(y)}
$$

Substitute expression (H.27) into (H.28) to get

$$
\partial_{B} \delta \geq \frac{1-\mathrm{MPT}}{Y-\frac{\zeta^{\mathrm{u}}}{1+\theta \zeta^{\mathrm{u}}} \int \mathcal{T}^{\prime}(y) D(y) d H(y)}
$$

where

$$
D(y) \equiv \frac{y}{1-\mathcal{T}^{\prime}(y)}+\theta y \operatorname{MPE}^{\mathrm{int}}(y)
$$

Total earnings response. We take similar steps and apply Lemma 1 and Proposition 1 to show that

$$
\begin{aligned}
\partial_{B} Y & =\mathbb{E}\left[\frac{\eta_{i}}{1+\theta \zeta_{i}^{\mathrm{c}}}-\frac{y_{i}^{*}}{1-\tau_{i}} \frac{\zeta^{\mathrm{u}}}{1+\theta \zeta_{i}^{\mathrm{c}}} \partial_{B} \delta\right]-\int y \lambda_{B}(y) d H(y) \\
& =\mathbb{E} \frac{\eta_{i}}{1+\theta \zeta_{i}^{\mathrm{c}}}-\int y \lambda_{B}(y) d H(y)-\partial_{B} \delta \frac{\zeta^{\mathrm{u}}}{1+\theta \zeta^{\mathrm{u}}} \int D(y) d H(y) \\
& \leq \mathbb{E} \frac{\eta_{i}}{1+\theta \zeta_{i}^{\mathrm{c}}}-\int y \lambda_{L}(y) d H(y)-\partial_{B} \delta \frac{\zeta^{\mathrm{u}}}{1+\theta \zeta^{\mathrm{u}}} \int D(y) d H(y) \\
& =\operatorname{MPE}-\partial_{B} \delta \frac{\zeta^{\mathrm{u}}}{1+\theta \zeta^{\mathrm{u}}} \int D(y) d H(y)
\end{aligned}
$$

By substituting equation (H.28) into the above expression, we end up with

$$
\partial_{B} Y \leq \mathrm{MPE}-(1-\mathrm{MPT}) \frac{\frac{\zeta^{\mathrm{u}}}{1+\theta \zeta^{\mathrm{u}}} \int D(y) d H(y)}{Y-\frac{\zeta^{\mathrm{u}}}{1+\theta \zeta^{\mathrm{u}}} \int \mathcal{T}^{\prime}(y) D(y) d H(y)},
$$

where $D(y)$ is defined in (H.29).

\section{H.6 Bounds for homogeneous compensated elasticities}

Another way to use Proposition 1 is to assume that there is no heterogeneity in compensated elasticities, i.e., $\zeta_{i}^{\mathrm{c}}=\zeta^{\mathrm{c}}$ for all $i$. We then obtain the following Corollary: 
Corollary 4. Suppose $\zeta_{i}^{c}=\zeta^{c}$ and $\theta_{i}=\theta$ for all $i$. Then

$$
\begin{aligned}
\partial_{B} \delta & \geq \frac{1-M P T}{Y-\frac{\zeta^{c}}{1+\theta \zeta^{c}} \int \mathcal{T}^{\prime}(y) D(y) d H(y)}, \\
\partial_{B} Y & \leq M P E-(1-M P T) \frac{\frac{\zeta^{c}}{1+\theta \zeta^{c}} \int D(y) d H(y)}{Y-\frac{\zeta^{c}}{1+\theta \zeta^{c}} \int \mathcal{T}^{\prime}(y) D(y) d H(y)},
\end{aligned}
$$

where $D(y) \equiv \frac{y}{1-\mathcal{T}^{\prime}(y)}+\frac{1+\theta \zeta^{c}}{\zeta^{c}} y M P E^{i n t}(y)$

Proof. As a preliminary step, it is useful to derive the object $\mathbb{E}_{y} \frac{\zeta_{i}^{\mathrm{u}}}{1+\theta_{i} \zeta_{i}^{\mathrm{c}}}$. By rearranging the intensive-margin earnings response (H.10) we get

$$
\eta_{i}=\left(1+\theta_{i} \zeta_{i}^{\mathrm{c}}\right) \partial_{L} y_{i}^{\mathrm{int}}
$$

Using Slutsky (5.4) we obtain

$$
\zeta_{i}^{\mathrm{u}}=\zeta_{i}^{\mathrm{c}}+\left(1-\tau_{i}\right)\left(1+\theta_{i} \zeta_{i}^{\mathrm{c}}\right) \partial_{L} y_{i}^{\mathrm{int}}
$$

By taking expectations conditional on $y$, we get

$$
\mathbb{E}_{y} \zeta_{i}^{\mathrm{u}}=\zeta^{\mathrm{c}}+\left[1-\mathcal{T}^{\prime}(y)\right]\left(1+\theta \zeta^{\mathrm{c}}\right) \mathbb{E}_{y} \partial_{L} y_{i}^{\mathrm{int}}
$$

where we used $\zeta_{i}^{\mathrm{c}}=\zeta^{\mathrm{c}}$ and $\theta_{i}=\theta$ for all $i$. By substituting expression (H.10) and applying Lemma 1, we obtain

$$
\mathbb{E}_{y} \zeta_{i}^{\mathrm{u}}=\zeta^{\mathrm{c}}+\left[1-\mathcal{T}^{\prime}(y)\right]\left(1+\theta \zeta^{\mathrm{c}}\right) \mathrm{MPE}^{\mathrm{int}}(y)
$$

and, therefore,

$$
\mathbb{E}_{y} \frac{\zeta_{i}^{\mathrm{u}}}{1+\theta \zeta^{\mathrm{c}}}=\frac{\zeta^{\mathrm{c}}}{1+\theta \zeta^{\mathrm{c}}}+\left[1-\mathcal{T}^{\prime}(y)\right] \operatorname{MPE}^{\mathrm{int}}(y)
$$

Next, we consider an increase in tax rates. By applying Lemma 1 and Proposition 1, it is easy to verify that

$$
\begin{aligned}
\partial_{B} \delta & =\frac{1-\mathbb{E} \tau_{i} \frac{\eta_{i}}{1+\theta \zeta^{\mathrm{c}}}+\int[\mathcal{T}(y)-\mathcal{T}(0)] \lambda_{B}(y) d H(y)}{Y-\mathbb{E} \frac{\tau_{i} y_{i}^{*}}{1-\tau_{i}} \frac{\zeta_{i}^{\mathrm{u}}}{1+\theta \zeta^{\mathrm{c}}}} \\
& \geq \frac{1-\mathbb{E} \tau_{i} \frac{\eta_{i}}{1+\theta \zeta^{\mathrm{c}}}+\int[\mathcal{T}(y)-\mathcal{T}(0)] \lambda_{L}(y) d H(y)}{Y-\mathbb{E}_{i} \frac{\tau_{i} y_{i}^{*}}{1-\tau_{i}} \frac{\zeta_{i}^{\mathrm{u}}}{1+\theta \zeta^{\mathrm{c}}}} \\
& =\frac{1-\operatorname{MPT}}{Y-\int \frac{\mathcal{T}^{\prime}(y) y}{1-\mathcal{T}^{\prime}(y)} \mathbb{E}_{y} \frac{\zeta_{i}^{\mathrm{u}}}{1+\theta \zeta^{\mathrm{c}}} d H(y)}
\end{aligned}
$$

By substituting expression (H.31) in (H.33), we get

$$
\partial_{B} \delta \geq \frac{1-\mathrm{MPT}}{Y-\frac{\zeta^{\mathrm{c}}}{1+\theta \zeta^{\mathrm{c}}} \int \mathcal{T}^{\prime}(y) D(y) d H(y)}
$$


where

$$
D(y) \equiv \frac{y}{1-\mathcal{T}^{\prime}(y)}+\frac{1+\theta \zeta^{\mathrm{c}}}{\zeta^{\mathrm{c}}} y \operatorname{MPE}^{\mathrm{int}}(y)
$$

Lastly, we consider the total earnings response. By applying Lemma 1 and Proposition 1, we can show that

$$
\begin{aligned}
\partial_{B} Y & =\mathbb{E}\left[\frac{\eta_{i}}{1+\theta \zeta^{\mathrm{c}}}-\frac{y_{i}^{*}}{1-\tau_{i}} \frac{\zeta_{i}^{\mathrm{u}}}{1+\theta \zeta^{\mathrm{c}}} \partial_{B} \delta\right]-\int y \lambda_{B}(y) d H(y) \\
& =\mathbb{E} \frac{\eta_{i}}{1+\theta \zeta^{\mathrm{c}}}-\int y \lambda_{B}(y) d H(y)-\mathbb{E}\left[\frac{y_{i}^{*}}{1-\tau_{i}} \frac{\zeta_{i}^{\mathrm{u}}}{1+\theta \zeta^{\mathrm{c}}}\right] \partial_{B} \delta \\
& \leq \mathbb{E} \frac{\eta_{i}}{1+\theta \zeta^{\mathrm{c}}}-\int y \lambda_{L}(y) d H(y)-\mathbb{E}\left[\frac{y_{i}^{*}}{1-\tau_{i}} \frac{\zeta_{i}^{\mathrm{u}}}{1+\theta \zeta^{\mathrm{c}}}\right] \partial_{B} \delta \\
& =\operatorname{MPE}-\partial_{B} \delta \frac{\zeta^{\mathrm{c}}}{1+\theta \zeta^{\mathrm{c}}} \int D(y) d H(y) .
\end{aligned}
$$

By substituting equation (H.33) in the above expression, we end up with

$$
\partial_{B} Y \leq \mathrm{MPE}-(1-\mathrm{MPT}) \frac{\frac{\zeta^{\mathrm{c}}}{1+\theta \zeta^{\mathrm{c}}} \int D(y) d H(y)}{Y-\frac{\zeta^{\mathrm{c}}}{1+\theta \zeta^{\mathrm{c}}} \int \mathcal{T}^{\prime}(y) D(y) d H(y)},
$$

where $D(y)$ is given by expression (H.34).

\section{H.7 Proof of Proposition 2}

Preliminaries. We consider a perturbation of the top income tax rate $\bar{\tau}$ that affects only taxpayers with income above some threshold $\bar{y}$. Any household $i$ with income $y_{i}^{*} \geq \bar{y}$ solves

$$
\max _{c_{i}, y_{i}} u_{i}\left(c_{i}, y_{i}\right)
$$

subject to

$$
c_{i}=(1-\bar{\tau}) y_{i}+n_{i}^{*}
$$

The first-order condition reads

$$
u_{i, y}\left((1-\bar{\tau}) y_{i}^{\mathrm{int}}+n_{i}^{*}, y_{i}^{\mathrm{int}}\right)=-(1-\bar{\tau}) u_{i, c}\left((1-\bar{\tau}) y_{i}^{\mathrm{int}}+n_{i}^{*}, y_{i}^{\mathrm{int}}\right)
$$

From the point of view of household $i$, an increase in the top tax rate of $d \bar{\tau}$ leads to an increase in unearned, or virtual, income by $\bar{y} d \bar{\tau}$ in each subsequent period if household $i$ continues to work. This implies that $\partial_{\tau} n_{i}^{*}=\bar{y}$. We then apply the implicit function theorem to show that

$$
\partial_{\tau} y_{i}^{\mathrm{int}}=-\frac{\left(\bar{y}-y_{i}^{*}\right)\left[u_{i, c y}+(1-\bar{\tau}) u_{i, c c}\right]+u_{i, c}}{(1-\bar{\tau})^{2} u_{i, c c}+2(1-\bar{\tau}) u_{i, c y}+u_{i, y y}},
$$


where $y_{i}^{*}=y_{i}^{\text {int }}$. By substituting expressions (H.1) and (H.2) into (H.35), we get

$$
\partial_{\tau} y_{i}^{\mathrm{int}}=\bar{y} \eta_{i}-\frac{y_{i}^{*}}{1-\bar{\tau}} \zeta_{i}^{\mathrm{u}}
$$

Tax revenues. Following the same steps as in the proof for Lemma 1, it is easy to verify that

$$
\partial_{\tau} \mathbb{E}_{\geq \bar{y}} \mathcal{T}(y)=\mathbb{E}_{\geq \bar{y}} \bar{\tau}\left[\bar{y} \eta_{i}-\frac{y_{i}^{*}}{1-\bar{\tau}} \zeta_{i}^{\mathrm{u}}\right]-\int_{\bar{y}}^{\infty}(\mathcal{T}(y)-\mathcal{T}(0)) \lambda_{\tau}(y) \frac{d H(y)}{1-H(\bar{y})}
$$

\section{H.8 Proof of Corollary 3}

Preliminaries. Only earnings above the threshold $\bar{y}$ are affected by the perturbation in $\bar{\tau}$. It is therefore useful to derive the object $\partial_{\tau} \mathbb{E}_{\geq \bar{y}} y_{i}^{*}$. Using expression (H.36), we can follow the same steps as in the proof for Lemma 1 to show that

$$
\partial_{\tau} \mathbb{E}_{\geq \bar{y}} y_{i}^{*}=\mathbb{E}_{\geq \bar{y}}\left[\bar{y} \eta_{i}-\frac{y_{i}^{*}}{1-\bar{\tau}} \zeta_{i}^{\mathrm{u}}\right]-\int_{\bar{y}}^{\infty} y \lambda_{\tau}(y) \frac{d H(y)}{1-H(\bar{y})} .
$$

This, in turn, implies that the marginal impact on total earnings is given by

$$
\partial_{\tau} Y=[1-H(\bar{y})] \bar{y}\left[\mathbb{E}_{\geq \bar{y}} \eta_{i}-\frac{a}{1-\bar{\tau}} \mathbb{E}_{\geq \bar{y}} \zeta_{i}^{\mathrm{u}}\right]-\int_{\bar{y}}^{\infty} y \lambda_{\tau}(y) d H(y),
$$

where $a \equiv \mathbb{E}_{\geq \bar{y}} \frac{y_{i}^{*}}{\bar{y}}$. In addition, we substitute the expression from Proposition 2 in (5.15), to show that

$$
\partial_{\tau} \mathcal{R}=[1-H(\bar{y})] \bar{y}\left[a-1+\bar{\tau}\left(\mathbb{E}_{\geq \bar{y}} \eta_{i}-\frac{a}{1-\bar{\tau}} \mathbb{E}_{\geq \bar{y}} \zeta_{i}^{\mathrm{u}}\right)\right]-\int_{\bar{y}}^{\infty}(\mathcal{T}(y)-\mathcal{T}(0)) \lambda_{\tau}(y) d H(y)
$$

Since $\lambda_{\tau}(y) \geq 0$ for all $y \geq \bar{y}$, we get

$$
\begin{aligned}
& \partial_{\tau} \mathcal{R} \leq[1-H(\bar{y})] \bar{y}\left[a-1+\bar{\tau}\left(\mathbb{E}_{\geq \bar{y}} \eta_{i}-\frac{a}{1-\bar{\tau}} \mathbb{E}_{\geq \bar{y}} \zeta_{i}^{\mathrm{u}}\right)\right], \\
& \partial_{\tau} Y \leq[1-H(\bar{y})] \bar{y}\left[\mathbb{E}_{\geq \bar{y}} \eta_{i}-\frac{a}{1-\bar{\tau}} \mathbb{E}_{\geq \bar{y}} \zeta_{i}^{\mathrm{u}}\right]
\end{aligned}
$$

Case $(a)$ in Corollary 3. If $\zeta_{i}^{\mathrm{u}} \geq 0$ for all $i$ who earn $y_{i}^{*} \geq \bar{y}$, then inequalities (H.39) and (H.40) can simply be written as

$$
\begin{aligned}
& \partial_{\tau} \mathcal{R} \leq[1-H(\bar{y})] \bar{y}\left[a-1+\bar{\tau} \mathbb{E}_{\geq \bar{y}} \eta_{i}\right], \\
& \partial_{\tau} Y \leq[1-H(\bar{y})] \bar{y} \mathbb{E}_{\geq \bar{y}} \eta_{i} .
\end{aligned}
$$

Since $\eta_{i} \leq 0$ and $\theta_{i} \geq 0$ for all $i$, Lemma 1 implies

$$
\overline{\operatorname{MPE}}^{\text {int }}=\mathbb{E}_{\geq \bar{y}} \frac{\eta_{i}}{1+\theta_{i} \zeta_{i}^{\mathrm{c}}} \geq \mathbb{E}_{\geq \bar{y}} \eta_{i}
$$


Given this relationship, we can write inequalities (H.41) and (H.42) as

$$
\begin{aligned}
& \partial_{\tau} \mathcal{R} \leq[1-H(\bar{y})] \bar{y}\left[a-1+\bar{\tau} \times \overline{\mathrm{MPE}}^{\mathrm{int}}\right], \\
& \partial_{\tau} Y \leq[1-H(\bar{y})] \bar{y} \times \overline{\mathrm{MPE}}^{\mathrm{int}} .
\end{aligned}
$$

Case $(b)$ in Corollary 3. If $\zeta_{i}^{\mathrm{u}}=\bar{\zeta}^{\mathrm{u}}$ for all $i$ who earn $y_{i}^{*} \geq \bar{y}$, then the same arguments as above allow us to write inequalities (H.39) and (H.40) as

$$
\begin{aligned}
& \partial_{\tau} \mathcal{R} \leq[1-H(\bar{y})] \bar{y}\left[a-1+\bar{\tau}\left(\overline{\operatorname{MPE}}^{\mathrm{int}}-\frac{a}{1-\bar{\tau}} \bar{\zeta}^{\mathrm{u}}\right)\right] \\
& \partial_{\tau} Y \leq[1-H(\bar{y})] \bar{y}\left[\overline{\operatorname{MPE}}^{\mathrm{int}}-\frac{a}{1-\bar{\tau}} \bar{\zeta}^{\mathrm{u}}\right] .
\end{aligned}
$$

\section{H.9 Increase in top marginal tax rates under homogeneous compensated elasticities}

We begin by deriving the object $\partial_{\tau} \mathbb{E}_{\geq \bar{y}} y_{i}^{*}$. We know from expression (H.36) that

$$
\partial_{\tau} y_{i}^{\mathrm{int}}=\bar{y} \eta_{i}-\frac{y_{i}^{*}}{1-\bar{\tau}} \zeta_{i}^{\mathrm{u}}
$$

Using Slutsky (5.4) we can write this as

$$
\partial_{\tau} y_{i}^{\mathrm{int}}=\left(\bar{y}-y_{i}^{*}\right) \eta_{i}-\frac{y_{i}^{*}}{1-\bar{\tau}} \zeta_{i}^{\mathrm{c}}
$$

Following the same steps as in the proof for Lemma 1, we can show that

$$
\partial_{\tau} \mathbb{E}_{\geq \bar{y}} y_{i}^{*}=\mathbb{E}_{\geq \bar{y}}\left[\left(\bar{y}-y_{i}^{*}\right) \eta_{i}-\frac{y_{i}^{*}}{1-\bar{\tau}} \zeta_{i}^{\mathrm{c}}\right]-\int_{\bar{y}}^{\infty} y \lambda_{\tau}(y) \frac{d H(y)}{1-H(\bar{y})} .
$$

This, in turn, implies that the marginal impact on total earnings is given by

$$
\partial_{\tau} Y=[1-H(\bar{y})] \bar{y}\left[(1-a) \mathbb{E}_{\geq \bar{y}} \eta_{i}-\frac{a}{1-\bar{\tau}} \mathbb{E}_{\geq \bar{y}} \zeta_{i}^{\mathrm{c}}\right]-\int_{\bar{y}}^{\infty} y \lambda_{\tau}(y) d H(y),
$$

where $a \equiv \mathbb{E}_{\geq \bar{y}} \frac{y_{i}^{*}}{\bar{y}}$. As above, we can use Slutsky (5.4) to rewrite the expression in Proposition 2. We get

$$
\partial_{\tau} \mathbb{E}_{\geq \bar{y}} \mathcal{T}\left(y_{i}^{*}\right)=\mathbb{E}_{\geq \bar{y}} \bar{\tau}\left[\left(\bar{y}-y_{i}^{*}\right) \eta_{i}-\frac{y_{i}^{*}}{1-\bar{\tau}} \zeta_{i}^{\mathrm{c}}\right]-\int_{\bar{y}}^{\infty}(\mathcal{T}(y)-\mathcal{T}(0)) \lambda_{\tau}(y) \frac{d H(y)}{1-H(\bar{y})}
$$

Substitute this expression in (5.15), to get

$$
\partial_{\tau} \mathcal{R}=[1-H(\bar{y})] \bar{y}\left[a-1+\bar{\tau}\left((1-a) \mathbb{E}_{\geq \bar{y}} \eta_{i}-\frac{a}{1-\bar{\tau}} \mathbb{E}_{\geq \bar{y}} \zeta_{i}^{\mathrm{c}}\right)\right]-\int_{\bar{y}}^{\infty}(\mathcal{T}(y)-\mathcal{T}(0)) \lambda_{\tau}(y) d H(y) .
$$


Since $\lambda_{\tau}(y) \geq 0$ for all $y \geq \bar{y}$, we get

$$
\begin{aligned}
& \partial_{\tau} \mathcal{R} \leq[1-H(\bar{y})] \bar{y}\left[a-1+\bar{\tau}\left((1-a) \mathbb{E}_{\geq \bar{y}} \eta_{i}-\frac{a}{1-\bar{\tau}} \mathbb{E}_{\geq \bar{y}} \zeta_{i}^{\mathrm{c}}\right)\right], \\
& \partial_{\tau} Y \leq[1-H(\bar{y})] \bar{y}\left[(1-a) \mathbb{E}_{\geq \bar{y}} \eta_{i}-\frac{a}{1-\bar{\tau}} \mathbb{E}_{\geq \bar{y}} \zeta_{i}^{\mathrm{c}}\right] .
\end{aligned}
$$

Since $\eta_{i} \leq 0$ and $\theta_{i} \geq 0$ for all $i$, Lemma 1 implies

$$
\overline{\operatorname{MPE}}^{\mathrm{int}}=\mathbb{E}_{\geq \bar{y}} \frac{\eta_{i}}{1+\theta_{i} \zeta_{i}^{\mathrm{c}}} \geq \mathbb{E}_{\geq \bar{y}} \eta_{i} .
$$

Given this relationship, we can write inequalities (H.45) and (H.46) as

$$
\begin{aligned}
& \partial_{\tau} \mathcal{R} \leq[1-H(\bar{y})] \bar{y}\left[a-1+\bar{\tau}\left((1-a) \times \overline{\operatorname{MPE}}^{\text {int }}-\frac{a}{1-\bar{\tau}} \bar{\zeta}^{\mathrm{c}}\right)\right], \\
& \partial_{\tau} Y \leq[1-H(\bar{y})] \bar{y}\left[(1-a) \times \overline{\operatorname{MPE}}^{\text {int }}-\frac{a}{1-\bar{\tau}} \bar{\zeta}^{\mathrm{c}}\right],
\end{aligned}
$$

where we used $\zeta_{i}^{\mathrm{c}}=\bar{\zeta}^{\mathrm{c}}$ for all $i$ who earn $y_{i}^{*} \geq \bar{y}$. 


\section{Extending the analysis in Section 5}

In this section we extend our analysis from Section 5 to allow for retirement. We do so by developing an overlapping generations (OLG) model with heterogeneous agents.

\section{I.1 A heterogeneous-agent OLG model}

There is a measure one of heterogeneous households. Each household $i$ lives for $T+K$ periods, where it can choose to work in each of the the first $T$ periods, but is unable to work in the subsequent $K$ periods of retirement. For the first $T$ periods, the household may receive labor income $y_{i, t}$, while for the last $K$ periods the household receives a social security transfer $S$. Utility of household $i$ in each of the first $T$ periods is given by $\mathfrak{u}_{i}$, defined in equation (5.7), while per-period utility thereafter is $u_{i}(c, 0)$. Households discount the future at rate $\beta=(1+\bar{r})^{-1}$ and maximize lifetime utility,

$$
\max _{\left\{c_{i, t}, y_{i, t}, n_{i, t}\right\}_{t}} \sum_{t=1}^{T} \beta^{t-1} \mathfrak{u}_{i}\left(c_{i, t}, y_{i, t}\right)+\sum_{t=T+1}^{T+K} \beta^{t-1} u_{i}\left(c_{i, t}, 0\right)
$$

subject to

$$
\begin{aligned}
& c_{i, t}=\left\{\begin{array}{ll}
y_{i, t}-\mathcal{T}\left(y_{i, t}\right)-\delta y_{i, t}+n_{i, t} & \text { if } t \leq T \\
S+n_{i, t} & \text { if } t>T
\end{array},\right. \\
& n_{i, t}=(1+\bar{r}) a_{i, t-1}-a_{i, t},
\end{aligned}
$$

and $a_{i, 0}$ are given initial assets. As in Section 5, we can split household $i$ 's problem (I.1) into two subproblems due to time-separability in lifetime utility. To study the outer (intertemporal) subproblem that characterizes the optimal choice of unearned income across the life cycle, we define the indirect utility functions,

$$
\begin{aligned}
V_{i}(n, \delta) & \equiv \max \left\{u_{i}(c, y) \mid c=y-\mathcal{T}(y)-\delta y+n\right\}, \\
\tilde{V}_{i}(n, \delta) & \equiv \max \left\{V_{i}(n, \delta), u_{i}(n-\mathcal{T}(0), 0)+v_{i}\right\}, \\
W_{i}(n) & \equiv u_{i}(S+n, 0)
\end{aligned}
$$

The indirect utility functions represent the maximal attainable utility of the inner (intratemporal) subproblems as a function of unearned income $n$ and an earnings tax surcharge $\delta$. The outer subproblem of household $i$ can then be written as

$$
\max _{\left\{n_{i, t}^{w}, n_{i, t}^{r}\right\}_{t}} \sum_{t=1}^{T} \beta^{t-1} \tilde{V}_{i}\left(n_{i, t}^{w}, 0\right)+\sum_{t=T+1}^{T+K} \beta^{t-1} W_{i}\left(n_{i, t}^{r}\right)
$$


subject to

$$
\sum_{t=1}^{T} \beta^{t-1} n_{i, t}^{w}+\beta^{T} \sum_{t=1}^{K} \beta^{t-1} n_{i, t}^{r}=(1+\bar{r}) a_{i, 0} .
$$

Given this formulation, it is then immediately clear that optimal choices $\left\{n_{i, t}^{w, *}, n_{i, t}^{r, *}\right\}_{t}$ are independent of $t$. Moreover, if household $i$ works in period $t^{\prime}$, then it works in all periods $t=1, \ldots, T$ and $\tilde{V}_{i}(\cdot, \cdot)$ can be replaced with $V_{i}(\cdot, \cdot)$ in maximization problem (I.2). The optimal bundle $\left\{n_{i}^{w, *}, n_{i}^{r, *}\right\}$ in this case is then the solution to the following system of equations:

$$
\begin{gathered}
V_{i, n}=W_{i, n}, \\
\frac{1-\beta^{T}}{1-\beta} n_{i}^{w, *}+\beta^{T} \frac{1-\beta^{K}}{1-\beta} n_{i}^{r, *}=(1+\bar{r}) a_{i, 0},
\end{gathered}
$$

where $V_{i, n}$ and $W_{i, n}$ denote the partial derivatives of $V_{i}(n, \delta)$ and $W_{i}(n)$ with respect to $n$, evaluated at $\left(n_{i}^{w, *}, 0\right)$ and $n_{i}^{r, *}$, respectively. Let $V_{i, n n}$ and $V_{i, n \delta}$ denote the partial derivatives of $V_{i, n}$ with respect to $n$ and $\delta$, respectively. Before we proceed, we make make the following assumption:

Assumption 1. The utility function $u_{i}(c, y)$ is such that $V_{i, n n}<0$ and $V_{i, n \delta} \geq 0$.

This is a natural assumption. By the envelope theorem, we have $V_{i, n}=u_{i, c}$. Thus, we assume that an increase in unearned income or a decrease in marginal tax rates decreases the marginal utility of consumption of household $i$. Lemma 2 provides sufficient conditions for that.

Lemma 2. $W_{i, n n} \leq 0 . V_{i, n n} \leq 0$ if $\eta_{i} \geq-1$ and $u_{i, c y} \geq 0 . V_{i, n \delta} \geq 0$ if $\zeta_{i}^{u} \geq 0$ and leisure is a normal good, or if $\zeta_{i}^{u}$ is sufficiently close to 0 .

Proof. See Appendix I.4.1.

\section{I.2 Marginal propensities: MPE and MPT}

As in Section 5, we first present the theoretical analogues to MPE and MPT that we estimated in Section 4. Suppose that wealth of household $i$ increases unexpectedly by the amount $L$. Without loss of generality, we assume that this occurs in year 1 of her life. We are interested in the marginal impact of this windfall. For any equilibrium variable $x\left(L^{\text {ann }}\right)$ that is differentiable in $L^{\text {ann }}$, let the marginal effect of this increase be defined as $\partial_{L} x \equiv \lim _{L^{\text {ann }} \rightarrow 0} \frac{x\left(L^{\mathrm{ann}}\right)-x(0)}{L^{\text {ann }}}$, where the annuitized value $L^{\text {ann }}$ is determined by equation (4.2) and given by

$$
L^{\mathrm{ann}}=\frac{1-\beta}{1-\beta^{T+K}} L
$$

We are interested in the average earnings and tax responses to a one dollar increase in this annuity. Lemma 3 provides a generalization of Lemma 1 when we allow for retirement.

Lemma 3. $\operatorname{MPE}(y)$ and $\operatorname{MPT}(y)$ are well-defined for all $y$ and satisfy

$$
\begin{aligned}
& \operatorname{MPE}(y)=\operatorname{MPE}^{\text {int }}(y)+\operatorname{MPE}^{\text {ext }}(y), \\
& \operatorname{MPT}(y)=\operatorname{MPT}^{\text {int }}(y)+\operatorname{MPT}^{\text {ext }}(y),
\end{aligned}
$$


where

$$
\begin{aligned}
\operatorname{MPE}^{\mathrm{int}}(y) & \equiv \mathbb{E}_{y} \frac{\eta_{i}}{1+\theta_{i} \zeta_{i}^{\mathrm{c}}} \partial_{L} n_{i}^{w, *}, & \operatorname{MPE}^{\mathrm{ext}}(y) & \equiv-y \lambda_{L}(y), \\
\operatorname{MPT}^{\text {int }}(y) & \equiv \mathcal{T}^{\prime}(y) \mathbb{E}_{y} \frac{\eta_{i}}{1+\theta_{i} \zeta_{i}^{\mathrm{c}}} \partial_{L} n_{i}^{w, *}, & \operatorname{MPT}^{\text {ext }}(y) & \equiv-[\mathcal{T}(y)-\mathcal{T}(0)] \lambda_{L}(y),
\end{aligned}
$$

and $\theta_{i} \equiv \frac{\mathcal{T}^{\prime \prime}\left(y_{i}^{*}\right) y_{i}^{*}}{1-\mathcal{T}^{\prime}\left(y_{i}^{*}\right)}$

Proof. All arguments are identical to the proof for Lemma 1, except $\partial_{L} n_{i}^{w, *}$ does not need to be equal to 1.

As in the case without retirement, Lemma 3 shows that the expressions for the $\operatorname{MPE}(y)$ and $\operatorname{MPT}(y)$ consist of two terms that capture intensive- and extensive-margin responses. The extensive-margin responses are proportional to $\lambda_{L}(y)$, which is simply the marginal propensity to stop working of households making $y$ dollars on average. The intensive-margin responses are proportional to $\mathbb{E}_{y} \frac{\eta_{i}}{1+\theta_{i} \zeta_{i}^{\mathrm{c}}} \partial_{L} n_{i}^{w, *}$, where in contrast to Lemma 1, we have an additional factor $\partial_{L} n_{i}^{w, *}$ that captures the savings response through the marginal impact on unearned income during the working life. To find $\partial_{L} n_{i}^{w, *}$, we consider the outer subproblem (I.2) of household $i$. The first-order conditions imply

$$
\begin{gathered}
V_{i, n}=W_{i, n}, \\
\frac{1-\beta^{T}}{1-\beta} n_{i}^{w, *}+\beta^{T} \frac{1-\beta^{K}}{1-\beta} n_{i}^{r, *}=(1+\bar{r}) a_{i, 0}+L .
\end{gathered}
$$

By differentiating both equations with respect to $L^{\text {ann }}$, we get

$$
\begin{aligned}
V_{i, n n} \partial_{L} n_{i}^{w, *} & =W_{i, n n} \partial_{L} n_{i}^{r, *}, \\
\frac{1-\beta^{T}}{1-\beta} \partial_{L} n_{i}^{w, *}+\beta^{T} \frac{1-\beta^{K}}{1-\beta} \partial_{L} n_{i}^{r, *} & =\frac{1-\beta^{T+K}}{1-\beta} .
\end{aligned}
$$

Note that when $K=0$, equation (I.5) implies that $\partial_{L} n_{i}^{w, *}=1$. This is the case without retirement that we considered in Section 5, where households increase their unearned income by $L^{\text {ann }}$ in each period following their lottery win. For $K \geq 0$, it is immediate to verify that the marginal effect on unearned income during the working life is given by

$$
\partial_{L} n_{i}^{w, *}=\frac{1-\beta^{T+K}}{1-\beta^{T}+\left(1-\beta^{K}\right) \beta^{T} \frac{V_{i, n n}}{W_{i, n n}}} \geq 0
$$

where $\partial_{L} n_{i}^{w, *} \geq 0$ follows from $\beta<1$ and $V_{i, n n}, W_{i, n n} \leq 0$ from Lemma 2. Universal Basic Income

We now extend the framework to analyze the introduction of a UBI of size $B$. We abstract from transitional dynamics and instead focus on the steady state when all agents live through the UBI system all their lives. Tax revenues in steady state are given by

$$
\mathcal{R}(B)=\mathbb{E}\left[-B+\delta(B) y_{i}^{*}(B)+\mathcal{T}\left(y_{i}^{*}(B)\right)\right]-\frac{K}{T+K}[\mathcal{T}(0)-S],
$$


where $\delta(B)$ is set such that $\mathcal{R}(B)=\mathcal{R}(0)$, i.e., revenue neutral. To understand this expression, note that we take expectations across all households, where households in retirement have $y_{i}^{*}(B)=0$. There is a measure $\frac{K}{T+K}$ of retired households, so the additional term $\frac{K}{T+K}[\mathcal{T}(0)-S]$ is simply an adjustment factor that takes into account that those households receive social security transfers $S$ rather than $\mathcal{T}(0)$.

In order to bound the effects of UBI, we begin by comparing the savings response to a one dollar increase in UBI and an annuity payment. Lemma 4 provides such a comparison.

Lemma 4. Suppose Assumption 1 is satisfied. If $\partial_{B} \delta \geq 0$ then $\partial_{B} n_{i}^{w, *} \geq \partial_{L} n_{i}^{w, *} \geq 0$.

Proof. See Appendix I.4.2.

To understand this result, consider a lottery with an implied annuity of the same size as the UBI. If marginal taxes increase under the UBI program, then Assumption 1 implies that consumption of household $i$ decreases in response to the increase in tax rates. This, in turn, implies that the household must save less for retirement in order to achieve a smooth consumption profile, which means that it allocates more unearned income to each period of the working life. Equipped with Lemma 4 we can now examine the implications of a UBI program on earnings, taxes and tax rates.

Proposition 3. The marginal impact of the UBI is

$$
\begin{aligned}
\partial_{B} \mathbb{E} \mathcal{T}\left(y_{i}^{*}(B)\right) & =\mathbb{E} \tau_{i}\left[\frac{\eta_{i}}{1+\theta_{i} \zeta_{i}^{c}} \partial_{B} n_{i}^{w, *}-\frac{y_{i}^{*}}{1-\tau_{i}} \frac{\zeta_{i}^{u}}{1+\theta_{i} \zeta_{i}^{c}} \partial_{B} \delta\right]-\int[\mathcal{T}(y)-\mathcal{T}(0)] \lambda_{B}(y) d H(y), \\
\partial_{B} \delta & =\frac{1-\mathbb{E}\left[\tau_{i} \frac{\eta_{i}}{1+\theta_{i} \zeta_{i}^{c}} \partial_{B} n_{i}^{w, *}\right]+\int[\mathcal{T}(y)-\mathcal{T}(0)] \lambda_{B}(y) d H(y)}{Y-\mathbb{E} \frac{\tau_{i} y_{i}^{*}}{1-\tau_{i}} \frac{\zeta_{i}^{u}}{1+\theta_{i} \zeta_{i}^{c}}} \\
\partial_{B} Y & =\mathbb{E}\left[\frac{\eta_{i}}{1+\theta_{i} \zeta_{i}^{c}} \partial_{B} n_{i}^{w, *}-\frac{y_{i}^{*}}{1-\tau_{i}} \frac{\zeta_{i}^{u}}{1+\theta_{i} \zeta_{i}^{c}} \partial_{B} \delta\right]-\int y \lambda_{B}(y) d H(y) .
\end{aligned}
$$

Moreover, if $\mathcal{T}(\cdot)$ is to the left of the peak of the Laffer curve, then $\lambda_{B}(y) \geq \lambda_{L}(y) \geq 0$ for all $y$ and $\partial_{B} \delta \geq 0$.

Proof. See Appendix I.4.3.

Proposition 3 represents a generalization of Proposition 1. The key difference is that the intensivemargin response to the unconditional cash transfer is now scaled by the marginal effects on unearned income $\partial_{B} n_{i}^{w, *}$. As shown in Lemma 4, higher marginal tax rates induce households to allocate more unearned income per period than they would have allocated following a pure increase in an annuity payment. This additional unearned income amplifies the intensive-margin earnings response. As a result, the bounds on tax rates and earnings responses that we derived in Section 5 remain valid.

Corollary 5. Suppose Assumption 1 is satisfied. Then Corollary 1 holds. Moreover, if $\partial_{L} n_{i}^{w, *} \approx 1$, then Corollary 2 holds as well.

Proof. See Appendix I.4.4. 
It is useful to observe that we can, in principle, measure the average effect on unearned income, $\mathbb{E} \partial_{L} n_{i}^{w, *}$, in the data using our capitalization approach from Section 4. Empirically, we showed in Figure 4.1a that the impact of winning on unearned income is quantitatively similar under the capitalization approach as compared to the annuitization approach. This, in turn, suggests that $\mathbb{E} \partial_{L} n_{i}^{w, *} \approx 1$.

\section{I.3 Top income tax rates}

Lastly, we examine the implications of an increase in top marginal tax rates. As in the previous section, we abstract from transitional dynamics and focus on the steady state when all households live through the post-reform tax system all their lives.

As in Section 5, we assume that $\mathcal{T}^{\prime}(y)$ converges to some level $\bar{\tau}$ for all incomes above some threshold $\bar{y}$. Let $a \equiv \mathbb{E}_{\geq \bar{y}} \frac{y_{i}^{*}}{\bar{y}}$ be the average earnings of households in the top bracket, normalized by $\bar{y}$.

We define $\partial_{\tau} x$ to be the marginal impact on variable $x$ from an increase in the top rate $\bar{\tau}$, as in our earlier definitions of $\partial_{L}$ and $\partial_{B}$. From the point of view of household $i$, an increase in top tax rates by $d \bar{\tau}$ is equivalent to an increase in unearned, or virtual, income by $\bar{y} d \bar{\tau}$ in each period of household $i$ 's working life. The corresponding increase in the present value of unearned income is therefore given by

$$
\sum_{t=1}^{T} \beta^{t-1} \bar{y} d \bar{\tau}=\frac{1-\beta^{T}}{1-\beta} \bar{y} d \bar{\tau} .
$$

To bound the effects of an increase in the top tax rate, it is useful to examine the marginal effects of the change in tax rates on savings and earnings.

Proposition 4. Suppose Assumption 1 is satisfied. Then, for all $i$ who earn $y_{i}^{*} \geq \bar{y}$,

$$
\begin{aligned}
\partial_{\tau} n_{i}^{w, *} & \geq \frac{1-\beta^{T}}{1-\beta^{T+K}} \bar{y} \partial_{L} n_{i}^{w, *} \\
\partial_{\tau} y_{i}^{i n t} & \leq \frac{1-\beta^{T}}{1-\beta^{T+K}} \bar{y} \partial_{L} n_{i}^{w, *}-\frac{y_{i}^{*}}{1-\bar{\tau}} \zeta_{i}^{u},
\end{aligned}
$$

where the intensive-margin earnings response satisfies

$$
\partial_{\tau} y_{i}^{i n t}=\eta_{i} \partial_{\tau} n_{i}^{w, *}-\frac{y_{i}^{*}}{1-\bar{\tau}} \zeta_{i}^{u}
$$

Proof. See Appendix I.4.5.

Expression (I.8) compares the effects of the tax reform on unearned income with the effects of a pure increase in the present value of unearned income implied by the tax reform while keeping tax rates fixed. Similar to our discussion of Lemma 4, expression (I.8) highlights that an increase in marginal tax rates induces households to allocate more unearned income per period during their working life than they would have allocated following a pure increase in wealth of size $\frac{1-\beta^{T}}{1-\beta^{T+K}} \bar{y}$. Proposition 4 shows that the intensivemargin earnings response to an increase in the top tax rate consists of two terms. The first term in expression (I.10) captures the standard income response that calls for a reduction in earnings by $\eta_{i}$ for every additional 
dollar of unearned income. The second term captures the intensive-margin response of earnings to higher tax rates. Importantly, we can derive a bound on the earnings response through the additional effect of higher marginal taxes on per-period unearned income. Using Lemma 3 and Proposition 4, we then obtain an extension of Corollary 3.

Corollary 6. Let $\overline{\mathrm{MPE}}^{\mathrm{int}} \equiv \mathbb{E}_{\geq \bar{y}} \mathrm{MPE}^{\mathrm{int}}(y)$.

(a) If $\zeta_{i}^{u} \geq 0$ for all $i$ who earn $y_{i}^{*} \geq \bar{y}$ then

$$
\begin{aligned}
& \partial_{\tau} \mathcal{R} \leq[1-H(\bar{y})] \bar{y}\left[a-1+\frac{1-\beta^{T}}{1-\beta^{T+K}} \bar{\tau} \times \overline{\mathrm{MPE}}^{\mathrm{int}}\right], \\
& \partial_{\tau} Y \leq[1-H(\bar{y})] \bar{y} \frac{1-\beta^{T}}{1-\beta^{T+K}} \times \overline{\mathrm{MPE}}^{\mathrm{int}} .
\end{aligned}
$$

(b) If $\zeta_{i}^{u}=\bar{\zeta}^{u}$ for all $i$ who earn $y_{i}^{*} \geq \bar{y}$ then

$$
\begin{aligned}
& \partial_{\tau} \mathcal{R} \leq[1-H(\bar{y})] \bar{y}\left[a-1+\bar{\tau}\left(\frac{1-\beta^{T}}{1-\beta^{T+K}} \times \overline{\mathrm{MPE}}^{\mathrm{int}}-\frac{a}{1-\bar{\tau}} \bar{\zeta}^{u}\right)\right], \\
& \partial_{\tau} Y \leq[1-H(\bar{y})] \bar{y}\left[\frac{1-\beta^{T}}{1-\beta^{T+K}} \times \overline{\mathrm{MPE}}^{\mathrm{int}}-\frac{a}{1-\bar{\tau}} \bar{\zeta}^{u}\right] .
\end{aligned}
$$

Proof. See Appendix I.4.6.

Corollary 6 is similar to Corollary 3 that we derived in Section 5. The only difference is that the intensive-margin MPE is scaled by the factor $\frac{1-\beta^{T}}{1-\beta^{T+K}}$ to account for the differences in the time horizon at which households can adjust their earnings. Assuming $T=40$ and $K=20$, and a post-tax interest rate $\bar{r}=2.5 \%$, implies $\frac{1-\beta^{T}}{1-\beta^{T+K}} \approx 0.8$. With an $\overline{\mathrm{MPE}}^{\text {int }} \approx-0.4$ and $a \approx 3$, a 1 percentage point increase in the tax rate $\bar{\tau}=0.5$ for the top $1 \%$ of households implies that earnings would decrease by at least $\$ 1,600$ and tax revenues would increase at most by $\$ 9,200$ for each household in the top 1 percent according to Case $(a)$ in Corollary 6. The corresponding numbers we report in Section 5 are $\$ 2,000$ and $\$ 9,000$. Thus, allowing for retirement has only a negligible effect on our quantitative conclusions from Section 5.

\section{I.4 Proofs}

\section{I.4.1 Proof of Lemma 2}

By the envelope theorem, we have

$$
V_{i, n}(n, \delta)=u_{i, c}\left(y_{i}^{\mathrm{int}}-\mathcal{T}\left(y_{i}^{\mathrm{int}}\right)-\delta y_{i}^{\mathrm{int}}+n, y_{i}^{\mathrm{int}}\right)
$$

where $y_{i}^{\text {int }}$ is the solution to problem (5.8) for some arbitrary $(n, \delta)$. Differentiate this expression with respect to $n$ and $\delta$, and evaluate at $\left(n_{i}^{w, *}, 0\right)$ to get

$$
\begin{aligned}
& V_{i, n n}=\left[1+\left(1-\tau_{i}\right) \partial_{n} y_{i}^{\mathrm{int}}\right] u_{i, c c}+u_{i, c y} \partial_{n} y_{i}^{\mathrm{int}}, \\
& V_{i, n \delta}=-\left[y_{i}^{\mathrm{int}}-\left(1-\tau_{i}\right) \partial_{\delta} y_{i}^{\mathrm{int}}\right] u_{i, c c}+u_{i, c y} \partial_{\delta} y_{i}^{\mathrm{int}},
\end{aligned}
$$


where $u_{i, c c}$ and $u_{i, c y}$ are evaluated at $\left(c_{i}^{\mathrm{int}}, y_{i}^{\mathrm{int}}\right)$, and $\partial_{n} y_{i}^{\mathrm{int}}=\frac{\eta_{i}}{1+\theta_{i} \zeta_{i}^{\mathrm{c}}}, \partial_{\delta} y_{i}^{\mathrm{int}}=-\frac{y_{i}^{\mathrm{int}}}{1-\tau_{i}} \frac{\zeta_{i}^{\mathrm{u}}}{1+\theta_{i} \zeta_{i}^{\mathrm{c}}}$. Expression (I.12) can be written as

$$
V_{i, n \delta}=-y_{i}^{\mathrm{int}} u_{i, c c}+\left[u_{i, c y}+\left(1-\tau_{i}\right) u_{i, c c}\right] \partial_{\delta} y_{i}^{\mathrm{int}} .
$$

We have $u_{i, c c} \leq 0$ by convexity, and therefore $-y_{i}^{\text {int }} u_{i, c c} \geq 0$. If $\zeta_{i}^{\mathrm{u}}$ is arbitrarily close to zero, then so is $\partial_{\delta} y_{i}^{\text {int }}$, which can be chosen to ensure that $V_{i, n \delta} \geq 0$.

Alternatively, for a fixed $\zeta_{i}^{\mathrm{u}} \geq 0$, we have $\partial_{\delta} y_{i}^{\text {int }} \leq 0$. If leisure is a normal good, $\eta_{i} \leq 0$, then $u_{i, c y}+\left(1-\tau_{i}\right) u_{i, c c} \leq 0$, and we find $V_{i, n \delta} \geq 0$. To see this, consider expression (H.6). The denominator must be negative, since it is the same denominator as in equation (H.7), and we have $\zeta_{i}^{\mathrm{c}} \geq 0$ and $u_{i, y} \leq 0$. Therefore the numerator in (H.6) must be positive. By substituting expression (H.4) in (H.6), we establish that $u_{i, c y}+\left(1-\tau_{i}\right) u_{i, c c} \leq 0$ if $\eta_{i} \leq 0$. Expression (I.11) can be written as

$$
V_{i, n n}=u_{i, c c}+\left[u_{i, c c}\left(1-\tau_{i}\right)+u_{i, c y}\right] \partial_{n} y_{i}^{\mathrm{int}}
$$

We have $u_{i, c c} \leq 0$ by convexity. Since leisure is assumed to be a normal good, $\eta_{i} \leq 0$, we have $\partial_{n} y_{i}^{\text {int }} \leq 0$ and $u_{i, c c}\left(1-\tau_{i}\right)+u_{i, c y} \leq 0$. If $u_{i, c y} \geq 0$ and $\eta_{i} \geq-1$, it is easy to verify that $V_{i, n n} \leq 0$.

By the envelope theorem, we also have

$$
W_{i, n}(n)=u_{i, c}(n+S, 0) .
$$

Differentiate this expression with respect to $n$ and evaluate at $n_{i}^{r, *}$ to get

$$
W_{i, n n}=u_{i, c c} .
$$

$W_{i, n n} \leq 0$ then follows directly from $u_{i, c c} \leq 0$

\section{I.4.2 Proof of Lemma 4}

We consider the outer subproblem (I.2) of a working household $i$ in year 1 of her life under UBI. Household $i$ solves

$$
\max _{n_{i}^{w}, n_{i}^{r}} \frac{1-\beta^{T}}{1-\beta} V_{i}\left(n_{i}^{w}, \delta(B)\right)+\beta^{T} \frac{1-\beta^{K}}{1-\beta} W_{i}\left(n_{i}^{r}\right)
$$

subject to

$$
\frac{1-\beta^{T}}{1-\beta} n_{i}^{w}+\beta^{T} \frac{1-\beta^{K}}{1-\beta} n_{i}^{r}=(1+\bar{r}) a_{i, 0}+\frac{1-\beta^{T+K}}{1-\beta} B,
$$

where $\frac{1-\beta^{T+K}}{1-\beta} B$ is the present value of the UBI payments. The first-order conditions imply

$$
\begin{gathered}
V_{i, n}=W_{i, n}, \\
\frac{1-\beta^{T}}{1-\beta} n_{i}^{w, *}+\beta^{T} \frac{1-\beta^{K}}{1-\beta} n_{i}^{r, *}=(1+\bar{r}) a_{i, 0}+\frac{1-\beta^{T+K}}{1-\beta} B .
\end{gathered}
$$


By differentiating both equations with respect to $B$, we get

$$
\begin{aligned}
V_{i, n n} \partial_{B} n_{i}^{w, *}+V_{i, n \delta} \partial_{B} \delta & =W_{i, n n} \partial_{B} n_{i}^{r, *}, \\
\frac{1-\beta^{T}}{1-\beta} \partial_{B} n_{i}^{w, *}+\beta^{T} \frac{1-\beta^{K}}{1-\beta} \partial_{B} n_{i}^{r, *} & =\frac{1-\beta^{T+K}}{1-\beta} .
\end{aligned}
$$

Rearrange these expressions to get

$$
\left[\frac{V_{i, n n}}{W_{i, n n}}+\beta^{-T} \frac{1-\beta^{T}}{1-\beta^{K}}\right] \partial_{B} n_{i}^{w, *}+\frac{V_{i, n \delta}}{W_{i, n n}} \partial_{B} \delta=\beta^{-T} \frac{1-\beta^{T+K}}{1-\beta^{K}} .
$$

Under Assumption 1, we have $\frac{V_{i, n \delta}}{W_{i, n n}} \leq 0$ and $\frac{V_{i, n n}}{W_{i, n n}} \geq 0$. If $\partial_{B} \delta \geq 0$, then

$$
\partial_{B} n_{i}^{w, *} \geq \frac{1-\beta^{T+K}}{1-\beta^{T}+\left(1-\beta^{K}\right) \beta^{T} \frac{V_{i, n n}}{W_{i, n n}}} \geq 0
$$

Substitute expression (I.6) in the inequality above to get

$$
\partial_{B} n_{i}^{w, *} \geq \partial_{L} n_{i}^{w, *} \geq 0
$$

\section{I.4.3 Proof of Proposition 3}

Preliminaries. As a preliminary step, we consider the inner subproblem (5.8) under the UBI program,

$$
\max _{c_{i}, y_{i}} u_{i}\left(c_{i}, y_{i}\right)
$$

subject to

$$
c_{i}=y_{i}-\mathcal{T}\left(y_{i}\right)-\delta(B) y_{i}+n_{i}^{w, *} .
$$

The first-order condition reads

$u_{i, y}\left(y_{i}^{\mathrm{int}}-\mathcal{T}\left(y_{i}^{\mathrm{int}}\right)-\delta(B) y_{i}^{\mathrm{int}}+n_{i}^{w, *}, y_{i}^{\mathrm{int}}\right)=-\left(1-\mathcal{T}^{\prime}\left(y_{i}^{\mathrm{int}}\right)-\delta(B)\right) u_{i, c}\left(y_{i}^{\mathrm{int}}-\mathcal{T}\left(y_{i}^{\mathrm{int}}\right)-\delta(B) y_{i}^{\mathrm{int}}+n_{i}^{w, *}, y_{i}^{\mathrm{int}}\right)$.

We apply the implicit function theorem to show

$$
\partial_{B} y_{i}^{\text {int }}=-\frac{\left(\partial_{B} n_{i}^{w, *}-y_{i}^{\text {int }} \partial_{B} \delta\right)\left[\left(1-\mathcal{T}^{\prime}\left(y_{i}^{\text {int }}\right)\right) u_{i, c c}+u_{i, c y}\right]-u_{i, c} \partial_{B} \delta}{-\mathcal{T}^{\prime \prime}\left(y_{i}^{\text {int }}\right) u_{i, c}+\left(1-\mathcal{T}^{\prime}\left(y_{i}^{\text {int }}\right)\right)^{2} u_{i, c c}+2\left(1-\mathcal{T}^{\prime}\left(y_{i}^{\text {int }}\right)\right) u_{i, c y}+u_{i, y y}} .
$$

Let $\mathcal{K}_{i} \equiv\left(1-\mathcal{T}^{\prime}\left(y_{i}^{\text {int }}\right)\right)^{2} u_{i, c c}+2\left(1-\mathcal{T}^{\prime}\left(y_{i}^{\text {int }}\right)\right) u_{i, c y}+u_{i, y y}$ and $\tau_{i} \equiv \mathcal{T}^{\prime}\left(y_{i}^{\text {int }}\right)$. We then write equation (I.19) as

$$
\partial_{B} y_{i}^{\text {int }}\left[1-\frac{\mathcal{T}^{\prime \prime}\left(y_{i}^{\text {int }}\right) u_{i, c}}{\mathcal{K}_{i}}\right]=-\frac{\left(1-\tau_{i}\right) u_{i, c c}+u_{i, c y}}{\mathcal{K}_{i}} \partial_{B} n_{i}^{w, *}+\frac{y_{i}^{\text {int }}}{1-\tau_{i}}\left[\frac{\left(1-\tau_{i}\right) u_{i, c c}+u_{i, c y}+\frac{u_{i, c}}{y_{i}^{\text {itt }}}}{\frac{\mathcal{K}_{i}}{1-\tau_{i}}}\right] \partial_{B} \delta
$$


By substituting expressions (H.2), and (H.3) into equation (I.20), we get

$$
\partial_{B} y_{i}^{\mathrm{int}}\left(1+\theta_{i} \zeta_{i}^{\mathrm{c}}\right)=\eta_{i} \partial_{B} n_{i}^{w, *}+\frac{y_{i}^{\mathrm{int}}}{1-\tau_{i}}\left[\frac{\left(1-\tau_{i}\right) u_{i, c c}+u_{i, c y}+\frac{u_{i, c}}{y_{i}^{\text {int }}}}{\frac{\mathcal{K}_{i}}{1-\tau_{i}}}\right] \partial_{B} \delta
$$

where $\theta_{i} \equiv \frac{y_{i}^{\text {int } \mathcal{T}^{\prime \prime}\left(y_{i}^{\text {int }}\right)}}{1-\tau_{i}}$. By substituting expression (H.1) into (I.21), we end up with

$$
\partial_{B} y_{i}^{\mathrm{int}}=\frac{\eta_{i}}{1+\theta_{i} \zeta_{i}^{\mathrm{c}}} \partial_{B} n_{i}^{w, *}-\frac{y_{i}^{\mathrm{int}}}{1-\tau_{i}} \frac{\zeta_{i}^{\mathrm{u}}}{1+\theta_{i} \zeta_{i}^{\mathrm{c}}} \partial_{B} \delta
$$

Total earnings response. We now show that $\partial_{B} Y \equiv \partial_{B} \mathbb{E} y_{i}^{*}$ is well-defined, and given by the expression in Proposition 3. Following similar steps as in the proof for Proposition 1, we can show that

$$
\partial_{B} Y \equiv \partial_{B} \mathbb{E} y_{i}^{*}=\int \mathbb{E}_{y} \partial_{B} y_{i}^{\text {int }} d H(y)-\int y \lim _{B \rightarrow 0} \frac{\Lambda_{B}(y, B)}{B} d H(y) .
$$

Since the earnings density $h(y)$ is assumed to respond smoothly to a perturbation in $B, \lambda_{B}(y) \equiv \lim _{B \rightarrow 0} \frac{\Lambda_{B}(y, B)}{B} \geq$ 0 exists for all $y$. Therefore, $\partial_{B} Y$ is well-defined. Furthermore, since $\Lambda_{B}(y, 0)=0$, we have $y_{i}^{\text {int }}(0)=$ $y_{i}^{*}(0)=y_{i}^{*}$. By substituting expression (I.22) in (I.23), we end up with

$$
\partial_{B} Y=\mathbb{E}\left[\frac{\eta_{i}}{1+\theta_{i} \zeta_{i}^{\mathrm{c}}} \partial_{B} n_{i}^{w, *}-\frac{y_{i}^{*}}{1-\tau_{i}} \frac{\zeta_{i}^{\mathrm{u}}}{1+\theta_{i} \zeta_{i}^{\mathrm{c}}} \partial_{B} \delta\right]-\int y \lambda_{B}(y) d H(y)
$$

Total tax responses. We take similar steps as in the proof for Proposition 1 to derive the expression for $\partial_{B} \mathbb{E} \mathcal{T}\left(y_{i}^{*}(B)\right)$. Specifically, we can show that

$$
\partial_{B} \mathbb{E} \mathcal{T}\left(y_{i}^{*}(B)\right)=\int \mathcal{T}^{\prime}(y) \mathbb{E}_{y} \partial_{B} y_{i}^{\text {int }} d H(y)-\int[\mathcal{T}(y)-\mathcal{T}(0)] \lim _{B \rightarrow 0} \frac{\Lambda_{B}(y, B)}{B} d H(y)
$$

Since the earnings density $h(y)$ is assumed to respond smoothly to a perturbation in $B, \lambda_{B}(y) \equiv \lim _{B \rightarrow 0} \frac{\Lambda_{B}(y, B)}{B} \geq$ 0 , exists for all $y$, and $\partial_{B} \mathbb{E} \mathcal{T}\left(y_{i}^{*}(B)\right)$ therefore is well-defined. By substituting expression (I.22) in (I.24), we get

$$
\partial_{B} \mathbb{E} \mathcal{T}\left(y_{i}^{*}(B)\right)=\mathbb{E} \tau_{i}\left[\frac{\eta_{i}}{1+\theta_{i} \zeta_{i}^{\mathrm{c}}} \partial_{B} n_{i}^{w, *}-\frac{y_{i}^{*}}{1-\tau_{i}} \frac{\zeta_{i}^{\mathrm{u}}}{1+\theta_{i} \zeta_{i}^{\mathrm{c}}} \partial_{B} \delta\right]-\int[\mathcal{T}(y)-\mathcal{T}(0)] \lambda_{B}(y) d H(y)
$$

where $\tau_{i} \equiv \mathcal{T}^{\prime}\left(y_{i}^{*}\right)$ and $y_{i}^{*}=y_{i}^{*}(0)=y_{i}^{\text {int }}(0)$.

Tax rate increase. In the first step, we derive the expression for $\partial_{B} \delta$ in Proposition 3. By differentiating equation (I.7), we get

$$
\partial_{B} \mathcal{R}=-1+Y \partial_{B} \delta+\partial_{B} \mathbb{E} \mathcal{T}\left(y_{i}^{*}(B)\right)
$$


By substituting expression (I.25) into equation (I.26), we get

$$
\partial_{B} \mathcal{R}=-1+Y \partial_{B} \delta+\mathbb{E} \tau_{i}\left[\frac{\eta_{i}}{1+\theta_{i} \zeta_{i}^{\mathrm{c}}} \partial_{B} n_{i}^{w, *}-\frac{y_{i}^{*}}{1-\tau_{i}} \frac{\zeta_{i}^{\mathrm{u}}}{1+\theta_{i} \zeta_{i}^{\mathrm{c}}} \partial_{B} \delta\right]-\int[\mathcal{T}(y)-\mathcal{T}(0)] \lambda_{B}(y) d H(y) .
$$

Since the UBI is assumed to be revenue neutral, we must have $\partial_{B} \mathcal{R}=0$. Therefore, $\partial_{B} \delta$ must satisfy

$$
\partial_{B} \delta=\frac{1-\mathbb{E} \tau_{i} \frac{\eta_{i}}{1+\theta_{i} \zeta_{i}^{\mathrm{c}}} \partial_{B} n_{i}^{w, *}+\int[\mathcal{T}(y)-\mathcal{T}(0)] \lambda_{B}(y) d H(y)}{Y-\mathbb{E} \frac{\tau_{i} y_{i}^{*}}{1-\tau_{i}} \frac{\zeta_{i}^{\mathrm{u}}}{1+\theta_{i} \zeta_{i}^{\mathrm{c}}}}
$$

In the second step, we prove that $\partial_{B} \delta \geq 0$. Using Lemma 3 and 4 , it is easy to verify that the numerator in expression (I.27) is positive. Thus, for $\partial_{B} \delta \geq 0$ to hold, we must show that the denominator in expression (I.27) is positive.

Let $\partial_{\delta} x \equiv \lim _{\delta \rightarrow 0} \frac{x(\delta)-x(0)}{\delta}$ be the marginal impact of an the labor tax surcharge $\delta$ on any variable $x$ that is differentiable in $\delta$. Since $\mathcal{T}(\cdot)$ is to the left of the peak of the Laffer curve, we must have

$$
\partial_{\delta} \mathcal{R}(\delta)=Y+\partial_{\delta} \mathbb{E} \mathcal{T}\left(y_{i}^{*}(\delta)\right)>0
$$

Following the same steps as above, we can show that

$$
\partial_{\delta} \mathbb{E} \mathcal{T}\left(y_{i}^{*}(\delta)\right)=\int \mathcal{T}^{\prime}(y) \mathbb{E}_{y} \partial_{\delta} y_{i}^{\text {int }} d H(y)-\int[\mathcal{T}(y)-\mathcal{T}(0)] \lambda_{\delta}(y) d H(y)
$$

To find $\partial_{\delta} y_{i}^{\text {int }}$, we apply the implicit function theorem to the first-order condition (I.18) to get

$$
\partial_{\delta} y_{i}^{\mathrm{int}}=\frac{\eta_{i}}{1+\theta_{i} \zeta_{i}^{\mathrm{c}}} \partial_{\delta} n_{i}^{w, *}-\frac{y_{i}^{*}}{1-\tau_{i}} \frac{\zeta_{i}^{\mathrm{u}}}{1+\theta_{i} \zeta_{i}^{\mathrm{c}}}
$$

We then consider the outer subproblem (I.13) to determine $\partial_{\delta} n_{i}^{w, *}$. The first-order conditions imply

$$
\begin{gathered}
V_{i, n}=W_{i, n}, \\
\frac{1-\beta^{T}}{1-\beta} n_{i}^{w, *}+\beta^{T} \frac{1-\beta^{K}}{1-\beta} n_{i}^{r, *}=(1+\bar{r}) a_{i, 0}+\frac{1-\beta^{T+K}}{1-\beta} B .
\end{gathered}
$$

By differentiating both equations with respect to $\delta$, we get

$$
\begin{aligned}
V_{i, n n} \partial_{\delta} n_{i}^{w, *}+V_{i, n \delta} & =W_{i, n n} \partial_{\delta} n_{i}^{r, *}, \\
\frac{1-\beta^{T}}{1-\beta} \partial_{\delta} n_{i}^{w, *}+\beta^{T} \frac{1-\beta^{K}}{1-\beta} \partial_{\delta} n_{i}^{r, *} & =0 .
\end{aligned}
$$


Rearrange these expressions to get

$$
\begin{aligned}
\partial_{\delta} n_{i}^{w, *} & =-\frac{\frac{V_{i, n \delta}}{W_{i, n n}}}{\frac{V_{i, n n}}{W_{i, n n}}+\beta^{-T} \frac{1-\beta^{T}}{1-\beta^{K}}}, \\
\partial_{\delta} n_{i}^{r, *} & =\frac{\left(1-\beta^{T}\right) \frac{V_{i, n \delta}}{W_{i, n n}}}{\beta^{T}\left(1-\beta^{K}\right) \frac{V_{i, n n}}{W_{i, n n}}+1-\beta^{T}} .
\end{aligned}
$$

Under Assumption 1, we have $\frac{V_{i, n \delta}}{W_{i, n n}} \leq 0$ and $\frac{V_{i, n n}}{W_{i, n n}} \geq 0$. This implies

$$
\begin{gathered}
\partial_{\delta} n_{i}^{w, *} \geq 0 \\
\partial_{\delta} n_{i}^{r, *} \leq 0
\end{gathered}
$$

By substituting expression (I.30) into (I.29), we get

$$
\partial_{\delta} \mathbb{E} \mathcal{T}\left(y_{i}^{*}(\delta)\right)=\mathbb{E} \tau_{i}\left[\frac{\eta_{i}}{1+\theta_{i} \zeta_{i}^{\mathrm{c}}} \partial_{\delta} n_{i}^{w, *}-\frac{y_{i}^{*}}{1-\tau_{i}} \frac{\zeta_{i}^{\mathrm{u}}}{1+\theta_{i} \zeta_{i}^{\mathrm{c}}}\right]-\int[\mathcal{T}(y)-\mathcal{T}(0)] \lambda_{\delta}(y) d H(y),
$$

and therefore

$$
\partial_{\delta} \mathcal{R}(\delta)=Y+\mathbb{E} \tau_{i}\left[\frac{\eta_{i}}{1+\theta_{i} \zeta_{i}^{\mathrm{c}}} \partial_{\delta} n_{i}^{w, *}-\frac{y_{i}^{*}}{1-\tau_{i}} \frac{\zeta_{i}^{\mathrm{u}}}{1+\theta_{i} \zeta_{i}^{\mathrm{c}}}\right]-\int[\mathcal{T}(y)-\mathcal{T}(0)] \lambda_{\delta}(y) d H(y)>0
$$

Since $\lambda_{\delta} \geq 0$ and taxes are increasing in earnings, we get

$$
Y+\mathbb{E} \tau_{i}\left[\frac{\eta_{i}}{1+\theta_{i} \zeta_{i}^{\mathrm{c}}} \partial_{\delta} n_{i}^{w, *}-\frac{y_{i}^{*}}{1-\tau_{i}} \frac{\zeta_{i}^{\mathrm{u}}}{1+\theta_{i} \zeta_{i}^{\mathrm{c}}}\right]>0
$$

Inequality (I.33) together with $\eta_{i} \leq 0$ further implies

$$
Y-\mathbb{E} \frac{\tau_{i} y_{i}^{*}}{1-\tau_{i}} \frac{\zeta_{i}^{\mathrm{u}}}{1+\theta_{i} \zeta_{i}^{\mathrm{c}}}>0
$$

which establishes that the denominator in expression (I.27) is positive. Therefore, $\partial_{B} \delta \geq 0$.

Marginal propensity to quit. Lastly, we prove that $\lambda_{B}(y) \geq \lambda_{L}(y) \geq 0$. Consider any household $i$ who receives a lottery $L$ equal to the present value of UBI payments $B$. Lemma 4 implies that the per-period utility from not working, $u_{i}\left(n_{i}^{w, *}-\mathcal{T}(0), 0\right)+v_{i}$, is weakly larger under UBI than under the lottery. As we established above, marginal taxes weakly increase under UBI, $\partial_{B} \delta \geq 0$. This, in turn, implies that the maximal attainable utility from working under UBI is weakly smaller than the maximal attainable utility from working under the lottery. Therefore, every household who wants quit under the lottery also wants to quit under UBI for a given change in unearned income $\Delta$. This implies $\Lambda_{L}(y, \Delta) \leq \Lambda_{B}(y, \Delta)$, and by taking the limit $\Delta \rightarrow 0$, we get $0 \leq \lambda_{L}(y) \leq \lambda_{B}(y)$. 


\section{I.4.4 Proof of Corollary 5}

Corollary 1 with retirement. We show that if Assumption 1 is satisfied and $\zeta_{i}^{\mathrm{u}} \geq 0$ for all $i$, then

$$
\partial_{B} \delta \geq \frac{1-\mathrm{MPT}}{Y}, \quad \partial_{B} Y \leq \mathrm{MPE} .
$$

From Proposition 3, we know that $\lambda_{B}(y) \geq \lambda_{L}(y) \geq 0$ and

$$
\partial_{B} \delta=\frac{1-\mathbb{E}\left[\tau_{i} \frac{\eta_{i}}{1+\theta_{i} \zeta_{i}^{c}} \partial_{B} n_{i}^{w, *}\right]+\int[\mathcal{T}(y)-\mathcal{T}(0)] \lambda_{B}(y) d H(y)}{Y-\mathbb{E} \frac{\tau_{i} y_{i}^{*}}{1-\tau_{i}} \frac{\zeta_{i}^{\mathrm{u}}}{1+\theta_{i} \zeta_{i}^{\mathrm{c}}}} .
$$

Therefore,

$$
\partial_{B} \delta \geq \frac{1-\mathbb{E}\left[\tau_{i} \frac{\eta_{i}}{1+\theta_{i} \zeta_{i}^{\mathrm{c}}} \partial_{B} n_{i}^{w, *}\right]+\int[\mathcal{T}(y)-\mathcal{T}(0)] \lambda_{L}(y) d H(y)}{Y-\mathbb{E} \frac{\tau_{i} y_{i}^{*}}{1-\tau_{i}} \frac{\zeta_{i}^{\mathrm{u}}}{1+\theta_{i} \zeta_{i}^{\mathrm{c}}}} .
$$

By Lemma 4, using $\partial_{B} n_{i}^{w, *} \geq \partial_{L} n_{i}^{w, *} \geq 0$, we can also write this as

$$
\partial_{B} \delta \geq \frac{1-\mathbb{E}\left[\tau_{i} \frac{\eta_{i}}{1+\theta_{i} \zeta_{i}^{c}} \partial_{L} n_{i}^{w, *}\right]+\int[\mathcal{T}(y)-\mathcal{T}(0)] \lambda_{L}(y) d H(y)}{Y-\mathbb{E} \frac{\tau_{i} y_{i}^{*}}{1-\tau_{i}} \frac{\zeta_{i}^{\mathrm{u}}}{1+\theta_{i} \zeta_{i}^{c}}} .
$$

Lastly, since $\mathcal{T}(\cdot)$ is assumed to be to the left of the peak of the Laffer curve, we know from the proof for Proposition 3 that $Y-\mathbb{E} \frac{\tau_{i} y_{i}^{*}}{1-\tau_{i}} \frac{\zeta_{i}^{\mathrm{u}}}{1+\theta_{i} \zeta_{i}^{\mathrm{c}}}>0$. If $\zeta_{i}^{\mathrm{u}} \geq 0$ for all $i$, we obtain

$$
\partial_{B} \delta \geq \frac{1-\mathbb{E}\left[\tau_{i} \frac{\eta_{i}}{1+\theta_{i} \zeta_{i}^{c}} \partial_{L} n_{i}^{w, *}\right]+\int[\mathcal{T}(y)-\mathcal{T}(0)] \lambda_{L}(y) d H(y)}{Y}=\frac{1-\mathrm{MPT}}{Y},
$$

where the equality follows from Lemma 3. Taking further into account $\eta_{i} \leq 0$ for all $i$ and $\partial_{B} \delta \geq 0$, we also find

$$
\begin{aligned}
\partial_{B} Y & =\mathbb{E}\left[\frac{\eta_{i}}{1+\theta_{i} \zeta_{i}^{\mathrm{c}}} \partial_{B} n_{i}^{w, *}-\frac{y_{i}^{*}}{1-\tau_{i}} \frac{\zeta_{i}^{\mathrm{u}}}{1+\theta_{i} \zeta_{i}^{\mathrm{c}}} \partial_{B} \delta\right]-\int y \lambda_{B}(y) d H(y) . \\
& \leq \mathbb{E} \frac{\eta_{i}}{1+\theta_{i} \zeta_{i}^{\mathrm{c}}} \partial_{B} n_{i}^{w, *}-\int y \lambda_{B}(y) d H(y) \\
& \leq \mathbb{E} \frac{\eta_{i}}{1+\theta_{i} \zeta_{i}^{\mathrm{c}}} \partial_{L} n_{i}^{w, *}-\int y \lambda_{L}(y) d H(y) \\
& =\text { MPE. }
\end{aligned}
$$


Corollary 2 with retirement. We show that if Assumption 1 is satisfied, and $\zeta_{i}^{\mathrm{u}}=\zeta^{\mathrm{u}}$ and $\theta_{i}=\theta$ for all $i$, then

$$
\begin{aligned}
\partial_{B} \delta & \geq \frac{1-\mathrm{MPT}}{Y-\frac{\zeta^{\mathrm{u}}}{1+\theta \zeta^{\mathrm{u}}} \int \mathcal{T}^{\prime}(y) D(y) d H(y)}, \\
\partial_{B} Y & \leq \mathrm{MPE}-(1-\mathrm{MPT}) \frac{\frac{\zeta^{\mathrm{u}}}{1+\theta \zeta^{\mathrm{u}}} \int D(y) d H(y)}{Y-\frac{\zeta^{\mathrm{u}}}{1+\theta \zeta^{\mathrm{u}}} \int \mathcal{T}^{\prime}(y) D(y) d H(y)},
\end{aligned}
$$

where $D(y) \equiv \frac{y}{1-\mathcal{T}^{\prime}(y)}+\theta y \operatorname{MPE}^{\text {int }}(y)$.

As a preliminary step, it is useful to consider the object $\mathbb{E}_{y} \frac{1}{1+\theta_{i} \zeta_{i}^{\mathrm{c}}}$. The intensive-margin earnings response in Lemma 3 implies

$$
\eta_{i}=\left(1+\theta_{i} \zeta_{i}^{\mathrm{c}}\right) \frac{\partial_{L} y_{i}^{\mathrm{int}}}{\partial_{L} n_{i}^{w, *}}
$$

Using Slutsky (5.4) we obtain

$$
\zeta_{i}^{\mathrm{c}}=\frac{\zeta_{i}^{\mathrm{u}}-\left(1-\tau_{i}\right) \frac{\partial_{L} y_{i}^{\mathrm{int}}}{\partial_{L} n_{i}^{w, *}}}{1+\theta_{i}\left(1-\tau_{i}\right) \frac{\partial_{L} y_{i}^{\mathrm{int}}}{\partial_{L} n_{i}^{w, *}}}
$$

Taking into account that $\partial_{L} n_{i}^{w, *} \approx 1$,we find

$$
\mathbb{E}_{y} \frac{1}{1+\theta \zeta_{i}^{\mathrm{c}}} \approx \frac{1+\theta\left[1-\mathcal{T}^{\prime}(y)\right] \mathbb{E}_{y} \partial_{L} y_{i}^{\mathrm{int}}}{1+\theta \zeta^{\mathrm{u}}}
$$

where we used $\zeta_{i}^{\mathrm{u}}=\zeta^{\mathrm{u}}$ and $\theta_{i}=\theta$. By applying Lemma 3, we then get

$$
\mathbb{E}_{y} \frac{1}{1+\theta \zeta_{i}^{\mathrm{c}}} \approx \frac{1+\theta\left[1-\mathcal{T}^{\prime}(y)\right] \mathbb{E}_{y} \operatorname{MPE}^{\mathrm{int}}(y)}{1+\theta \zeta^{\mathrm{u}}} .
$$

Tax rate increase. With $\zeta_{i}^{\mathrm{u}}=\zeta^{\mathrm{u}}$ and $\theta_{i}=\theta$ for all $i$,we know from Proposition 3 that

$$
\partial_{B} \delta=\frac{1-\mathbb{E} \tau_{i} \frac{\eta_{i}}{1+\theta \zeta_{i}^{\mathrm{c}}} \partial_{B} n_{i}^{w, *}+\int[\mathcal{T}(y)-\mathcal{T}(0)] \lambda_{B}(y) d H(y)}{Y-\zeta^{\mathrm{u}} \mathbb{E} \frac{\tau_{i} y_{i}^{*}}{1-\tau_{i}} \frac{1}{1+\theta \zeta_{i}^{\mathrm{c}}}}
$$

Using $\lambda_{B}(y) \geq \lambda_{L}(y)$ and $\partial_{B} n_{i}^{w, *} \geq \partial_{L} n_{i}^{w, *} \geq 0$,we obtain

$$
\partial_{B} \delta \geq \frac{1-\mathbb{E} \tau_{i} \frac{\eta_{i}}{1+\theta \zeta_{i}^{c}} \partial_{L} n_{i}^{w, *}+\int[\mathcal{T}(y)-\mathcal{T}(0)] \lambda_{L}(y) d H(y)}{Y-\zeta^{\mathrm{u}} \mathbb{E} \frac{\tau_{i} y_{i}^{*}}{1-\tau_{i}} \frac{1}{1+\theta \zeta_{i}^{\complement}}}
$$

By applying Lemma 3, we can write this as

$$
\partial_{B} \delta \geq \frac{1-\mathrm{MPT}}{Y-\zeta^{\mathrm{u}} \mathbb{E} \frac{\tau_{i} y_{i}^{*}}{1-\tau_{i}} \frac{1}{1+\theta \zeta_{i}^{\mathrm{c}}}}
$$


By substituting expression (I.34), we end up with

$$
\partial_{B} \delta \geq \frac{1-\mathrm{MPT}}{Y-\frac{\zeta^{\mathrm{u}}}{1+\theta \zeta^{\mathrm{u}}} \int \mathcal{T}^{\prime}(y) D(y) d H(y)}
$$

where $D(y) \equiv \frac{y}{1-\mathcal{T}^{\prime}(y)}+\theta y \operatorname{MPE}^{\mathrm{int}}(y)$.

Total earnings response. By taking similar steps as above, it is easy to verify that

$$
\begin{aligned}
\partial_{B} Y & =\mathbb{E}\left[\frac{\eta_{i}}{1+\theta \zeta_{i}^{\mathrm{c}}} \partial_{B} n_{i}^{w, *}-\frac{y_{i}^{*}}{1-\tau_{i}} \frac{\zeta^{\mathrm{u}}}{1+\theta \zeta_{i}^{\mathrm{c}}} \partial_{B} \delta\right]-\int y \lambda_{B}(y) d H(y) \\
& \leq \mathbb{E}\left[\frac{\eta_{i}}{1+\theta \zeta_{i}^{\mathrm{c}}} \partial_{L} n_{i}^{w, *}-\frac{y_{i}^{*}}{1-\tau_{i}} \frac{\zeta^{\mathrm{u}}}{1+\theta \zeta_{i}^{\mathrm{c}}} \partial_{B} \delta\right]-\int y \lambda_{L}(y) d H(y) \\
& \leq \operatorname{MPE}-\partial_{B} \delta \frac{\zeta^{\mathrm{u}}}{1+\theta \zeta^{\mathrm{u}}} \int D(y) d H(y) .
\end{aligned}
$$

Substitute equation (I.35) to get

$$
\partial_{B} Y \leq \mathrm{MPE}-(1-\mathrm{MPT}) \frac{\frac{\zeta^{\mathrm{u}}}{1+\theta \zeta^{\mathrm{u}}} \int D(y) d H(y)}{Y-\frac{\zeta^{\mathrm{u}}}{1+\theta \zeta^{\mathrm{u}}} \int \mathcal{T}^{\prime}(y) D(y) d H(y)}
$$

\section{I.4.5 Proof of Proposition 4}

We consider a perturbation of the top income tax rate $\bar{\tau}$ that affects only taxpayers with income above some threshold $\bar{y}$. Any household $i$ with income $y_{i}^{*} \geq \bar{y}$ solves

$$
\max _{c_{i}, y_{i}} u_{i}\left(c_{i}, y_{i}\right)
$$

subject to

$$
c_{i}=(1-\bar{\tau}) y_{i}+n_{i}^{w, *}
$$

The first-order condition reads

$$
u_{i, y}\left((1-\bar{\tau}) y_{i}^{\mathrm{int}}+n_{i}^{w, *}, y_{i}^{\mathrm{int}}\right)=-(1-\bar{\tau}) u_{i, c}\left((1-\bar{\tau}) y_{i}^{\mathrm{int}}+n_{i}^{w, *}, y_{i}^{\mathrm{int}}\right)
$$

We apply the implicit function theorem to show

$$
\partial_{\tau} y_{i}^{\text {int }}=-\frac{\left(\partial_{\tau} n_{i}^{w, *}-y_{i}^{*}\right)\left[u_{i, c y}+(1-\bar{\tau}) u_{i, c c}\right]+u_{i, c}}{(1-\bar{\tau})^{2} u_{i, c c}+2(1-\bar{\tau}) u_{i, c y}+u_{i, y y}},
$$

where $y_{i}^{*}=y_{i}^{\text {int }}$. By substituting expressions (H.1) and (H.2) into (I.36), we get

$$
\partial_{\tau} y_{i}^{\mathrm{int}}=\eta_{i} \partial_{\tau} n_{i}^{w, *}-\frac{y_{i}^{*}}{1-\bar{\tau}} \zeta_{i}^{\mathrm{u}}
$$


To find $\partial_{\tau} n_{i}^{w, *}$ we consider the outer problem (I.2), taking into account that the present value of unearned income increased by $\frac{1-\beta^{T}}{1-\beta} \bar{y} d \bar{\tau}$. The first-order conditions imply

$$
\begin{aligned}
V_{i, n} & =W_{i, n}, \\
\frac{1-\beta^{T}}{1-\beta} n_{i}^{w, *}+\beta^{T} \frac{1-\beta^{K}}{1-\beta} n_{i}^{r, *} & =(1+\bar{r}) a_{i, 0}+\frac{1-\beta^{T}}{1-\beta} \bar{y} d \bar{\tau} .
\end{aligned}
$$

By differentiating both equations with respect to $d \bar{\tau}$, we get

$$
\begin{aligned}
V_{i, n n} \partial_{\tau} n_{i}^{w, *}+V_{i, n \tau} & =W_{i, n n} \partial_{\tau} n_{i}^{r, *}, \\
\frac{1-\beta^{T}}{1-\beta} \partial_{\tau} n_{i}^{w, *}+\beta^{T} \frac{1-\beta^{K}}{1-\beta} \partial_{\tau} n_{i}^{r, *} & =\frac{1-\beta^{T}}{1-\beta} \bar{y} .
\end{aligned}
$$

Rearrange these expressions to get

$$
\left[\frac{V_{i, n n}}{W_{i, n n}}+\beta^{-T} \frac{1-\beta^{T}}{1-\beta^{K}}\right] \partial_{\tau} n_{i}^{w, *}+\frac{V_{i, n \tau}}{W_{i, n n}}=\beta^{-T} \frac{1-\beta^{T}}{1-\beta^{K}} \bar{y}
$$

Under Assumption 1, we have $\frac{V_{i, n \tau}}{W_{i, n n}} \leq 0$ and $\frac{V_{i, n n}}{W_{i, n n}} \geq 0$. Therefore,

$$
\partial_{\tau} n_{i}^{w, *} \geq \bar{y} \frac{1-\beta^{T}}{1-\beta^{T}+\beta^{T}\left(1-\beta^{K}\right) \frac{V_{i, n n}}{W_{i, n n}}} .
$$

Substitute expression (I.6) in the above inequality to get

$$
\partial_{\tau} n_{i}^{w, *} \geq \frac{1-\beta^{T}}{1-\beta^{T+K}} \bar{y} \partial_{L} n_{i}^{w, *} \geq 0
$$

This relationship, together with equation (I.37) and $\eta_{i} \leq 0$, implies

$$
\begin{aligned}
\partial_{\tau} y_{i}^{\mathrm{int}} & =\eta_{i} \partial_{\tau} n_{i}^{w, *}-\frac{y_{i}^{*}}{1-\bar{\tau}} \zeta_{i}^{\mathrm{u}} \\
& \leq \frac{1-\beta^{T}}{1-\beta^{T+K}} \bar{y} \partial_{L} n_{i}^{w, *}-\frac{y_{i}^{*}}{1-\bar{\tau}} \zeta_{i}^{\mathrm{u}} .
\end{aligned}
$$

\section{I.4.6 Proof of Corollary 6}

Preliminaries. As a preliminary step, we derive the objects $\partial_{\tau} \mathbb{E}_{\geq \bar{y}} y_{i}^{*}$ and $\partial_{\tau} \mathbb{E}_{\geq \bar{y}} \mathcal{T}(y)$. Given the expression for $\partial_{\tau} y_{i}^{\text {int }}$ in Proposition 4, we can follow the same steps as in the proof for Lemma 1 to show that

$$
\begin{gathered}
\partial_{\tau} \mathbb{E}_{\geq \bar{y}} y_{i}^{*}=\mathbb{E}_{\geq \bar{y}}\left[\eta_{i} \partial_{\tau} n_{i}^{w, *}-\frac{y_{i}^{*}}{1-\bar{\tau}} \zeta_{i}^{\mathrm{u}}\right]-\int_{\bar{y}}^{\infty} y \lambda_{\tau}(y) \frac{d H(y)}{1-H(\bar{y})} . \\
\partial_{\tau} \mathbb{E}_{\geq \bar{y}} \mathcal{T}\left(y_{i}^{*}\right)=\mathbb{E}_{\geq \bar{y}} \bar{\tau}\left[\eta_{i} \partial_{\tau} n_{i}^{w, *}-\frac{y_{i}^{*}}{1-\bar{\tau}} \zeta_{i}^{\mathrm{u}}\right]-\int_{\bar{y}}^{\infty}(\mathcal{T}(y)-\mathcal{T}(0)) \lambda_{\tau}(y) \frac{d H(y)}{1-H(\bar{y})}
\end{gathered}
$$


From expression (I.40), it then follows immediately that the marginal impact on total earnings is given by

$$
\partial_{\tau} Y=[1-H(\bar{y})]\left[\mathbb{E}_{\geq \bar{y}} \eta_{i} \partial_{\tau} n_{i}^{w, *}-\frac{\bar{y} a}{1-\bar{\tau}} \mathbb{E}_{\geq \bar{y}} \zeta_{i}^{\mathrm{u}}\right]-\int_{\bar{y}}^{\infty} y \lambda_{\tau}(y) d H(y) .
$$

where $a \equiv \mathbb{E}_{\geq \bar{y}} \frac{y_{i}^{*}}{\bar{y}}$. As in Section 5.4, the marginal impact of an increase in the top tax rate on tax revenue is given by

$$
\partial_{\tau} \mathcal{R}=[1-H(\bar{y})]\left[\mathbb{E}_{\geq \bar{y}}\left[y_{i}^{*}-\bar{y}\right]+\partial_{\tau} \mathbb{E}_{\geq \bar{y}} \mathcal{T}\left(y_{i}^{*}\right)\right] .
$$

By substituting expression (I.41) in (I.42), we find that

$$
\partial_{\tau} \mathcal{R}=[1-H(\bar{y})]\left[\bar{y}(a-1)+\mathbb{E}_{\geq \bar{y}} \bar{\tau}\left(\eta_{i} \partial_{\tau} n_{i}^{w, *}-\frac{\bar{y} a}{1-\bar{\tau}} \zeta_{i}^{\mathrm{u}}\right)\right]-\int_{\bar{y}}^{\infty}(\mathcal{T}(y)-\mathcal{T}(0)) \lambda_{\tau}(y) d H(y)
$$

Since $\lambda_{\tau}(y) \geq 0$ for all $y \geq \bar{y}$, we get

$$
\begin{aligned}
& \partial_{\tau} \mathcal{R} \leq[1-H(\bar{y})]\left[\bar{y}(a-1)+\bar{\tau}\left(\mathbb{E}_{\geq \bar{y}} \eta_{i} \partial_{\tau} n_{i}^{w, *}-\frac{\bar{y} a}{1-\bar{\tau}} \mathbb{E}_{\geq \bar{y}} \zeta_{i}^{\mathrm{u}}\right)\right], \\
& \partial_{\tau} Y \leq[1-H(\bar{y})]\left[\mathbb{E}_{\geq \bar{y}} \eta_{i} \partial_{\tau} n_{i}^{w, *}-\frac{\bar{y} a}{1-\bar{\tau}} \mathbb{E}_{\geq \bar{y}} \zeta_{i}^{\mathrm{u}}\right] .
\end{aligned}
$$

Case $(a)$ in Corollary 3. If $\zeta_{i}^{\mathrm{u}} \geq 0$ for all $i$ who earn $y_{i}^{*} \geq \bar{y}$, then inequalities (I.43) and (I.44) can be written as

$$
\begin{aligned}
& \partial_{\tau} \mathcal{R} \leq[1-H(\bar{y})]\left[\bar{y}(a-1)+\bar{\tau} \mathbb{E}_{\geq \bar{y}} \eta_{i} \partial_{\tau} n_{i}^{w, *}\right] \\
& \partial_{\tau} Y \leq[1-H(\bar{y})] \mathbb{E}_{\geq \bar{y}} \eta_{i} \partial_{\tau} n_{i}^{w, *} .
\end{aligned}
$$

Lemma 3 implies that

$$
\overline{\mathrm{MPE}}^{\mathrm{int}}=\mathbb{E}_{\geq \bar{y}} \frac{\eta_{i}}{1+\theta_{i} \zeta_{i}^{\mathrm{c}}} \partial_{L} n_{i}^{w, *}
$$

Since $\eta_{i} \leq 0$ and $\theta_{i} \geq 0$ for all $i$, we then have

$$
\overline{\operatorname{MPE}}^{\mathrm{int}}=\mathbb{E}_{\geq \bar{y}} \frac{\eta_{i}}{1+\theta_{i} \zeta_{i}^{\mathrm{c}}} \partial_{L} n_{i}^{w, *} \geq \mathbb{E}_{\geq \bar{y}} \eta_{i} \partial_{L} n_{i}^{w, *}
$$

Using the relationship between $\partial_{L} n_{i}^{w, *}$ and $\partial_{\tau} n_{i}^{w, *}$ in Proposition 4, we can write (I.47) as

$$
\overline{\operatorname{MPE}}^{\mathrm{int}} \geq \frac{1-\beta^{T+K}}{\left(1-\beta^{T}\right) \bar{y}} \mathbb{E}_{\geq \bar{y}} \eta_{i} \partial_{\tau} n_{i}^{w, *}
$$

and therefore

$$
\frac{1-\beta^{T}}{1-\beta^{T+K}} \bar{y} \overline{\mathrm{MPE}}^{\mathrm{int}} \geq \mathbb{E}_{\geq \bar{y}} \eta_{i} \partial_{\tau} n_{i}^{w, *}
$$


Given this relationship, we can write inequalities (I.45) and (I.46) as

$$
\begin{aligned}
& \partial_{\tau} \mathcal{R} \leq[1-H(\bar{y})] \bar{y}\left[a-1+\frac{1-\beta^{T}}{1-\beta^{T+K}} \bar{\tau} \overline{\mathrm{MPE}}^{\mathrm{int}}\right] \\
& \partial_{\tau} Y \leq[1-H(\bar{y})] \bar{y} \frac{1-\beta^{T}}{1-\beta^{T+K}} \overline{\mathrm{MPE}}^{\mathrm{int}} .
\end{aligned}
$$

Case $(b)$ in Corollary 3. If $\zeta_{i}^{\mathrm{u}}=\bar{\zeta}^{\mathrm{u}}$ for all $i$ who earn $y_{i}^{*} \geq \bar{y}$, then the same arguments as above allow us to write inequalities (I.43) and (I.44) as

$$
\begin{aligned}
& \partial_{\tau} \mathcal{R} \leq[1-H(\bar{y})] \bar{y}\left[a-1+\bar{\tau}\left(\frac{1-\beta^{T}}{1-\beta^{T+K}} \overline{\mathrm{MPE}}^{\mathrm{int}}-\frac{a}{1-\bar{\tau}} \bar{\zeta}^{\mathrm{u}}\right)\right] \\
& \partial_{\tau} Y \leq[1-H(\bar{y})] \bar{y}\left[\frac{1-\beta^{T}}{1-\beta^{T+K}} \overline{\mathrm{MPE}}^{\mathrm{int}}-\frac{a}{1-\bar{\tau}} \bar{\zeta}^{\mathrm{u}}\right] .
\end{aligned}
$$




\section{J Discussion of findings and comparison with existing work}

Our paper is related to several other studies of the effect of lottery winnings on earnings. The three most closely-related ones are Imbens, Rubin and Sacerdote (2001), Cesarini, Lindqvist, Notowidigdo and Östling (2017) (CLNO) and Picchio, Suetens and van Ours (2018). Imbens, Rubin and Sacerdote (2001) use mail survey responses of a small number of lottery winners in one state in the U.S. (Massachusetts). Like us, both CLNO and Picchio, Suetens and van Ours (2018) use administrative data (from Sweden and the Netherlands, respectively) and estimate the effect of lottery winnings on various measures of labor market outcomes.

Our work is difficult to compare directly to Imbens, Rubin and Sacerdote (2001) for two reasons. First, they restrict their treated group to individuals winning prizes that were required to be paid out in equal installments over 20 years rather than a one-time payment. Second, their data does not include either taxes or labor market responses of the spouse. It is also difficult to compare our work directly to Picchio, Suetens and van Ours (2018), in part because they do not account for income taxes, but also because they do not calculate income effects and labor supply elasticities. ${ }^{48} \mathrm{CLNO}$, on the other hand, is a particularly relevant comparison to our study. They report various estimates of wealth effects that are directly comparable to our estimates in Section 3. In addition, they use these wealth effects to estimate a structural model of labor supply, and calculate marginal propensities to earn as well as compensated and uncompensated elasticities of labor supply. Using these calculations they argue that income effects are at most modest.

We proceed to re-examine CLNO's conclusion about the size of income effects in two steps. In the first step, we compare our estimated wealth effects with the ones reported in CLNO. While winner earnings are substantially more responsive in the U.S. compared to Sweden, we find that accounting for spousal responses and labor income taxation helps explain part of the differences in the estimates across countries. In the second step, we re-estimate their model on their own data, but now accounting for spousal responses and labor income taxation. The estimates we obtain for Sweden are more comparable to the sizable MPE and income effects we report in Sections 4 and 5 for the U.S. Nonetheless, large differences remain: even after adjustment, our estimates are approximately twice as large as those obtained for Sweden. This suggests that generalizing the results from Sweden to the U.S. may warrant some care.

\section{J.1 Comparison of wealth effects}

CLNO estimate the effect of winning the lottery on total labor earnings of the winner as well as total labor earnings of the household. In Table J.1 we summarize their findings and compare them to our estimated wealth effects. Across both papers, we see that the estimated post-tax earnings responses of lottery winners are negative and non-negligible (see Panel A in Table J.1). In our data, the winner reduces her post-tax total earnings by 1.6 dollars each period per 100 dollars of winnings; in CLNO this value is 0.6 dollars. However, the response of the post-tax total earnings of the winner underestimates the full extent of the labor market response for two reasons.

\footnotetext{
${ }^{48}$ In their Table D1, Picchio, Suetens and van Ours (2018) report unconditional wealth effect estimates for the winner for event times $\ell=1,2,3$. Their average estimated wealth effect is very similar to the analogous estimate in Cesarini, Lindqvist, Notowidigdo and Östling (2017), Table 3.
} 
First, taxes introduce a substantial wedge between pre- and post-tax wage earnings responses, especially in Sweden. In the U.S., winners reduce their pre-tax earnings by 2 dollars each period per 100 dollars of winnings compared to 1.6 dollars after taxes, implying an average retention rate of around 82 percent. In Sweden, on the other hand, the wedge between pre- and post-tax earnings responses is substantially larger. With an average retention rate of just over 50 percent, winner earnings responses almost double and increase to 1.1 dollars each period per 100 dollars of winnings. Second, once we include spousal earnings, estimated wealth effects increase even further. In the U.S., they increase to 2.3 dollars each period per 100 dollars of winnings - an approximate 20 percent increase. By comparison, in Sweden they increase by about 23 percent, to 1.3 dollars per 100 dollars of winnings.

Taken together, the results in Table J.1 show how responses measured post-tax and only for the winner understate the responses measured pre-tax for the entire household. In the U.S., pre-tax household responses are 1.5 times larger than post-tax winner earnings responses, whereas in Sweden they are 2.3 times larger. As a consequence, the relative gap in wealth effects between the U.S. and Sweden decreases by around 35 percent once we account for spousal responses and labor income taxation.

Table J.1: Literature review of wealth effects of lottery winnings

\begin{tabular}{|c|c|c|c|}
\hline \multicolumn{4}{|c|}{ Panel A: Post-Tax Earnings Responses } \\
\hline Paper & Post-Tax Earnings Measure & Post-Tax Lottery Winnings & Wealth Effect \\
\hline (1) & (2) & (3) & (4) \\
\hline Cesarini, Lindqvist, Notowidigdo, and Östling (2017) & Winner Total Labor Earnings & Total & -0.576 \\
\hline Our estimate & Winner Total Labor Earnings & Total & -1.597 \\
\hline \multicolumn{4}{|c|}{ Panel B: Pre-Tax Earnings Responses } \\
\hline Paper & Pre-Tax Earnings Measure & Post-Tax Lottery Winnings & Wealth Effect \\
\hline (1) & (2) & (3) & (4) \\
\hline Cesarini, Lindqvist, Notowidigdo, and Östling (2017) & Winner Total Labor Earnings & Total & -1.066 \\
\hline Our estimate & Winner Total Labor Earnings & Total & -1.955 \\
\hline Cesarini, Lindqvist, Notowidigdo, and Östling (2017) & Per-Adult Total Labor Earnings & Per-Adult & -1.306 \\
\hline Our estimate & Per-Adult Total Labor Earnings & Per-Adult & -2.339 \\
\hline
\end{tabular}

Notes: This table presents a comparison of our estimated wealth effects with the ones reported in Cesarini, Lindqvist, Notowidigdo and Östling (2017) (CLNO). In Panel A we compare our estimates of the post-tax total labor earnings responses of the lottery winner per 100 dollars of post-tax winnings to the corresponding value reported in CLNO, Table 3. In Panel B we compare our estimate of the pre-tax earnings responses per 100 dollars of post-tax winnings to the corresponding values reported in CLNO. The winner total labor earnings response is reported in CLNO, Table 3; the household total labor response is reported in CLNO, Table 6. 